UNIVERSIDAD POLITÉCNICA DE VALENCIA

Departamento de Ingeniería Gráfica

\title{
Análisis del uso de dispositivos móviles en el desarrollo de estrategias de mejora de las habilidades espaciales
}

\author{
Tesis Doctoral
}

Norena N. Martín Dorta

Directores:

Dr. D. Manuel Contero González

Dr. D. José Luis Saorín Pérez

Valencia, Diciembre 2009 



\title{
A toda mi familia,
}

\author{
A mi madre \\ muy especialmente a ella, por el gran \\ esfuerzo realizado durante todos estos años \\ y por el cariño que me muestra cada día \\ A mis hermanos, \\ por estar siempre que les pido ayuda \\ A mis hijos, \\ por el tiempo que les he robado y porque sin \\ ellos mi vida no sería igual
}

A mi marido, por su apoyo y su cariño 



\section{Agradecimientos}

\section{A Manuel Contero y Jose Luis Saorín,}

directores de esta tesis, por haberme ofrecido la posibilidad de llevar a cabo este trabajo, pero sobre todo por el gran esfuerzo realizado para cumplir con los objetivos planteados.

A todos mis compañeros del Departamento de Expresión Gráfica en la Universidad de La Laguna, en especial a Jorge Martín Gutiérrez, por su colaboración incondicional, y a Rosa Navarro, por estar siempre que la necesitamos.

A los revisores externos de la tesis

por su atenta lectura y por sus sugerencias de mejora.

A los investigadores en habilidades espaciales

por abrir un camino 



\section{Análisis del uso de dispositivos móviles en el desarrollo de estrategias de mejora de las habilidades espaciales}

\section{Resumen}

Las nuevas interfaces de usuario y los recientes desarrollos en el campo de las comunicaciones móviles han creado un amplio abanico de posibilidades para los usuarios y para el diseño y el acceso a los materiales de aprendizaje.

Esta tesis explora las oportunidades que nos ofrecen las nuevas interfaces usuario y la utilización de dispositivos móviles de pantalla táctil, con la intención de ofrecer cursos intensivos de mejora de las habilidades espaciales a los estudiantes de ingeniería con mayores dificultades en este ámbito.

Con este propósito y en este contexto se abordan:

- Nuevas herramientas y nuevos formatos: SketchUp y los dispositivos móviles de pantalla táctil,

- Nuevos contextos: la educación a distancia y

- Medida de la satisfacción de los usuarios: evaluación de los cursos realizados.

Con este objetivo, este trabajo se estructura en base a dos líneas de actuación, diferenciadas en función del soporte utilizado y conectadas por su desarrollo temporal:

1. Se desarrollan dos estudios de campo con estudiantes de primer curso de ingeniería, un primer estudio utilizando el software SketchUp y otro con una aplicación web interactiva denominada "Building with blocks”. Estos dos trabajos se muestran efectivos en la mejora de las habilidades espaciales.

2. Los resultados obtenidos nos permiten abordar el diseño de nuevos materiales sobre dispositivos móviles de pantalla táctil. Se elaboran dos tipologías:

- Un entorno web interactivo en formato plano (2D), optimizado para dispositivos tipo iPod Touch. Se diseña y evalúa un curso online programado para cinco días con este material. El curso muestra su efectividad en la mejora de las habilidades espaciales y es valorado con un alto grado de satisfacción por los estudiantes. 
- Una aplicación para teléfonos móviles de pantalla táctil que nos permite la construcción de modelos de cubos en un entorno tridimensional y que ha sido desarrollada para el sistema operativo Windows Mobile. La herramienta es testeada y mejorada en una prueba de usabilidad con un grupo de usuarios. Finalmente, se realiza un estudio de campo que permite obtener conclusiones preliminares que apuntan en la dirección de que esta aplicación mejora las habilidades espaciales de los estudiantes sometidos a un entrenamiento específico.

\section{Palabras clave}

Habilidades Espaciales, Visión espacial, DAT-SR, MRT, Aprendizaje móvil, Educación en ingeniería, Ingeniería Gráfica 


\section{Anàlisi de l'ús de dispositius mòbils en el desenvolupament d'estratègies de millora de les habilitats espacials}

\section{Resum}

Les noves interfícies d'usuari i els recents avanços en el camp de les comunicacions mòbils han creat un ampli ventall de possibilitats per als usuaris i per al disseny i l'accés als materials d'aprenentatge.

Esta tesi explora les oportunitats que ens oferixen les noves interfícies d'usuari i la utilització de dispositius mòbils de pantalla tàctil, amb la intenció d'oferir cursos intensius de millora de les habilitats espacials als estudiants d'enginyeria amb més dificultats en este àmbit.

Amb este propòsit i en este context s'aborden:

- Noves ferramentes i nous formats: SketchUp i els dispositius mòbils de pantalla tàctil,

- Nous contextos: l'educació a distància i

- Mesura de la satisfacció dels usuaris: avaluació dels cursos realitzats.

Amb este objectiu, este treball s'estructura basant-se en dos línies d'actuació, diferenciades en funció del suport utilitzat i connectades pel seu desenvolupament temporal:

1. Es realitzen dos estudis de camp amb estudiants de primer curs d'enginyeria, un primer estudi utilitzant el programa SketchUp i un altre amb una aplicació web interactiva denominada "Building with blocks". Estos dos treballs es mostren efectius en la millora de les habilitats espacials.

2. Els resultats obtinguts ens permeten abordar el disseny de nous materials sobre dispositius mòbils de pantalla tàctil. S'elaboren dos tipologies:

- Un entorn web interactiu en format pla (2D), optimitzat per a dispositius tipus iPod Touch. Es dissenya i avalua un curs on-line programat per a cinc dies amb este material. El curs mostra la seua efectivitat en la millora de les habilitats espacials i és valorat amb un alt grau de satisfacció pels estudiants.

- Una aplicació per a telèfons mòbils de pantalla tàctil que ens permet la construcció de models de cubs en un entorn 
tridimensional i que ha sigut desenvolupada per al sistema operatiu Windows Mobile. La ferramenta és analitzada i millorada en una prova d'usabilitat amb un grup d'usuaris. Finalment, es realitza un estudi de camp que permet obtindre conclusions preliminars que apunten en la direcció que esta aplicació millora les habilitats espacials dels estudiants sotmesos a un entrenament específic.

\section{Paraules clau}

Habilitats Espacials, Visió espacial, DAT-SR, MRT, Aprenentatge mòbil, Educació en enginyeria, Enginyeria Gràfica 


\section{Use mobile devices to developing strategies to improve spatial abilities}

\section{Abstract}

Advances in technology, user interfaces and recent developments in the field of communications (Wi-Fi, GPRS, 3G, etc.), have created a wide range of possibilities for users and for the design and access to learning contents.

This thesis attempts to harness the opportunities for mobility and the new user interfaces that handheld touch screen devices offer, in a non-formal learning context, with a view to offer intensive courses to improve spatial skills of engineering students with the greatest difficulties in this area.

With a view to developing spatial ability, this research has addresses:

- New tools and new formats: SketchUp and touch-screen mobile devices,

- New contexts: distance education, and

- User satisfaction.

This work is structured around two main priorities, differentiated by the medium used and connected by its temporal development:

1. They develop two field studies with first-year engineering students, a first study using SketchUp software and another with an interactive web application called "Building with blocks". These two works are shown effective in improving spatial skills.

2. These results allow us to approach the design of new materials touch screen mobile devices. Two types:

- An interactive web content (2D), optimized for iPod Touch. This research has addressed two endpoints: first of all, to analyse the effects that training can have on spatial visualisation using the educational content developed for this pilot study; and second, to evaluate the experience of users in the use of handheld touch screen devices and their degree of satisfaction with the on-line learning course proposed.

- The purpose of this project was to design a $3 \mathrm{D}$ construction mobile game for $3 \mathrm{D}$ spatial visualization training, with the aim of familiarizing users with a $3 \mathrm{D}$ environment and improving their understanding of the $2 \mathrm{D}-3 \mathrm{D}$ relationship. This paper describes the architecture of the system that we developed, which includes 
several different applications: (a) a mobile game played on touchscreen devices to permit students to resolve exercises in a $3 \mathrm{D}$ environment; (b) a PC application, to permit the teacher to design exercises and manage users; and (c) a server application and a database to collect and manage data. Satisfaction questionnaires and observation records were kept of work done by the users in order to evaluate the mobile game. The results show a high degree of satisfaction with the game and that users realize how useful this game can be for the proposed aims.

\section{Keywords}

Spatial abilities, spatial visualization, Differential Aptitude Test - Spatial Relations Subset, DAT-SR, Mental Rotation Test, MRT, Mobile Learning, Engineering Education, Engineering Graphics 


\section{Índice}

CAPÍTULO I: INTRODUCCIÓN........................................................19

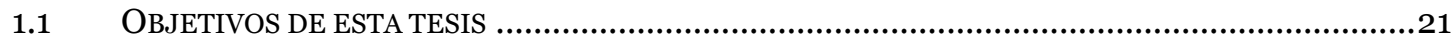

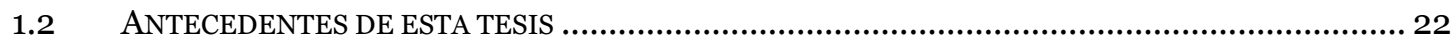

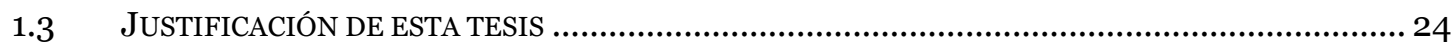

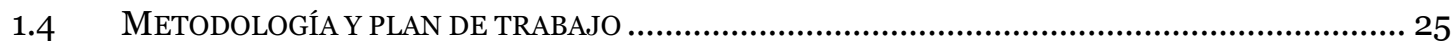

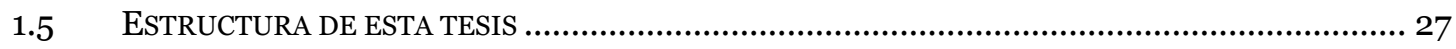

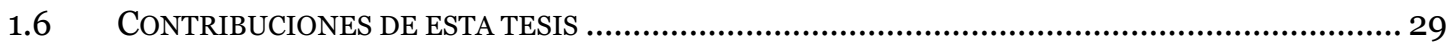

1.7 PROYECTOS DE INVESTIGACIÓN, ARTÍCULOS PUBLICADOS Y PONENCIAS PRESENTADAS EN

CONGRESOS COMO CONSECUENCIA DE LA REALIZACIÓN DE ESTA TESIS .......................................3

CAPÍTULO II: MARCO TEÓRICO.................................................. 33

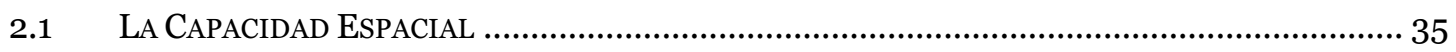

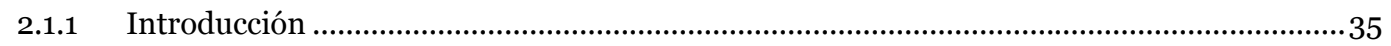

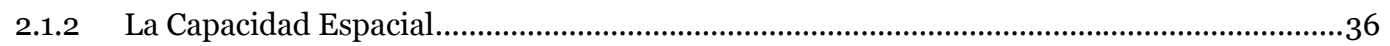

2.1.3 Breve reseña histórica de la investigación sobre la capacidad espacial ...............................40

2.1.4 La relación de las habilidades espaciales con la ingeniería ................................................42

2.1.5 La importancia de estas habilidades en el ámbito de la ingeniería ......................................4

2.1.6 Las habilidades espaciales y las herramientas de mejora....................................................45

2.1.7 Cursos intensivos de mejora de las habilidades espaciales en la Universidad de La

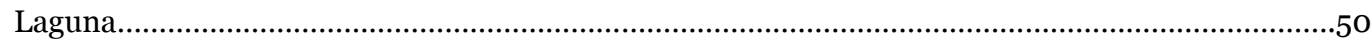

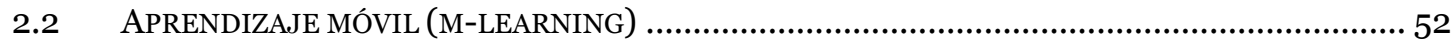

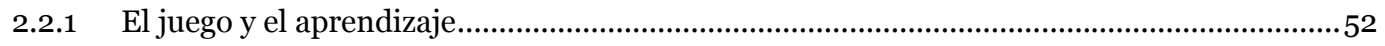

2.2.2 Aprendizaje móvil (Mobile Learning) ............................................................................ 53

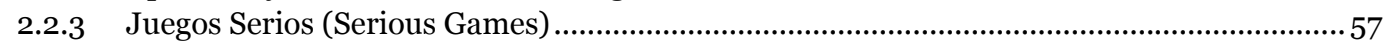

2.2.4 Investigación en el campo del Aprendizaje móvil .............................................................59

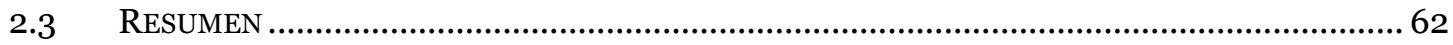

CAPÍTULO III: EL MODELADO 3D COMO HERRAMIENTA DE MEJORA DE

LAS HABILIDADES ESPACIALES .................................................. 65

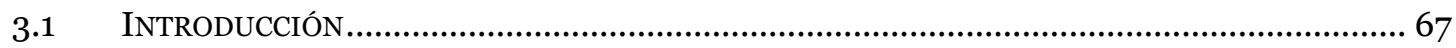

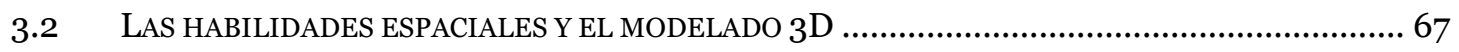

3.3 CURSOS DE MEJORA DE LAS HABILIDADES ESPACIALES MEDIANTE MODELADO 3D ................6 69

$3.4 \quad$ SOFTWARE DE MODELADO NO TÉCNICO............................................................................. 74

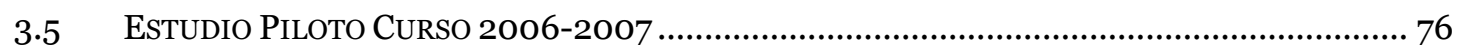

3.5.1 Introducción y Justificación................................................................................................. 76

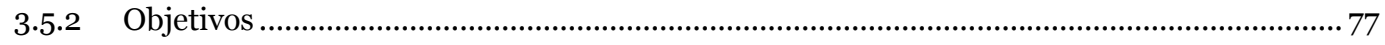

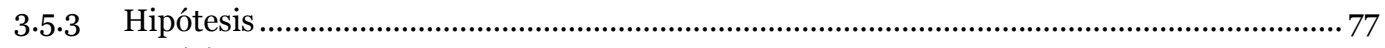

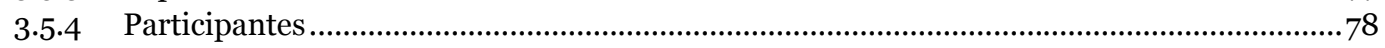

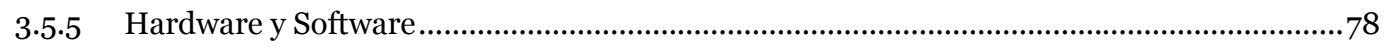

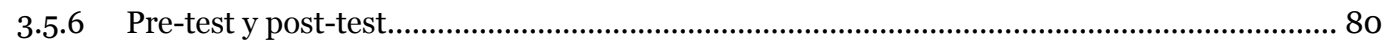

3.5.7 Material didáctico de Técnicas de Expresión Gráfica ........................................................ 80

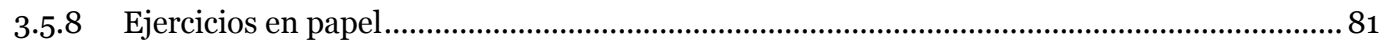

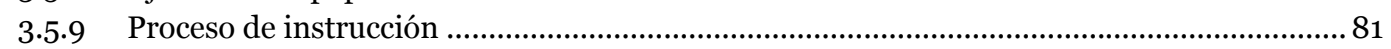

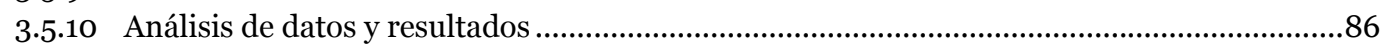

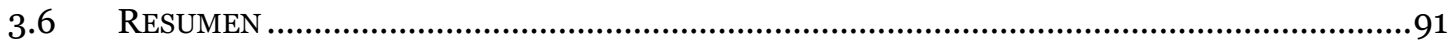

CAPÍTULO IV: LOS CONTENIDOS WEB INTERACTIVOS SOBRE DISPOSITIVOS MÓVILES COMO HERRAMIENTA DE MEJORA DE LAS HABILIDADES ESPACIALES ............................................................. 93

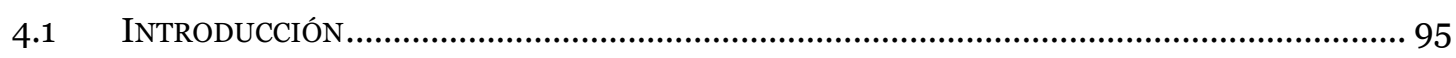

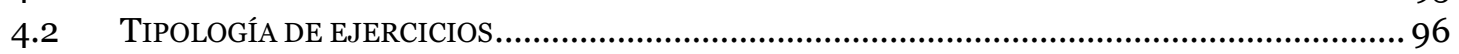




\begin{tabular}{|c|c|c|}
\hline \multirow{2}{*}{\multicolumn{3}{|c|}{..............97 }} \\
\hline & & \\
\hline & 2. & 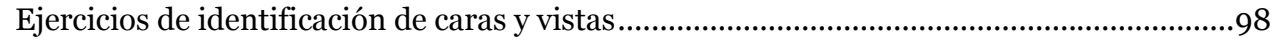 \\
\hline & 3 . & 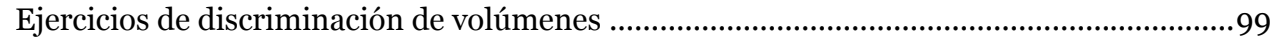 \\
\hline & 4. & 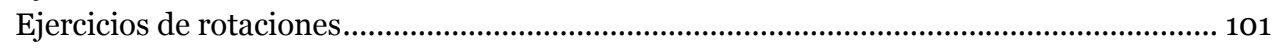 \\
\hline & 5 . & Ejercicios de Secciones \\
\hline & & UDIO PILOTO CURSO 2008-2009.... \\
\hline & 4.3.1 & Participantes \\
\hline & 4.3 .2 & Materiales \\
\hline & $4.3 \cdot 3$ & Procedimiento .... \\
\hline $4 \cdot 4$ & & LISIS DE DATOS.... \\
\hline & 4.4.1 & ................................109 \\
\hline & 4.4.2 & Después del entrenamiento espacial \\
\hline & 4.4 .3 & 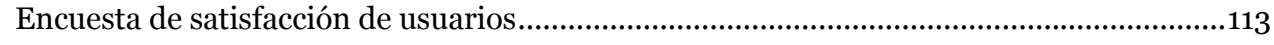 \\
\hline & RE & ULTADOS \\
\hline & $\begin{array}{l}4.5 \cdot 1 \\
4.6 .2\end{array}$ & 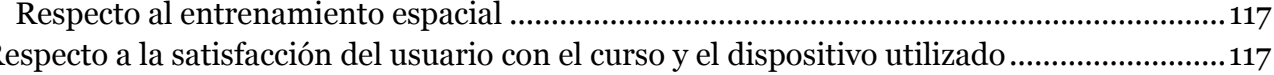 \\
\hline & & MEN \\
\hline
\end{tabular}

\section{CAPÍTULO V: DISEÑO, IMPLEMENTACIÓN Y EVALUACIÓN DE UNA ARQUITECTURA SOBRE DISPOSITIVOS MÓVILES DE PANTALLA TÁCTIL}

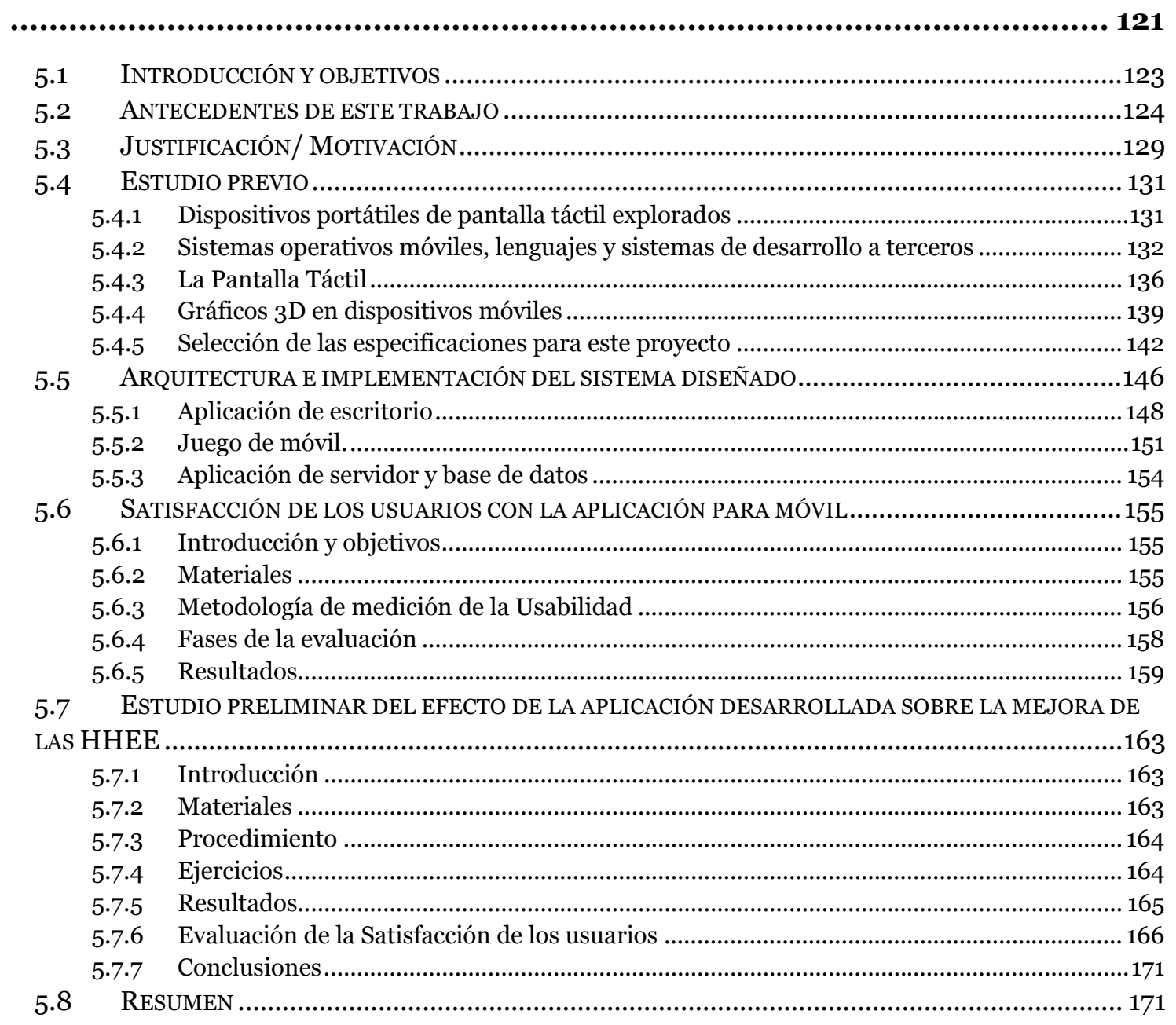

CAPÍTULO VI: CONCLUSIONES Y FUTUROS TRABAJOS ................... 175

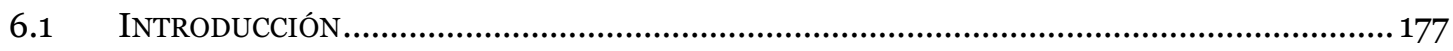

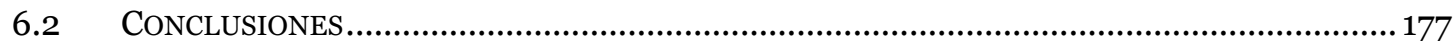


6.2.1 Conclusiones sobre la utilización del modelado 3D como herramienta de mejora de las HHEE.

6.2.2 Conclusiones sobre la utilización de los contenidos Web interactivos sobre dispositivos móviles de pantalla táctil como herramienta de la mejora de las HHEE..

6.2.3 Conclusiones sobre el diseño, implementación y evaluación de la arquitectura de un sistema para el entrenamiento espacial..........................................................................................180

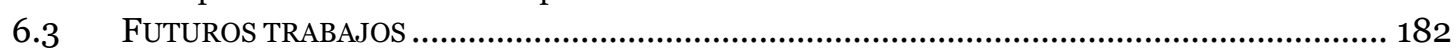

REFERENCIAS ...............................................................................185

ANEXOS

Anexo I.- Encuesta previa realizada a los participantes del curso de SketchUp ..............199

Anexo II.- Guía de referencia rápida de SketchUp ........................................................200

Anexo III.- Instrucciones del Test de Rotación Mental ..................................................... 201

Anexo IV.- Instrucciones del Test de DAT-SR...............................................................202

Anexo V.- Instrucciones del Material didáctico de Técnicas de Expresión Gráfica de

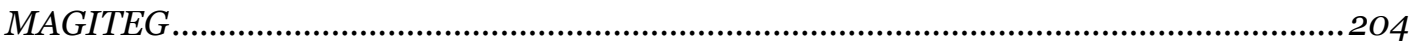

Anexo VI.- Ejercicios en papel dados a los participantes en la $2^{a}$ fase ............................208

Anexo VII.- Ejercicios realizados por los participantes en la $1^{a}$ fase en el aula.............. 210

Anexo VIII.- Ejercicios realizados por los participantes en la $1^{a}$ fase (trabajo en casa). .216

Anexo IX.- Ejercicios realizados por los participantes en la segunda fase....................... 222

Anexo X.- Ejercicios realizados por los participantes en la $3^{a}$ fase (trabajo en grupo). 225

Anexo XI.- Puntuaciones obtenidas en el curso de SketchUp ..........................................229

Anexo XII.- Análisis estadístico del curso con SketchUp ..................................................230

Anexo XIII.- Clasificación de ejercicios para la mejora de las habilidades espaciales .... 235

Anexo XIV.- Encuesta de satisfacción en el curso web con los iPods ............................... 243

Anexo XV.- Puntuaciones obtenidas en el curso web con los iPods...................................246

Anexo XVI.- Análisis estadístico del curso web con los iPods..........................................248

Anexo XVII.- Actividades del grupo de trabajo...............................................................251

Anexo XVIII.- Puntuaciones obtenidas en el curso Building with Blocks ........................ 253

Anexo XIX.- Encuesta de Perfil de Usuarios .................................................................... 254

Anexo XX.- Consentimiento informado .......................................................................... 257

Anexo XXI.- Instrucciones para los observadores ...................................................... 259

Anexo XXII.- Instrucciones para los usuarios.............................................................261

Anexo XXIII.- Encuesta de satisfacción de usuarios......................................................... 262

Anexo XXIV.- Encuesta de satisfacción de usuarios $2009(n=26)$................................. 265 


\section{Índice de figuras}

Figura 1. Aptitud, Habilidad y Capacidad Espacial.

Figura 2. Sub-factores y test de medida de la capacidad espacial ...................................39

Figura 3. (a) Manual de entrenamiento de Sorby; (b) y (c) Programa de entrenamiento de la Universidad de Pennsylvania; (d) Juego interactivo de S. Crown; (e) y (f) Multiview Drawing de la Universidad de Purdue; (g) Isometric Drawing Tool;

(h) Taller de Visión Espacial; (i) Mesa de visión espacial.........................................49

Figura 4. Ejemplo de interfaz caligráfica......................................................................... 51

Figura 5. Proceso de construcción de un sólido mediante e-CIGRO ............................... 51

Figura 6.- Un directivo de @Last Software anuncia la compra de la empresa por parte de Google ..................................................................................................................... 75

Figura 7.- Un directivo de @Last Software anuncia la compra de la empresa por parte

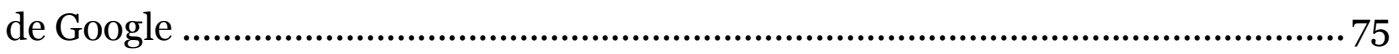

Figura 8.- Laboratorio de Expresión Gráfica del Área de Expresión Gráfica en la

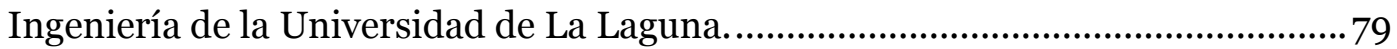

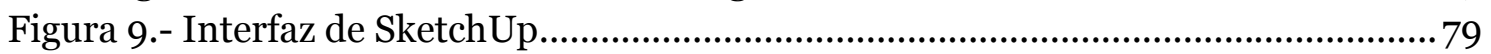

Figura 10- Maletín Maditeg de "Modelos de tres vistas y cortes" .................................. 80

Figura 11.- Ejemplo de representaciones axonométricas utilizadas en los ejercicios en

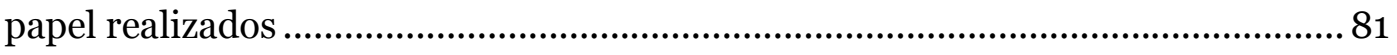

Figura 12.- Imagen de la pieza utilizada en la explicación de las funciones del programa

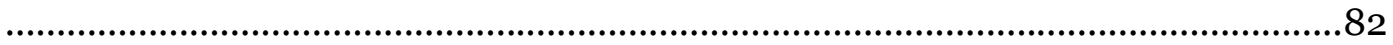

Figura 13.- Pieza modelada para conocer las órdenes básicas de SketchUp...................82

Figura 14.- Modelos realizados por los estudiantes en la actividad 1.1 del primer nivel 83

Figura 15.- Ejemplo de dos modelos realizados por dos estudiantes en la segunda actividad 1.2, del primer nivel de entrenamiento..................................................84

Figura 16.- Ejemplo de un modelo realizado por los estudiantes en el segundo nivel ...85

Figura 17.- Ejemplo de pieza realizada en el tercer nivel por un estudiante.....................86

Figura 18.- Puntuaciones medias del MRT y DAT:SR por género: hombres $(\mathrm{H}) \mathrm{y}$

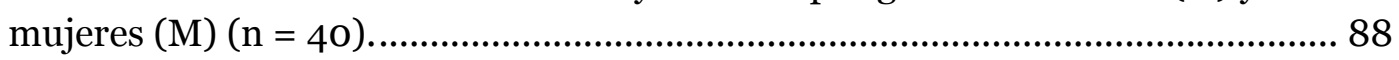

Figura 19.- Puntuaciones de los estudiantes en el MRT. ............................................89

Figura 20.- Puntuaciones de los estudiantes en el DAT-SR. ........................................89

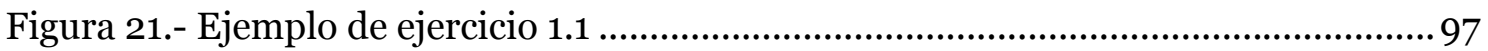

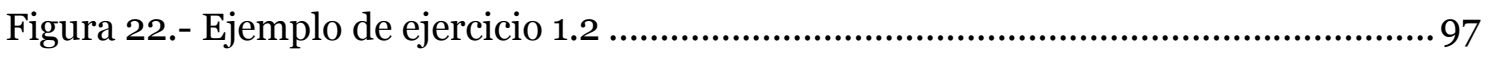

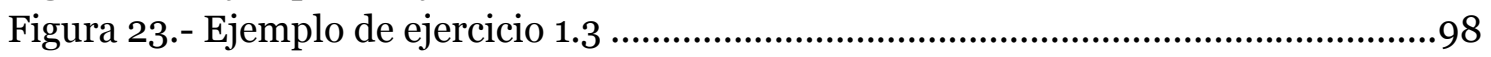

Figura 24.- Ejemplo de ejercicio 2.1 ...........................................................................98

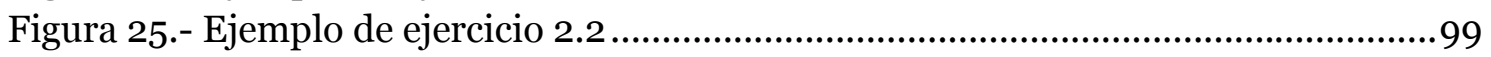

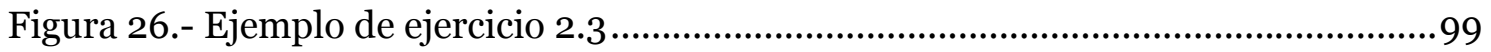

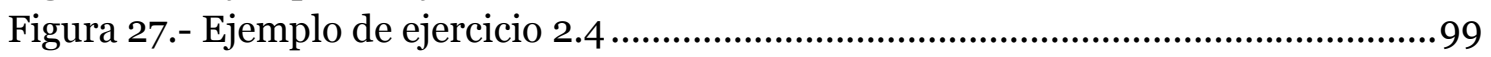

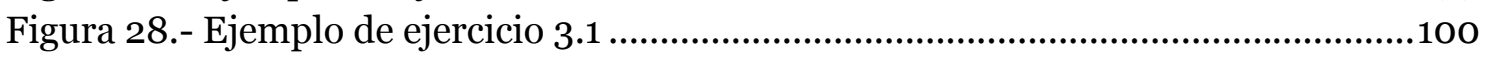

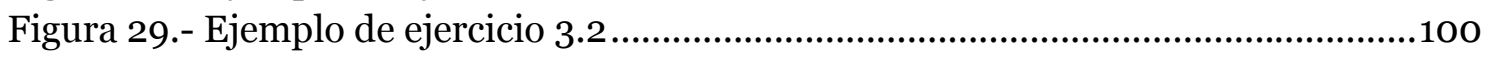

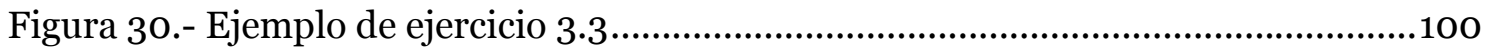

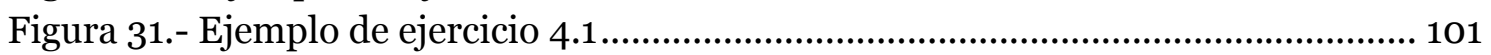

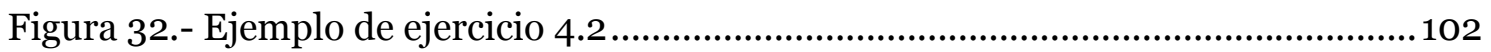

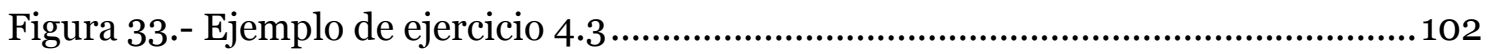

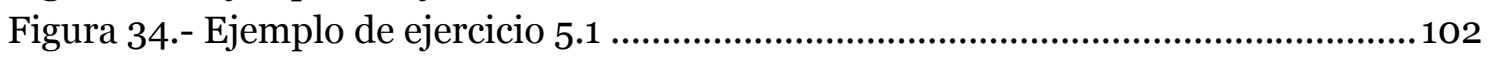

Figura 35.- Ejemplo de ejercicio 5.2 ............................................................................ 103 


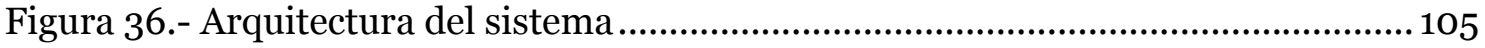

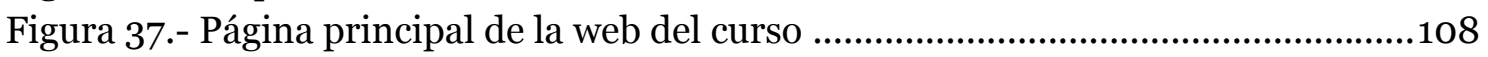

Figura 38.- Un estudiante realizando el módulo2 en los pasillos de la universidad ....108

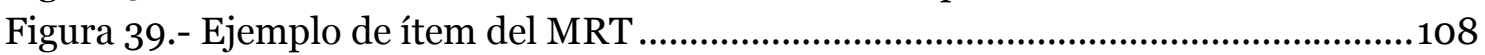

Figura 40.- Puntuaciones medias en el pre- y post-test para el grupo Experimental y de

Control $(\mathrm{n}=68)$ 112

Figura 41.- Puntuaciones en el pre- y post-test para el grupo Experimental y de Control

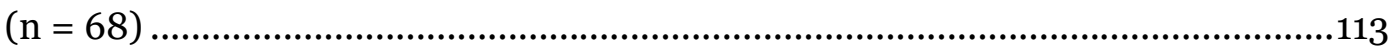

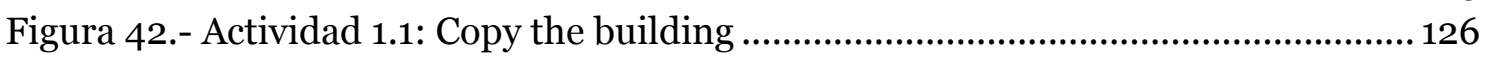

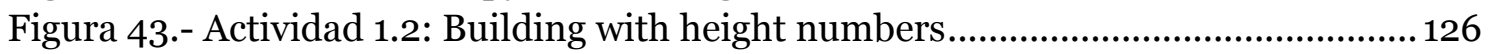

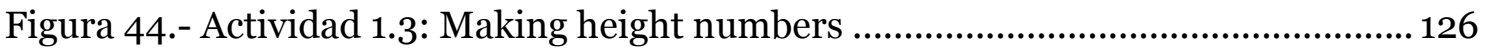

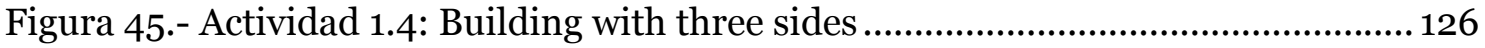

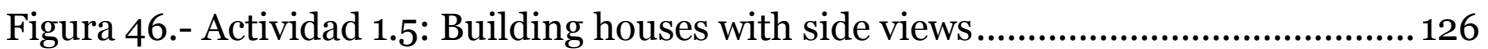

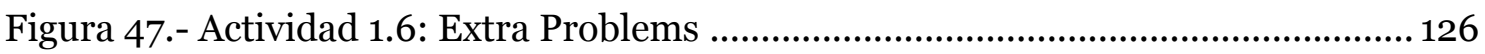

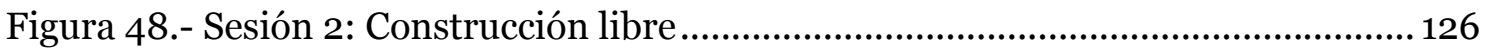

Figura 49.- Actividad 2.1: Building freely: del 3D en papel al 3D en PC........................126

Figura 50.- Actividad 2.2: Building freely: de las vistas al 3D en PC ............................126

Figura 51.- Puntuaciones medias en el MRT (izquierda) y DAT:SR (derecha) $(n=12) .129$

Figura 52.- Presencia de los SSOO para DDMM en el mercado (Noviembre 2008).... 143

Figura 53.- Arquitectura de la aplicación móvil........................................................... 145

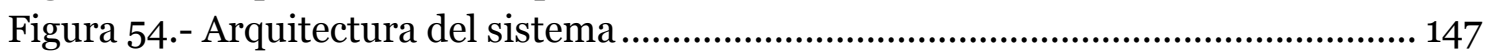

Figura 55.- Interfaz de de la aplicación de escritorio: gestión de usuarios ..................... 149

Figura 56.- Interfaz de de la aplicación de escritorio: creación de ejercicios ................ 149

Figura 57.- Interfaz de de la aplicación de escritorio: creación de competiciones .......150

Figura 58.- Interfaz de de la aplicación de escritorio: estadísticas ..............................150

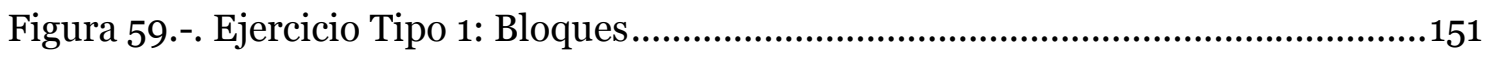

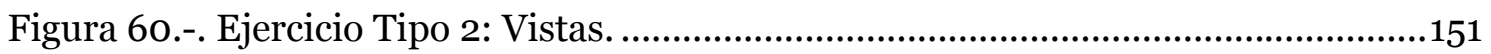

Figura 61.- Ayuda sobre vistas ortogonales normalizadas..........................................151

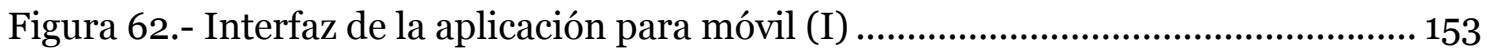

Figura 63.- Interfaz de la aplicación para móvil (II)...................................................... 154

Figura 64.- Flujo de datos desde las aplicaciones al servidor........................................154

Figura 65.- Un usuario realizando el test de usabilidad ................................................ 156

Figura 66.- Esquema de las etapas y fases del estudio de usabilidad ........................... 157

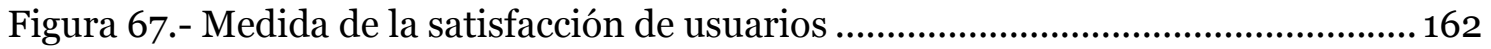

Figura 68.- La aplicación ejecutándose en un dispositivo HTC Touch Cruise ............... 163

Figura 69.- Puntuaciones medias del pre- y post-test para el grupo Experimental y de

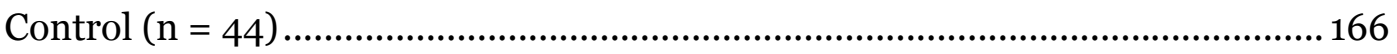

Figura 70.- Valoración de los participantes de la experiencia con el aparato................167

Figura 71.- Valoración de los participantes del contenido del curso (I)......................... 167

Figura 72.- Valoración de los participantes del contenido del curso (II) .......................168

Figura 73.- Valoración de los participantes de su experiencia con la aplicación...........168

Figura 74.- Valoración de los participantes del formato del curso..................................169

Figura 75.- valoración global del curso...................................................................... 170

Figura 76.- Tiempos medios de cada Competición ...................................................... 170 


\section{Índice de tablas}

Tabla 1. Períodos en la investigación de la capacidad espacial (Mohler, 2008).

Tabla 2.- Resumen de cursos que utilizan el modelado en el entrenamiento de las habilidades espaciales

Tabla 3 (Continuación).- Resumen de cursos que utilizan el modelado en el entrenamiento de las habilidades espaciales ......................................................... 73

Tabla 4.- Resumen de datos de los participantes........................................................78

Tabla 5.- Actividades realizadas en el programa de entrenamiento ...............................82

Tabla 6.- Resumen descriptivo de las variables utilizadas en el curso con SketchUp ....87

Tabla 7.- Niveles de significación del curso................................................................... 87

Tabla 8.- Puntuaciones medias en los pre y post-test y ganancias en los cuatro cursos.

Tabla 9.- Niveles de significación de Pre-test vs Pos-test para cada curso.................90

Tabla 10.- Resumen de los módulos y niveles del curso ..............................................106

Tabla 11.- Sumario de actividades realizadas en este estudio......................................109

Tabla 12.- Puntuaciones medias, ganancias y desviaciones típicas por grupo y género (n = 68)

Tabla 13.- Resultados de la ANOVA para el pretest por grupo y género y sus

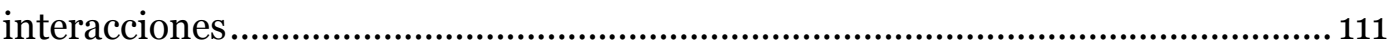

Tabla 14.- Resultados de la ANCOVA para el PostMRT por grupo y género y sus

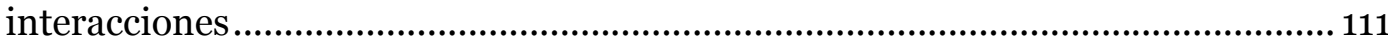

Tabla 15.- Respuestas de los estudiantes a la encuesta sobre su experiencia con el iPod ( $\mathrm{n}=38)$ .114

Tabla 16.- Resumen de las respuestas de los estudiantes a la encuesta sobre su experiencia con el curso $(n=38)$ 115

Tabla 17.-Tabla resumen de las actividades del curso "Building with Blocks" .............. 125

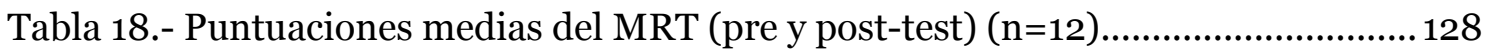

Tabla 19.- Sistemas Operativos Móviles y sus características (Andrade, 2009).............141

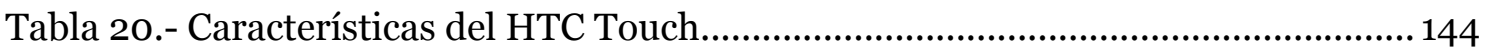

Tabla 21.- Especificaciones del hardware y software .................................................... 152

Tabla 22.- Problemas encontrados en la $1^{\text {a }}$ Fase y medidas a adoptar ...........................161

Tabla 23.- Características del hardware del HTC Touch Cruise y del software instalado

Tabla 24.- Sumario de actividades realizadas en este estudio........................................ 165

Tabla 25.- Resumen descriptivo de las variables ......................................................... 165 
Capítulo I: Introducción

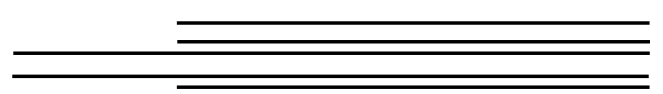





\subsection{Objetivos de esta tesis}

Este trabajo comienza a desarrollarse como continuación de una nueva línea de investigación abierta por D. Manuel Contero y D. Jose Luis Saorín en el año 2003, que se materializó en la tesis doctoral titulada "Estudio del efecto de la aplicación de tecnologías multimedia y del modelado basado en bocetos en el desarrollo de las habilidades espaciales" (Saorín, 2006) y en diversos trabajos publicados en revistas científicas (Contero, Naya, Company, Saorin, \& Conesa, 2005; Contero, Company, Saorin, \& Naya, 2006).

El objetivo de esa tesis fue determinar en qué medida las nuevas tecnologías (recursos web online y programas de bocetado por ordenador) son útiles para la mejora de las habilidades espaciales que requiere la profesión de ingeniero.

Ese trabajo mostró que la utilización de aplicaciones web era una estrategia alternativa al uso de ejercicios en papel. Estas aplicaciones parecían obtener muy buena acogida por parte de los estudiantes.

Este fue el motivo que animó a proponer, como continuación de esa línea de investigación, el desarrollo de nuevos contenidos electrónicos o aplicaciones pseudo-lúdicas, cuyo objetivo fuera la mejora de habilidades espaciales y que permitiera mejorar estas habilidades.

En este contexto, el trabajo de investigación que se detalla en los siguientes capítulos se propone como objetivos generales:

- Elaborar nuevas herramientas que puedan contribuir al desarrollo de las habilidades espaciales.

- Proponer estas herramientas en forma de "cursos intensivos de corta duración" o "cursos cero" a los estudiantes en los que se detecte niveles más bajos de habilidades espaciales.

- Aportar nuevos formatos e interfaces de usuario (dispositivos móviles de pantalla táctil) con la finalidad de utilizarlos como un instrumento motivador

- Explorar la utilización de la educación a distancia para los cursos de mejora de las habilidades espaciales. 
A partir del planteamiento realizado, los objetivos específicos que se plantean son los siguientes:

- Revisión bibliográfica sobre el concepto de habilidades espaciales.

- Valorar la utilización de herramientas de modelado 3D en el desarrollo de las habilidades espaciales

- Valorar la utilización de nuevos soportes de hardware en el desarrollo de las habilidades espaciales.

- Valorar la utilización de formatos de enseñanza a distancia en cursos intensivos de mejora de las habilidades espaciales.

- Valorar la motivación de los estudiantes ante los nuevos soportes y formatos.

\subsection{Antecedentes de esta tesis}

Como se ha comentado en el apartado anterior, esta línea de investigación comienza a desarrollarse en el año 2003 por los directores de esta tesis. Se plantearon una serie de preguntas:

- ¿Qué se entiende por habilidades espaciales?

- ¿Por qué son importantes?

- ¿Qué relación tienen con la ingeniería?

- ¿Qué características tienen los sujetos con buenas habilidades espaciales?

- ¿Se pueden determinar parámetros, en las personas, en las herramientas o en los métodos docentes que ayuden a mejorar la adquisición de estas habilidades?

- ¿Podemos diseñar estrategias de mejora para los sujetos con bajos niveles de habilidades espaciales?

- ¿Pueden desarrollarse tecnologías con interfaces amigables para el usuario que ayuden a su desarrollo?

Por su relación con esta tesis, se resume el trabajo desarrollado y se enumeran las contribuciones que, hasta el momento, nos aportan los trabajos llevados a cabo en el seno de esta línea de investigación y que han sido objeto de distintas publicaciones:

- Se realizó una revisión del estado del arte sobre las habilidades espaciales (HHEE) desde 1920 hasta el año 2006, tanto desde el punto de vista psicológico como desde la perspectiva más ingenieril. Se 
referenciaron los estudios que relacionaban la profesión de ingeniero y un buen nivel de HHEE. Además realizó un resumen de los test de medición y de las herramientas y cursos de mejora. Se consideró que las habilidades espaciales estaban formadas por dos subcomponentes o sub-factores: las Relaciones Espaciales y la Visión Espacial. Se seleccionaron dos test de medida: El Test de Rotación Mental (MRT) (Vanderberg \& Kuse, 1978) y el Test de Aptitudes Diferenciales, subtest de Relaciones Espaciales (DAT-SR) (Bennett, Seashore, \& Wesman, 2000), comprobando que el uso de estos dos test permite obtener una medida completa de las habilidades espaciales.

- Se llevó a cabo un estudio de campo con alumnos de primer curso de titulaciones técnicas de la Universidad de La Laguna. Se administraron los test MRT y DAT-SR al comienzo del curso académico 2004-2005 con el objetivo de conocer el nivel de los estudiantes a su entrada a la Universidad. Se seleccionaron aquellos estudiantes con peores resultados y se dividieron en tres grupos. Cada grupo recibió un curso intensivo de mejora de habilidades espaciales. El primer curso realizó ejercicios en papel, el segundo desarrolló ejercicios mediante recursos web on-line y el tercero mediante la utilización de la aplicación eCIGRO, herramienta de bocetado por ordenador desarrollada por el grupo Regeo ${ }^{1}$. Realizados los cursos, se volvieron a administrar los test a los alumnos. Los resultados obtenidos indican que los tres cursos intensivos mejoran las habilidades espaciales de los estudiantes, obteniendo unos resultados muy similares en todos ellos.

- El análisis de los datos del trabajo de campo permitió obtener, entre otras, las siguientes conclusiones:

1. El uso de los dos test DAT y MRT, se revela como un sistema sólido de medida de las habilidades espaciales, puesto que miden dos sub-factores de esta habilidad.

2. Hay variables específicas que afectan a cada una de estas sub-habilidades espaciales: el género o la práctica habitual con videojuegos. Los datos revelan que las mujeres tienen un nivel medio (al entrar en la universidad) menor en las habilidades de rotación espacial que los hombres. Además, aquellos alumnos que se manifiestan aficionados a los 
videojuegos obtienen, de media, mejores resultados en el test de rotación espacial.

3. Los cursos intensivos de corta duración se revelan como sistemas viables para mejorar las habilidades espaciales. Los tres cursos de seis horas de duración realizados se mostraron válidos y sin diferencias significativas entre ellos, en la medición mediante los test DAT y MRT. La utilización de aplicaciones web se mostró como una estrategia alternativa al método de ejercicios en papel. Dichas aplicaciones obtienen una muy buena acogida, (apreciación subjetiva), por parte de los alumnos.

\subsection{Justificación de esta tesis}

La investigación más reciente en el campo de las habilidades espaciales se centra en la relación de éstas con las nuevas tecnologías. El rápido crecimiento de las tecnologías de la información y de la comunicación y el hábil manejo que de estas tecnologías tienen los estudiantes de hoy día ha propiciado nuevas formas de educación.

Los avances de la tecnología, las nuevas interfaces de usuario y los recientes desarrollos en el campo de las comunicaciones móviles, tales como Wi-Fi, Bluetooth y las tecnologías de comunicación globales, como GPS, GSM, GPRS, 3G y los sistemas vía satélite, han creado un abanico de posibilidades para los usuarios y para el diseño y el acceso a los materiales de aprendizaje.

El uso de pequeños dispositivos móviles, tales como teléfonos móviles, Ultra móviles (UMPC), PDAs, Smartphones o consolas de videojuegos, es un tema que está levantando gran expectación en la actualidad y sobre el que se están realizando interesantes iniciativas empresariales y proyectos de investigación (IAML, 2009).

En estos últimos tiempos, se está produciendo un cambio en el sistema de acceso a los recursos. Comenzó con el denominado Aprendizaje electrónico (E-learning), cambiando de un modelo de enseñanza presencial a un modelo de enseñanza, en menor o mayor medida, asistida por medios electrónicos. Esto ha evolucionado en los últimos años al denominado Aprendizaje móvil (mobile learning o M-learning), resultado del cambio en la plataforma de acceso a los contenidos: del ordenador 
personal a los dispositivos móviles o dispositivos portátiles (de mano) de pequeñas dimensiones.

Esta tesis trata de explorar las oportunidades que nos ofrecen las nuevas interfaces de usuario y la flexibilidad que confiere la utilización de dispositivos de hardware de pequeñas dimensiones, en un contexto de educación no formal.

El trabajo de esta tesis se fundamenta en la necesidad de localizar a los estudiantes que, a su entrada a la Universidad, dispongan de niveles de habilidades espaciales inferiores a la media. Con el objetivo de ofrecer a estos estudiantes "cursos intensivos" de mejora de las habilidades espaciales, la investigación que se detalla en los siguientes capítulos trata de aportar nuevas herramientas y formatos (el modelado $3 \mathrm{D}$ y los dispositivos móviles de pantalla táctil) y valorar la satisfacción de los usuarios con los cursos recibidos.

\subsection{Metodología y plan de trabajo}

Esta tesis se estructura en base a dos líneas de actuación, diferenciadas en función del soporte utilizado y conectadas por su desarrollo temporal:

1. Se desarrollan dos experiencias de trabajo en entornos $3 \mathrm{D}$ en ordenador:

- Se lleva a cabo el diseño y evaluación de un curso de mejora de las HHEE, utilizando el software gratuito de modelado 3D SketchUp (Capítulo III).

- Se realiza además un curso denominado "Building with blocks", que explora la utilización de la construcción con cubos tipo Lego@ para la mejora de las HHEE (Capítulo IV: Antecedentes).

2. Los resultados obtenidos en estos estudios exploratorios nos permiten abordar el diseño de nuevos materiales de aprendizaje sobre dispositivos móviles de pantalla táctil. En este sentido se elaboran dos tipologías de materiales:

- Un entorno web interactivo (en formato plano 2d), optimizado para dispositivos tipo iPod Touch. Se diseña y evalúa un curso on-line programado para cinco días con este material. El curso muestra su efectividad en la mejora de las habilidades espaciales y es valorado con un alto grado de satisfacción por los estudiantes. 
- Una aplicación para teléfonos móviles de pantalla táctil que nos permite la construcción de modelos de cubos en un entorno tridimensional y que ha sido desarrollada para el sistema operativo Windows Mobile. La herramienta es testeada y mejorada en una prueba de usabilidad con un grupo de usuarios. Finalmente, se realiza un estudio de campo que permite obtener conclusiones preliminares que apuntan en la dirección de que esta aplicación mejora las habilidades espaciales de los estudiantes sometidos a un entrenamiento específico.

Las tareas fundamentales desarrolladas se detallan a continuación:

1. Definición del marco de trabajo: las etapas y los parámetros que se pretenden obtener en la investigación.

2. Revisión bibliográfica: tomando como referencia la tesis doctoral y los trabajos publicados en los que se fundamenta esta tesis. Se realiza una base de datos de referencias bibliográficas relacionadas con las habilidades espaciales, disponible en la web http://degarin.com/moodle.

3. Creación y mantenimiento de un sitio web para la línea de investigación en habilidades espaciales, disponible en la web http://degarin.com/dehaes.

4. Elaboración de una versión electrónica de los test DAT-SR y MRT, disponible en la web http://degarin.com/moodle.

5. Diseño de una encuesta para la recogida de datos de los estudiantes referente a género, edad, aficiones, uso de dispositivos móviles, uso de la tecnología, motivación, etc.).

6. Diseño de una encuesta para la recogida de datos referente a la satisfacción de los usuarios con el curso desarrollado.

7. Diseño y desarrollo de las pruebas de campo de cursos intensivos de mejora de las habilidades espaciales mediante modelado $3 \mathrm{D}$.

8. Catalogación de los ejercicios y/o herramientas usadas en la mejora de las habilidades espaciales. Evaluación de la posibilidad de adaptarlos a un formato electrónico para su uso en un dispositivo móvil. Proponer nuevas herramientas para el desarrollo de las habilidades espaciales.

9. Estudio de los dispositivos móviles del mercado, los sistemas operativos y lenguajes de programación que soportan estos dispositivos. 
10.Propuesta de ejercicios a implementar en los soportes móviles y elección de los dispositivos y sistema operativo viable.

11. Prueba de campo de las herramientas desarrolladas para dispositivos móviles: se realizó un entrenamiento intensivo con un grupo de usuarios de diferentes características y se evaluó.

12. Análisis de los datos de las pruebas realizadas.

13. Elaboración de una propuesta de mejora y perfeccionamiento de las aplicaciones.

14. Implementación de las mejoras.

15. Análisis de los resultados obtenidos.

16. Redacción del trabajo realizado.

En lo referente al trabajo de campo realizado en esta tesis, la metodología utilizada consiste en seleccionar una muestra de estudiantes de distintas carreras técnicas. Se desarrolló en tres etapas:

1. Recogida de datos y medición de las Habilidades Espaciales al inicio de curso.

2. Selección de alumnos (voluntarios y/o según su nivel de habilidades espaciales) para la realización de los cursos de mejora.

3. Realización de los cursos de mejora y medición de las habilidades al final de dichos cursos.

4. Recogida de datos acerca de la satisfacción de los usuarios con el curso recibido.

\subsection{Estructura de esta tesis}

Esta Tesis se ha dividido en seis capítulos, con el contenido que se indica a continuación:

\section{CAPITULO I: Introducción}

Contiene una descripción general que justifica la realización de la tesis, el contexto en que se ha llevado a cabo, los antecedentes existentes, sus objetivos, metodología y plan de trabajo, estructura y principales contribuciones. 


\section{CAPITULO II: Marco Teórico}

En este apartado, se realiza una breve reseña histórica sobre la investigación en el campo de las habilidades espaciales y su relación con la ingeniería, los test de medida y los factores que influyen sobre los niveles de estas habilidades.

Además se expone una justificación no exhaustiva de la relación entre juegos y aprendizaje. Se acerca al concepto de aprendizaje móvil (mlearning) y a las distintas experiencias desarrolladas en este campo.

\section{CAPITULO III: Curso intensivo de mejora de las habilidades espaciales mediante modelado 3D.}

Este capítulo propone una nueva metodología de apoyo al desarrollo de las relaciones espaciales y de la visión espacial, mediante el uso del software de modelado $3 \mathrm{D}$ SketchUp@C. Se expone la experiencia llevada a cabo con estudiantes de primer curso de la Titulación de Ingeniería Técnica de Obras Públicas de la Universidad de La Laguna durante el Curso Académico 2006-2007. Se compara con una experiencia anterior llevada a cabo en el curso 2004-2005.

\section{CAPITUlO IV: Curso Web optimizado para dispositivos móviles de pantalla táctil}

En este capítulo se detalla el diseño, desarrollo e implementación de un material web optimizado para dispositivos móviles de pantalla táctil tipo iPod Touch y su evaluación en el desarrollo de las habilidades espaciales. Se valora la satisfacción de los usuarios con el curso recibido y se recogen sus opiniones y sugerencias.

\section{CAPITULO IV: Diseño, implementación y evaluación de una arquitectura para el entrenamiento espacial sobre dispositivos móviles de pantalla táctil}

Este capítulo aborda el diseño y la implementación de la arquitectura de un sistema formado por 4 componentes: (1) aplicación de escritorio, (2) aplicación 3D para dispositivo móvil, (3) aplicación servidor y (4) base de datos, destinada al entrenamiento espacial de los estudiantes. Se realiza la evaluación de dos versiones de prueba de la aplicación móvil y un estudio de campo que permite obtener conclusiones preliminares que apuntan en 
la dirección de que esta aplicación mejora las habilidades espaciales. Se persigue que los usuarios se familiaricen con el entorno $3 \mathrm{~d}$ y puedan mejorar el entendimiento de la relación $2 \mathrm{~d}-3 \mathrm{~d}$, en un contexto de educación no formal (juegos electrónicos). La novedad de este sistema es que se ha diseñado e implementado en dispositivos móviles de pantalla táctil, un formato novedoso en el campo de la instrucción espacial, que nos permiten una interfaz más intuitiva y natural, cercana a los juegos de construcción tipo Lego $\mathbb{C}$.

El trabajo descrito en este capítulo es fruto de la colaboración entre la investigadora Isabel Sánchez Berriel, del Área de Ciencias de la Computación e Inteligencia Artificial de la Universidad de La Laguna (ULL), y la autora de esta tesis, del Grupo de Investigación en Habilidades Espaciales (Dehaes) de la ULL, en el seno del proyecto fin de carrera titulado "Construyendo con bloques: Juego 3D para la mejora de las Habilidades Espaciales en Dispositivos Móviles usando J2ME”, realizado por los ingenieros informáticos Miguel Jonás Bravo García y Juan Antonio Hernández Cordovez y leído en el mes de Diciembre del año 2008 (Bravo-García, Hernández-Cordovez, Sánchez-Berriel, 2008).

\section{Parte V: CONCLUSIONES Y FUTUROS TRABAJOS}

Por último, se indican las conclusiones del trabajo presentado, indicando cuales han sido las principales aportaciones y contribuciones de la tesis. Igualmente se indica cuáles pueden ser las líneas futuras de trabajo, señalando aquellas de mayor interés.

\subsection{Contribuciones de esta tesis}

Se destacan las siguientes contribuciones originales de esta tesis:

1. Diseño y evaluación de un curso intensivo mediante modelado 3D:

- Utilización de una herramienta de software de modelado 3D, gratuita y de interfaz sencilla.

- Evaluación de resultados en la mejora de las HHEE.

- Puesta a disposición de la comunidad científica el contenido del curso desarrollado.

2. Caracterización de los materiales utilizados en la literatura para la mejora de las habilidades espaciales.

3. Utilización de una nueva plataforma para la mejora de las habilidades espaciales: los dispositivos móviles de pantalla táctil. 
4. Diseño, desarrollo e implementación de un material web optimizado para dispositivos móviles de pantalla táctil y su programación en forma de curso intensivo. Este material elaborado se pone a disposición del público en distintos formatos, abriendo la posibilidad de utilizarlo como material docente en distintos niveles educativos: bachiller, ciclos formativos, cursos cero, etc.

5. Una aplicación para teléfonos móviles de pantalla táctil que nos permite la construcción de modelos de cubos en un entorno tridimensional, que ha sido desarrollada para dispositivos móviles de pantalla táctil sobre el sistema operativo Windows Mobile. Todo ello encuadrado dentro de la arquitectura de un sistema en la que el profesor elabora un conjunto de ejercicios, que luego el estudiante realiza en la aplicación móvil. Este trabajo se lleva a cabo conjuntamente con el Área de Ciencias de la Computación e Inteligencia Artificial de la ULL, en el seno del proyecto fin de carrera titulado "Construyendo con bloques: Juego 3D para la mejora de las Habilidades Espaciales en Dispositivos Móviles usando J2ME”, realizado por los ingenieros informáticos Miguel Jonás Bravo García y Juan Antonio Hernández Cordovez y leído en el mes de Diciembre del año 2008 (Bravo-García, Hernández-Cordovez, Sánchez-Berriel, 2008).

6. Utilización de la educación a distancia sobre dispositivos móviles (mobile learning) en un curso intensivo de mejora de las habilidades espaciales.

7. Valoración de la satisfacción de los estudiantes con los cursos desarrollados:

- Valoración de la satisfacción de los usuarios sobre la utilización de los nuevos soportes (dispositivos móviles de pantalla táctil) en la mejora de las HHEE.

- Valoración de la satisfacción de los usuarios sobre la utilización de los cursos a distancia en la mejora de las HHEE. 


\subsection{Proyectos de investigación, artículos publicados y ponencias presentadas en congresos como consecuencia de la realización de esta tesis}

\section{Proyectos de Investigación:}

1. "EVALUACIÓN Y DESARROLLO DE COMPETENCIAS ASOCIADAS A LA CAPACIDAD DE VISIÓN ESPACIAL EN LOS NUEVOS TÍTULO DE GRADO DE INGENIERÍA".

Programa de Estudios y Análisis 2009 del Ministerio de Educación.

Responsable: D. Jose Luis Saorín Pérez.

Participantes: Jose Luis Saorín Pérez, Manuel Contero González, Fernando Naya Sanchís, Rosa E. Navarro Trujillo, Jorge Martín Gutiérrez y Norena N. Martín Dorta.

Fecha de concesión: Agosto de 2009.

Duración: un año.

Presupuesto: 13.310,00 Euros.

Objetivos del proyecto: Este proyecto trata de estudiar el perfil de los estudiantes a su entrada a la Universidad (el género, la edad, la formación recibida, las aficiones, su habilidad con las nuevas tecnologías, etc.) y su relación con los niveles de habilidades espaciales. Esto permitirá diseñar propuestas de cursos intensivos en distintos formatos adaptados a las características de los usuarios.

\section{Artículos en revistas indexadas en el Journal Citation Index:}

1. Martín-Dorta, N., Saorin, J., \& Contero, M. (2008). Development of a Fast Remedial Course to Improve the Spatial Abilities of Engineering Student. Journal of Engineering Education, 27 (4), 505-514.

2. Martín, J., Saorín, JL., Martín-Dorta, N., Contero, M. Do video games improve spatial abilities of engineering students? International Journal of Engineering Education. Aceptado para su publicación.

Artículos en revistas indexadas en el Expanded Journal Citation Index:

1. Saorín, JL., Martín-Dorta, N., Martín, J., Navarro, R. \& Contero, M. (2009). La capacidad de visión espacial y su relación con la ingeniería. DYNA Ingeniería e Industria, 84 (9). 


\section{Congresos y Jornadas:}

1. Martín, J., Martín-Dorta, N., Saorín, J.L., Navarro, R. (2009). Desarrollo de Habilidades Espaciales en Estudiantes de Ingeniería. Poster presentado en las jornadas "Semana de la Investigación en la Ingeniería 2009", celebradas en la E.T.S. de Ingeniería Civil e Industrial de la Universidad de La Laguna. Enero de 2009.

2. Martín, J., Martín-Dorta, N., Saorín, J.L., Navarro, R., Contero, M. (2009). La capacidad de visión espacial en el contexto del EEES. XXI Congreso Internacional de Ingeniería Gráfica, 10-12 Junio, Lugo. ISBN 978-84-96351-54-7.

3. Martín, N., Martín, J., Saorín, J.L., Navarro, R., Contero, M. (2008). Propuesta de actividades para el desarrollo de las habilidades espaciales en los estudiantes de ingeniería. 20 Congreso Internacional de Ingeniería Gráfica, Junio, Valencia. ISBN 978-84-8363-275-8.

4. Martín, J., Martín, N., Saorín, J.L., Contero, M., Navarro, R. (2008). Aplicaciones web para el desarrollo de las habilidades espaciales. 20 Congreso Internacional de Ingeniería Gráfica, Junio, Valencia. ISBN 978-84-8363-275-8 (Poster).

5. Navarro, R., J.L. Saorín, N. Martín, J. Martín. (2006). Expresión Gráfica en Arquitectura e Ingeniería y el desarrollo de visión y habilidades espaciales de los alumnos en las carreras técnicas. Congreso Apega 2006: Asociación de profesores de Expresión Gráfica aplicada a la edificación, Madrid.

6. Martín, J., Martín, N., J. L. Saorín, R. Navarro. (2006). Campus virtual en la docencia de Expresión Gráfica en la Ingeniería en la Universidad de La Laguna. Congreso Internacional de Ingeniería Gráfica. ISBN 84689-8593-7 (Poster).

7. Saorín J. L., Navarro, R., Martín, N. y Contero M. (2005). Las habilidades espaciales y el programa de expresión gráfica en las carreras de ingeniería. International Conference on Engineering and Computer Education ICECE05. Madrid. ISBN: 84-609-8149-5. 
Capítulo II: Marco Teórico

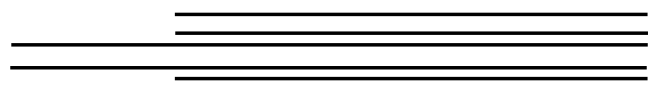





\subsection{La Capacidad Espacial}

\subsubsection{Introducción}

En el último medio siglo, la capacidad espacial ha recibido un reconocimiento creciente y, a pesar de que no se le haya prestado tanta atención como a las capacidades verbales y numéricas, la investigación acentúa su importancia en los campos tradicionales de la ingeniería y el arte, así como en prácticamente cualquier aspecto de la vida. Con repercusiones en casi todos los campos científicos y técnicos, la capacidad espacial sigue siendo un campo activo de investigación, especialmente en el ámbito de la ingeniería. Este trabajo pretende exponer el estado de los conocimientos actuales sobre esta capacidad, dentro de las capacidades intelectuales del individuo. Al ser dicha materia competencia de los estudios de psicología, se ha procurado sintetizar la información sobre este tema.

La capacidad espacial es aceptada por distintos autores a lo largo de la historia como una componente de la inteligencia. La definición de la inteligencia no es una tarea sencilla y, en realidad, no existe una definición única, ya que dependiendo del enfoque con el que se aborde, aparecen distintas facetas de la misma (Andrés Pueyo, 2001). Definida por Spearman (1927), fue considera por este autor como "la capacidad de obtener y crear información nueva, útil y aplicable a partir de informaciones sensoriales ya existentes, que se manifiestan en el comportamiento o la actividad mental del sujeto". Existen diversas ramas de la psicología que la estudian y distintos enfoques que abordan el concepto: la psicología cognitiva, la psicología diferencial, la psicología evolutiva, la psicología experimental, la antropología, etc. En función de estos enfoques aparecen distintos modelos de inteligencia: factorial, computacional, global, de desarrollo, culturales, etc. Nuestro trabajo se centra en el enfoque factorial, estudiado por la psicología psicométrica, que establece que las diferencias individuales en la cognición humana, pueden medirse a través del rendimiento en los test de inteligencia y que la inteligencia misma se puede definir, por tanto, por las variaciones de las puntuaciones en estos test, según las personas. El resultado de esos test es una medida, ampliamente utilizada y conocida como Cociente Intelectual (CI). El CI se obtiene a partir de la intersección de los resultados de una serie de sub-test, que tratarán de medir diferentes 
aspectos de las capacidades de un individuo (Andrés Pueyo \& Jayme Zaro, 1998).

Por otra parte, desde que los psicólogos han estudiado científicamente la inteligencia, se ha visto necesario distinguir entre Rendimiento Mental o Cognitivo e Inteligencia (Andrés Pueyo, 2001). Rendimiento, se refiere a la aplicación conjunta, por parte de una persona, de unos recursos, capacidades y disposiciones psicológicas para resolver un problema. En el rendimiento influyen variables como la motivación, el interés, la personalidad, las expectativas, la inteligencia, etc. Sin embargo, medir una capacidad (Inteligencia), significa medir la potencialidad de un individuo en un área dada. Por ejemplo, conociendo la capacidad numérica de una persona, podemos, quizás, predecir su rendimiento en actividades relacionadas con las matemáticas. Para medir el Rendimiento existen varios procedimientos, el examen es el más habitual. Los test de inteligencia nos sirven como herramienta de medida de la Inteligencia y existe un acuerdo sobre la validez de sus resultados que la experiencia ha demostrado acertado. Es importante señalar esta distinción entre Rendimiento e Inteligencia, porque habitualmente los únicos datos disponibles de los estudiantes de ingeniería son el resultado de los exámenes, o lo que es lo mismo, la evaluación del rendimiento académico. Aunque estos resultados dependen en gran medida de los valores de inteligencia, no son el único parámetro del que dependen.

\subsubsection{La Capacidad Espacial}

Con el objetivo de entender qué es la capacidad espacial, creemos necesario distinguir entre aptitud, habilidad y capacidad espacial, términos relacionados entre sí, pero que se vienen utilizando de forma indistinta y que pueden crear cierta confusión conceptual. La Aptitud Espacial es definida como el potencial innato que un individuo tiene para visualizar, previo a que pueda realizar cualquier tipo de entrenamiento o tarea que pueda afectarle. Sin embargo, la Habilidad Espacial puede ser adquirida a través del entrenamiento. Algunos individuos pueden disponer de un mayor grado de aptitud innata, pero la mayoría de la gente puede adiestrar esta habilidad a través de la práctica (Sorby, Wysocky, \& Baartmans, 2003). La aptitud espacial contiene una carga mayoritariamente genética o hereditaria. Por ejemplo, todos los seres humanos nacemos con una cierta aptitud para hablar, pensar o caminar. La habilidad espacial, sin embargo, requiere del aprendizaje y 
del entrenamiento para poder concretarse. Por último, la Capacidad Espacial supone la integración de aptitudes, habilidades y/o destrezas (ver Figura 1) (Sánchez Carlessi \& Reyes Romero, 2003).

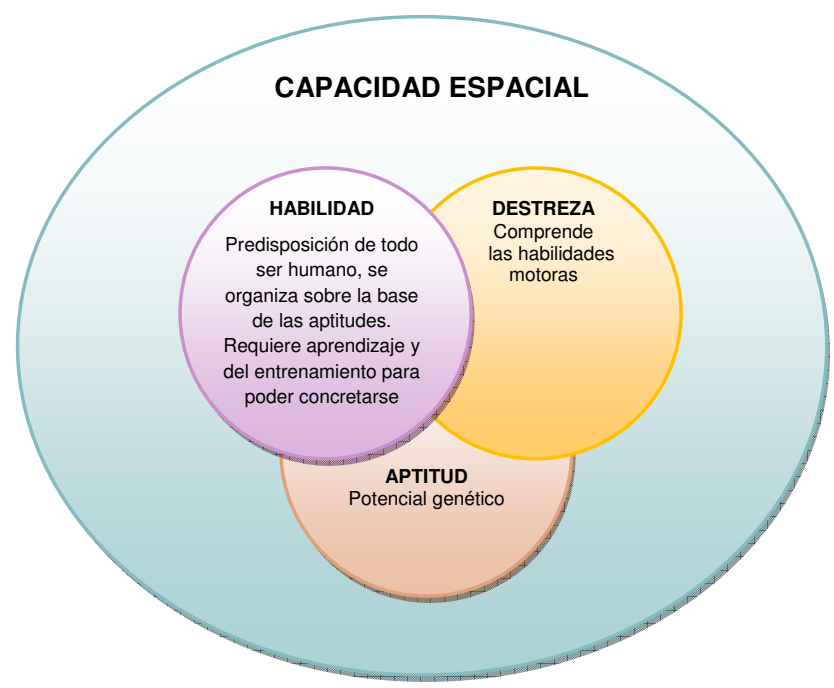

Figura 1. Aptitud, Habilidad y Capacidad Espacial

La definición de capacidad espacial no es una tarea sencilla. En realidad no existe una definición única puesto que dependiendo del enfoque con que el que se aborde, aparecen distintas facetas de la misma. Podemos entender que es la habilidad de manipular mentalmente los objetos y sus partes en un espacio bidimensional y tridimensional. Desde la perspectiva de su medición, la podemos entender como la habilidad de realizar rotaciones y comparaciones de cubos bidimensionales $y$ tridimensionales por un lado (Relaciones espaciales) y la habilidad de reconocer piezas tridimensionales mediante plegado y desplegado de sus caras (Visión Espacial) (Saorín, 2006).

Los términos Capacidad, Habilidad, Aptitud o Competencia son utilizados en la vida cotidiana con significados distintos a los expresados en este trabajo. En el ámbito de esta tesis, la Capacidad Espacial se entiende como una componente de la Inteligencia (Factor Espacial), en el contexto de la psicología y de la posibilidad de medirla mediante test psicotécnicos. Esta capacidad integra aptitud, destreza y habilidad. Utilizaremos el término de Habilidades Espaciales para referirnos a la parte de la capacidad espacial que podemos adiestrar mediante entrenamiento. 


\subsubsection{Componentes de la Capacidad Espacial}

Todos los investigadores coinciden en considerar la capacidad espacial como un factor fundamental en los modelos de Inteligencia. No existe, sin embargo, el mismo acuerdo a la hora de determinar si esa capacidad está formada a su vez por varias sub-capacidades. Al analizar la bibliografía existente se encuentran varias perspectivas para establecer su clasificación y varias pruebas dominantes para obtener resultados cuantitativos. Entre las clasificaciones más importantes se encuentra la realizada por Linn y Petersen entre 1974 y 1982, que llevaron a cabo un meta-análisis sobre todos los test dedicados a medir la visión espacial (Linn \& Petersen, 1986) y los clasificaron en tres categorías:

- Percepción espacial: Habilidad de determinar relaciones espaciales a pesar de la existencia de otras informaciones que pueden distraer al sujeto.

- Visión Espacial: Habilidad de manipular información visual compleja cuando para producir una solución correcta se necesitan varias etapas.

- Rotación Espacial: Habilidad de rotar en nuestra imaginación, rápida y acertadamente figuras de dos o tres dimensiones.

A pesar de esta división en tres categorías, en estos últimos años, una gran cantidad de autores simplifican esta clasificación usando sólo dos categorías (McGee, 1979; Burnet \& Lane, 1980; Pellegrino, Alderton, \& Shute, 1984; Clements \& Battista, 1992; Olkun, 2003) (ver Figura 2):

- Relaciones espaciales: Habilidad de realizar rotaciones y comparaciones en cubos bidimensionales y tridimensionales. (Incluiría las rotaciones espaciales y la percepción espacial de la anterior clasificación)

- Visión Espacial: Habilidad de reconocer piezas tridimensionales mediante plegado y desplegado de sus caras.

\subsubsection{Medida de la capacidad espacial}

Existen múltiples instrumentos diseñados exclusivamente para medir las habilidades espaciales. Algunos autores como Eliot y Smith (1983) han llegado a recopilar más de 200 test diferentes. A la hora de seleccionar este instrumento es necesario tener en cuenta varios aspectos, entre los 
que podemos destacar, que debe ser una herramienta validada por trabajos de campo, diseñada para medir la componente de la inteligencia que deseamos y utilizada en estudios similares a los que pretendemos desarrollar, con el objetivo de que se puedan comparar los resultados. Teniendo en cuenta el contexto proporcionado por las experiencias previas (Devon, Engle, Foster, Sathianathan, \& Turner, 1994; Sorby \& Baartmans, 2000; Gerson, Sheryl, Wisocki, \& Baartmans, 2001; Saorín, 2006), nuestro grupo de investigación quiere destacar especialmente dos instrumentos que han sido ampliamente utilizados en las investigaciones en el ámbito de la ingeniería: el Test de Rotación Mental (MRT) (Vanderberg \& Kuse, 1978), para medir el factor de Relaciones Espaciales, y el Test Relaciones Espaciales de la batería de Test de Aptitudes Diferenciales (DAT -SR) (Bennett, Seashore, \& Wesman, 2000), para medir el factor de Visión Espacial (ver Figura 2).

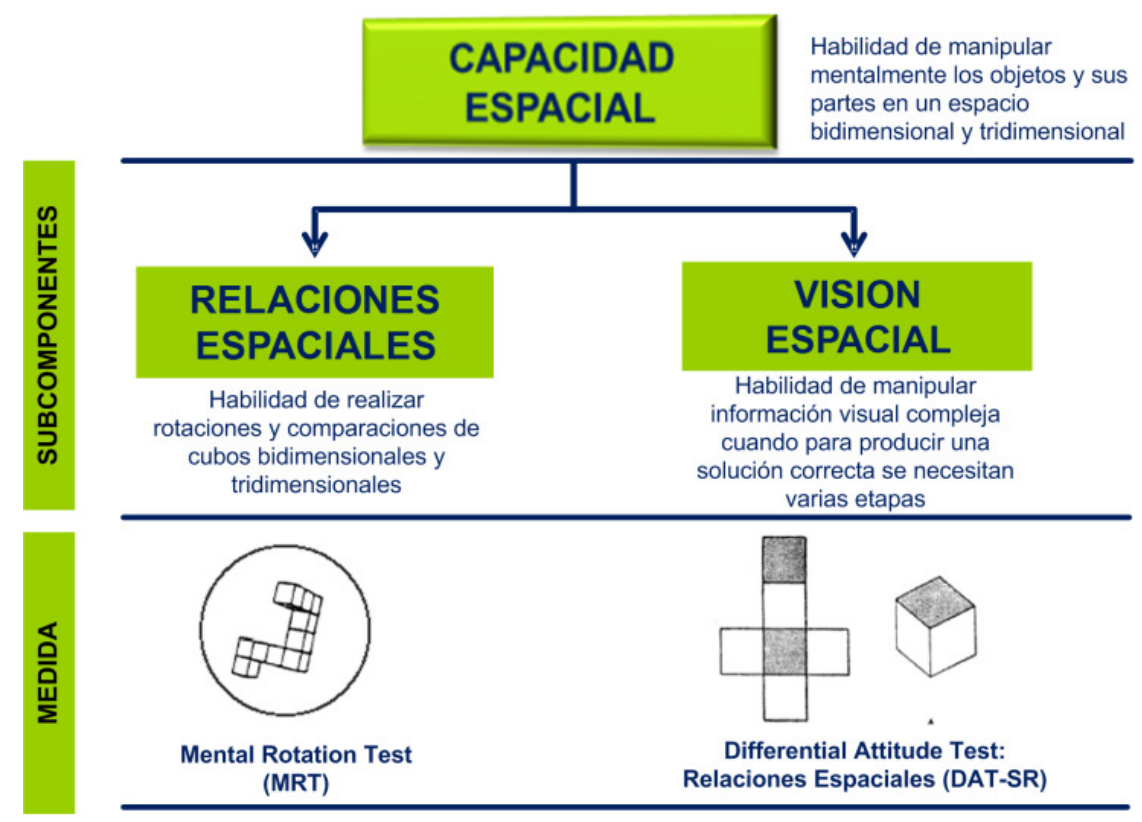

Figura 2. Sub-factores y test de medida de la capacidad espacial

En 1978, Vanderberg y Kuse se inspiraron en los trabajos de Shepard y Metzler sobre rotaciones mentales para crear un test denominado Mental Rotation Test (M.R.T). Es interesante recalcar que los resultados obtenidos por Vanderberg y Kuse en 1978 al aplicar este test, indicaron claramente una diferencia entre hombres y mujeres, independientemente de su edad (ver instrucciones del test en Anexo III).

El test DAT-SR pertenece a la batería DAT (Differential Attitude Test), creada por George K. Bennet y Alexander G. Wesman en el año 1947. En 
1967, ediciones TEA llevó a cabo la adaptación española, bajo la dirección de Mariano Yela. Es usado en España para medir el CI, por lo que lleva muchos años en el mercado y se tienen muchos datos. Aparece en los últimos años una nueva versión denominada DAT-5, basada en la Forma $\mathrm{C}$ de la $5^{\mathrm{a}}$ versión Americana. Existen dos formas $\left(\begin{array}{lll}1 & \mathrm{y} & 2\end{array}\right)$ que corresponden a niveles de dificultad diferentes. La forma 1 es más sencilla y puede usarse para la evaluación de subalternos y operarios. La forma 2 es adecuada para evaluar a técnicos licenciados y mandos (ver instrucciones del test en Anexo IV).

\subsubsection{Breve reseña histórica de la investigación sobre la capacidad espacial}

Ya por el año 1880, Francis Galton informa de los estudios que desarrolla sobre imágenes mentales. Desde entonces, los investigadores han intentado definir las habilidades espaciales de muchas maneras y desde distintas perspectivas, discutiendo sobre los sub-factores que la componen y sobre los métodos para medirla. El International Dictionary of Spatial Tests (Eliot \& Smith, 1983) y más recientemente el estudio de revisión de James L. Mohler (Mohler, 2008), identifican cuatro fases en la investigación en este campo.

La primera fase (ver Tabla 1) abarca las contribuciones desde 1880 a 1940, donde los investigadores identifican la capacidad espacial como un factor independiente de la Inteligencia General. Aunque es Galton quien en 1880 inicia la investigación, no es hasta principios de 1920 cuando comienzan a aparecer las publicaciones que ponen su atención en la capacidad espacial. El trabajo de Thorndike (1921), Kelly (1928) y Thurstone (1938) es responsable de que sea considerada una capacidad independiente de la Inteligencia General.

En la segunda fase, desde los años 1940 hasta 1960, se centran en intentar definir la capacidad espacial e identificar los sub-factores principales que la componen. Debido a las distintas técnicas utilizadas y el uso de diferentes test, se adoptaron nombres y definiciones contradictorias. Además, se incluyó la discusión sobre el número de sub-factores considerados (Hegarty \& Waller, 2004). Pero es a consecuencia de la evaluación a gran escala de las Fuerzas Aéreas de los Estados Unidos (Army Air Force, AAF), realizada por L.G. Humphreys, cuando la capacidad espacial obtiene un importante respaldo (Guilford \& 
Zimmerman, 1947). Al final de este periodo los investigadores estaban de acuerdo en que la capacidad espacial no era un sistema unitario y que existían diversos test para medirla (citado en Eliot \& Smith, 1983).

Tabla 1. Períodos en la investigación de la capacidad espacial (Mohler, 2008)

\begin{tabular}{ll}
\hline \multicolumn{1}{c}{ Período } & \multicolumn{1}{c}{ Temas } \\
\hline $1880-1940$ & $\begin{array}{l}\text { Los estudios psicométricos identifican la capacidad espacial } \\
\text { como un factor independiente de la Inteligencia General }\end{array}$ \\
\hline $1940-1960$ & $\begin{array}{l}\text { Existe acuerdo en que la capacidad espacial está formada } \\
\text { por múltiples factores. Comienzan a emerger los estudios de } \\
\text { evaluación }\end{array}$ \\
\hline $1960-1980$ & $\begin{array}{l}\text { Estudios psicométricos sobre los aspectos cognitivos. } \\
\text { Aparecen estudios sobre las diferencias y el desarrollo de la } \\
\text { capacidad espacial en los individuos }\end{array}$ \\
\hline $1980-. .$. & $\begin{array}{l}\text { Efecto de la tecnología en la medida, la evaluación y el } \\
\text { desarrollo }\end{array}$ \\
\hline
\end{tabular}

La tercera fase, entre 1960 y 1980, intentó determinar las relaciones que podían existir entre la capacidad espacial y variables como el género, el desarrollo cognitivo, la edad, las experiencias previas y los estilos de aprendizaje. Los estudios psicométricos de Witkin (1950) y Gardner (1957) pusieron su atención en cuestiones cognitivas como los estilos de aprendizaje. Piaget e Inhelder (1971) examinaron la forma en que la capacidad espacial se desarrolla desde la infancia hasta la edad adulta. El trabajo de Maccoby y Jacklin (1974) es una buena contribución de referencia en lo que a diferencias de género se refiere.

Desde 1980 hasta hoy, los investigadores se han centrado en el impacto de la tecnología en la evaluación y la mejora de la capacidad espacial. En este periodo también se han realizado diversos meta-análisis sobre los estudios anteriores, nuevas clasificaciones y agrupaciones de las componentes de la capacidad espacial. En 1983, Eliot y Smith recopilan más de 200 instrumentos de medida (test), utilizados en las investigaciones que abordaban este tema. Consideran tres categorías: La Percepción Espacial, la Rotación Mental y la Visualización Espacial. Otros autores (Pellegrino, Alderton, \& Shute, 1984; Clements \& Battista, 1992) consideraron dos categorías o factores que configuran la capacidad espacial: las Relaciones Espaciales y La Visión Espacial. 
Como hemos visto, a lo largo del siglo XX ha existido un largo e intenso debate en torno a la inteligencia y a los factores que la componen. Como resumen, podemos considerar que la estructura de la Inteligencia incluye una componente denominada Capacidad Espacial, que dicha capacidad se puede dividir en varias subcomponentes (dos o tres dependiendo de los autores) y que la inteligencia y sus diferentes componentes se pueden medir mediante test, cuyos resultados deben ser comparables mediante una serie de escalas y coeficientes. De esta historia de 100 años de investigación, una cosa parece estar clara: la capacidad espacial es un conjunto de tareas y habilidades cognitivas complejas, acerca de las que todavía hay muchas preguntas.

\subsubsection{La relación de las habilidades espaciales con la ingeniería}

Al revisar la bibliografía, parece existir una referencia implícita al hecho de que los ingenieros requieren un buen nivel de habilidades espaciales para su labor profesional (Ferguson, 1992). Los ingenieros han investigado en este ámbito casi desde los primeros momentos en los que se identificó como una componente de la inteligencia. Los primeros estudios sobre esta relación aparecen a principios del siglo $\mathrm{XX}$, en informes que correspondían a la Armada Americana o a las oficinas de empleo de Estados Unidos y Gran Bretaña. Utilizaron encuestas que relacionaban esta habilidad y el correcto desempeño de la profesión de ingeniero. El uso de test de inteligencia con fines de selección se utilizó por primera vez en el año 1917 en Estados Unidos, con el objetivo de seleccionar a las personas que iban al ejército, además de para filtrar a los inmigrantes que acudían en masa al país (Miller, 1996). En esta época, antes de que apareciera el factor espacial, una de las componentes secundarias de la inteligencia era la denominada inteligencia mecánicopráctica. Los primeros trabajos que se realizaron para determinar la influencia de la inteligencia en el desempeño laboral, asociaron dicha componente con el trabajo en talleres. Aunque no se refiere exactamente al trabajo en ingeniería podríamos considerar dicho estudio como el primero que asocia la profesión de ingeniero con alguna habilidad relacionada con la inteligencia. La batería de test espaciales Minesota Paper Form Board, Spatial Relation y Packing Block Test demostraron que existía correlación entre este factor y el éxito laboral en profesiones asociadas a talleres. En 1928, la Society for the Promotion of Engineering Education (SPEE) crea la división de Dibujo en Ingeniería y en 1937 se 
empieza a publicar y a investigar sobre el área. Utilizaron el cuestionario, "The Value to the engineer of power to visualize", enviado a 200 Ingenieros de Diseño en Estados Unidos, con el que concluyeron que la habilidad para visualizar era indispensable para el trabajo del ingeniero.

Durante los años 40, a consecuencia de la Segunda Guerra Mundial, la armada norteamericana realizó importantes contribuciones en el campo de los test de inteligencia. En estos años, los mejores investigadores trabajaban para el ejército y dispusieron de miles de reclutas para probar empíricamente sus teorías. En estos años se avanza decisivamente en la comprensión del factor espacial, concentrando los esfuerzos en el desarrollo de contenidos curriculares orientados a mejorar las habilidades espaciales de los ingenieros.

En la década de los 50, la Oficina de Empleo de los Estados Unidos utilizó los test espaciales para clasificar las posibles ofertas que ofrecía a los demandantes de empleo. En un informe, dicha agencia, relaciona los buenos resultados en estos test con la conveniencia de asignar empleos en las ramas de Ingeniería, Ciencia, Dibujo y Diseño. En 1953, la American Society for Engineering Education ${ }^{2}$ (ASEE) revisa el curriculum de ingeniería, pidiendo que se enfatizara en el desarrollo de las habilidades espaciales, dirigidas a bocetado e interpretación de planos. Años después, otro autor americano escribe un artículo, que luego refleja en un libro, donde demostró correlación entre los test de habilidades espaciales y el éxito en las carreras técnicas y que se ha convertido en un manual de referencia en este tema (Smith, 1964).

Como vemos, en estos primeros estudios, los test espaciales eran considerados más útiles que los verbales para predecir el éxito en escuelas técnicas. Ésta, es la razón por la que estos test han sido utilizados durante mucho tiempo para este propósito. Todo este trabajo avala la tesis de la existencia de una relación entre la profesión de ingeniero y las habilidades espaciales.

${ }^{2}$ http://www.asee.org/ 


\subsubsection{La importancia de estas habilidades en el ámbito de la ingeniería}

Distintos autores relacionan un alto nivel de estas capacidades con el éxito en carreras técnicas. El pensamiento espacial es esencial para el pensamiento científico y se utiliza para representar y manipular información en el aprendizaje y en la resolución de problemas (Smith, 1964; McGee, 1979; Clements \& Battista, 1992). Parece evidente que estas habilidades se utilizan ampliamente en la ingeniería, arquitectura y construcción. En determinadas profesiones, como por ejemplo para los controladores de tránsito aéreo, esta capacidad es "especialmente relevante para un desempeño eficiente" y se utiliza además en las pruebas de selección de los aspirantes (Halpern, 1986; Contreras, Colom, Hernandez, \& Santacreu, 2003).

En el ámbito de la Universidad Española, las Órdenes publicadas en BOE, por las que se establecen los requisitos para la verificación de los títulos universitarios oficiales que habilitan para el ejercicio de distintas profesiones técnicas, disponen como competencia a adquirir para los títulos de ingeniería, dentro de la formación básica, la "Capacidad de visión espacial y conocimiento de las técnicas de representación gráfica, tanto por métodos tradicionales de geometría métrica y geometría descriptiva, como mediante las aplicaciones de diseño asistido por ordenador". La Capacidad de Visión Espacial está presente en la formación básica de un gran número de titulaciones de grado con competencias profesionales: Ingeniero Industrial, Ingeniero de la Edificación, Ingeniero de Minas, Ingeniero Civil, Ingeniero Aeronáutico, Ingeniero Agrónomo, Ingeniero Forestal, Ingeniero Naval, Ingeniero de Telecomunicaciones, Ingeniero en Topografía, etc.

Este trabajo pretende ofrecer nuevas herramientas para los estudiantes que acceden a la Universidad y que presentan niveles más bajos de habilidades espaciales. Se elaboran distintas propuestas de "cursos intensivos de corta duración" o "cursos cero", aportando distintas herramientas y formatos: el modelado $3 \mathrm{D}$ y varios contenidos interactivos elaborados para dispositivos móviles de pantalla táctil.

Además, se abren nuevas expectativas para la utilización de estas herramientas, en estudiantes más jóvenes de etapas educativas previas a la Universidad, como en la Enseñanza Secundaria Obligatoria (ESO), Bachiller, módulos profesionales, etc. 


\subsubsection{Las Habilidades Espaciales, el género y la edad}

Desde la influyente publicación de Maccoby y Jacklin (1974), las diferencias de género en tareas espaciales, y concretamente en tareas de rotación mental, han sido extensamente debatidas. Las investigaciones avalan la existencia de diferencias de género en favor de los hombres en habilidades espaciales, principalmente debida a los procesos relacionados con la subcomponente de rotación mental. El meta-análisis de Linn and Petersen (1986) sugiere que esto depende del tipo de tarea espacial: se encuentran pequeñas diferencias en percepción visual, mayores diferencias en tareas de rotación mental a favor de los hombres, y no se encuentran diferencias en tareas de visualización espacial. Esto provoca que muchas mujeres no accedan a titulaciones de ingeniería, que tengan mayor dificultad en afrontarlas o que las abandonen prematuramente. Se observan mayores diferencias en tareas de rotación mental en la población adolescente y adulta, en contraste con las pocas diferencias encontradas entre niños y niñas pre-adolescentes (Voyer, Voyer, \& Bryden, 1995).

Relacionado con esto, la investigación ha encontrado que las habilidades espaciales se ven afectadas por la edad del individuo. Mejora con la edad en la infancia, pero declina en los adultos (Pak, 2001). Piaget e Inhelder (1971) realizaron importantes aportaciones en su intento de explicar cómo y cuando se desarrolla en los sujetos los aspectos relacionados con las habilidades espaciales. Las HHEE, en su contexto de habilidades que se pueden entrenar, alcanzan un máximo entre los 14 y 18 años para después ir bajando lentamente. Es por ello que, a partir de los 18 años, la edad juega en contra del nivel de habilidades espaciales.

\subsubsection{Las habilidades espaciales y las herramientas de mejora}

Algunos autores han basado su trabajo en la hipótesis de que las habilidades espaciales se pueden mejorar si se utilizan herramientas adecuadas que faciliten la comprensión de los conceptos y de las relaciones entre las representaciones bidimensionales y las tridimensionales. La aparición de las nuevas tecnologías ha propiciado que, desde mediados de los años noventa, distintos grupos de investigación hayan propuesto herramientas novedosas para la mejora de estas habilidades. 
La mayoría de los estudios comenzaron en Estados Unidos, en universidades que ya trabajaron estos temas a principios de siglo XX, colaborando con la SPEE (Society for the Promotion of Engineering Education) o la ASEE. Sin embargo, por diversos motivos (guerras mundiales, falta de consenso en cuanto a las habilidades espaciales y su medición...) quedaron en suspenso hasta la década de los ochenta, fecha en la que empiezan a surgir muchos trabajos desde el ámbito de la ingeniería. Poco a poco, el interés del tema, salta desde Estados Unidos a otros países, para encontrarnos actualmente en una situación en la que es fácil detectar trabajos en este ámbito de conocimiento en todo el mundo. En concreto en España, el primer trabajo referenciado del que tenemos constancia es la tesis doctoral de José Domínguez de Posada de la Universidad Politécnica de Madrid (1994).

Los trabajos realizados en los últimos años se han desarrollado en las direcciones principales que destacamos a continuación:

- La medición de habilidades espaciales de los estudiantes que entran a la universidad, estudiando los factores previos que pueden condicionar esos resultados: género, edad, experiencias previas, etc.

- La medición del efecto de las asignaturas de Expresión Gráfica en la población Universitaria.

- El desarrollo de herramientas multimedia o basadas en tecnologías web.

- Creación de cursos de intensificación, dado que se detecta que algunos estudiantes llegan con deficiencias en este apartado y que esto puede suponer un indicador de su posible fracaso en los estudios de ingeniería.

El espectro de trabajos y enfoques es amplio, sin embargo, por la amplitud de sus investigaciones y por la continuidad que han demostrado, es interesante resaltar los trabajos dirigidos por Sheryl A. Sorby de la Universidad Tecnológica de Michigan (MTU), quizás el grupo más activo en este campo. Sus primeros trabajos se remontan a principios de los noventa. También la Universidad de Purdue ha creado un test, desarrollado por R.B.Guay en 1976 y bastante utilizado por los investigadores americanos; el PSVT:R (Purdue Spatial Visualization TestVisualization of Rotation). Destacaremos a continuación las que 
consideramos como algunas de las herramientas disponibles más interesantes relacionadas con la instrucción espacial.

Precisamente desde la Universidad Tecnológica de Michigan (MTU), Sheryl A. Sorby, como resultado de más de de diez años de investigación, ha publicado un manual de diez módulos para la mejora de las habilidades espaciales (Sorby, Wysocky, \& Baartmans, 2003). Permite trabajar con ejercicios de isometrías a través de la construcción con bloques, de vistas ortogonales normalizadas, de cortes y de secciones, de rotaciones, etc. Además del libro de texto, la publicación viene acompañada de un CD-ROM, que basado en tecnología flash, complementa al soporte de papel. La aplicación usa formas coloreadas que simulan formas tridimensionales. También ofrece efectos interactivos, creando la experiencia de un juego de ordenador para los estudiantes (ver Figura 3a).

Desde la Universidad de Pennsylvania, Katheryn Hollyday y otros (Hollyday-Darr, Blasko, \& Dwyer, 2000) crean el "Visualization Assessment and Training Program"3, un programa de evaluación y entrenamiento de las habilidades espaciales, accesible de momento sólo para los miembros de esta Universidad (ver Figura $3 \mathrm{~b}$ y Figura $3 \mathrm{c}$ ). Dispone de un sistema de evaluación de tres componentes de las habilidades espaciales: la rotación mental, la visualización espacial y la percepción espacial. Está en fase de desarrollo, pero parece un recurso interesante. Ahmad Rafi y otros (Rafi, Samsudin, \& Ismail, 2006) comprueban la eficacia de este material en un estudio comparativo en 2006. Además estos autores desarrollan y validan una herramienta para la mejora de la rotación mental (Rafi \& Samsudin, 2009).

El profesor Stephen W. Crown, de la Universidad de Texas-Pan American, alberga en su página institucional una web multimedia ${ }^{4}$, que comprende un conjunto de juegos interactivos, video tutoriales, lecciones teóricas que refuerzan los contenidos de la asignatura de Ingeniería Gráfica que imparte. Mediante pruebas y encuestas de satisfacción demuestra que el impacto de su herramienta ha sido positivo sobre los estudiantes (Crown, 2001) (ver Figura 3d).

3 https://www.courses.psu.edu/metbd/metbd247b dgb6/VIZ/

4 http://crown.panam.edu/EG/games 
Conolly y Maicher (Connolly \& Maicher, 2005) desarrollan desde la Universidad de Purdue el "Multiview Drawing", un tutorial interactivo para el entrenamiento del dibujo de vistas normalizadas y el desarrollo de las habilidades espaciales. Dada una perspectiva isométrica de una pieza, el programa permite dibujar una vista y corrige automáticamente el resultado de la misma5 (ver Figura 3e y Figura 3f).

Illuminations es un sitio web que nace de la asociación entre el Consejo Nacional de Profesores de Matemáticas de los Estados Unidos y el Consorcio MarcoPolo. El sitio ofrece el enlace a muchas herramientas interesantes, incluyendo Isometric Drawing Tool, un applet interactivo que permite crear de forma dinámica dibujos isométricos sobre una plantilla de puntos. Isometric Drawing Tool ${ }^{6}$ permite a los usuarios dibujar figuras utilizando líneas, caras, o cubos, además de disponer de una herramienta que nos permite ver las vistas de alzado, planta y perfil derecho o la vista 3D de los modelos creados (ver Figura 3g).

En el ámbito nacional, la Universidad de Burgos ofrece el Taller de Visión Espacial7, un curso web basado en los ejercicios del libro "Ejercicios para el desarrollo de la percepción espacial" (Pérez \& Serrano, 1998), y estructurado en cinco módulos: identificación de superficies, identificación de vistas, discriminación de volúmenes, rotaciones, recuentos y un último nivel dedicado a la evaluación (ver Figura $3 \mathrm{~h}$ ).

En la Universidad de Oviedo, Morán, Rubio, Gallego, Suárez y Martín (2008) han creado una serie de aplicaciones para mejorar las habilidades espaciales a través de tres ejercicios con diferente grado de dificultad: la mesa de visión espacial, vistas de un cubo y el desarrollo de un tetraedro (ver Figura 3 i).

${ }^{5}$ http://kellenmaicher.com/portfolio/projects/multiview.html

${ }^{6} \mathrm{http}: / /$ illuminations.nctm.org/ActivityDetail.aspx? ID $=125$

7 http://www2.ubu.es/expgraf/expgrain/visualizacion3d/index2.shtml 


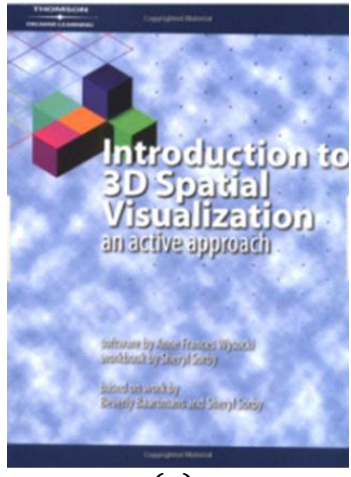

(a)

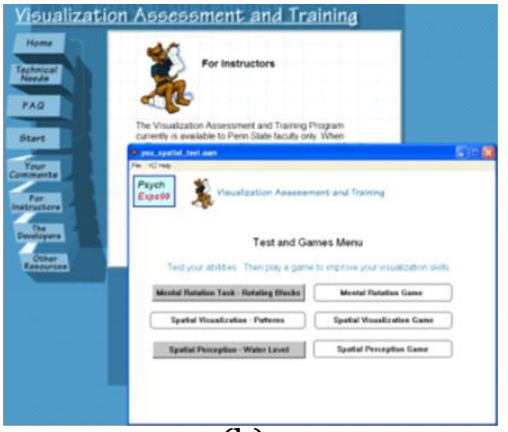

(b)

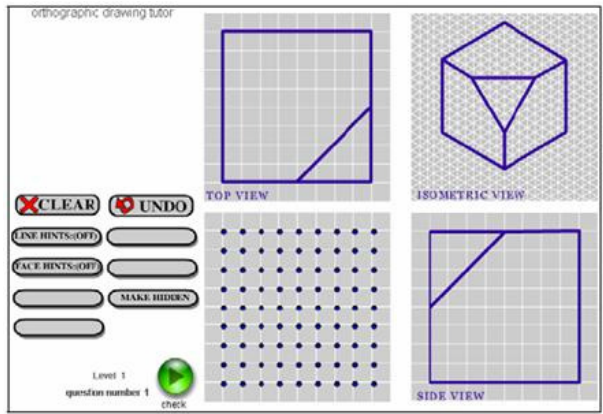

(c)

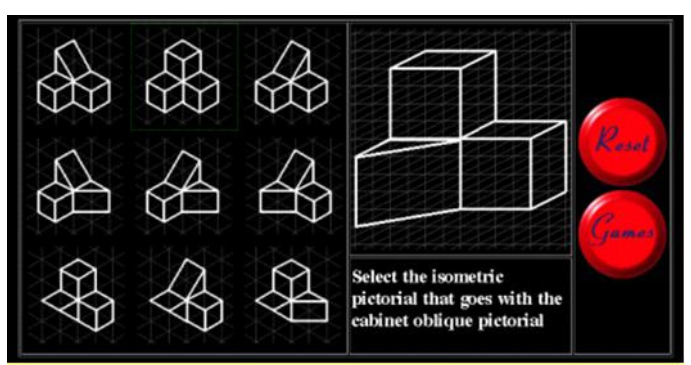

(d)

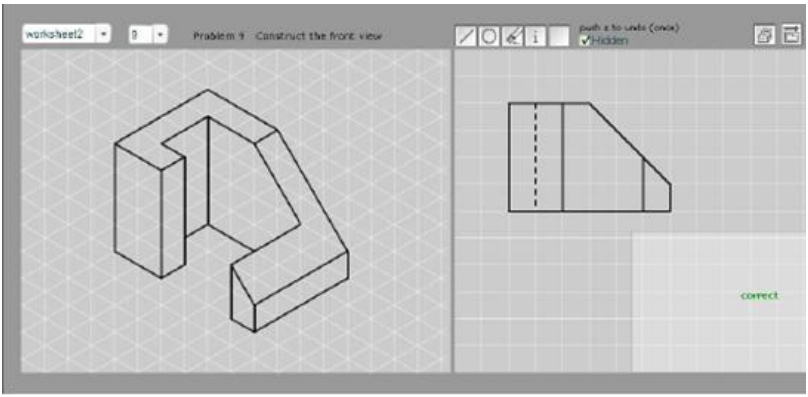

(f)

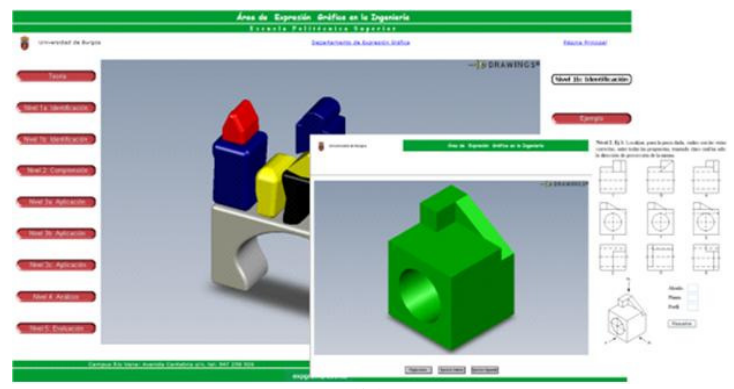

(h)

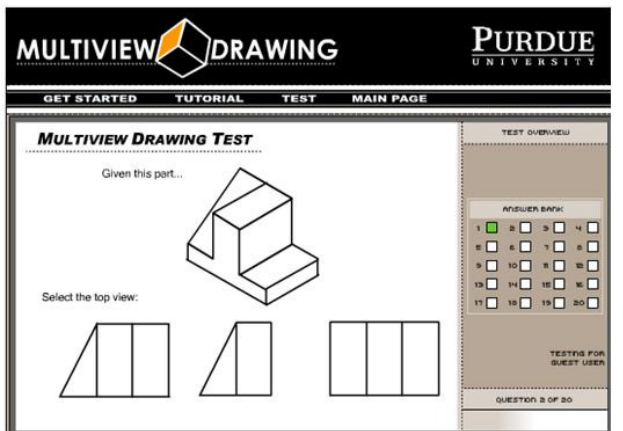

(e)

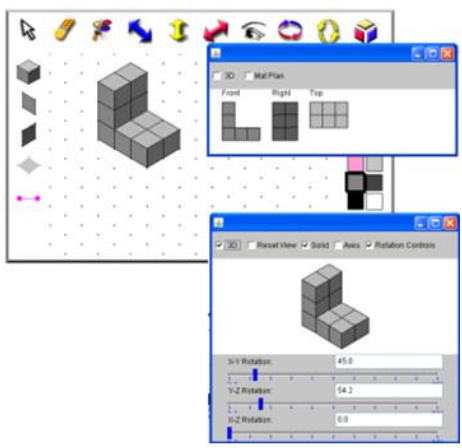

(g)

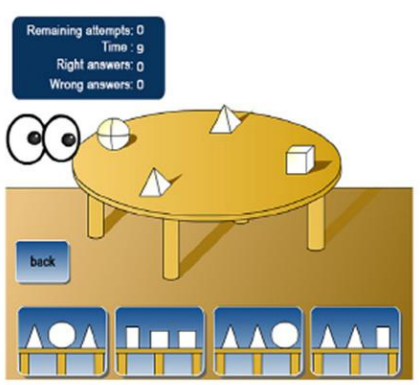

(i)

Figura 3. (a) Manual de entrenamiento de Sorby; (b) y (c) Programa de entrenamiento de la Universidad de Pennsylvania; (d) Juego interactivo de S. Crown; (e) y (f) Multiview Drawing de la Universidad de Purdue; (g) Isometric Drawing Tool; (h) Taller de Visión Espacial; (i) Mesa de visión espacial 


\subsubsection{Cursos intensivos de mejora de las habilidades espaciales en la Universidad de La Laguna}

Las investigaciones llevadas a cabo apoyan la idea de que las habilidades espaciales pueden ser adiestradas y mejoradas con la práctica. Se han realizado numerosos estudios para identificar las técnicas que se podrían usar. Las líneas principales de estos cursos de mejora las podemos clasificar en:

- Ejercicios tradicionales de lápiz y papel.

- Ejercicios con objetos físicos manipulables.

- Juegos y material multimedia.

- Aplicaciones $\mathrm{CAD}^{8}$ 2D, aplicaciones $\mathrm{CAD}$ 3D.

El Grupo Dehaes ${ }^{9}$, grupo de investigación en Habilidades Espaciales, formado por investigadores de la Universidad de La Laguna y de la Universidad Politécnica de Valencia, viene desarrollando desde el año 2004 diversas líneas de investigación centradas en el estudio de las habilidades espaciales de los estudiantes que acceden a titulaciones técnicas.

En el otoño del año 2004, se lleva a cabo el primer estudio en forma de cursos intensivos de mejora, con el objetivo principal de mejorar las HHEE de los estudiantes a su entrada a la Universidad y proporcionar un banco de pruebas para elaborar estrategias de actuación. Se utilizaron los test MRT y DAT-SR para detectar los alumnos con niveles más bajos de habilidades espaciales y para evaluar los resultados. Se testearon a 461 estudiantes, que lograron una puntuación media de 16,75 puntos en el MRT y de 42,96 en el DAT-SR. Se diseñaron tres cursos intensivos de seis horas de duración (Cursos A, B y C) para los estudiantes con puntuaciones más bajas. El curso A fue dedicado a desarrollar ejercicios en papel, organizándolos por nivel de dificultad y teniendo en cuenta la estructura suministrada por Pérez y Serrano, en su libro "Ejercicios para el desarrollo de la percepción espacial" (Pérez \& Serrano, 1998). El segundo curso (B), denominado "multimedia", entrenó con una serie de aplicaciones pseudo-lúdicas que se encuentran disponibles en Internet. El tercer curso (C), está basado en la utilización de una aplicación 
educacional de modelado basado en bocetos (denominada eCIGRO), desarrollada por el grupo de investigación Regeo de la UPV y de la Jaume I y que utiliza una tableta gráfica (o un Tablet-PC) para sustituir al lápiz y papel clásicos. Dicha herramienta permite la visualización en tres dimensiones de las perspectivas isométricas planas dibujadas sobre la pantalla. El alumno realiza ejercicios de dibujo en perspectiva, bocetados a mano, de los cuales tendrá que obtener las vistas normalizadas (ver Figura 4 y Figura 5).

Los cursos se desarrollaron durante las primeras semanas del primer cuatrimestre de entrada a la Universidad, para que los datos no pudieran ser distorsionados por el resultado de cursar el resto de asignaturas, sobre todo Expresión Gráfica. Todos los cursos mejoraron de forma significativa las habilidades espaciales medidas con los test MRT y DAT-SR. El aumento medio experimentado en los cursos intensivos de 6 horas de duración, fue de 4,3 puntos en el test MRT y de 7,8 puntos en el test DATSR. A pesar de que se han encontrado algunas diferencias en función del tipo de curso en los test, podemos concluir que no se observan grandes variaciones en las mejoras que producen los diferentes cursos sobre las habilidades espaciales. La búsqueda de diferencias requiere un estudio específico que acote los tipos de ejercicios y el tipo de curso desarrollado.

Este trabajo, desarrollado en el marco de la Tesis doctoral del Dr. D. Jose Luis Saorín Pérez, director de esta tesis que se presenta, sienta las bases de la línea de investigación que dan origen a los resultados del trabajo aquí descrito.

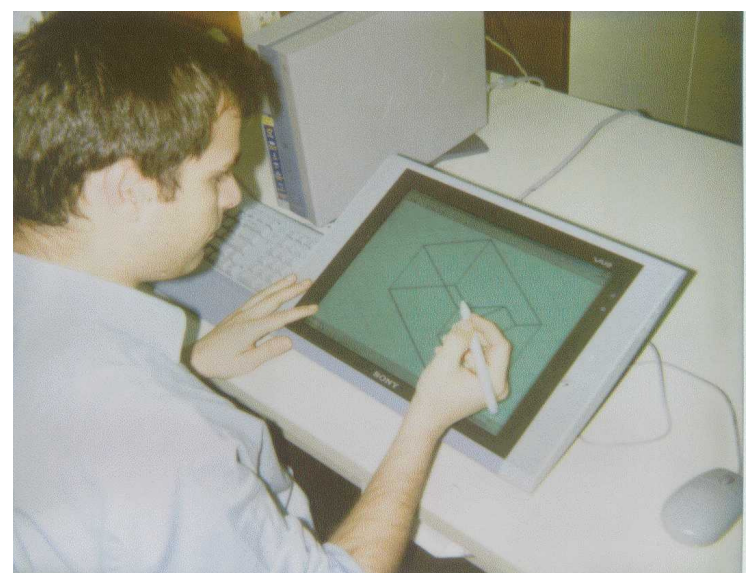

Figura 4. Ejemplo de interfaz caligráfica

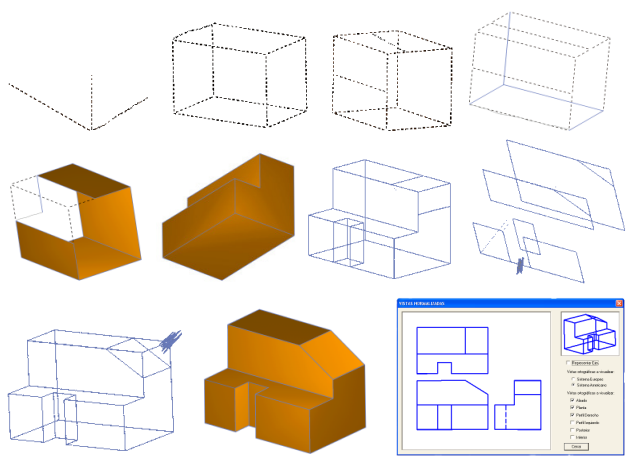

Figura 5. Proceso de construcción de un sólido mediante e-CIGRO 


\subsection{Aprendizaje móvil (m-learning)}

\subsubsection{El juego y el aprendizaje}

El juego ha sido considerado un componente esencial del aprendizaje, ya sea como causa, como fenómeno que lo facilita o como parte del acto creativo. Todas las teorías modernas del aprendizaje y la enseñanza, sin excepción, le asignan a las variables motivacionales internas y a las características atractivas de la tarea una relevancia esencial a la hora de proponer mejoras en el aprendizaje. Patricia Sarlé y Ricardo Rosas (Sarlé \& Rosas, 2005) consideran que "desde la perspectiva psicológica, es posible distinguir diferentes enfoques en relación a la función del juego en el desarrollo infantil humano". Distinguiremos aquí las que relacionan la importancia del juego sobre el aprendizaje, especialmente los postulados de Groos, Piaget y Vigotski.

Jugar, en sus diversas formas, constituye una parte importante del desarrollo cognitivo y social de los niños (Piaget J. , 1951; Provost, 1990). Distintos autores han analizado el impacto de los juegos en la educación y existe un amplio apoyo a la evidencia empírica de los efectos positivos de la utilización de los juegos de ordenador como herramientas de instrucción (Amory, Naicker, Vincent, \& Adams, 1999). Varios estudios han encontrado que es beneficioso para el rendimiento escolar, el desarrollo de habilidades cognitivas, la motivación hacia el aprendizaje y la atención y concentración (Rosas, et al., 2003).

Karl Groos (1861-1945) postuló la teoría del juego como "anticipación funcional". Este autor plantea que el organismo humano viene preparado biológicamente para anticipar funcionalmente el desarrollo de algunas destrezas biológicas por medio del juego (Gross, 1901). La importancia del concepto de "anticipación funcional" radica en concebir al juego infantil como un campo de ensayo de habilidades y destrezas que serán útiles en momentos, contextos y situaciones diferentes de las que son aprendidas mediante el juego.

Para Piaget, el juego es una palanca del aprendizaje y sobre ello señala: "siempre que se ha conseguido transformar en juego la iniciación a la lectura, el cálculo o la ortografía, se ha visto a los niños apasionarse por estas ocupaciones que ordinariamente se presentan como desagradables..." (Ulloa Reyes, 2008).

Piaget y Vigotski difieren fuertemente en su concepción de la relación entre juego y aprendizaje. Si para Piaget, el juego es consecuencia de un 
determinado nivel de desarrollo, para Vigotski el juego es causa de desarrollo. Según Vigotski, por medio del juego el niño crea un espacio imaginario en el que amplía de manera autónoma su zona de desarrollo próximo. El niño, en el juego, hace ensayos de conductas más complejas, de mayor madurez de las que hace en la actividad cotidiana, lo cual le permite enfrentarse a problemas que no están presentes todavía en su vida, y a solucionarlos de la manera más idónea posible, sin el apremio de sufrir las consecuencias que se podrían derivar de una solución errónea”.

J.S. Bruner (1984), en un estudio experimental, encontró que los efectos más significativos del juego respecto de la solución de problemas fueron sobre todo la forma relajada y emocionalmente equilibrada de enfrentarse a las dificultades de la tarea que tenían los niños que jugaban frente a los que no jugaban, y como este modo de seguridad y tranquilidad personal incidía en el logro de las metas propuestas.

\subsubsection{Aprendizaje móvil (Mobile Learning)}

Las tecnologías de la información y comunicación (TICs) han venido a revolucionar en muchos aspectos la vida del ser humano y el ámbito educativo no ha sido una excepción. El aprendizaje móvil (mobile learning ó m-learning) es definido como la impartición de educación y formación por medio de dispositivos móviles, tales como PDAs, iPods, smartphones (teléfonos inteligentes) y teléfonos móviles. Se considera una evolución natural del e-learning o aprendizaje electrónico, diferenciándose de ese en que el uso de la tecnología móvil confiere flexibilidad al aprendizaje, dado que los estudiantes pueden aprender en "cualquier momento y en cualquier lugar".

El m-learning es un concepto nuevo en el ámbito pedagógico del aprendizaje. El primer trabajo publicado que pone su atención en el aprendizaje móvil surge en el año 2000, en la revista Computers \& Education, donde Mike Sharples ${ }^{10}$ (Sharples, 2000) examinó el potencial de los nuevos diseños apoyados en tecnologías móviles que permitieran mejorar los programas de aprendizaje permanente y las oportunidades de educación continua para adultos. Muchas, si no todas, de las ideas planteadas en este trabajo de Sharples siguen evolucionando y son de

${ }^{10}$ http://www.lsri.nottingham.ac.uk/msh/ 
gran interés en el m-learning hoy en día. Sharples es uno de los investigadores más activos en el campo del aprendizaje móvil.

Donna Abernathy, en el artículo "Get Ready for M-Learning", alerta sobre el potencial de este tipo de aprendizaje. Abernathy observa que el mlearning no tratar de sustituir el PC, sino que ayudará a complementar los objetivos de aprendizaje de las empresas con herramientas instantáneas.

Entre 2002 y 2006, comenzaron a aparecer numerosos estudios indicando que las tecnologías que soportan el m-learning se están expandiendo y que comienzan a ser comunes en una gran variedad de entornos de aprendizaje.

Seppala y Alamaki (2003) investigaron la formación e instrucción de profesores finlandeses, utilizando la tecnología móvil en el aula. Sus experiencias e inquietudes con la nueva tecnología se centraron en varios factores. En primer lugar, señalaron que, dado que el $98 \%$ de los estudiantes universitarios de Finlandia era propietario de teléfonos móviles (2002), la enseñanza a través de las oportunidades que nos ofrece el aprendizaje móvil, parece ser un paso importante en la revolución digital del aprendizaje. En el estudio que llevaron a cabo usaron SMS (servicio de mensajes de texto cortos) e imágenes, que almacenaron en un servidor central. Los usuarios de este sistema podían descargar el material en cualquier momento para su revisión y estudio. Los profesores consideraron como segunda característica ventajosa la "posibilidad de tomar notas en cualquier momento y la capacidad para trabajar los contenidos durante el tiempo que diariamente dedicaban al desplazamiento en tren, autobús, etc.”. Seppala y Alamaki llegaron a la conclusión de que M-learning tiene una multitud de ventajas, y que esta tecnología tiene un lugar en los modelos de enseñanza del futuro.

Attewell (2003) abordó una pregunta que muchos educadores y algunos empleadores han tenido sobre el aprendizaje móvil, especialmente en relación con los usuarios más jóvenes. Algunos estudios han cuestionado si el uso de los mensajes de texto (SMS) podrían ser perjudiciales para la formación en gramática (vocabulario y ortografía) de los estudiantes. Attewell está de acuerdo en que estos temas son preocupaciones a tener en cuenta, y sugiere más investigación sobre el aprendizaje móvil. Jill Attewell, junto con Mark Sharples, es una de las investigadoras más activas en el campo del aprendizaje móvil.

Los investigadores también han estudiado la manera en que se está generalizando la tecnología móvil hoy día y la manera en que se expande. 
Según Wagner y Wilson (2005), en la actualidad los teléfonos móviles en América superan a los teléfonos de línea fija, y los dispositivos inalámbricos están ganando terreno con la ayuda de los lugares de trabajo y de las comunidades WiFi. Los autores hacen una distinción importante entre la m-Learning y e-Learning. Ellos argumentan que como los nuevos dispositivos y herramientas proporcionan a los educadores más opciones para llegar a los estudiantes de hoy. La comunidad educativa debe reconocer que el modelo de "comando y control" ("command and control”), típico de las estructuras de la enseñanza convencional, está siendo reemplazada con la oportunidad de hacer realmente el aprendizaje colaborativo.

Rushby (2005) exploró este tipo de aprendizaje desde una perspectiva laboral. Compara los beneficios de la libertad de ubicación con los tradicionales modelos de e-Learning de los que muchas disponen. $\mathrm{Su}$ trabajo sugiere que el m-Learning es superior a los antiguos formatos de aprendizaje empleados. Contempla que este aprendizaje está actualmente limitado por la tecnología (memoria, velocidad, capacidad de almacenamiento). Rushby considera que el m-learning es más probable que sea aprobado primero por el sector empresarial y que una mayor investigación puede mejorar las oportunidades en este campo. Considera además que las escuelas de secundaria y las universidades deberían ser capaces de recoger esta tecnología y encontrar su uso pedagógico.

Thornton y Houser (2005) han reflejado en estudios recientes los datos y opiniones recogidas sobre m-Learning y su uso en una universidad japonesa. En Japón se usa habitualmente la navegación web a través de teléfonos móviles, PDAs y otros dispositivos portátiles y la población está acostumbrada a ello. En su estudio, los investigadores evaluaron los resultados de aprendizaje alcanzados sobre el material de clase, usando teléfonos móviles, tanto a través del correo electrónico y el uso de tecnología WAP (Wireless Application Protocol), en una web habilitada para teléfonos móviles. Los resultados de sus experimentos eran particularmente reveladores. Los investigadores observaron mejoras en las puntuaciones de entre $35 \%$ y un $75 \%$ (pre y post), con respecto a los mismos materiales en papel. Las reacciones de los estudiantes a esta nueva oportunidad de aprendizaje fueron positivas, aunque más para los ensayos con PDAs que para los teléfonos móviles. Los investigadores señalaron que las conexiones web y las tarifas de acceso desde los teléfonos móviles en Japón son habituales y de bajo coste, lo que permite que la distribución de material educativo a través de ellos sea un proceso 
relativamente fácil. Hacen hincapié en que la interactividad en el contenido parece un método de enseñanza superior en comparación con las páginas web tradicionales.

Wagner (2005) examina el estado actual de la tecnología móvil en América. Cita ejemplos en los que la tecnología móvil ha provocado importantes impactos en la vida de las personas, tales como ayudar a encontrar supervivientes tras el tsunami del Océano Índico de 2004. Señala que mientras que los dispositivos móviles sean el instrumento de que más disponen los trabajadores de oficina y los estudiantes, el panorama tecnológico irá cambiando y será cada vez más favorable al mLearning, a través de la expansión de las redes inalámbricas y de la caída de los precios del hardware y de las tarifas de acceso.

Wagner subraya que, si bien la tecnología móvil puede ser tremendamente útil, la información en sí misma debe ser el centro de la mayor parte de la atención de un educador, y que la mejora del contenido es el mejor enfoque para asegurar que el m-learning sea efectivo para todas las partes. Al abordar los obstáculos a los que se enfrenta la calidad de las experiencias en aprendizaje móvil, Wagner reconoce que la disposición del dispositivo necesario (PDAs, móviles de gama alta) es el más importante escollo que se encuentra en el camino hacia un uso generalizado de esta tecnología. Sin embargo, comenta que muchas universidades están adoptando medidas para corregir esta deficiencia, haciendo estos los dispositivos más accesibles. Los estudiantes señalan la flexibilidad que aporta un dispositivo móvil para ayudar en su proceso de aprendizaje.

Corlett et al. (2005) realizan un estudio sobre una pequeña clase de estudiantes en la Universidad de Birmingham, a los que facilitaron una PDA inalámbrica durante un semestre, con el fin de explorar las posibilidades y limitaciones del m-learning en un ambiente universitario. Los problemas que encontraron fueron, en su mayoría, de carácter técnico: memoria limitada de los dispositivos o duración de la batería. También hubo algunos problemas con el software utilizado. Al final del año escolar, se realizaron foros de discusión y se administraron una serie de cuestionarios. Las experiencias de los estudiantes fueron heterogéneas. En general opinaban que las PDAs no estaban a la altura de las expectativas. Limitaciones del hardware de los dispositivos utilizados y los problemas de software son suficientes para que los estudiantes ofrezcan puntuaciones más bajas que en otros estudios. Sin embargo, los autores ven estos datos como información de apoyo que puede ayudar a mejorar 
el hardware y la tecnología de estos dispositivos, que están cada vez más presentes en los centros educativos.

El número de artículos que evalúan el aprendizaje por medio de tecnologías móviles se están incrementando. Gómez (2007) expone cómo las lecciones y conferencias elaboradas por estudiantes utilizando dispositivos móviles están evolucionando. Se examinaron los podcasts, archivos de audio y vídeo, y de cómo éstos pueden ser fácilmente incorporados en los cursos. En general, los resultados fueron muy bien valorados. Después de un período inicial de formación y aclimatación, se evaluó los comentarios de los docentes y los estudiantes sobre la experiencia personal. Los estudiantes gozan de la capacidad para poder escuchar las materias en el momento que lo deseen. Una característica adicional, a la que se dio gran valor, fue el hecho de la información está fácilmente disponible cuando los estudiantes están lejos de sus lugares físicos de trabajo. Gómez informó también de que las barreras todavía existen. Haciéndose eco de lo dicho por Wagner (2005), dice, entre otras cuestiones, que no todos los estudiantes tienen acceso al hardware necesario (Gómez, 2007).

La importancia del m-learning en la sociedad del conocimiento es, obviamente, cada vez mayor. Una búsqueda rápida en el Journal Citation Index revela una gran cantidad de trabajos relacionados con este tema. Para estar al día de los últimos trabajos de campo realizados en este ámbito se recomienda la consulta de las revistas Computers \& Education, Journal of Computer Assisted Learning, British Journal of Educational Technology y Journal of Educational Technology \& Society, entre otras.

\subsubsection{Juegos Serios (Serious Games)}

Destacamos a continuación una nueva tendencia emergente, los llamados "Serious Games". Clark Abt utilizó el término en su libro Serious Games, publicado en 1977. Dio una útil definición general, que sigue siendo aplicable hoy día: "Reducido a su esencia formal, un juego es una actividad entre dos o más, independiente de la toma de decisiones, que tratan de alcanzar unos objetivos en un contexto limitado. Una definición más convencional diría que un juego es un contexto con las normas entre los adversarios tratando de alcanzar objetivos.

No existe una definición única de los Juegos Serios, aunque por lo general se entiende que son aquellos juegos que se utilizan para el entrenamiento, 
la publicidad, la simulación, o la educación. Se puede entender también que abarca los juegos de conceptos, tecnologías e ideas de aplicaciones no dedicadas al entretenimiento. Los Juegos Serios están destinados a un público mayor, fuera de la escuela primaria o secundaria.

Mike Zyda proporcionó una actualización a la expresión (en su artículo 2005 en IEEE Computer, titulado "De la simulación visual a la realidad virtual a los juegos"), que va desde el juego al juego serio, pasando por el video juego:

- Juego: "una competición física o mental, que desempeña de acuerdo a unas reglas, con el objetivo de premiar o divertir al participante."

- Video Juego: "una competición mental, jugado en ordenador de acuerdo con determinadas normas de diversión, recreación, o ganar un juego".

- Juego serios: "un concurso mental, jugado en ordenador de conformidad con las normas específicas que utiliza el entretenimiento para el gobierno o la formación en las empresas de, educación, salud, política pública y comunicación estratégica objetivos."

Mucho tiempo antes de que el término "Serious Game" fuera usado ampliamente con la Iniciativa de Juegos serios ${ }^{11}$ en 2002, los juegos ya se estaban usando con propósitos distintos del mero entretenimiento. A final de 1990, los investigadores comienzan a examinar la utilidad de los juegos para otros propósitos, contribuyendo al creciente interés de utilizar los juegos con nuevos fines. En 2002, el Woodrow Wilson International Center for Scholars en Washington DC, puso en marcha la "Serious Games Initiative", con el objetivo de fomentar el desarrollo de juegos que se ocupan de cuestiones de política y gestión. En 2004 comienzan a aparecer juegos centrados en áreas diversas: como ejemplo los "Games for Change", que se centran en cuestiones sociales, y "Games for Health" que pone su atención en las aplicaciones médicas.

Hoy día es común el manejo de este tipo de juegos en consolas de mano, tipo Nintendo DS, PSP, PDAs, o smartphones ${ }^{12}$. Ejemplos de ello pueden ser los juegos de refuerzo de habilidades mentales, tipo Brain Training, o Tetris, de aprendizaje de idiomas, como English training, $\mathrm{u}$ otros. Todos estos juegos están hechos para ofrecer una participación, auto-refuerzo de

${ }^{11} \mathrm{http}: / /$ seriousgamessource.com/features/feature_052606_games_for_health.php

$12 \mathrm{http}: / /$ www.seriousgames.es/ 
contexto en el que educar y motivar a los jugadores. En este ambiente nacen los dos proyectos descritos en los capítulos IV y V de esta tesis, con el objetivo de elaborar una aplicación lúdica para dispositivos móviles táctiles para el entrenamiento de las HHEE, buscando un buen entendimiento de la relación $2 \mathrm{~d}-3 \mathrm{~d}$, tan necesario para las materias de Expresión Gráfica, en un formato de educación no formal.

\subsubsection{Investigación en el campo del Aprendizaje móvil}

A pesar de ser este un ámbito de investigación reciente (desde el año 2000 como se ha comentado anteriormente), los trabajos y los proyectos de investigación son muy numerosos. Por este motivo destacamos a continuación sólo los proyectos de investigación de mayor envergadura, por el ámbito de actuación o por el impacto de los mismos, y de las instituciones más relevantes en el campo del m-learning.

\section{Proyectos:}

- From E-learning to M-learning (1999-2002).

(http://learning.ericsson.net/mlearning2/project one/index.html) Este proyecto es dirigido por Ericson Education Ireland, desarrollando cursos para teléfonos móviles, smarthphones y PDAs. Abordó por primera vez el problema pedagógico del desarrollo de aprendizaje móvil en PDAs, realizando ambientes didácticos confortables por medio de Microsoft Reader Works.

- Mobile Learning: The Next Generation of Learning (20002006).(http://learning.ericsson.net/mlearning2/documentation.sh tml) Proyecto dirigido por Ericson Education Ireland. La principal actividad el proyecto fue colocar los cursos de aprendizaje en smartphones.

- IST M-learning Project (2002-2004) (www.m-learning.org). Fue desarrollado por la agencia Learning and Skills Development Agency (LSDA) del Reino Unido. Fue un proyecto de investigación europeo con una importante dimensión social, que trata de motivar y cubrir los regazos educativos de los jóvenes de entre 16 y 20 años que se encontraban desempleados, ofreciéndoles cursos sobre teléfonos móviles en el campo de la literatura, aritmética y relaciones sociales. 
- MOBIlearn (2001-2005) (www.mobilearn.org). Es un proyecto formado 24 socios de distintas instituciones de países Europeos, de Israel, Suiza, EEUU y Australia. Financiado con 6 millones de euros, sus objetivos principales fueron la definición de modelos de soporte teóricos y validaciones empíricas para la efectiva enseñanza, aprendizaje y tutorización en ambientes móviles, el diseño instruccional y desarrollo de contenidos, el desarrollo de una arquitectura referencial para aprendizaje móvil, entre otros. Tiene un periodo de 2001 al 2005 .

- Eduinnova (1997-...) (www.eduinnova.com). Este proyecto nació en la Pontificia Universidad Católica de Chile, surge para transferir el trabajo de investigación y desarrollo al ámbito educativo mediante el uso de tecnologías móviles en el aula, para apoyar el proceso de instrucción, la evaluación de los contenidos incluidos en el currículo escolar y el papel del docente en relación con la gestión del aula. Actualmente es incorporado en el ámbito educativo de varios países de sudamérica, como Chile, Brasil, Argentina. Es un proyecto a tener en cuenta por los importantes logros conseguidos: publicaciones premios, etc.

- Edumóvil (http://mixtli.utm.mx/ resdi/Edumovil.pdf). Es una iniciativa que surge a finales del 2003 para auxiliar el proceso de enseñanza aprendizaje de los niños de nivel primaria. Cuyo objetivo es lograr que el niño comprenda a través de juegos en dispositivos móviles temas donde presente dificultad de aprendizaje.

- MoLeNET (http://www.molenet.org.uk/). Es uno de los proyectos más importantes del Reino Unido. 115 colegios y 29 escuelas están implicados en el proyecto. Aproximadamente 10.000 alumnos participaron en 2007/08 y cerca de 20.000 estudiantes han participado a finales del año académico 2008/09, junto con más de 4.000 funcionarios. Incluye multitud de proyectos, asociados al LSN's Technology Enhanced Learning Research Centre del Reino Unido, que abarcan ámbitos como: la investigación en el impacto del m-learning en la retención, el rendimiento y la progresión académica, el impacto en la enseñanza y el aprendizaje o la investigación en tecnología y métodos pedagógicos.

- Dmovil (http://dmovil.cc.uah.es/DMovil/). Infraestructura para la promoción, creación y distribución de contenidos info-educativos y juegos de calidad sobre tecnologías móviles Proyecto español, en el que interviene la Universidad de Alcalá y subvencionado por el Plan Avanza, que tiene como objetivos desarrollar contenidos 
digitales para el diseño e implementación de juegos para terminales móviles, y crear una infraestructura tecnológica necesaria para promocionar el uso y acceso a los contenidos digitales desarrollados.

\section{Instituciones y centros de investigación:}

- Universidad de Birmingham. Es designada en 2003 como el Centro Europeo de Microsoft de referencia para la investigación en aprendizaje móvil.

- Universidad de Nottinghan. Mike Sharples es referente en la investigación en el campo del aprendizaje móvil.

- LSN's Technology Enhanced Learning Research Centre. Centro de investrigación en el Reino Unido sobre tecnologías para le mejora del aprendizaje. Jill Atewell es su directora, también referente en la investigación en el campo del aprendizaje móvil.

- Emobility (http://www.emobility.eu.org/). Plataforma europea integrada por las principales empresas de comunicaciones móviles, desarrolladores de software para móviles, centros de investigación, universidades, etc.; con el objetivo de garantizar el desarrollo y éxito de las comunicaciones móviles europeas. Es una red europea de referencia para el desarrollo de programas innovadores.

- International Association for Mobile Learning(IAMLearn) (http://mlearning.noe-kaleidoscope.org/). Asociación Internacional de aprendizaje móvil.

- Leonardo programme in UK (http://www.leonardo.org.uk/). Programa de financiación europeo para la mejora del aprendizaje y las buenas prácticas.

- Universidad de Purdue. (http://www.e-games.tech.purdue.edu/mobileGames.asp)

- Instituto Tecnológico de Massachusetts (MIT). (http://education.mit.edu/drupal/ar/projects) 


\subsection{Resumen}

Como hemos visto, a lo largo del siglo XX ha existido un largo e intenso debate en torno a la inteligencia y a los factores que la componen. Como resumen podemos decir que es considerado que la estructura de la Inteligencia incluye una componente denominada Capacidad Espacial, que dicha capacidad se puede dividir en varias sub-componentes y que la inteligencia y sus diferentes sub-componentes se pueden medir mediante test, cuyos resultados deben ser comparables mediante una serie de escalas y coeficientes.

Además, de acuerdo con el trabajo llevado a cabo durante estos años por el grupo de investigación Dehaes (Contero, Naya, Company, Saorin, \& Conesa, 2005; Contero, Company, Saorin, \& Naya, 2006; Saorín, 2006), podemos resumir una serie de aportaciones que forman parte de los fundamentos aceptados para la realización de esta tesis:

- El uso de los test MRT y DAT-SR nos permite medir dos subcomponentes de la capacidad espacial.

- Los resultados nos indican que hay variables específicas que afectan a cada una de estas sub-componentes: el género, la edad, la práctica con videojuegos y la procedencia de los estudiantes y sus experiencias previas.

- Los cursos intensivos de corta duración han demostrado ser efectivos en la mejora de las habilidades espaciales de los estudiantes a su entrada en la Universidad.

- La utilización de material multimedia es una estrategia alternativa al método de ejercicios en papel. Estas aplicaciones obtienen una muy buena acogida, por parte de los alumnos.

Por otro lado, las tecnologías de la información y comunicación (TICs) han venido a revolucionar en muchos aspectos la vida del ser humano y el ámbito educativo no ha sido una excepción. Surge en el año 2000 el denominado aprendizaje móvil (m-learning), evolución del ya conocido aprendizaje electrónico (e-learning), ofreciendo nuevas oportunidades al aprendizaje, por su capacidad de conferir flexibilidad, dado que los estudiantes pueden disponer de materiales de aprendizaje en cualquier momento y en cualquier lugar. 
Del trabajo realizado hasta el momento, surgen nuevas líneas de investigación, algunas de las cuales intentaremos abordar en esta tesis:

- Sería interesante desarrollar programas específicos para los sectores de población en los que se ha detectado niveles de HHEE inferiores a la media.

- Puesto que las aplicaciones multimedia son muy apreciadas por los estudiantes, parece que el desarrollo de nuevas herramientas podría ser una línea interesante de actuación. La combinación entre los avances en tecnología de hardware y software y la investigación en el campo de las HHEE, nos permite ofrecer nuevas herramientas para las mejora de estas habilidades en los estudiantes de ingeniería. 

Capítulo III: El modelado 3D como herramienta de mejora de las habilidades espaciales

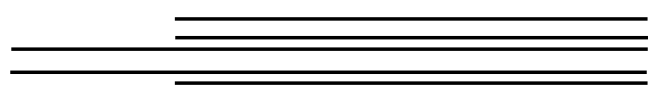





\subsection{Introducción}

En general, los planes de estudio de las carreras técnicas incluyen varias asignaturas relacionadas con la Ingeniería Gráfica, en las cuales, al menos durante un año, los estudiantes reciben una formación básica en Sistemas de Representación, Dibujo a mano alzada, Normalización y Diseño Asistido por Ordenador (CAD). Aunque ningún programa tradicional incluye un entrenamiento específico para las habilidades espaciales, el uso de las proyecciones ortogonales normalizadas usadas con el objetivo de representar figuras en tres dimensiones, obligaba a los alumnos a desarrollar estas habilidades a lo largo del curso.

En este trabajo se planteó la cuestión de si el uso de entornos en tres dimensiones puede ser una metodología válida para mejorar las habilidades espaciales. Con este objetivo se diseña un curso intensivo para el desarrollo de las HHEE, que utiliza un software gratuito de modelado 3D. A continuación se describe el estudio piloto, el análisis realizado y los resultados y conclusiones obtenidos.

\subsection{Las habilidades espaciales y el modelado 3D}

Las técnicas de modelado han sufrido una gran evolución, desde aquellos primitivos sistemas CAD de finales de los años 6o, que básicamente se empleaban como sustitutos de los tableros de dibujo, hasta el posterior desarrollo tecnológico, que ha permitido, mediante el empleo de diferentes tipos de modelos geométricos, la creación y la manipulación de objetos tridimensionales cada vez de mayor complejidad.

El software de modelado ha sido hasta hace poco tiempo una tecnología accesible sólo a los profesionales técnicos. Antes de esto, los ordenadores y el software no tenían la capacidad de manejar los algoritmos complejos requeridos para representar e interpretar objetos. Además, el uso de este software requería un período de entrenamiento normalmente largo y complicado.

S.E. Wiley (1990) en "Computer Graphics and the Development of Visual Perception in Engineering Graphics Curricula”, presenta un modelo de programa que sirve para desarrollar la percepción espacial en un sentido amplio. También realiza un programa de contenidos desarrollados por ordenador. Todos parten del objeto real y terminan con representaciones 
3D. Indica que el trabajo con modelos sólidos 3D y con animaciones ayudaría al desarrollo de las HHEE.

J.A. Leach (1992) en "Utilization of Solid Modeling in Engineering Graphics Courses" afirma que el uso de modelado sólido genera habilidades espaciales que son diferentes de las de crear o leer planos de ingeniería convencionales.

C.L. Miller (1992) en "Enhancing The Spatial Abilities of Freshman Engineering Graphics Through the use of Real and computer-aided Models", indica que el uso de modelos reales y generados por ordenador permite a los estudiantes avanzar más en visión espacial que los métodos tradicionales.

T. J. Sexton (1992) en "Effect of Spatial Visualization: Introducing Basic Engineering Graphics Concepts using CAD Technology”, compara la metodología tradicional (uso de proyecciones ortogonales) con el uso de modelos alámbricos 3D. Utilizó para medir las HHEE el test MRT y sus conclusiones fueron que el uso de modelos $3 \mathrm{D}$ no proporciona mejoras significativas frente al método tradicional con respecto a las habilidades espaciales de los alumnos, pero que es un método válido.

Devon, Engle, Foster, Sathianathan y Turner (1994) en "The Effect of Solid Modelling Software on 3D Visualization" compara trabajar con modelos alámbricos frente al modelado sólido, indicando que el uso de modelado sólido mejora las habilidades espaciales más que el uso de modelado alámbrico (Saorín, 2006).

Barr y Juricic (1994) demandaron que el proceso de diseño se cambiaba de bidimensional a tridimensional.

Según Godfrey (1999), como consecuencia del cambio que ha producido pasar de diseñar en dos dimensiones a diseñar modelos tridimensionales, "el estudio de las HHEE ha experimentado un cambio de paradigma" y es necesaria una investigación más profunda para entender los cambios que ha provocado la introducción del modelado 3D. Además Godfrey afirma que "el trabajo con modelos sólidos tridimensionales quita la abstracción bidimensional y lo hace más conveniente para el empleo como un método para el desarrollo de la visión espacial".

Las investigaciones llevadas a cabo en el campo de las habilidades espaciales y el CAD, sugieren que podría haber una relación entre las habilidades espaciales de un individuo y su capacidad de utilizar un software 3D (Alias, Gray, \& Black, 2002; Yue \& Chen, 2001). Sorby (1999) concluye que "las habilidades espaciales de una persona, medidas por el 
test MCT (Mental Cutting Test) son un factor significativo en su capacidad de interactuar con un ambiente tridimensional en ordenador". Gaughran (2002) también apoya esto argumentando "que el uso creativo del software CAD depende en gran medida de la capacidad cognitiva de los usuarios de visualizar el diseño y de interactuar con el modelo". Ault (2003) precisa que "es asumido por muchos que el uso de modelado sólido realza las habilidades espaciales de los estudiantes". Sin embargo las investigaciones de Ault (2003), Sorby (1999) y Yue y Chen (2001) concluyen que "el trabajo con software tridimensional no mejora las habilidades espaciales de los estudiantes de modo significativo" (Sorby, 1999).

\subsection{Cursos de mejora de las habilidades espaciales mediante modelado 3D}

Se han realizado numerosos estudios para identificar técnicas para el desarrollo de las habilidades espaciales. Distintos autores han realizado investigaciones usando ejercicios con piezas manipulables para mejorar las habilidades espaciales (Alias, Black, \& Gray, 2002; Ben-Chaim, Lappan, \& Hougang, 1998; Duesbury \& O'Neil, 1996; Harman, Humphrey, \& Goodale, 1999). Los ejercicios que usan modelos de bloques, al estilo de las construcciones de Lego $®$, fueron encontrados eficaces por Alias, Black y Gray (2002) y Ben-Cham, Lappan y Houang (1988). Otros investigadores (Harman, Humphrey, \& Goodale, 1999; Sorby S. , 1999) concluyen que "manipular la imagen de un objeto por ordenador es suficiente para mejorar las habilidades espaciales”.

Otra estrategia de instrucción, además del uso de ejercicios con objetos manipulables, ha sido los ejercicios tradicionales de lápiz y papel (sketching). Sorby y Baartmans (1996) encontraron que las actividades de bocetado que forman parte de los programas tradicionales de ingeniería gráfica (proyección ortográfica, dibujo isométrico) producen mejora de las HHEE, una posición apoyada por Lord (1985) y Sorby y Baartmans (1996). Alias, Black y Gray (2002) y Ben-Cham, Lappan y Houang (1998), combinaron los ejercicios de manipulación de objetos reales con el bocetado, encontrando que existe gran variedad de ejercicios que mejoran las HHEE. Sorby (1999) hace una distinción entre los cursos que contienen CAD y los cursos que implican dibujo a mano alzada, 
encontrando que "la mejora obtenida en los cursos de dibujo a mano eran más altos que los obtenidos en cualquiera de los cursos de CAD".

En los últimos tiempos, con el avance de la tecnología y de los programas $\mathrm{CAD}$ y de modelado, se han realizado numerosas investigaciones sobre la utilización de estas herramientas para la mejora de las HHEE. Gillespie (1995) estudió los efectos que sobre las habilidades espaciales tenían los tutoriales para la enseñanza del modelado sólido. $\mathrm{Su}$ experimento se desarrolló con estudiantes matriculados en un curso de ingeniería gráfica de la Universidad de Idaho. Cuarenta y uno completaron el estudio y fueron divididos en tres grupos. Cada grupo pasó tres pruebas test: el Mental Rotation Test (Vanderberg \& Kuse, 1978); el Paper Folding Test (Ekstrom, French, Harman, \& Dermen, 1976) y el Rotated Block Test. El Rotated Block Test fue desarrollado por Gillespie y es similar al "Purdue Spatial Visualization Test/Test of Rotations" (PSVT/TR) (Guay, 1976). Uno de los grupos fue sometido durante diez semanas a diecisiete módulos sobre modelado sólido. Los dos grupos de control recibieron las clases tradicionales de $\mathrm{CAD}$ en dos dimensiones. Todos los grupos mejoraron sus puntuaciones del pre-test al post-test, pero fue el grupo de experimentación el que mejoró significativamente respecto de los dos grupos de control.

Desde el estudio de Gillespie en 1995, la tecnología de modelado sólido y el software han cambiado mucho. En aquella época, el software utilizaba los modelos alámbricos, operaciones booleanas, y el movimiento mediante sistemas de coordenada de usuario (UCS). El software moderno tiende a ser más simple y más eficiente. Las imágenes son más realistas con representaciones renderizadas, lo que hace que la visualización sea más fácil y mejora las ventajas de usar el modelado sólido.

Frey y Baird (2000) estudiaron los efectos sobre las habilidades espaciales de usar Prototipado Rápido. El estudio utilizó un prototipo físico sencillo y estudió como las experiencias previas en CAD afectan a estas habilidades. Aunque ellos no encontraron ninguna diferencia significativa con el uso del Prototipado Rápido, sus datos mostraron que los aumentos de las puntuaciones en los test (pre y post del Minnesota Paper Forms Board Test (Likert \& Quasha, c.1995, 1970)) se relacionaban con la experiencia previa en dibujo. Los estudiantes fueron divididos en cuatro grupos basados en los niveles de experiencia o exposición al dibujo y el CAD: 1) ninguna experiencia de dibujo; 2) alguna experiencia de dibujo; 3) experiencia de CAD 2D y 3D; y 4) experiencia en Prototipado Rápido. De los 68 estudiantes, los que no tenían experiencia previa en 
dibujo obtenían las puntuaciones más bajas. Los que tenían experiencia previa en dibujo a mano tenían puntuaciones ligeramente más altas, pero eran los estudiantes con experiencia previa en CAD y modelado sólido los que alcanzaban las puntuaciones más altas.

Devon, Engel, Foster, Sathianathan, \& Turner (1994) examinaron los efectos del software de modelado sólido sobre habilidades espaciales. Para la experimentación se estudiaron trece grupos de una clase de iniciación a la ingeniería gráfica para determinar si el software de modelado sólido "Silver Screen", en comparación con el CAD en dos dimensiones y el modelado mediante modelos alámbricos, producía mejora de las puntuaciones. El Mental Rotation Test se usó como instrumento de medición. Los seis grupos del semestre de primavera tuvieron beneficios significativos. Esto demostró que la utilización del modelado sólido aumentó las habilidades espaciales por encima de la utilización del CAD en dos dimensiones. Con estas consideraciones los investigadores sugieren como investigaciones futuras la posibilidad de profundizar en el efecto del modelado sólido sobre las habilidades espaciales, la posibilidad de utilizar otro software, etc.

Godfrey (1999) estudió las habilidades espaciales usando modelado sólido en 76 estudiantes de carreras técnicas. El grupo de control recibió clases de CAD 2D y el grupo de experimentación recibió entrenamiento en modelado sólido. Los estudiantes pasaron el test PSVT/VR en las semanas 9 y 16 del curso. No se detectaron diferencias significativas entre los grupos, pero había diferencias entre la 9 semana y la 16. El grupo de modelado sólido mostró beneficios en las 9 primeras semanas y el grupo de 2D mostró beneficios en el período entre la semana 9 y 16 . Godfrey afirma que esto sugiere una progresión de enseñanza lógica que va del modelado sólido al más abstracto diseño asistido por ordenador en dos dimensiones.

La Tabla 2 y Tabla 3 muestran un resumen de las investigaciones más relevantes que relacionan las habilidades espaciales y el modelado sólido o el CAD 2D y 3D. 
CAPÍTULO III: EL MODELADO 3D COMO HERRAMIENTA DE MEJORA DE LAS HHEE

\begin{tabular}{|c|c|c|c|c|c|c|}
\hline Autor & $\begin{array}{l}\text { Universidad/Paí } \\
\mathrm{s}\end{array}$ & Año & Alu. & $\begin{array}{lll}\begin{array}{l}\text { Programa } \\
\text { asignatura }\end{array} & \text { de la } \\
\end{array}$ & Test & Resumen de conclusiones \\
\hline $\begin{array}{l}\text { Grandinscak y } \\
\text { Lewis } \\
\text { (1995) }\end{array}$ & $\begin{array}{l}\text { Royal Melbourne } \\
\text { Institute of } \\
\text { Technology } \\
\text { /University of } \\
\text { Melbourne } \\
\text { Australia }\end{array}$ & 1995 & 101 & $\begin{array}{l}\text { Realiza diferentes } \\
\text { cambios en el } \\
\text { contenido del } \\
\text { programa }\end{array}$ & MCT & $\begin{array}{l}\text { Hay mejora de las habilidades espaciales en los grupos } \\
\text { estudiados. Sin embargo la mejora no parece que dependa del } \\
\text { programa académico } \\
\text { Da algunas recomendaciones, como que la visión espacial es } \\
\text { importante y que el uso de herramientas CAD por sí mismo no } \\
\text { mejora las habilidades espaciales. Cambiar el entorno de } \\
\text { aprendizaje de la Expresión Gráfica no sólo es introducir el } \\
\text { ordenador, hay que reflexionar sobre el tipo de ejercicios }\end{array}$ \\
\hline $\begin{array}{l}\text { Duesbury y } \\
\text { O’ Neil } \\
(1996)\end{array}$ & $\begin{array}{l}\text { University of } \\
\text { Southern California } \\
\text { EEUU }\end{array}$ & 1995 & 43 & $\begin{array}{l}\text { CAD 3D } \\
\text { (modelos alámbricos) }\end{array}$ & $\begin{array}{l}\text { VIZ, Test of } \\
\text { Paper } \\
\text { Folding, } \\
\text { Surface } \\
\text { Developme } \\
\text { nt TEst }\end{array}$ & $\begin{array}{l}\text { Parece que el manejo de aplicaciones CAD 3D no mejora la } \\
\text { habilidad de visualizar objetos definidos mediante sus vistas } \\
\text { ortogonales. Sin embargo el uso de CAD obtiene unos } \\
\text { resultados generales que mejoran las habilidades espaciales y } \\
\text { motiva a los participantes }\end{array}$ \\
\hline $\begin{array}{l}\text { Sorby y } \\
\text { Baartmans } \\
(1996)\end{array}$ & $\begin{array}{l}\text { Michigan } \\
\text { Technology } \\
\text { University } \\
\text { EEUU }\end{array}$ & 1996 & 535 & $\begin{array}{l}\text { Modelado Sólido } \\
\text { (IDEAS) }\end{array}$ & PSVT:R & $\begin{array}{l}\text { El modelado sólido mejora la visión espacial. Además señalan } \\
\text { que hay diferencias entre hombres y mujeres y que el test } \\
\text { PSVT:R es un predictor del éxito en la asignatura de } \\
\text { Expresión Gráfica }\end{array}$ \\
\hline $\begin{array}{l}\text { Frey y Baird } \\
(2000)\end{array}$ & $\begin{array}{l}\text { University of } \\
\text { Missouri } \\
\text { EEUU }\end{array}$ & 1995 & 34 & $\begin{array}{l}\text { Incluye el prototipado } \\
\text { rápido dentro del } \\
\text { programa del curso }\end{array}$ & $\begin{array}{l}\text { Revised } \\
\text { Minnesota } \\
\text { Paper Form } \\
\text { Board }\end{array}$ & $\begin{array}{l}\text { El prototipado rápido NO mejora las habilidades espaciales (Sí } \\
\text { el dibujo clásico y Sí el CAD 3D) }\end{array}$ \\
\hline
\end{tabular}

Tabla 2.- Resumen de cursos que utilizan el modelado en el entrenamiento de las habilidades espaciales 
CAPÍTULO III: EL MODELADO 3D COMO HERRAMIENTA DE MEJORA DE LAS HHEE

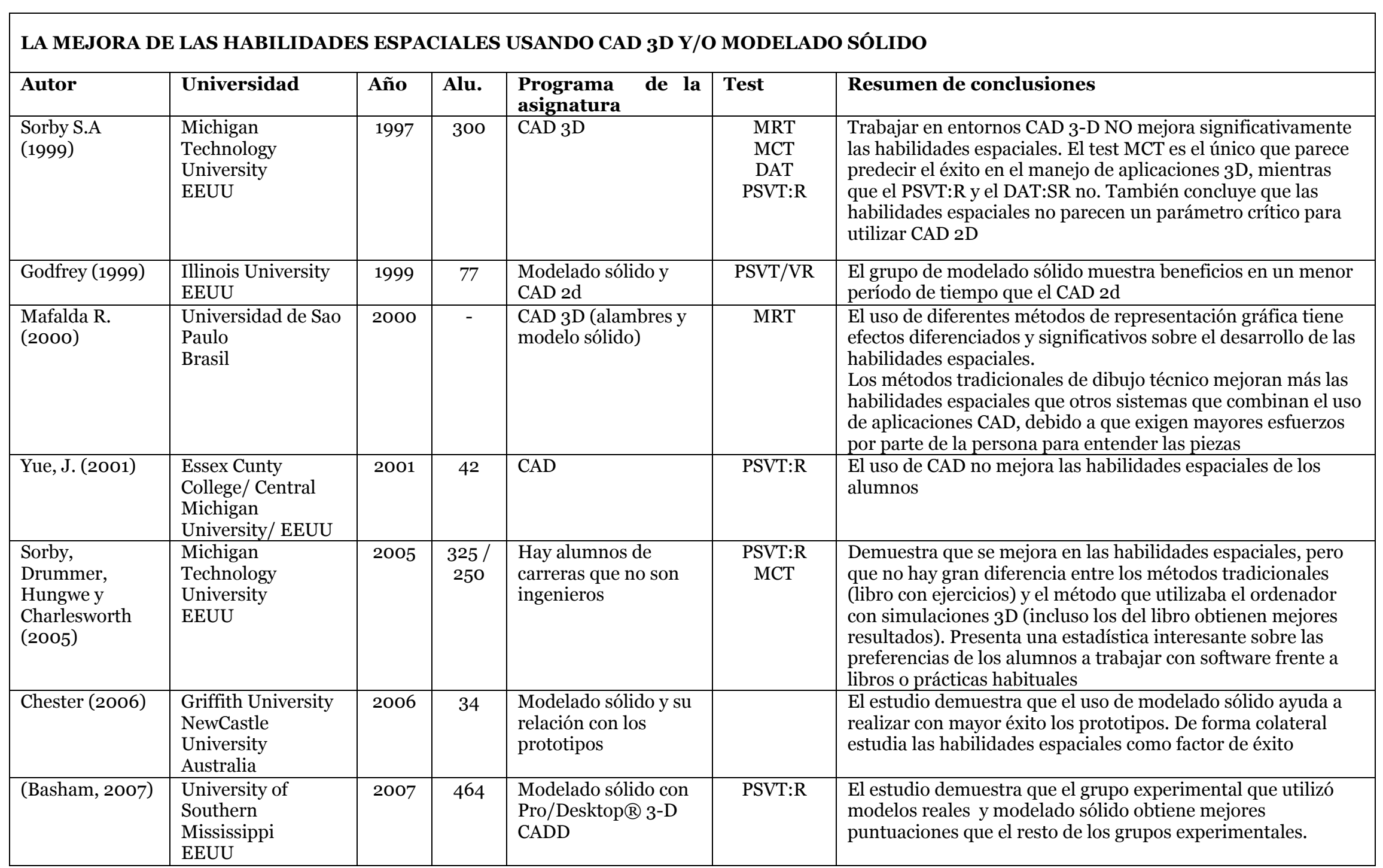

Tabla 3 (Continuación).- Resumen de cursos que utilizan el modelado en el entrenamiento de las habilidades espaciales 


\subsection{Software de modelado no técnico}

Posiblemente durante los últimos años, y debido a la bajada de precios del software y de los ordenadores capaces de manejarlo, surge un software de modelado que denominamos "no técnico" y que se pone al alcance de la mayor parte de negocios e instituciones educativas. A causa de esto, en poco tiempo salen al mercado multitud de productos que ponen al alcance de cualquier usuario la posibilidad de construir modelos en tres dimensiones. Es necesario destacar que este tipo de software no se puede comparar en sus características y posibilidades del software comercial, tipo Pro/Engineer, Autodesk Inventor, SolidWorks, Solid Edge, etc. Lo que ha cambiado posiblemente es la posibilidad de que cualquier persona, con pocos conocimientos técnicos, pueda realizar un modelo tridimensional en muy poco tiempo.

En Febrero de 2006 la empresa Google compra @Last Software, empresa creadora de SketchUp, un software modelado en $3 \mathrm{D}$, que ya se estaba usando para algunos plugins de Google Earth (ver Figura 6 y Figura 7).

Queremos destacar algunas de las características que hacen que este software haya abierto un nuevo camino en el campo de aplicaciones de modelado sólido "no técnico":

- Es un software gratuito. Google lo adquiere a principios de 2006 y pocos meses después pone a disposición una versión gratuita en la red. La medida, a pesar de lo que en un primer momento podríamos pensar, hizo que la empresa experimentara un importante aumento en las ventas de la versión de pago SketchUp Pro, que añade algunas funcionalidades a la aplicación.

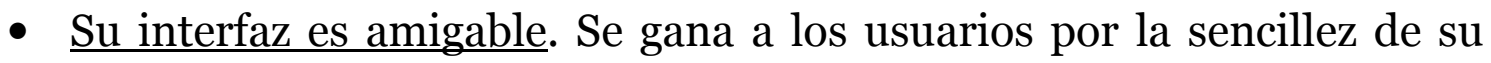
entorno: pocas órdenes y muy intuitivas.

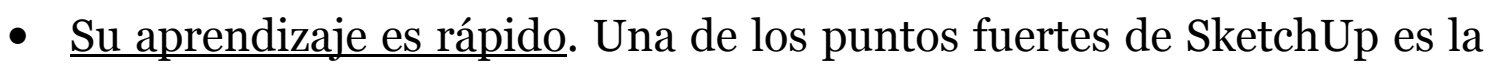
rapidez con la que se puede comenzar a usar: conocer unas pocas funciones es suficiente para poder crear modelos tridimensionales rápidamente. Se diferencia así de los programas técnicos que requieren, en general, un largo proceso de tutorización para dominar su uso y crear modelos en tres dimensiones.

- Dispone de la posibilidad de situar los modelos creados en Google Earth (sólo en la versión de pago), lo que se ha convertido en el gran atractivo del software y lo que ha permitido dar venta al paquete comercial. Antes, muchos creadores (ingenieros, arquitectos, 
diseñadores, artistas) diseñaban sus obras y debían pagar un alto precio para el marketing del producto. Ahora, en muchos de estos casos, la combinación de SketchUp con Google Earth permite que podamos ver el proyecto de un puente, de una casa o de una escultura en su ubicación real y tomar decisiones sobre su diseño, la adecuación al entorno, etc.

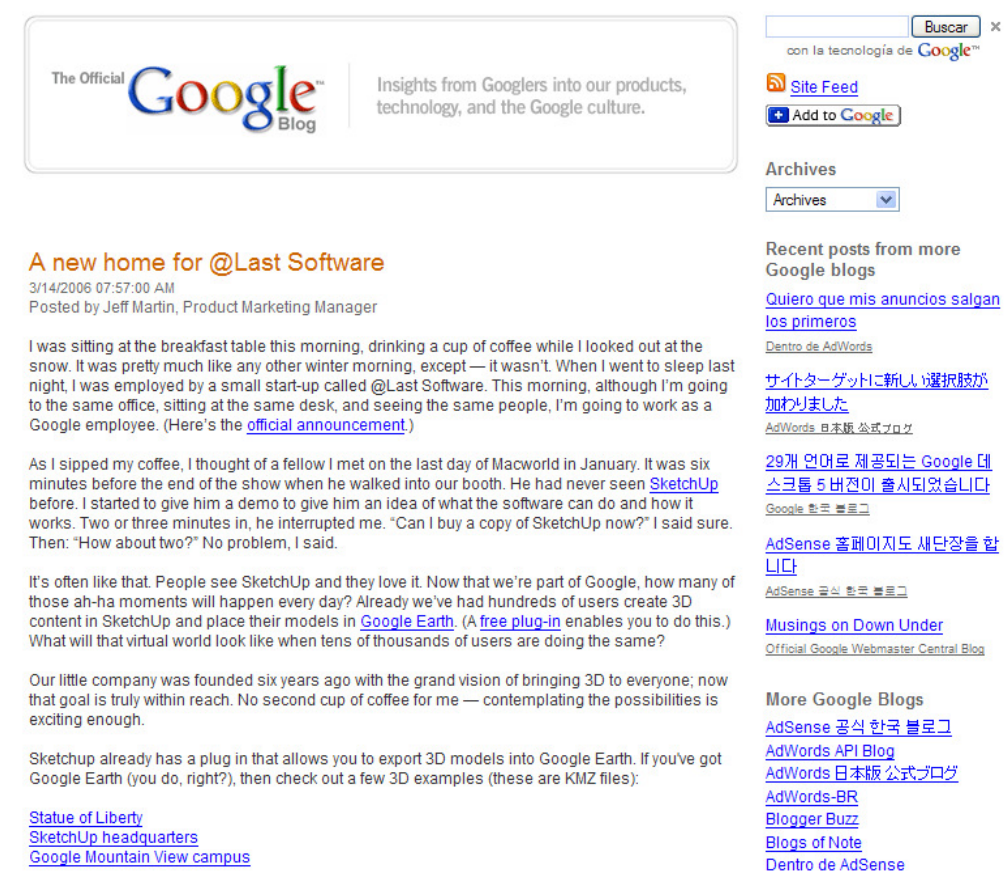

Figura 6.- Un directivo de @Last Software anuncia la compra de la empresa por parte de Google

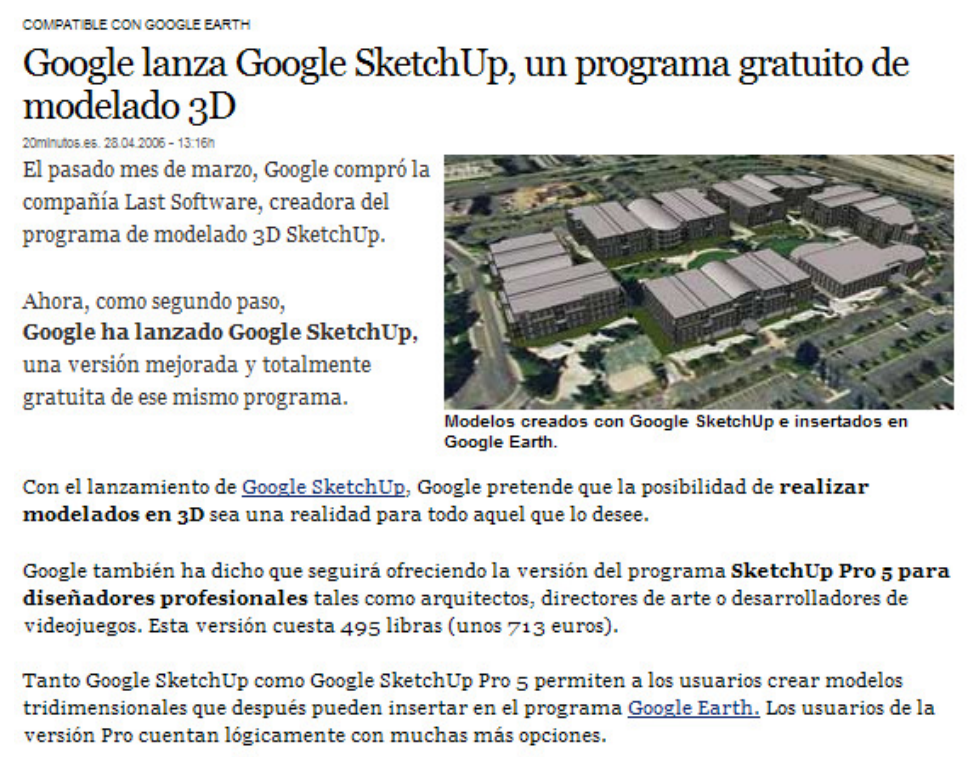

Figura 7.- Un directivo de @Last Software anuncia la compra de la empresa por parte de Google 


\subsection{Estudio Piloto Curso 2006-2007}

\subsubsection{Introducción y Justificación}

En muchas universidades españolas es práctica común ofrecer a los estudiantes de primer año de ingeniería, una serie de cursos de preparación del acceso a la universidad, llamados coloquialmente "Cursos Cero", para mejorar sus conocimientos en asignaturas básicas como matemáticas, física, química o expresión gráfica. Estos cursos normalmente se imparten unas semanas antes del inicio oficial del semestre académico. La participación es voluntaria y son cursos reconocidos como créditos de libre elección en el currículum personal del estudiante.

Este estudio piloto se ha desarrollado para obtener una experiencia previa, con el objetivo de diseñar un curso intensivo de mejora de las HHEE para los estudiantes a su entrada a la universidad, en forma de "Curso Cero". El objetivo es poder situar a los participantes en niveles de HHEE próximos a la media de la población Universitaria.

Conociendo las posibilidades del software descrito en el apartado anterior, y después de haber llevado a cabo distintas experiencias de cursos de mejora de las habilidades espaciales en la Universidad de La Laguna (Contero, Naya, Company, Saorin, \& Conesa, 2005; Contero, Company, Saorin, \& Naya, 2006; Saorín, 2006), este trabajo nace del planteamiento de una serie de preguntas:

- ¿El uso de entornos en tres dimensiones puede ser una metodología válida para mejorar las habilidades espaciales?

- ¿Puede este tipo de software ayudarnos a mejorar las habilidades espaciales de nuestros estudiantes?

- ¿Qué mejora puede aportar respecto de las experiencias anteriores detalladas en la literatura científica?

- ¿Se puede diseñar un curso de mejora de las habilidades espaciales haciendo uso de esta herramienta?

La búsqueda de respuestas a estas cuestiones constituye la base de la experiencia que describimos en este capítulo. Este trabajo propone una nueva metodología de apoyo al desarrollo de las relaciones espaciales y de la visión espacial, mediante el uso del modelado 3D. Se expone la experiencia llevada a cabo con los alumnos de primer curso de la Titulación de Ingeniería Técnica de Obras Públicas de la Universidad de La Laguna durante el Curso Académico 2006-2007. Se compara esta 
experiencia con una anterior llevada a cabo en el curso 2004-2005, en la que se evaluaron las habilidades espaciales de un grupo de 461 alumnos de carreras técnicas de la Universidad de La Laguna y se realizaron tres cursos intensivos de corta duración.

\subsubsection{Objetivos}

Los objetivos concretos que se pretenden con esta investigación son los siguientes:

- Desarrollar un curso intensivo con software de modelado 3D y comprobar si es una herramienta válida para la mejora de las habilidades espaciales y valorar en qué medida.

- Comparar diferentes estrategias y herramientas:

$\checkmark$ ejercicios en papel,

$\checkmark$ aplicaciones multimedia on-line,

$\checkmark$ interfaces caligráficas y

$\checkmark$ modelado 3D con SketchUp

- Obtener resultados que nos permitan elaborar una estrategia docente en forma de curso intensivo.

- Disponer de una experiencia previa que nos permita elaborar nuevos contenidos sobre dispositivos móviles para la mejora de las habilidades espaciales.

\subsubsection{Hipótesis}

En base a las experiencias realizadas por otros investigadores, las hipótesis de trabajo, de las que partimos como referencia son las siguientes.

- Hay parámetros que afectan a los resultados de los test de capacidad espacial.

- Las habilidades espaciales se pueden mejorar mediante un entrenamiento específico.

- El modelado 3D es una herramienta válida para este objetivo.

- Las asignaturas de Expresión Gráfica tienen un efecto positivo sobre las habilidades espaciales.

El estudio realizado, nos servirá para rechazar o validar las afirmaciones anteriores. Debemos destacar que contamos en este estudio con la limitación de que hemos realizado el experimento con los alumnos de una única titulación y hemos llevado a cabo la experimentación dentro de las horas de dedicación de la asignatura al desarrollo de las habilidades 
espaciales. Han participado todos los alumnos que voluntariamente estaban interesados y no se ha realizado ninguna selección previa de los mismos.

\subsubsection{Participantes}

Han participado 40 alumnos voluntarios del primer curso de la titulación de Ingeniería Técnica de Obras Públicas de la Universidad de La Laguna. A partir de los datos obtenidos de una encuesta que han rellenado, podemos saber que la mayoría tienen edades comprendidas entre 18 y 20 años, habiendo estudiado aproximadamente la mitad de ellos alguna asignatura de dibujo en niveles medios de enseñanza. El $65 \%$ son varones y la mayoría no trabajan y creen tener dificultades con las habilidades espaciales (ver datos de la encuesta en el Anexo I y características de la muestra en la Tabla 4).

Tabla 4.- Resumen de datos de los participantes

\begin{tabular}{lcccc}
\hline \multicolumn{1}{c}{ TITULACIÓN } & ASIGNATURA & CURSO & TIPO & ALUMNOS \\
\hline $\begin{array}{l}\text { Ingeniería Técnica } \\
\text { de Obras Públicas }\end{array}$ & $\begin{array}{c}\text { Expresión Gráfica } \\
\text { y Cartográfica }\end{array}$ & $1^{\mathbf{0}}$ & $\begin{array}{c}\text { Semestral } \\
(1 \mathrm{er})\end{array}$ & 40 \\
\hline
\end{tabular}

\subsubsection{Hardware y Software}

Se han usado en esta experiencia ordenadores Pentium IV, a 2,80 GHz, con 512 MB RAM bajo sistema operativo Windows XP y el software Google Sketchup 5, en su versión gratuita ${ }^{13}$, situados en un aula de prácticas de Expresión Gráfica de la Ingeniería de la Universidad de La Laguna (ver Figura 8).

SketchUp es un programa de modelado $3 \mathrm{D}$, pero con la diferencia fundamental de que no siendo una aplicación técnica nos permite plasmar una idea en un entorno tridimensional, de una forma rápida e intuitiva. El software CAD 3D, tipo ProEngineer, Autodesk Inventor, SolidWorks o Solid Edge, son herramientas potentes, pero en ocasiones excesivamente complicadas para realizar elementos sencillos. SketchUp es una aplicación sencilla, con una curva de aprendizaje casi plana. Actualmente tiene dos versiones: una gratuita (Google SketchUp), y otra de pago (SketchUp Pro). SketchUp Pro se diferencia de la versión gratuita en que permite importar y exportar gran cantidad de formatos de archivo y crear

${ }^{13}$ http://sketchup.google.com/product/ 
presentaciones interactivas. También se puede utilizar para imprimir en dispositivos de alta resolución, colocar los modelos en Google Earth y cargarlos en la Galería 3D.

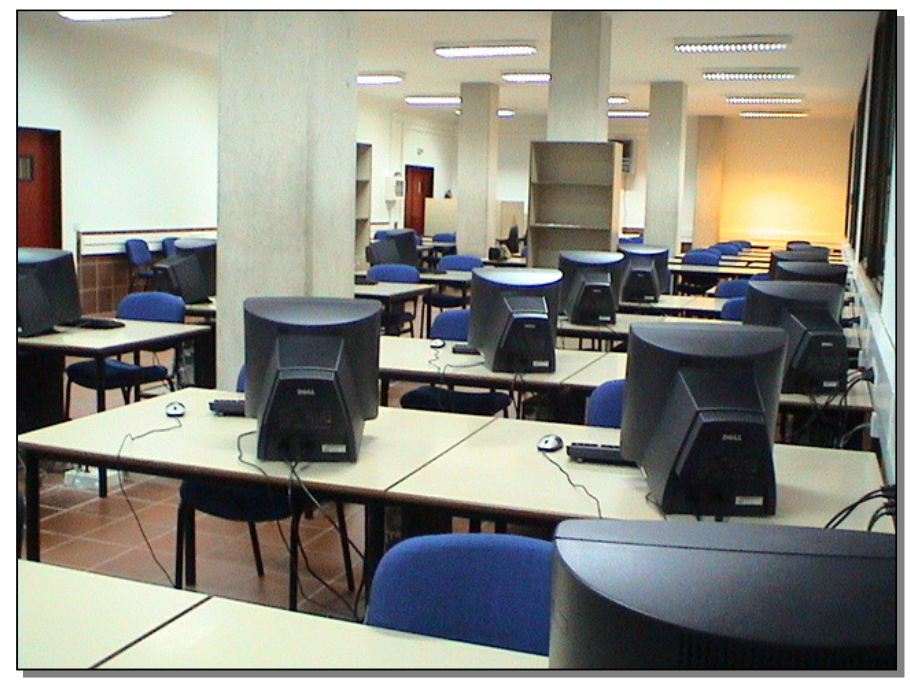

Figura 8.- Laboratorio de Expresión Gráfica del Área de Expresión Gráfica en la Ingeniería de la Universidad de La Laguna.

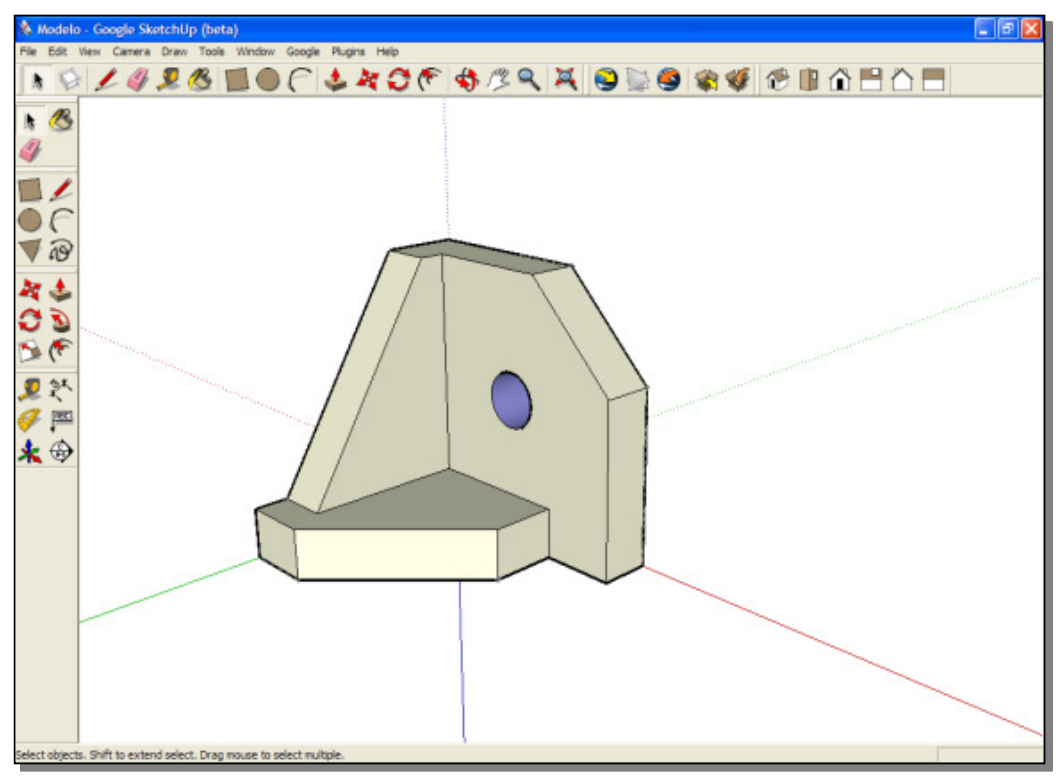

Figura 9.- Interfaz de SketchUp

SketchUp tiene una interfaz sencilla y menos comandos que aprender que otros programas. Al comenzar, la aplicación muestra una vista en planta y los ejes de coordenadas diferenciados por colores. Permite mostrar las diversas vistas de alzado, lateral o perspectiva, para ayudar en el modelado. Con este software lo normal es trabajar directamente en tres 
dimensiones (ver Figura 9). Se encuentran ciertas similitudes con otros programas técnicos, como AutoCAD, en los sistemas de selección de objetos, referencias dinámicas, órdenes de dibujo y de edición, etc. El Anexo II muestra la Guía de referencia rápida del programa y en la web de la aplicación se puede encontrar distintos tutoriales de ayuda.

\subsubsection{Pre-test y post-test}

Cada participante ha realizado dos test en papel antes y después de llevar a cabo el experimento, con el objetivo de poder evaluar los resultados:

- el Mental Rotation Test (MRT), que se usará para valorar las relaciones espaciales y,

- el Differential Aptitude Test - Spatial Relations Subset (DAT -SR), que se usará para valorar la capacidad de visión espacial.

En el Anexo III figuran las instrucciones dadas a los estudiantes en cada uno de los test.

\subsubsection{Material didáctico de Técnicas de Expresión Gráfica}

En esta experiencia se ha utilizado el Maletín M2: "Modelos de tres vistas y cortes”, material didáctico de Técnicas de Expresión Gráfica de la empresa Suministros Maditeg (Suministros Maditeg, 1997), mostrado en la Figura 10.

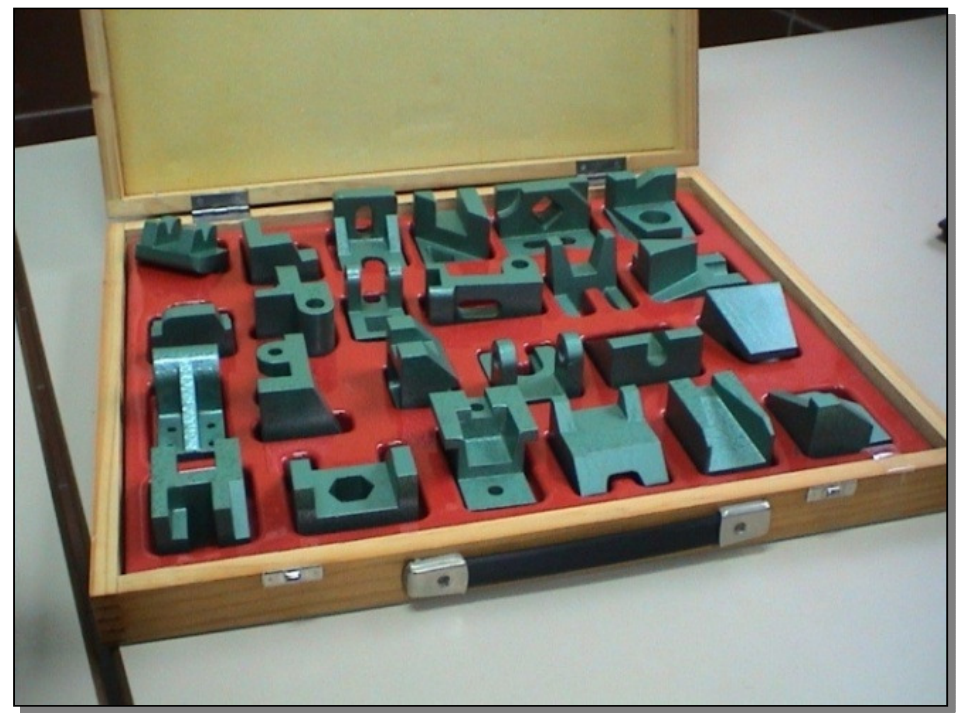

Figura 10- Maletín Maditeg de "Modelos de tres vistas y cortes" 
El material está formado por 24 piezas, construidas de aluminio fundido, mecanizadas casi todas sus superficies y pintadas en verde. El tamaño de las piezas es muy manejable, aproximadamente 60x55x45 mm. A los modelos se acompaña un folleto con la definición geométrica de las distintas piezas (ver Anexo V).

\subsubsection{Ejercicios en papel}

En la Figura 11 se muestra un ejemplo de las representaciones axonométricas, facilitadas a los estudiantes para afrontar el segundo y tercer nivel de aprendizaje (ver Anexo VI).
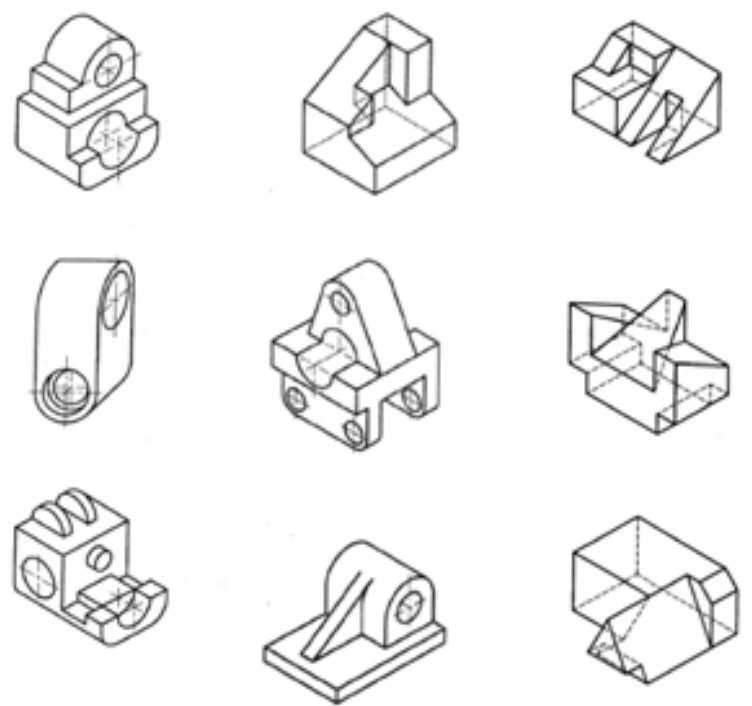

Figura 11.- Ejemplo de representaciones axonométricas utilizadas en los ejercicios en papel realizados

\subsubsection{Proceso de instrucción}

El curso de entrenamiento se organizó en tres sesiones: 8 horas en el aula de informática y aproximadamente 4 horas de trabajo en casa.

- Nivel 1: Iniciación (3 horas en aula y 2 horas de trabajo en casa).

- Nivel 2: Perfeccionamiento (3 horas en aula).

- Nivel 3: Trabajo en grupo (2 horas en aula y 2 horas fuera del aula).

El estudio piloto abarca una serie de actividades, planificadas según su grado de dificultad y que se detallan en la Tabla 5 . 
Tabla 5.- Actividades realizadas en el programa de entrenamiento

\begin{tabular}{|c|c|c|c|c|}
\hline NIVEL & & DESCRIPCION & TIEMPO & SEMANA \\
\hline \multirow[b]{2}{*}{ NIVEL 1: INICIACION } & 1.1 & $\begin{array}{l}\text { Construir modelos 3D a } \\
\text { partir de piezas reales }\end{array}$ & $\begin{array}{c}3 \\
\text { horas en aula }\end{array}$ & \multirow[b]{2}{*}{1} \\
\hline & 1.2 & Modelar objetos cotidianos & $\begin{array}{c}2 \\
\text { horas de trabajo } \\
\text { en casa }\end{array}$ & \\
\hline $\begin{array}{l}\text { NIVEL 2: } \\
\text { PERFECIONAMIENTO }\end{array}$ & & $\begin{array}{l}\text { Construir modelos } 3 \mathrm{D} \text { a } \\
\text { partir de una vista } \\
\text { isométrica dada en papel }\end{array}$ & $\begin{array}{c}3 \\
\text { horas en aula }\end{array}$ & 2 \\
\hline \multirow{3}{*}{$\begin{array}{l}\text { NIVEL 3: } \\
\text { DE LAS VISTAS } \\
\text { ORTOGONALES AL } \\
\text { MODELO 3D }\end{array}$} & 3.1 & $\begin{array}{l}\text { Construir modelos } 3 \mathrm{D} \\
\text { dadas las vistas } \\
\text { ortogonales normalizadas. }\end{array}$ & $\begin{array}{c}2 \\
\text { horas en aula }\end{array}$ & \multirow{2}{*}{3} \\
\hline & 3.1 & Trabajo en grupo & $\begin{array}{c}2 \\
\text { horas de trabajo } \\
\text { en casa }\end{array}$ & \\
\hline & & TOTAL & $\begin{array}{l}8 \text { horas en aula } \\
+4 \text { horas de } \\
\text { trabajo en casa }\end{array}$ & $\begin{array}{c}3 \\
\text { Semanas }\end{array}$ \\
\hline
\end{tabular}

NIVEL 1.- Iniciación (3 horas en aula y 2 horas de trabajo en casa)

En esta primera etapa, el objetivo es realizar un entrenamiento básico del manejo del software SketchUp. Los estudiantes aprenden el funcionamiento de los comandos más importantes del programa, usando una pieza sencilla que ellos construyen a la vez que reciben las explicaciones (ver Figura 12 y Figura 13). Aprenden a crear líneas, polígonos, dar medida a los objetos y moverse en el entorno tridimensional. Además se familiarizan con las extrusiones (“Empujar/tirar"), considerada como la operación básica de construcción.

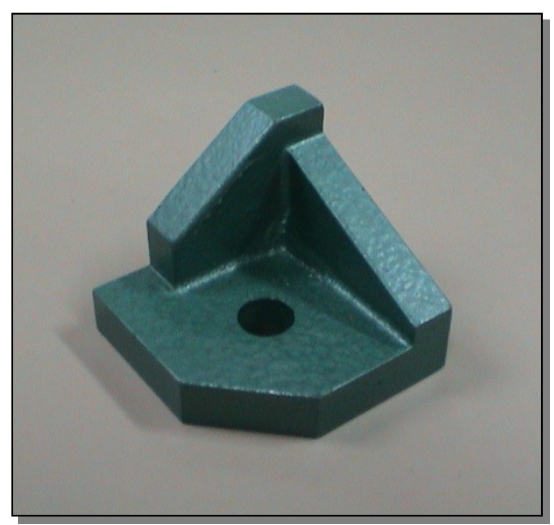

Figura 12.- Imagen de la pieza utilizada en la explicación de las funciones del programa

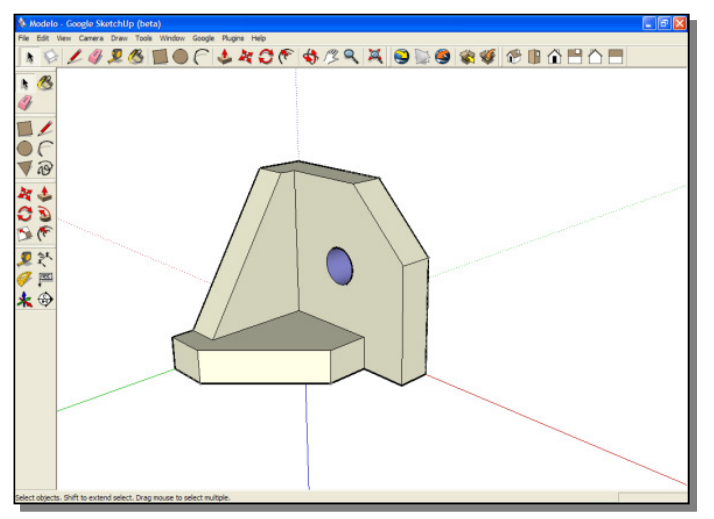

Figura 13.- Pieza modelada para conocer las órdenes básicas de SketchUp 
La ventaja de esta herramienta, según la experiencia de los profesores que han llevado a cabo el curso, es que el tiempo dedicado a manejarla es muy corto. En el Anexo II se refleja un esquema de las órdenes más importantes del programa.

A continuación se les facilita a los estudiantes una pieza del Maletín M2: "Modelos de tres vistas y cortes (Suministros Maditeg, 1997) para que modelen en tres dimensiones. Se les recomendó que realizaran un croquis del objeto, donde colocarán las dimensiones tomadas antes de comenzar a dibujar.

La Figura 14 muestra el resultado de algunos de los modelos realizados por los alumnos.
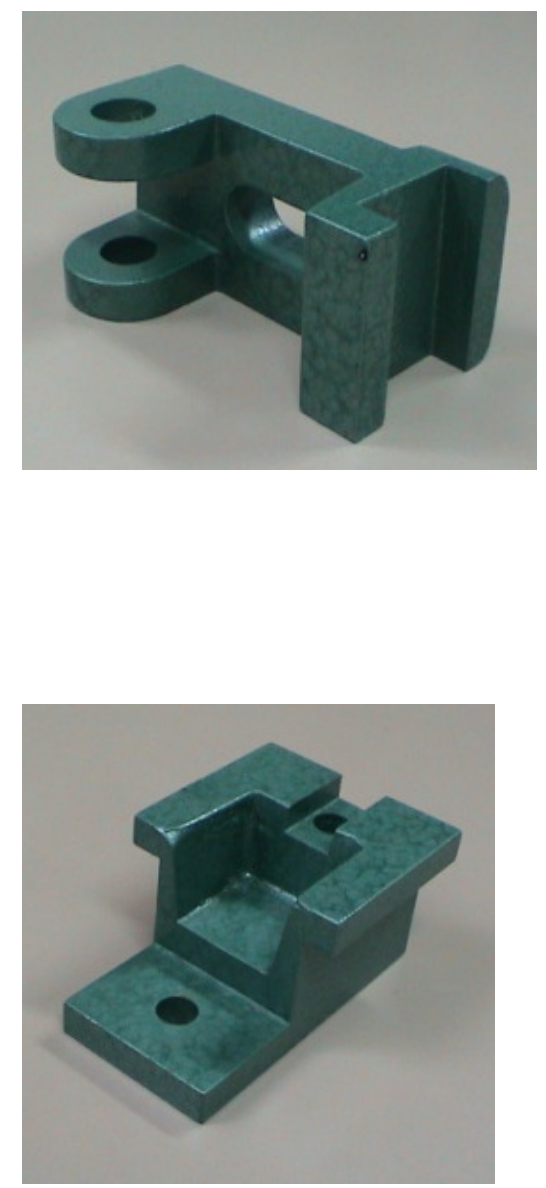

M. Cortijo Fernández

Figura 14.- Modelos realizados por los estudiantes en la actividad 1.1 del primer nivel 
Como actividad complementaria fuera del aula, se les propuso que modelaran un objeto cotidiano, tomando sus medidas y construyéndolo en tres dimensiones (ver Figura 15). El objetivo era que se familiarizaran definitivamente con las tres dimensiones de los objetos a través de la reproducción. Se les indicó que dedicaran aproximadamente 2 horas en casa a la construcción de estas piezas. En el Anexo VII y Anexo VIII figuran algunos de los ejercicios realizados por los estudiantes en esta fase.

Este nivel de iniciación tuvo una duración aproximada de cinco horas, distribuidas de la siguiente forma: media hora para el funcionamiento de la aplicación, dos horas y media para el desarrollo de las piezas en el aula $\mathrm{y}$ dos horas para modelar objetos cotidianos fuera del aula.
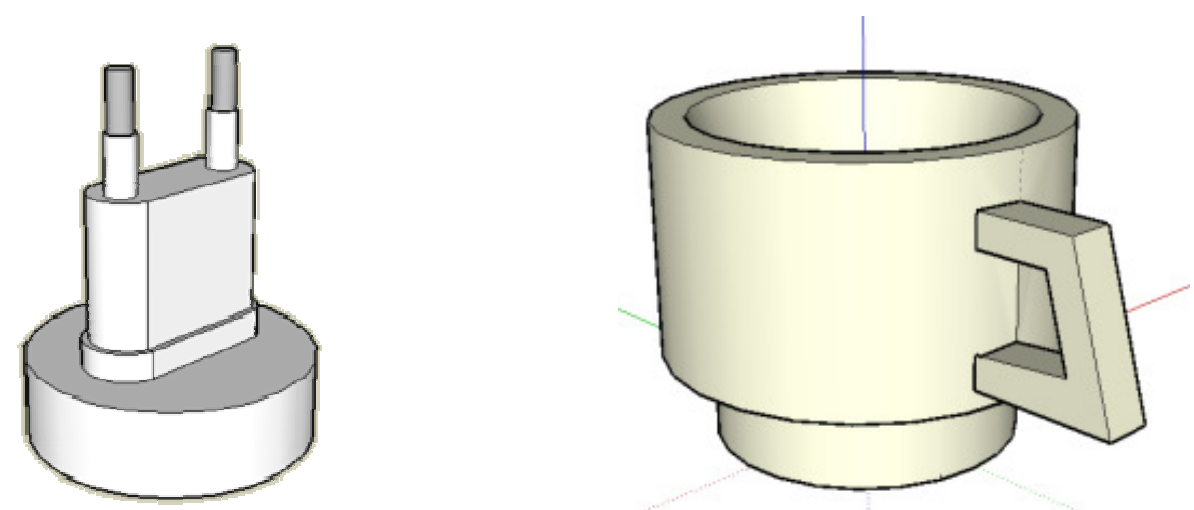

Figura 15.- Ejemplo de dos modelos realizados por dos estudiantes en la segunda actividad 1.2, del primer nivel de entrenamiento

Como resumen de esta fase hay que destacar que:

- La mayoría de los estudiantes no parecen tener dificultad en el uso del software (apreciación subjetiva).

- En muchos casos, se trata de estudiantes que desarrollan su primera experiencia de medición de piezas. El primer nivel de este curso les ayuda a comprender la importancia del boceto como método rápido de definir la geometría de una pieza. Además se familiarizan con la toma de datos y las características dimensionales de las piezas. 


\section{NIVEL 2.- Perfeccionamiento: del 3D en papel al 3D en SketchUp.}

En esta fase los alumnos tienen que construir modelos 3D a partir de las vistas isométricas de las piezas dadas en papel, como se muestra en el ejemplo de la Figura 16. Durante la primera hora que dura la sesión, se trata de detectar si son capaces de interpretar el volumen tridimensional a partir de la representación bidimensional dada en papel. Es importante aclarar que en esta fase no se imparte ninguna lección teórica o práctica de los contenidos de vistas ortogonales normalizadas o perspectiva, por lo que los estudiantes estarán en diferentes condiciones en función de los conocimientos previos que hayan adquirido en otros niveles de enseñanza (bachiller, formación profesional, etc.). Tiene una duración de tres horas y en el Anexo IX figuran los ejercicios realizados por los alumnos en esta fase (Pérez \& Serrano, 1998).

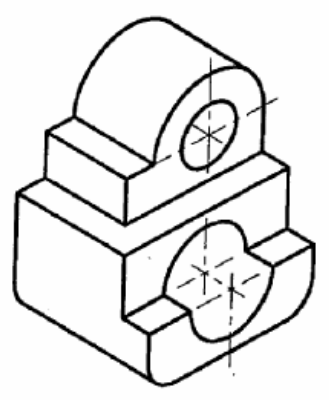

Ejercicio propuesto

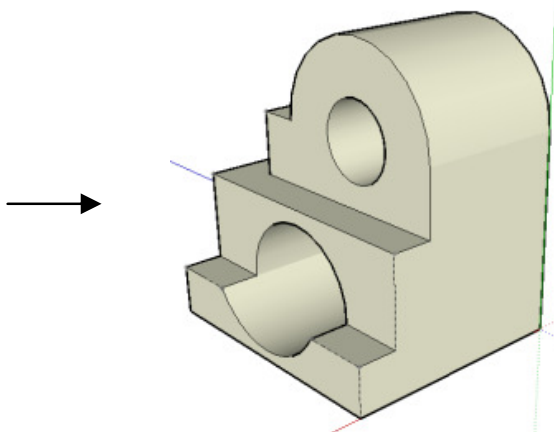

Ejercicio resuelto

Figura 16.- Ejemplo de un modelo realizado por los estudiantes en el segundo nivel

\section{NIVEL 3.- De las vistas ortogonales al modelo 3D}

En esta fase, como se muestra en la Figura 17, los estudiantes tienen que construir modelos 3D a partir de las vistas ortogonales normalizadas facilitadas por el profesor. Reciben indicaciones teóricas sobre los principios generales de representación, concretamente del Sistema Europeo de Vistas Normalizadas, porque se valora necesaria para poder abordar este nivel. A priori, identificamos esta etapa como una de las que presenta mayor grado de dificultad en el modelo de aprendizaje propuesto, por lo que se propone abordarla en dos fases: una primera de reflexión individual y otra de trabajo en grupo. Se les propone la formación de grupos de trabajo de 3 a 5 componentes para resolver las tareas propuestas y exponer los resultados. Los objetivos del trabajo en pequeños grupos era invitar a los estudiantes a compartir, discutir, 
defender su posición ante los demás compañeros, utilizar esta experiencia como medio para implicar a los estudiantes que habitualmente no participan y establecer un clima de cooperación. En el Anexo X figuran los ejercicios realizados.

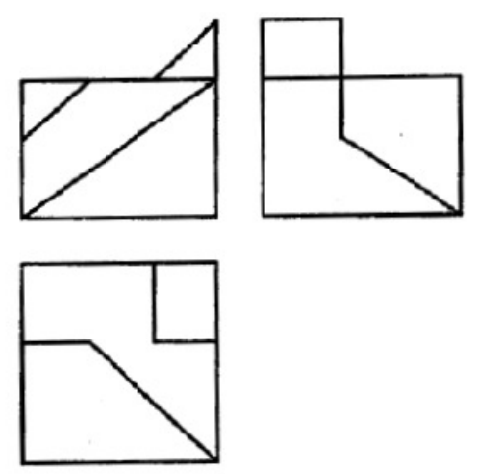

Ejercicio propuesto

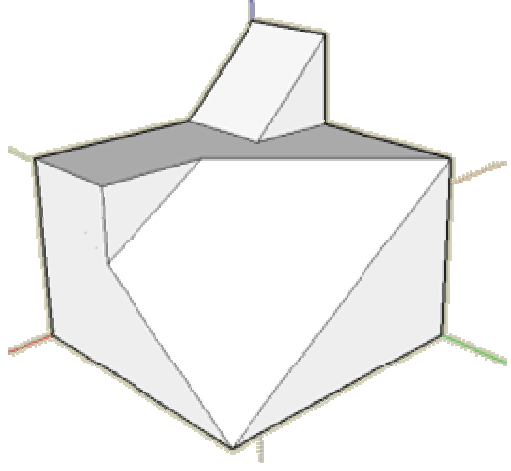

Ejercicio resuelto

Figura 17.- Ejemplo de pieza realizada en el tercer nivel por un estudiante.

Esta etapa ha sido valorada muy positivamente por los estudiantes. Se ha implicado activamente en el proceso de aprendizaje a los alumnos: los grupos hacen una propuesta de solución y el resto participa discutiéndola, mejorándola o reflexionando sobre las distintas soluciones posibles, con ayuda del profesor. La puesta en común de los resultados, se realiza en una exposición en clase ante el resto de compañeros. Este proceso ha sido muy fructífero y nos ha servido para poder resolver gran cantidad de ejercicios en un corto espacio de tiempo: una hora total de exposición.

Una vez finalizada la experiencia se publicaron los resultados de las piezas elaboradas tanto de forma individual, como del trabajo en grupo. Esto ha servido para una segunda etapa de reflexión individual sobre los ejercicios y sus posibles soluciones, además de que ha supuesto para los estudiantes un signo de valoración del esfuerzo realizado en todo este proceso de enseñanza-aprendizaje.

\subsubsection{Análisis de datos y resultados}

Como se comentó anteriormente, el estudio se ha realizado con 40 alumnos de la Titulación de Ingeniería Técnica de Obras Públicas de La Universidad de La Laguna, a principio de curso académico, durante el mes de Octubre de 2006. Se lleva a cabo durante las primeras semanas del curso con el objetivo de eliminar la influencia de los contenidos 
impartidos en otras materias, especialmente Expresión Gráfica, y así evitar que otros factores pudieran interferir en los test de medida de las habilidades espaciales.

La Tabla 6 muestra las puntuaciones medias obtenidas por los estudiantes antes (Pre) y después (Post) de realizar el curso de intensificación y las ganancias medias, para los test MRT y DAT-SR. Como referencia, en un estudio llevado a cabo en la Universidad de La Laguna durante el otoño de 2004 sobre 461 estudiantes, la puntuación media al inicio del curso fue de 16,71 en el MRT y de 42,96 en el DAT-SR. Estas puntuaciones fueron obtenidas a principio de curso, en estudiantes que cursaban alguna titulación técnica y accedían por primera vez a la Universidad (Saorín, 2006). Al final del cuatrimestre se volvió a testear a los estudiantes, con el objetivo de analizar el efecto de cursar materias de Expresión Gráfica sobre las habilidades espaciales. La ganancia media fue de 8,06 en el MRT y de 7,17 en el DAT-SR (Contero, Naya, Company, Saorin, \& Conesa, 2005; Contero, Company, Saorin, \& Naya, 2006).

Tabla 6.- Resumen descriptivo de las variables utilizadas en el curso con SketchUp

\begin{tabular}{llcccccc}
\hline & \multicolumn{3}{c}{ MRT } & \multicolumn{3}{c}{ DAT:SR } \\
\hline & & $\begin{array}{c}\text { Pre MRT } \\
\text { (s.d.) }\end{array}$ & $\begin{array}{c}\text { Post MRT } \\
\text { (s.d.) }\end{array}$ & $\begin{array}{c}\text { Gain MRT } \\
\text { (s.d.) }\end{array}$ & $\begin{array}{c}\text { Pre-DAT } \\
\text { (s.d.) }\end{array}$ & $\begin{array}{c}\text { Post DAT } \\
\text { (s.d.) }\end{array}$ & $\begin{array}{c}\text { Ganancia } \\
\text { DAT } \\
\text { (s.d.) }\end{array}$ \\
\hline SketchUp & Total & 19,03 & 24,50 & 5,48 & 41,58 & 49,88 & 8,30 \\
$2006-07$ & $\mathrm{n}=40$ & $(7,60)$ & $(8,50)$ & $(5,66)$ & $(10,34)$ & $(7,47)$ & $(6,73)$ \\
\cline { 2 - 8 } $\mathrm{n}=40$ & Hombre & 21,28 & 27,24 & 5,96 & 42,36 & 50,52 & 8,16 \\
& $\mathrm{n}=25$ & $(7,25)$ & $(7,72)$ & $(4,20)$ & $(11,05)$ & $(7,22)$ & $(7,77)$ \\
\cline { 2 - 8 } & Mujer & 15,27 & 19,93 & 4,67 & 40,27 & 48,80 & 8,53 \\
& $\mathrm{n}=15$ & $(6,83)$ & $(7,95)$ & $(7,60)$ & $(9,25)$ & $(8,00)$ & $(4,76)$ \\
\hline \multicolumn{2}{l}{ s.d. = desviación estándar } & & & & & &
\end{tabular}

Para el análisis estadístico, se parte de la hipótesis nula (Ho): "los valores medios de habilidades espaciales no han variado después del entrenamiento". Se aplica la prueba t-Student para series emparejadas y se obtienen los p-valores que representan la probabilidad de que dicha hipótesis sea cierta (ver Tabla 7).

Tabla 7.- Niveles de significación del curso.

\begin{tabular}{lll}
\hline & MRT & DAT-SR \\
\hline Curso con SketchUp & $p<0.001$ & $p<0.001$ \\
\hline
\end{tabular}


Se puede comprobar que el nivel de significación no llega en ningún caso al $1^{\circ} \%$ o, de hecho se ha de destacar que el p-valor es muy bajo. Es por ello que se rechaza la hipótesis nula en todos los casos y podemos afirmar con un nivel de significación superior al 99,9\% que la variación media del grupo estudiado ha experimentado un aumento. Es decir, que existe un efecto del curso de intensificación con SketchUp sobre el valor medio de las habilidades espaciales medidas por los test MRT y DAT-SR. El efecto obtenido es el de aumentar dichas habilidades en los sujetos sometidos al entrenamiento. Del análisis estadístico se puede concluir que las habilidades espaciales experimentan un aumento significativo medio de 5 puntos en el caso del test MRT y de 8 puntos en el test DAT-SR. Además se ha comprobado, aplicando t-Student para muestras independientes, que la ganancia experimentada en el curso no depende del género $(\mathrm{p}=0,552$ y $\mathrm{p}=0,868$, respectivamente). Esto se puede apreciar en la Tabla 6 , donde observamos que la ganancia media obtenida por hombres y mujeres es similar en cada uno de los test.

La Figura 18 muestra las puntuaciones medias obtenidas en los test MRT y DAT-SR. Los resultados son mostrados por género: hombres $(\mathrm{H})$ y mujeres (M). La parte izquierda del gráfico muestra los resultados para el MRT y la parte derecha para el DAT-SR.

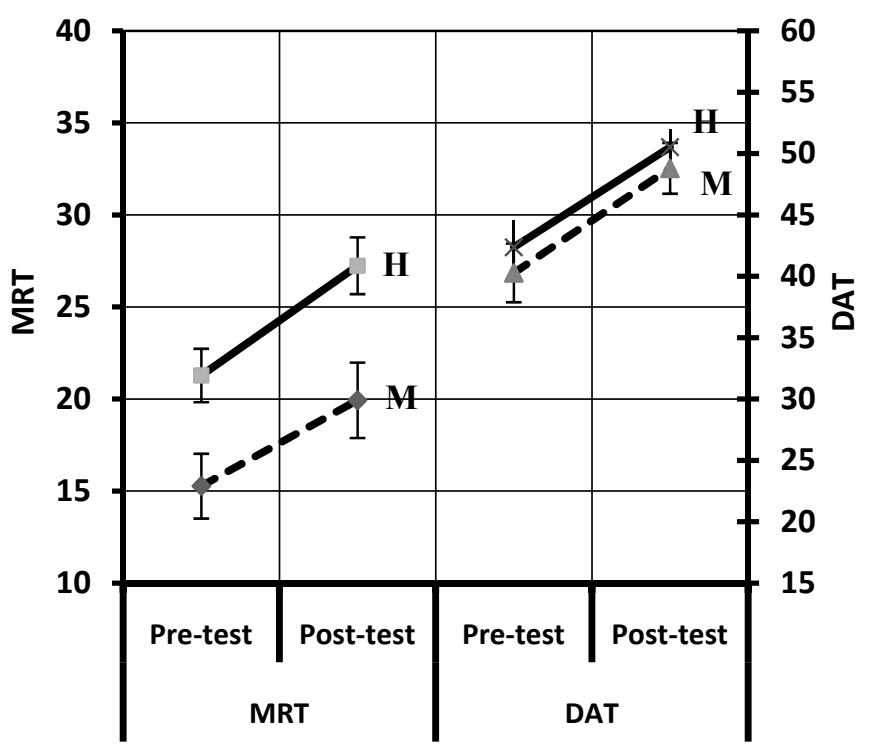

Figura 18.- Puntuaciones medias del MRT y DAT:SR por género: hombres $(\mathrm{H})$ y mujeres $(M)(n=40)$.

La Figura 19 y la Figura 20 muestran como existe una estrecha relación entre los valores iniciales y finales en cada uno de los test. 
Trabajos previos ya han realizado análisis con la finalidad de encontrar las relaciones existentes entre los valores iniciales y finales de los test, en función de parámetros como el género, la edad, las experiencias previas, el empleo de tiempo de ocio con videojuegos, etc.

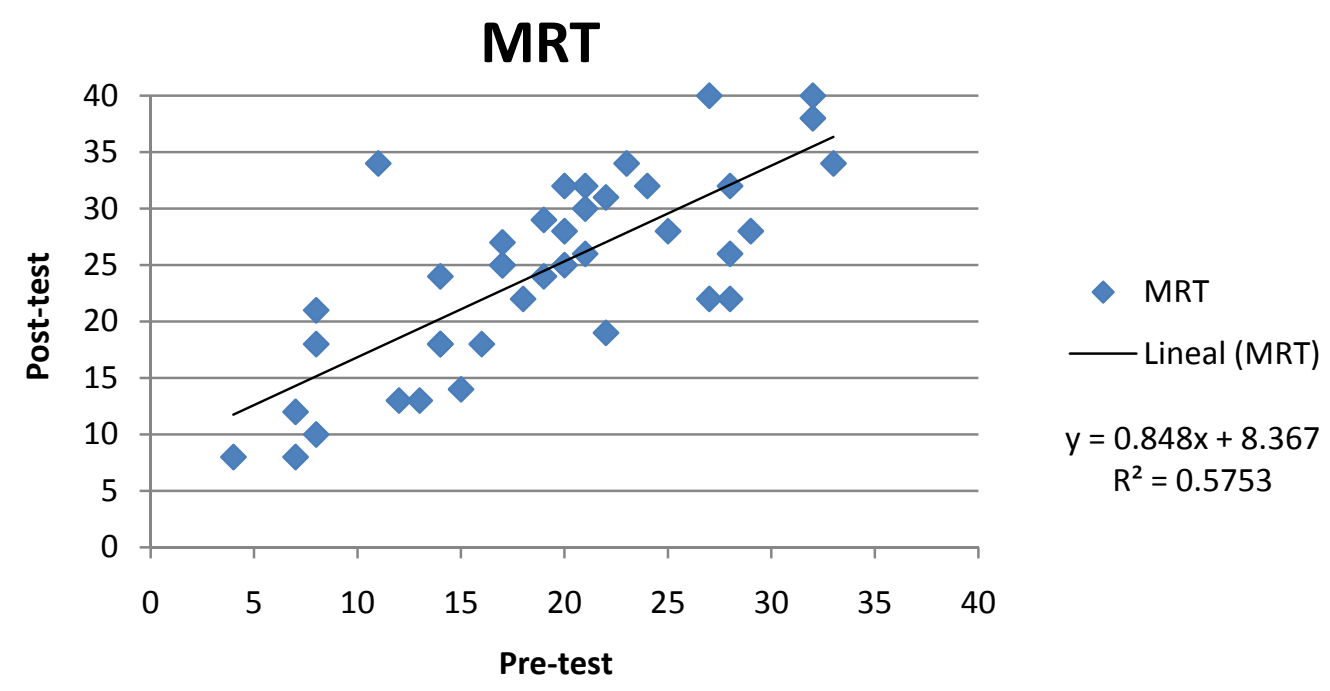

Figura 19.- Puntuaciones de los estudiantes en el MRT.

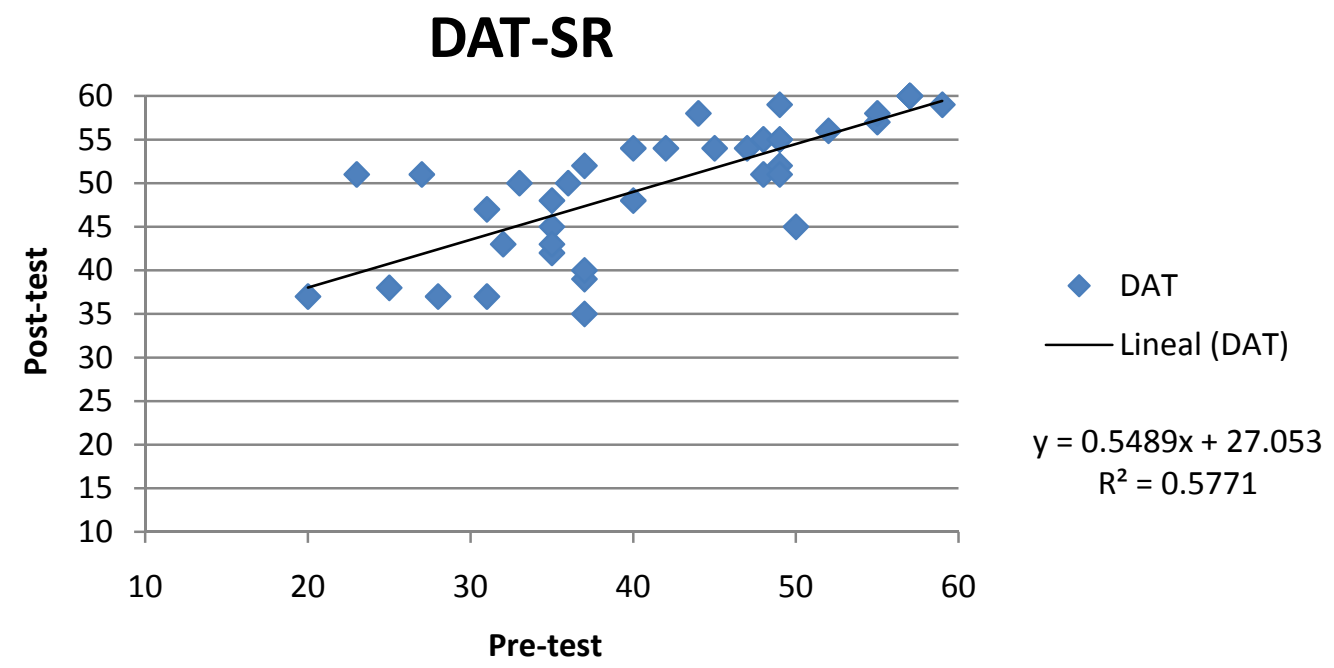

Figura 20.- Puntuaciones de los estudiantes en el DAT-SR.

En esta experiencia llevada a cabo se encuentra que la relación existente entre los pre- y post-test se puede expresar como se muestra en la Ecuación 1 y la Ecuación 2:

PostMRT $=8,367+0,848^{*}$ PreMRT, con un Coeficiente de Correlación de Pearson de $\mathrm{r}=0,758$

Ecuación 1.- Relación entre el PostMRT y el PreMRT 
PostDAT-SR $=27,053+0,549 *$ PreDAT-SR (pre-test) con un Coeficiente de correlación de Pearson de $\mathrm{r}=0,760$.

Ecuación 2.- Relación entre el PostMRT y el PreMRT

\section{Comparación con los resultados obtenidos en el curso 2004-2005}

Durante el curso académico 2004-05, se llevó a cabo un estudio sobre las habilidades espaciales en las carreras técnicas en la Universidad de La Laguna (Saorín, 2006). Después de pasar los test (MRT y DAT-SR) al principio del curso y detectar aquellos alumnos con valores de habilidades espaciales inferiores a la media de la clase, se diseñaron tres tipos de cursos de intensificación de 6 horas de duración cada uno. Se formaron tres grupos para realizar los cursos intensificación. El primer grupo (1) fue un curso de intensificación basado en ejercicios en papel, el segundo grupo (2) usó aplicaciones Web y el tercer grupo (3) usó una aplicación de bocetado por ordenador denominada e-CIGRO, desarrollada por el grupo de investigación Regeo (Regeo, 2009). Al finalizar la experiencia los estudiantes completaron de nuevo los dos test.

Con el objetivo de comparar con estos cursos (1, 2 y 3), se seleccionó, a partir de la muestra total de 40 estudiantes, una sub-muestra de los alumnos con peores resultados en alguno de los test $(n=12)$. La Tabla 8 muestra el resumen de puntuaciones medias obtenidas en los cursos.

Tabla 8.- Puntuaciones medias en los pre y post-test y ganancias en los cuatro cursos.

\begin{tabular}{llcccccc}
\hline No & Curso & $\begin{array}{c}\text { PreMRT } \\
\text { (s.d.) }\end{array}$ & $\begin{array}{c}\text { PostMRT } \\
\text { (s.d.) }\end{array}$ & $\begin{array}{c}\text { Ganancia } \\
\text { MRT } \\
\text { (s.d.) }\end{array}$ & $\begin{array}{c}\text { Pret } \\
\text { DAT:SR } \\
\text { (s.d.) }\end{array}$ & $\begin{array}{c}\text { Post } \\
\text { DAT:SR } \\
\text { (s.d.) }\end{array}$ & $\begin{array}{c}\text { Ganancia } \\
\text { DAT:SR } \\
\text { (s.d.) }\end{array}$ \\
\hline $1^{*}$ & $\begin{array}{l}\text { Ejercicios en } \\
\text { Papel } \\
n=17 / 6\end{array}$ & 8,18 & 13,53 & 5,35 & 28,47 & 39,35 & 10,88 \\
& $(4,60)$ & $(6,12)$ & $(4,35)$ & $(8,57)$ & $(10,09)$ & $(5,48)$ \\
\hline $2^{*}$ & Web & 9,60 & 13,27 & 3,36 & 30,53 & 35,67 & 5,13 \\
& $\begin{array}{l}n=15 / 6 \\
\text { horas }\end{array}$ & $(4,46)$ & $(4,80)$ & $(5,85)$ & $(5,40)$ & $(5,60)$ & $(5,25)$ \\
\hline $3^{*}$ & $\begin{array}{l}\text { E-Cigro } \\
n=20 / 6\end{array}$ & 7,85 & 12,05 & 4,20 & 33,00 & 40,40 & 7,40 \\
& horas & $(3,56)$ & $(5,33)$ & $(4,49)$ & $(6,26)$ & $(8,92)$ & $(5,92)$ \\
\hline 4 & $\begin{array}{l}\text { SketchUp } \\
n=12 / 12\end{array}$ & 10,58 & 16,83 & 6,25 & 31,00 & 43,42 & 12,42 \\
& $(4,32)$ & $(7,77)$ & $(6,55)$ & $(7,41)$ & $(6,24)$ & $(7,59)$ \\
\hline horas & & & & & &
\end{tabular}

*Cursos: 1, 2 y 3 (Saorín, 2006)/ s.d.= desviación estándar 
Se lleva a cabo un análisis de varianza (ANOVA) para determinar si existían diferencias entre los distintos cursos desarrollados. El efecto del tipo de entrenamiento no se encontró significativo para el test $\mathrm{MRT}\left(\mathrm{F}_{3}, 60\right.$ $=0,83$ y $p$-valor $=0,483$ ). Sin embargo para el test DAT-SR, si existieron diferencias significativas $\left(\mathrm{F}_{3}, 60=4,35\right.$ y p-valor $\left.=0,008\right)$. El test de Tukey indicó que la ganancia media en el grupo 2 (grupo de herramientas web) fue significativamente más bajo que en los grupos 1 (ejercicios en papel) y 4 (SketchUp). El curso 3 (Aplicación E-Cigro) no mostró diferencias significativas respecto a los otros dos grupos. Los datos de las puntuaciones obtenidas por los estudiantes y del análisis estadístico realizado con el software SPSS, en su versión 17, figuran en el Anexo XI y en el Anexo XII respectivamente. La Tabla 9 muestra los niveles de significación cuando se comparan los valores de los pre-test y post-test para cada uno de los grupos de este estudio.

Tabla 9.- Niveles de significación de Pre-test vs Pos-test para cada curso.

\begin{tabular}{llll}
\hline No & Curso & MRT & DAT:SR \\
\hline 1 & Ejercicios Papel & $p<0,001$ & $p<0,001$ \\
\hline 2 & Web & $p=0,043$ & $p=0,002$ \\
\hline 3 & E-Cigro & $p<0,001$ & $p<0,01$ \\
\hline 4 & SketchUp & $p=0,007$ & $p<0.001$ \\
\hline
\end{tabular}

\subsection{Resumen}

Desde la experiencia en el diseño y la evaluación del curso intensivo para la mejora de las habilidades espaciales mediante modelado 3D, descrito en este Capítulo, se puede concluir lo siguiente:

- El desarrollo de las habilidades espaciales se puede mejorar con un programa de entrenamiento específico. El programa de actividades detallado en este estudio, utilizando el software SketchUp, ha demostrado ser una buena opción, según los resultados obtenidos y el análisis realizado.

- Los cursos intensivos de mejora de las habilidades espaciales, de 6 a 12 horas de duración, pueden proporcionar un importante aumento de los niveles de capacidad de visión espacial. La ganancia media en el curso intensivo con SketchUp fue de alrededor de 5 puntos en el MRT y de 8 puntos en el DAT-SR, que se puede comparar con los 8 puntos 
en el MRT y 9 puntos en el DAT-SR alcanzados al final de un cuatrimestre, tras cursar una asignatura de Expresión Gráfica (Saorín, 2006).

- Con el entrenamiento específico que aquí se describe, tanto hombres como mujeres tienen un aumento medio similar en ambos test.

- Respecto a la tipología de ejercicios, el estudio descrito en este capítulo ha demostrado que, tanto el modelado $3 \mathrm{D}$ de piezas físicas como la realización de ejercicios más tradicionales (construcción de modelos a partir de una perspectiva en papel o a partir de las vistas diédricas), mejora las habilidades espaciales.

Podemos concluir que esta investigación demostró que el curso descrito en este trabajo es una opción válida para poner en marcha un curso de mejora de las habilidades espaciales para los estudiantes a su entrada a la Universidad, en forma de "Curso Cero" o de curso de inicio. Esto permitiría elevar el nivel medio de habilidades espaciales a los estudiantes con mayores dificultades.

Se abren además nuevas expectativas para la utilización de esta herramienta en estudiantes más jóvenes (bachiller, ESO, etc.), por su gratuidad y facilidad de uso, lo que podría conseguir que las nuevas generaciones lleguen mejor preparadas a la Universidad. 
Capítulo IV: Los contenidos Web interactivos sobre dispositivos móviles como herramienta de mejora de las habilidades espaciales

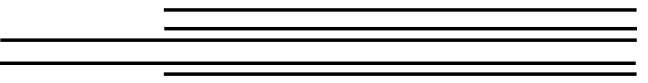





\section{1 Introducción}

Los informes sobre tecnologías de la información y comunicación de estos últimos tiempos ponen su atención en la nueva "Era Móvil", "where phones are carried everywhere, banks are accessed from holes in the wall, cars are becoming travelling offices, airplane seats are entertainment centers, computer games are handheld, and advertising is ubiquitous. We now have the opportunity to design learning differently...14" (Sharples, 2006).

Los avances en la tecnología, las interfaces de usuario y los recientes desarrollos en el campo de las comunicaciones móviles, tales como Wi-Fi, Bluetooth y las tecnologías de comunicación globales, como GPS, GSM, GPRS, 3G y los sistemas vía satélite, han creado un gran abanico de posibilidades para los usuarios de la tecnología.

Actualmente los dispositivos móviles en general: sean PDAs, teléfonos móviles, consolas de videojuego, Ultra Mobile PCs (UMPC), etc., tienden a disponer cada vez más de algunas o varias de estas tecnologías. Además, la mejora en las pantallas y las nuevas interfaces, unido a las capacidades multimedia y de almacenaje para podcasts, vídeos, fotos, archivos, etc., facilitan la interacción con una gran variedad de contenidos (Informe Horizon, 2008).

El hecho de que muchos estudiantes ya posean y lleven consigo dispositivos móviles de este tipo es un factor clave, por las posibilidades que pueden ofrecer a los procesos de enseñanza-aprendizaje. Algunos proyectos ya están mostrando como los dispositivos portátiles de mano pueden ofrecer nuevas oportunidades para la enseñanza, complementando la clase tradicional con un aprendizaje flexible, "en cualquier momento y lugar". Este tipo de aprendizaje se puede definir como: "Cualquier tipo de aprendizaje que ocurre cuando el aprendiz no está en un lugar fijo, en una ubicación predeterminada, o el aprendizaje que ocurre cuando el alumno se aprovecha de las oportunidades ofrecidas por las tecnologías móviles” (Faux, McFarlane, Roche, \& Facer, 2006).

14 “... cuando los teléfonos nos transportan a cualquier sitio, los bancos son accesibles desde huecos en las paredes, los coches comienzan a ser oficinas móviles, los asientos de los aviones son centros de entretenimiento, los juegos de ordenador pasan a ser juegos portátiles y la publicidad es ubicua. Tenemos la oportunidad de diseñar un aprendizaje diferente..." 
La investigación más reciente en el campo de las habilidades espaciales se centra en la relación de éstas con las nuevas tecnologías. El rápido crecimiento de las tecnologías de la información y de la comunicación y el hábil manejo de estas tecnologías que tienen los estudiantes de hoy día ha propiciado nuevas formas de educación. El uso de pequeños dispositivos móviles, tales como teléfonos móviles, PCs, Ultra móviles (UMPC), PDAs, Smartphones o consolas de videojuegos, es un tema que está levantando gran expectación en la actualidad y sobre el que se están realizando interesantes iniciativas empresariales y proyectos de investigación (IAML, 2009).

El trabajo que se describe en este capítulo trata de aprovechar oportunidades de movilidad y las nuevas interfaces de usuario que nos ofrecen los dispositivos de mano de pantalla táctil, en un contexto de educación no formal, con el objetivo de desarrollar las habilidades espaciales.

\subsection{Tipología de ejercicios}

Basándonos en el material publicado por los distintos investigadores en este ámbito y que se resume en el apartado 2.1.5 del Capítulo II de esta tesis, se ha elaborado una caracterización de las tipologías de ejercicios utilizados en la literatura para la mejora de las habilidades espaciales. Esta clasificación se refleja en el Anexo XIII.

Se han seleccionado aquellos ejercicios que nos permiten una representación plana (en imagen 2D) y que se puedan encajar en pantallas de pequeñas dimensiones. Es importante comentar este aspecto, porque, aunque pueden existir algunas tipologías más, es posible que no se puedan representar fácilmente en el formato que hemos preestablecido.

Tipologías de ejercicios utilizados en este trabajo:

- Ejercicios de modelos de cubos

- Ejercicios de identificación de caras y vistas

- Ejercicios de discriminación de volúmenes

- Ejercicios de rotaciones

- Ejercicios de cortes y secciones 


\section{Ejercicios de modelos de cubos}

Esta caracterización se ha basado en la publicación de Sheryl Sorby (Sorby, Wysocky, \& Baartmans, 2003) y los ejercicios del Instituto Freudenthal de Ciencia y Matemáticas de la Universidad de Utrecht (The Freudenthal Institute for Science and Mathematics Education, 2004). Son ejercicios basados en la construcción de modelos de cubos. Se distinguen tres tipos de ejercicios:

Ejercicio tipo 1.1: ¿Cuántos cubos faltan? (ver Figura 21). Este ejercicio es una propuesta nueva, no existiendo específicamente así en la literatura. Se da un modelo de bloques a la derecha y se pide identificar en la planta codificada por alturas de la izquierda el número de bloques que faltan en una posición que se marca con una interrogación en rojo. La planta codificada indica con un número, el número de bloques que se colocan apilados en esa posición.
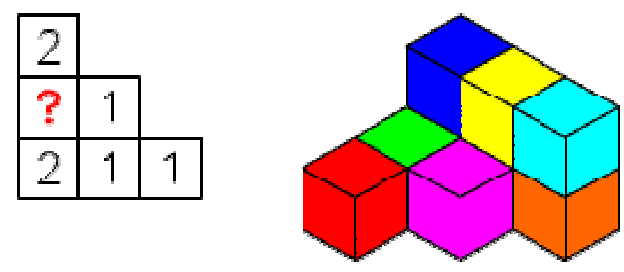

Figura 21.- Ejemplo de ejercicio 1.1

Ejercicio tipo 1.2: ¿Qué volumen corresponde a la planta dada? A, B, C ó D (ver Figura 22). El ejercicio consiste en relacionar la planta codificada con alguno de los modelos propuestos: A, B, C ó D. Sólo hay una solución.

\section{\begin{tabular}{|l|l|l|}
\hline 3 & 2 & 1 \\
\hline
\end{tabular}}

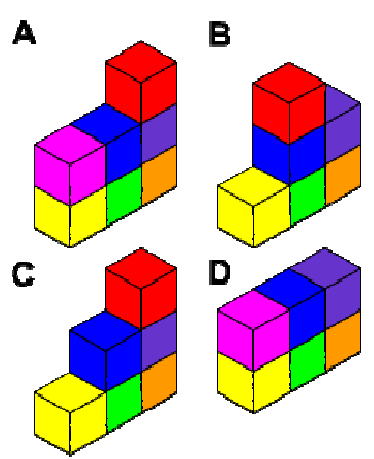

Figura 22.- Ejemplo de ejercicio 1.2

Ejercicio tipo 1.3: ¿Es posible? Sí ó No (ver Figura 23). Este ejercicio está inspirado en la web "Impossible World" (Alexeev, 2001-2009). Se 
trata de discriminar si las figuras propuestas son posibles de construir en un mundo real utilizando cubos.

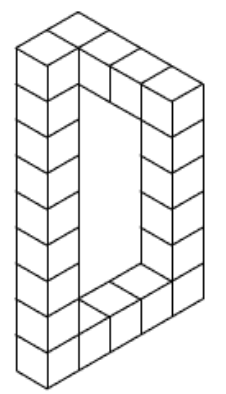

Figura 23.- Ejemplo de ejercicio 1.3

\section{Ejercicios de identificación de caras y vistas}

Se pide la identificación de caras y vistas ortogonales normalizadas, dada la vista isométrica de un modelo. Se inspira en los applets del Instituto Freudenthal de Ciencia y Matemáticas de la Universidad de Utrecht (The Freudenthal Institute for Science and Mathematics Education, 2004), en los ejercicios del profesor Stephen W. Crown (Crown, 2001) y en la publicación de Sheryl Sorby (Sorby, Wysocky, \& Baartmans, 2003).

Ejercicio tipo 2.1: ¿Cuál es la cara coloreada en rojo? 1, 2, 3, 4 ó 5 (ver Figura 24). Este ejercicio propone localizar la cara coloreada en rojo del modelo, en las vistas ortogonales normalizadas. La respuesta será un número que se corresponda con esa cara: 1, 2, 3, 4 ó 5 .

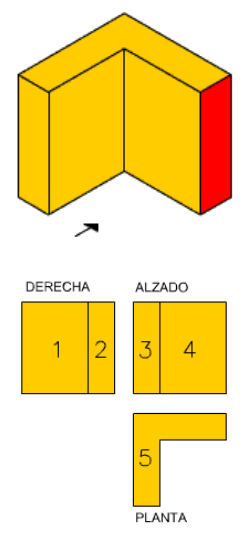

Figura 24.- Ejemplo de ejercicio 2.1

Ejercicio tipo 2.2: ¿Cuál es la vista que se muestra? Vista de frente, Vista superior, vista derecha (ver Figura 25). Este ejercicio pide determinar la vista mostrada de un modelo isométrico dado: vista 
superior o planta, vista de frente o alzado, vista izquierda o perfil izquierdo, etc.

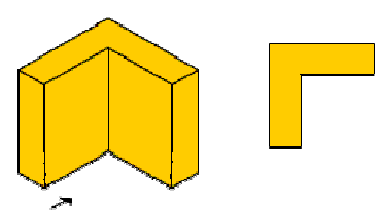

Figura 25.- Ejemplo de ejercicio 2.2

Ejercicio tipo 2.3: ¿A qué pieza corresponde la vista mostrada? 1 a 6 (ver Figura 26). Este ejercicio pide que determinar a qué piezas de las seis mostradas corresponde la vista mostrada.

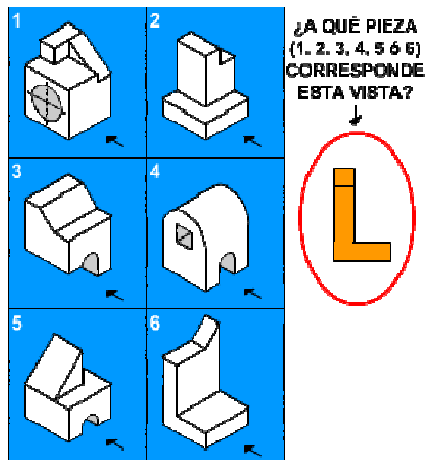

Figura 26.- Ejemplo de ejercicio 2.3

Ejercicio tipo 2.4: ¿Qué vista corresponde al modelo isométrico mostrado? A, B ó C (ver Figura 21). Este ejercicio pide determinar qué vista corresponde, de las tres propuestas, al modelo isométrico mostrado.

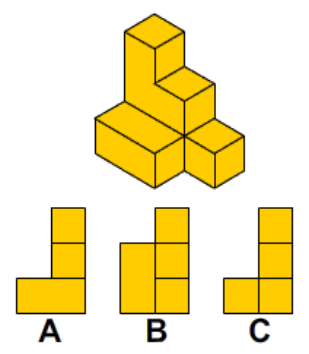

Figura 27.- Ejemplo de ejercicio 2.4

\section{Ejercicios de discriminación de volúmenes}

Esta tipología de ejercicios busca que los estudiantes se familiaricen con los modelos isométricos y sus distintos puntos de vista y sean capaces de relacionar los modelos isométricos y un conjunto de vistas ortogonales normalizadas (alzado, planta y perfil). Se inspira en los ejercicios del profesor Stephen W. Crown (Crown, 2001) y en la publicación de Sheryl Sorby (Sorby, Wysocky, \& Baartmans, 2003). 
Ejercicio tipo 3.1: ¿A qué volumen corresponden estas vistas? 1 a 12 (ver Figura 21). Este ejercicio propone localizar, de entre 12 propuestos, el modelo cuyas vistas (alzado, planta y perfil derecho) se muestran a la derecha.

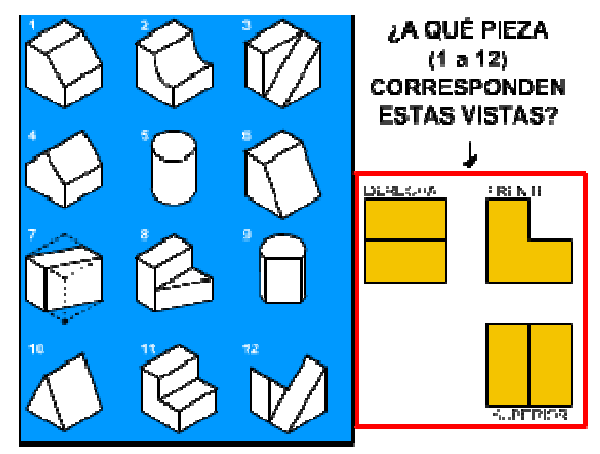

Figura 28.- Ejemplo de ejercicio 3.1

Ejercicio tipo 3.2: ¿A qué volumen corresponde? 1 a 9 (ver Figura 29). Este ejercicio trata de buscar de entre 9 modelos el que es igual al mostrado a la derecha y que puede estar girado.

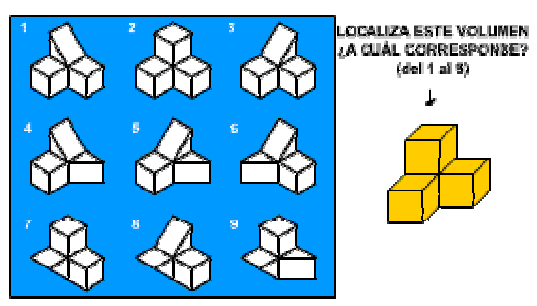

Figura 29.- Ejemplo de ejercicio 3.2

Ejercicio tipo 3.3: ¿A qué volumen corresponden estas vistas? A, B, C ó D (ver Figura 30). Este ejercicio pide determinar el modelo que corresponde, de entre los cuatro propuestos, a las vistas ortogonales normalizadas (alzado, planta y perfil).

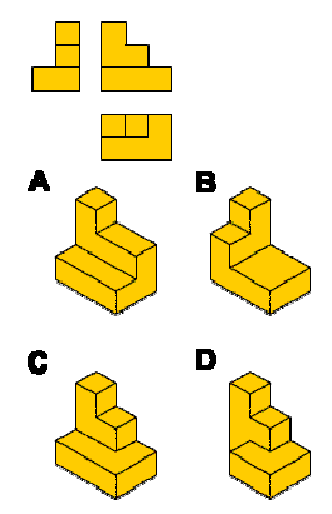

Figura 30.- Ejemplo de ejercicio 3.3 


\section{Ejercicios de rotaciones}

Esta caracterización de ejercicios de rotaciones, aborda las tareas que requieren el esfuerzo mental de realizar giros a los modelos propuestos, mediante ejercicios en los que los estudiantes tienen que identificar vistas o volúmenes a los que se les ha aplicado una rotación de 90, 180 o 270 grados respecto a un eje. Se inspira en los ejercicios del cuarto módulo del Taller de Visión Espacial de la Universidad de Burgos (Dpto. Expresión Gráfica. Universidad de Burgos, 2007) y en la publicación de Sheryl Sorby (Sorby, Wysocky, \& Baartmans, 2003).

Ejercicio tipo 4.1: ¿Qué vista corresponde a la pieza si la giro $90^{\circ}, 180^{\circ}$ ó $270^{\circ}$ ? , B ó C (ver Figura 31). Consta de nueve ejercicios. Las experiencias previas con ejercicios de rotaciones realizados con estudiantes sugieren que propongamos este primer nivel, como un nivel de aprendizaje del Módulo, puesto que nos hemos encontrado en otros entrenamientos que son ejercicios en los que suelen encontrar mayor nivel de dificultad. La tarea consiste en determinar qué vistas de alzado se corresponden con la pieza cuando ésta ha girado $90^{\circ}, 180^{\circ}$ ó $270^{\circ}$ alrededor de alguno de los 3 ejes marcados. El punto de vista es fijo, siempre en la dirección marcada con una flecha rellena en negro.

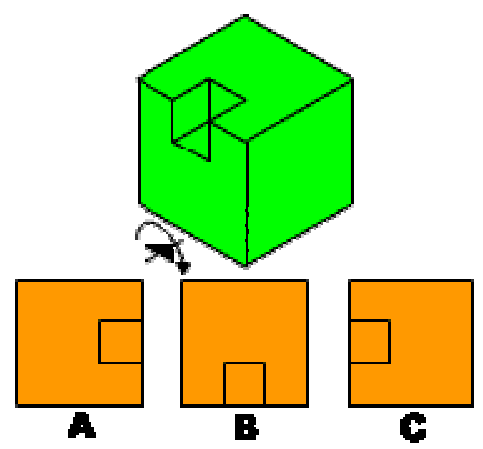

Figura 31.- Ejemplo de ejercicio 4.1

Ejercicio tipo 4.2: ¿Qué vista corresponde a la pieza si la giro $90^{\circ}, 180^{\circ}$ ó $270^{\circ}$ ? A, B ó C (ver Figura 32). Este ejercicio es igual al anterior, sólo que las piezas mostradas son de mayor dificultad. 


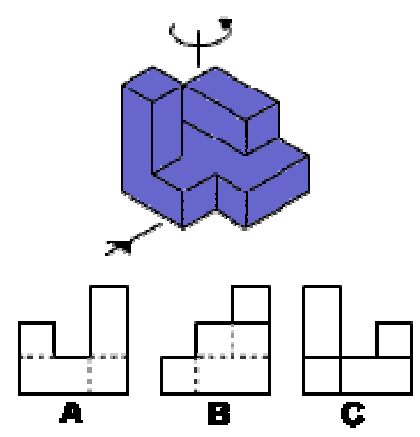

Figura 32.- Ejemplo de ejercicio 4.2

Ejercicio tipo 4.3: ¿Cuánto tengo que girar la pieza de la izquierda, alrededor del eje marcado, para que se muestre como a la derecha? $90^{\circ}$, $180^{\circ}$ ó $270^{\circ}$ (ver Figura 33). Consta de diez ejercicios. La tarea consiste en determinar cuántos grados $\left(90^{\circ}, 180^{\circ}\right.$ ó $\left.270^{\circ}\right)$ tengo que girar la pieza de la izquierda, alrededor del eje marcado, para que se muestre como a la derecha.

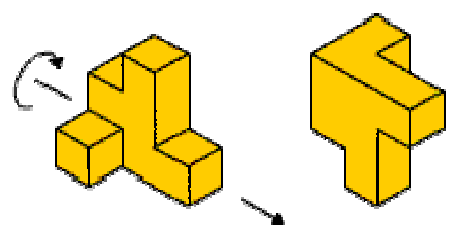

Figura 33.- Ejemplo de ejercicio 4.3

\section{Ejercicios de Secciones}

Este quinto y último módulo, Secciones, pide al estudiante identificar los cortes y/o las secciones practicadas a las piezas mostradas. Se utilizan ejercicios de la publicación de Sheryl Sorby (Sorby, Wysocky, \& Baartmans, 2003) y los ejercicios de cortes y secciones de J.A. Cuadrado (Cuadrado, 2009).

Ejercicio tipo 5.1: ¿Qué sección produce el plano? A, B, C ó D (ver Figura 34). Consta de 5 ejercicios en los que se practica secciones a piezas sencillas. Se utiliza también de iniciación a este módulo.

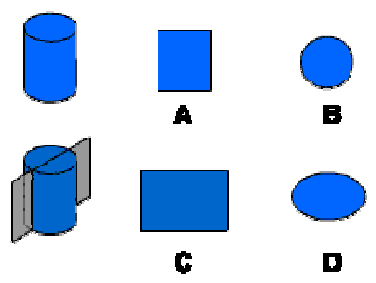

Figura 34.- Ejemplo de ejercicio 5.1 
Ejercicio tipo 5.2: ¿A qué pieza corresponde la sección mostrada? A, B, $\mathrm{C}$ ó D (ver Figura 35). Consta de 20 ejercicios en los que se practican los cortes y secciones a piezas con un mayor grado de dificultad. Se han utilizado los ejercicios de Santiago Cuadrado J.A. Cuadrado (Cuadrado, 2009), configurando las imágenes a un tamaño que pudiera ser visualizado en dispositivos de $320 \times 480$ de resolución.

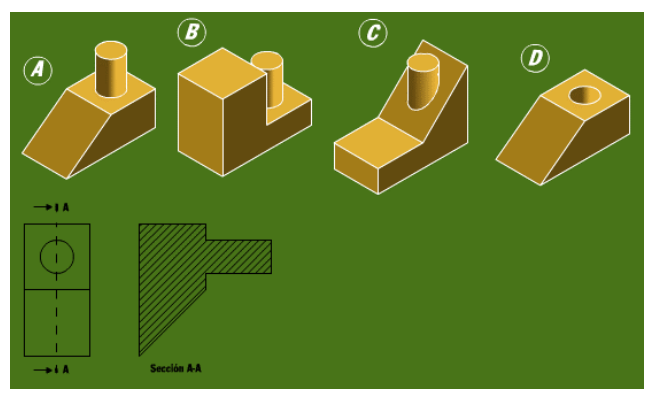

Figura 35.- Ejemplo de ejercicio 5.2

\subsection{Estudio Piloto Curso 2008-2009}

Este estudio piloto ha sido diseñado para obtener una experiencia previa, con el objetivo de elaborar un curso intensivo de mejora de las habilidades espaciales para aquellos estudiantes de ingeniería que entran a la Universidad con niveles inferiores a la media. Los objetivos concretos de esta investigación son los siguientes:

1. Analizar los efectos que sobre las habilidades espaciales puede producir el entrenamiento mediante el material didáctico descrito en este trabajo, $\mathrm{y}$

2. Evaluar la experiencia de los usuarios con los dispositivos móviles de pantalla táctil, un formato novedoso en el ámbito del entrenamiento espacial,

3. Valorar la satisfacción de los usuarios con el formato de curso a distancia (mobile learning).

\subsubsection{Participantes}

Han participado 68 estudiantes voluntarios del primer curso de las titulaciones de Ingeniería Técnica de Obras Públicas, Ingeniería Técnica 
Industrial, especialidad en electrónica industrial e Ingeniería Técnica Industrial, especialidad en Mecánica, de la Universidad de La Laguna. Veintitrés mujeres y cuarenta y cinco hombres, con una media de edad de 20 años (rango 17-28). Los participantes no tienen experiencia previa con dispositivos móviles de pantalla táctil. Este estudio utiliza dos grupos de trabajo: un grupo experimental y un grupo de control. El grupo experimental lo forman 38 estudiantes (26 hombres y 12 mujeres), que voluntariamente realizan el programa de entrenamiento, y el grupo de control, formado por 30 estudiantes (19 hombres y 11 mujeres), que no realiza ningún entrenamiento durante la semana que dura este estudio.

\subsubsection{Materiales}

\subsubsection{Material Didáctico}

Basándonos en el material publicado por los distintos investigadores en este ámbito, que resumimos en el apartado $\mathrm{n}^{0}$ 2.1.5 del Capítulo II (La capacidad espacial y las herramientas de mejora), se elaboró una clasificación de tipologías de ejercicios y se propuso una serie de módulos y niveles que se detallan en el apartado $\mathrm{n}^{0} 3$ de este capítulo (tipología de ejercicios). Se estructura, por tanto, un curso en 5 módulos con su niveles correspondientes (entre 2 y 4 por módulo). La Tabla 10 muestra la tipología de ejercicios contemplados en este programa, que se han descrito detalladamente en el apartado anterior.

El sistema diseñado está formado por (ver Figura 36iError! No se encuentra el origen de la referencia.):

- (1) Base de datos, que contiene los datos de usuario y recopila los resultados de los ejercicios.

- (2) Cuestionarios web, donde los estudiantes resuelven las colecciones de ejercicios (cada cuestionario corresponde a un nivel). Los cuestionarios fueron adaptados para optimizar su aspecto a dispositivos de pantalla táctil de 3,5 pulgadas.

- (3) Web. Este entorno se elaboró en lenguaje Html y código ASP, utilizando el framework "Universal iPhone UI Kit" (Martín-Lafuente, 2009), que nos permite una interfaz optimizada para múltiples dispositivos de hardware: tanto para el iPhone o el iPod Touch, como para PDAs, PCs, etc.

Los cuestionarios y la base de datos se han elaborado con el software comercial Web Quiz XP (Smart Lite Software, 2009), que nos ofrece un 
acceso de administrador a la base de datos de usuarios. AutoCad(C) (Autodesk Corporation, 2009) y Adobe Flash (C) (Adobe, 2009) se utilizaron para el diseño y coloreado de las imágenes de los cuestionarios.

Cada uno de los niveles dispone de un video explicativo en el que se exponen los contenidos necesarios para abordar los ejercicios que se proponen. Estos videos se han elaborado con el software Adobe Flash (C) (Adobe, 2009) y Apple QuickTime Pro (C) (Apple, 2008).

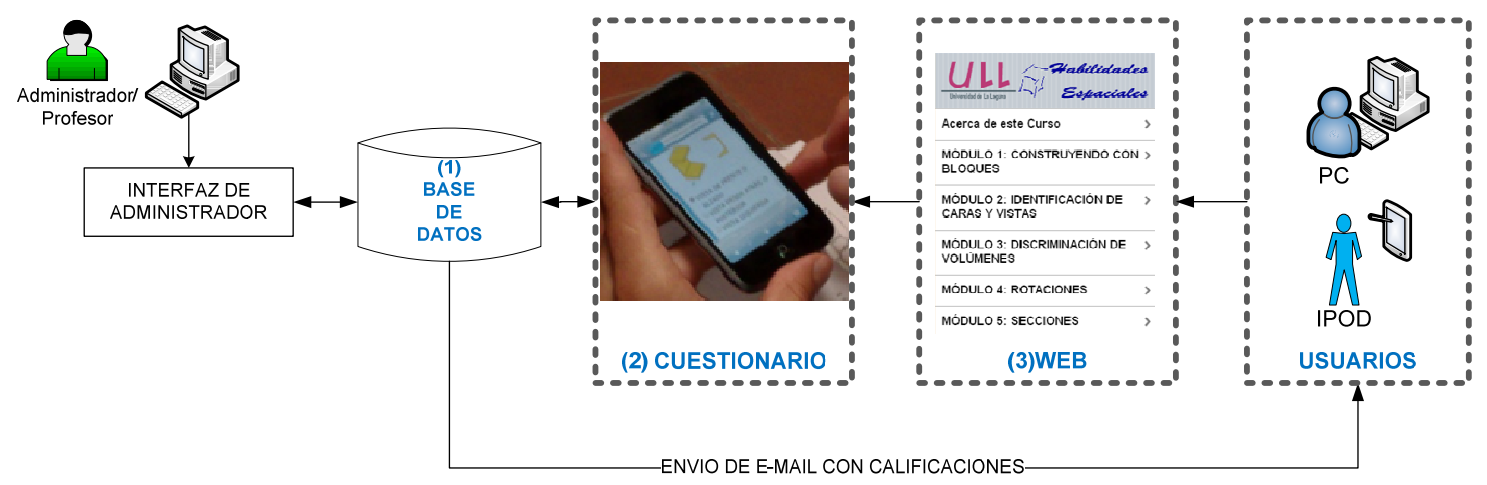

Figura 36.- Arquitectura del sistema 
Tabla 10.- Resumen de los módulos y niveles del curso

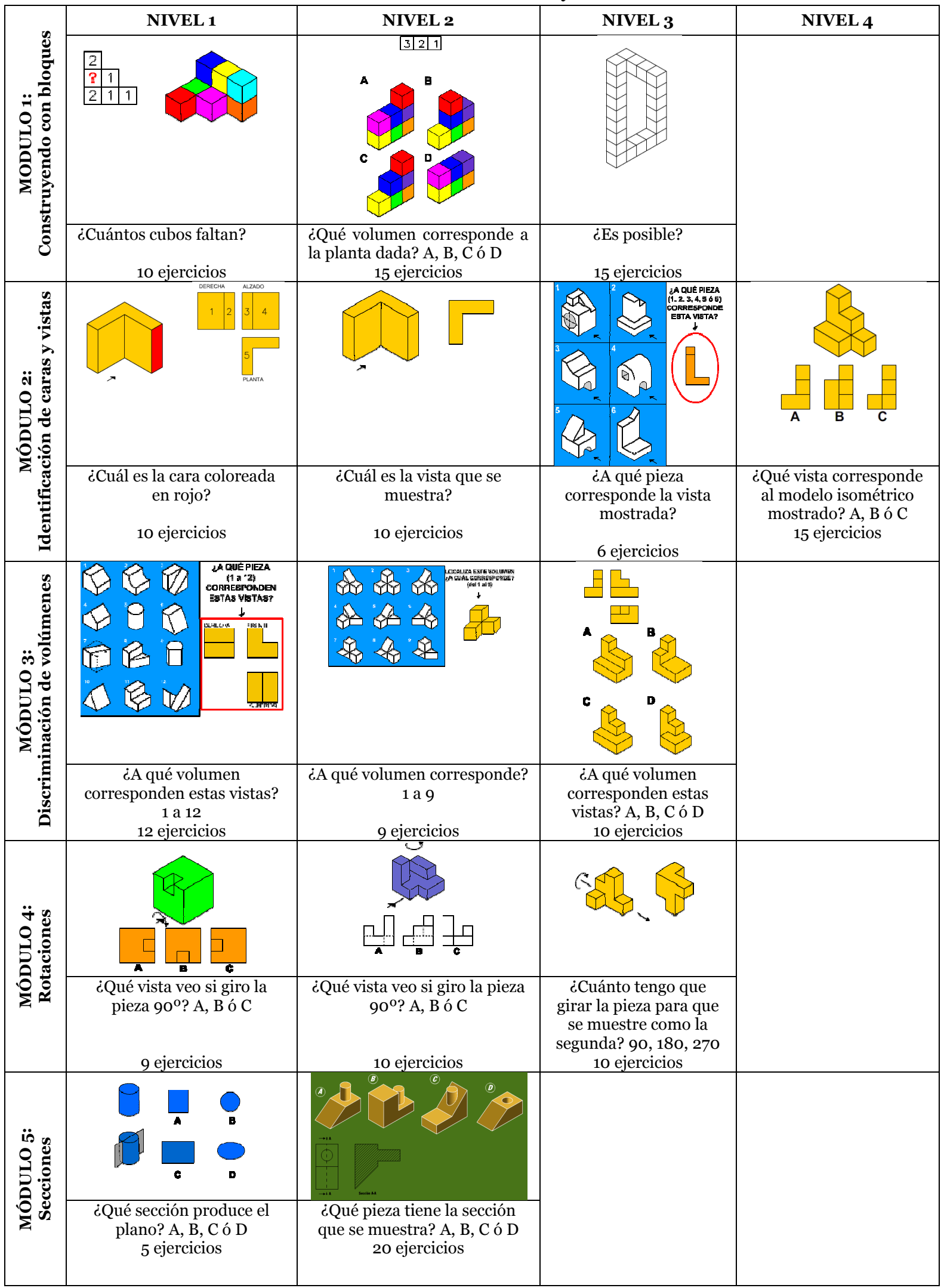




\subsubsection{Hardware y Software}

Aunque tanto el material como el estudio han sido diseñados e implementados sobre dispositivos Ipod Touch y iPhone, hemos de destacar que el curso es accesible desde cualquier PC, PDAs o cualquier dispositivo móvil en general que tenga un tamaño mínimo de pantalla de 3,5 pulgadas y preferiblemente con pantalla táctil. El navegador del dispositivo debe ser capaz de leer código HTML, CSS y ASP, que por otro lado son características habituales en estos aparatos (ver Figura $37 \mathrm{y}$ Figura 38).

\subsubsection{Pre- y post-test}

Cada participante ha completado el Mental Rotation Test (MRT) (Vanderberg \& Kuse, 1978) (ver Figura 39), antes y después de participar en esta experiencia, con el objetivo de poder evaluar el aumento que produce el curso sobre las habilidades espaciales de los individuos. Contiene 20 items divididos en dos sets de diez. Cada ítem consiste en una figura de muestra y cuatro figuras adicionales de las cuales, dos corresponden a la de muestra giradas un cierto grado y las otras dos no corresponden con la muestra. El tiempo límite es de 6 minutos, dividido en dos periodos: 3 minutos para cada 10 items. La puntuación total es de 40 puntos, obteniendo 2 puntos por cada ítem resuelto correctamente, 1 punto si se localiza sólo una de las rotaciones y no se marca ninguna otra figura y o puntos si alguna de las respuestas marcadas es incorrecta.

Este test también ha sufrido el proceso de validación que indica un grado de fiabilidad o consistencia de 0,88 , en una muestra de 3.268 adultos (Vanderberg \& Kuse, 1978), así como su validación como elemento para la medición de las habilidades espaciales. Es interesante recalcar que los resultados obtenidos por Vanderberg y Kuse en 1978 indicaron claramente una diferencia entre hombres y mujeres, independientemente de su edad. 


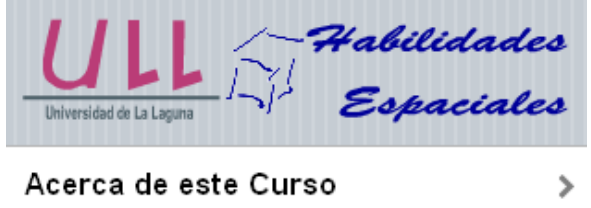

MÓDULO 1: CONSTRUYENDO CON > BLOQUES

MÓDULO 2: IDENTIFICACIÓN DE > CARAS Y VISTAS

MÓDULO 3: DISCRIMINACIÓN DE > VOLÚMENES

MÓDULO 4: ROTACIONES

MÓDULO 5: SECCIONES

Figura 37.- Página principal de la web del curso

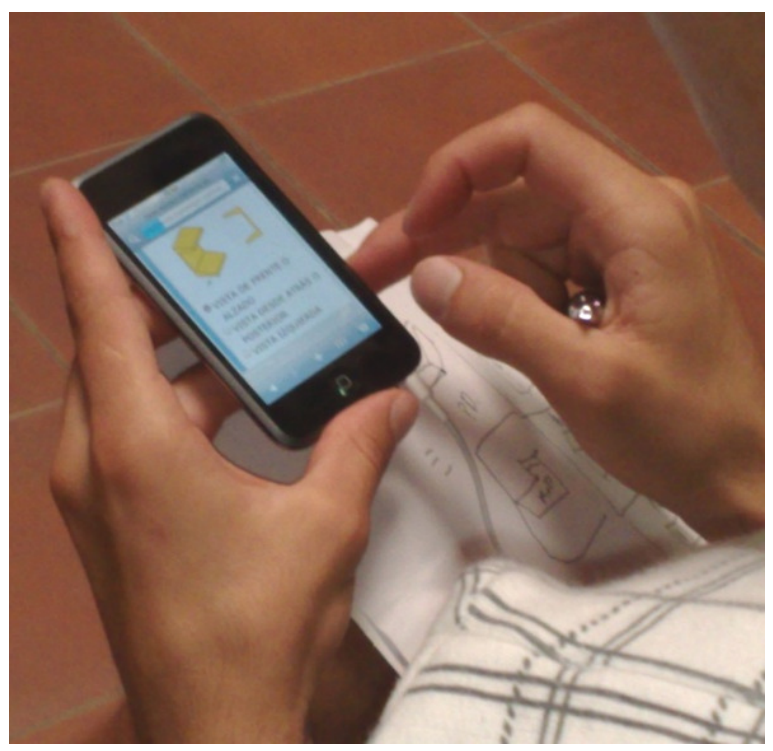

Figura 38.- Un estudiante realizando el módulo2 en los pasillos de la universidad
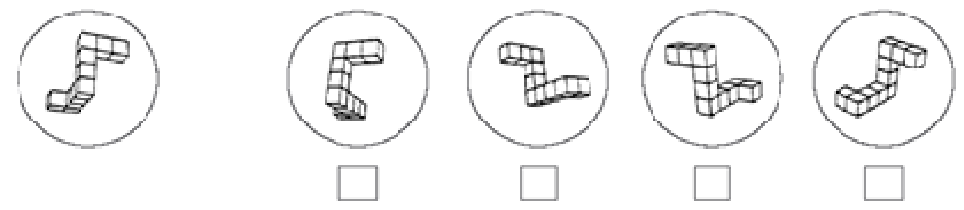

Figura 39.- Ejemplo de ítem del MRT

\subsubsection{Encuesta de satisfacción de usuarios}

Después de completar el post-test (MRT), los participantes respondieron algunas cuestiones acerca de la experiencia desarrollada. Los participantes valoraron su satisfacción con el material didáctico y con el uso del Ipod, usando una escala de Likert. Esta encuesta fue diseñada teniendo en cuenta las utilizadas en otros estudios en los que se utilizan material de aprendizaje para dispositivos móviles. En el Anexo XIV figura la encuesta utilizada.

\subsubsection{Procedimiento}

Este estudio utiliza dos grupos de trabajo: un grupo experimental y un grupo de control. El grupo experimental lo forman 38 estudiantes (26 hombres y 12 mujeres) que voluntariamente realizan el programa de entrenamiento, y el grupo de control, formado por 30 estudiantes (19 hombres y 11 mujeres), no realiza ningún entrenamiento durante la 
semana que dura este estudio. El programa de entrenamiento se ha desarrollado en formato no presencial, durante una semana. Cada día realizaron uno de los cinco módulos propuestos (de lunes a viernes), disponiendo de dos días adicionales para completar los ejercicios que por distintos motivos no pudieron resolver en la fecha prevista. La semana anterior al entrenamiento, los estudiantes realizan el pre-test y rellenan una encuesta de perfil de usuarios. Con los datos obtenidos, y según la disponibilidad que muestran para realizar el entrenamiento, el grupo experimental es citado en un aula de la universidad. Se les explica la programación del curso y realizan una breve práctica para familiarizarse con el dispositivo. La Tabla 11 muestra las actividades realizadas en este estudio con los estudiantes, tanto del grupo experimental como del grupo de control.

Tabla 11.- Sumario de actividades realizadas en este estudio

\begin{tabular}{|c|c|c|c|}
\hline Semana & Día & & Actividades \\
\hline \multirow[t]{2}{*}{ Semana 1} & 1 & Lunes & $\begin{array}{l}\text { Pre-test y Encuesta de perfil de usuarios (grupo } \\
\text { experimental y de control) }\end{array}$ \\
\hline & 2 & Viernes & $\begin{array}{l}\text { Entrega de los dispositivos y explicación de la } \\
\text { programación del curso (grupo experimental) }\end{array}$ \\
\hline \multirow[t]{7}{*}{ Semana 2} & 3 & Lunes & Módulo 1 \\
\hline & 4 & Martes & Módulo 2 \\
\hline & 5 & Miércoles & Módulo 3 \\
\hline & 6 & Jueves & Módulo 4 \\
\hline & 7 & Viernes & Módulo 5 \\
\hline & 8 & Sábado & $\begin{array}{l}\text { Completar los niveles/módulos no resueltos, si fuera } \\
\text { necesario }\end{array}$ \\
\hline & 9 & Domingo & $\begin{array}{l}\text { Completar los niveles/módulos no resueltos, si fuera } \\
\text { necesario }\end{array}$ \\
\hline Semana 3 & 10 & Martes & $\begin{array}{l}\text { Post-test (grupo experimental y de control) } \\
\text { Encuesta de satisfacción de usuarios (grupo } \\
\text { experimental) }\end{array}$ \\
\hline
\end{tabular}

\subsection{Análisis de datos}

\subsubsection{Antes del entrenamiento espacial}

El estudio piloto se llevó a cabo con 68 estudiantes de ingeniería, al comienzo del curso académico 2008-2009. Se trata de evitar así la influencia de cursar otras materias en los resultados de los test de medida. Se utilizó el Test de Rotación Mental en esta experiencia. Las puntuaciones medias en el pre-test fueron de 14,13 puntos para mujeres $(n=23)$ y de 20,02 puntos para los hombres $(n=45)$. La Tabla 12 muestra las puntuaciones medias y desviaciones típicas por grupo y género, 
obtenidas por los participantes en el pre-test, en el post-test y la ganancia media apreciada.

Con el objetivo de evaluar si existen diferencias entre los participantes en este estudio, por grupos (experimental vs control) o por género (hombre vs mujer) en los niveles de habilidades espaciales, medidos con el MRT, se realiza un Análisis de varianza (ANOVA) con interacciones. Antes del entrenamiento, para el pre-MRT se encuentra que no existen diferencias significativas entre los grupos de entrenamiento (experimental vs control), $\mathrm{F}(1,64)=1,254, \mathrm{p}$-valor=0,267. Respecto al género, las diferencias en las puntuaciones medias entre hombres y mujeres fueron estadísticamente significativas, $\mathrm{F}(1,64)=8,907$, p-valor $=0,004$. Sin embargo la interacción entre el género y el grupo se muestra no significativa, $\mathrm{F}(1,64)=1,019$, $\mathrm{p}$-valor $=0,317$. La Tabla 13 resume los resultados del análisis de varianza para el pre-MRT.

Como resumen podemos decir que el análisis muestra que no existen diferencias significativas entre los dos grupos de este estudio, encontrándose a priori diferencias significativas por género, lo que concuerda con los estudios de la literatura científica sobre este tema que apuntan a una diferencia en los niveles de rotación espacial entre hombres y mujeres (Vanderberg \& Kuse, 1978).

Tabla 12.- Puntuaciones medias, ganancias y desviaciones típicas por grupo y género (n $=68)$

\begin{tabular}{lllccc}
\hline Grupo & Género & $\mathbf{N}$ & $\begin{array}{c}\text { PreMRT } \\
\text { Media } \\
\text { (s.d.) }\end{array}$ & $\begin{array}{c}\text { PostMRT } \\
\text { Media } \\
(\text { s.d. })\end{array}$ & $\begin{array}{c}\text { Ganancia } \\
\text { Media } \\
(\text { s.d. })\end{array}$ \\
\hline Control & Hombres & 19 & $\begin{array}{c}19,89 \\
(10,03)\end{array}$ & $\begin{array}{c}22,37 \\
(9,96)\end{array}$ & $\begin{array}{c}2,47 \\
(2,84)\end{array}$ \\
\cline { 2 - 6 } & Mujeres & 11 & $\begin{array}{c}11,91 \\
(5,24)\end{array}$ & $\begin{array}{c}12,91 \\
(5,15)\end{array}$ & $\begin{array}{c}1,00 \\
(2,05)\end{array}$ \\
\cline { 2 - 6 } & Total & \multirow{2}{*}{30} & 16,97 & 18,90 & 1,93 \\
& & & $(9,34)$ & $(9,60)$ & $(2,64)$ \\
\hline \multirow{2}{*}{ Experimental } & Hombres & 26 & 20,12 & 28,54 & 8,42 \\
& & & $(7,23)$ & $(6,98)$ & $(7,80)$ \\
\cline { 2 - 6 } & Mujeres & 12 & 16,17 & 23,33 & 7,17 \\
& & & $(6,51)$ & $(8,96)$ & $(5,52)$ \\
\cline { 2 - 6 } & Total & \multirow{2}{*}{38} & 18,87 & 26,89 & 8,03 \\
& & $(7,17)$ & $(7,93)$ & $(7,11)$ \\
\hline Total & Hombres & 45 & 20,02 & 25,93 & 5,91 \\
& & & $(8,42)$ & $(8,82)$ & $(6,83)$ \\
\cline { 2 - 6 } & Mujeres & 23 & 14,13 & 18,35 & 4,22 \\
& & & $(6,20)$ & $(8,97)$ & $(5,21)$ \\
\cline { 2 - 6 } & Total & 68 & 18,03 & 23,37 & 5,34 \\
& & $(8,19)$ & $(9,52)$ & $(6,34)$ \\
\hline
\end{tabular}

* Los valores se expresan como media (desviación estándar). 


\subsubsection{Después del entrenamiento espacial}

Se lleva a cabo un análisis de covarianza de dos factores (ANCOVA), tomando como Hipótesis nula $\left(\mathrm{H}_{0}\right)$ que los valores medios de habilidades espaciales no varían después del entrenamiento. Se ha utilizado el postMRT como variable dependiente, el PreMRT como covariable y el grupo y género como variables independientes. Adicionalmente se han calculado diferentes interaccciones entre los factores (sexo, grupo) y entre los factores y las covariables (preMRT), dejando finalmente en el modelo la interacción PreMRT* grupo.

El análisis de ANCOVA se resume en la Tabla 14. La Figura 40 muestra gráficamente las puntuaciones medias obtenidas por los grupos. Los resultados se muestran por sexo: hombre $(\mathrm{H})$ y mujer $(\mathrm{M})$.

Tabla 13.- Resultados de la ANOVA para el pretest por grupo y género y sus interacciones

\begin{tabular}{llllll}
\hline Fuente & $\begin{array}{l}\text { Suma de } \\
\text { cuadrados }\end{array}$ & gl & $\begin{array}{l}\text { Media de } \\
\text { cuadrados }\end{array}$ & F & Sig, \\
\hline Grupo & 75,582 & 1 & 75,582 & 1,254 &, 267 \\
Sexo & 536,788 & 1 & 536,788 & 8,907 &, 004 \\
Grupo *Sexo & 61,420 & 1 & 61,420 & 1,019 &, 317 \\
Error & 3857,019 & 64 & 60,266 & & \\
Total & 4489,941 & 67 & & & \\
\hline
\end{tabular}

Tabla 14.- Resultados de la ANCOVA para el PostMRT por grupo y género y sus interacciones

\begin{tabular}{llllll}
\hline & $\begin{array}{l}\text { Suma de } \\
\text { cuadrados }\end{array}$ & gl & S & Media de \\
Fuente & 454.957 & 1 & 454.957 & 16.745 & $.000^{* *}$ \\
\hline Grupo & 83.911 & 1 & 83.911 & 3.088 & .084 \\
Sexo & 2204.208 & 1 & 2204.208 & 81.130 & $.000^{* *}$ \\
PreMRT & 137.962 & 1 & 137.962 & 5.078 & $.028^{*}$ \\
Grupo*PreMRT & 1711.647 & 63 & 27.169 & & \\
Error & 6069.809 & 67 & & & \\
Total & \multicolumn{7}{r}{${ }^{*} \mathrm{p}<.05,{ }^{* *} \mathrm{p}<.01$} & & & & &
\end{tabular}


GRUPO DE CONTROL

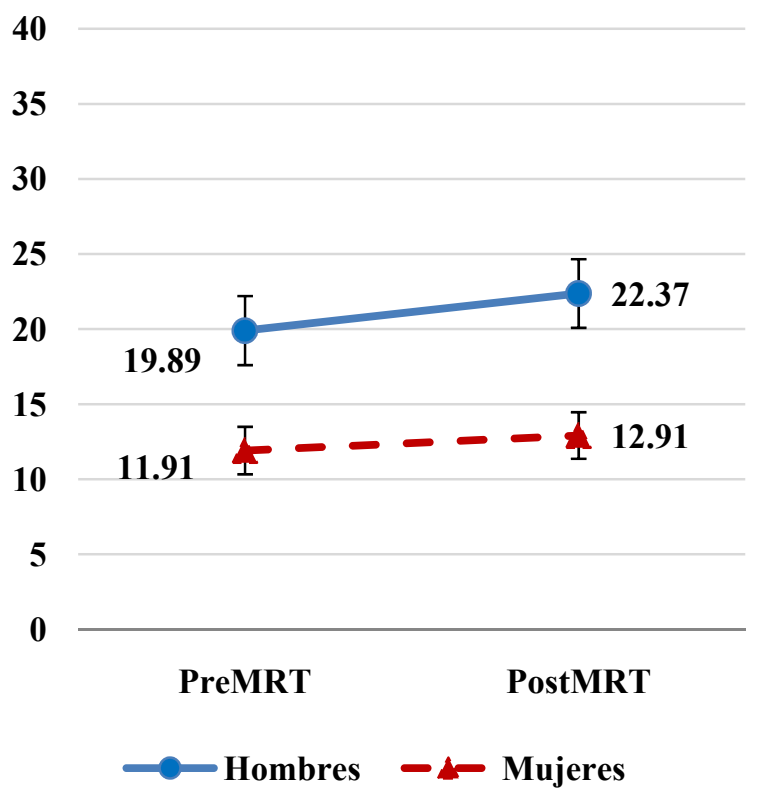

\section{GRUPO EXPERIMENTAL}
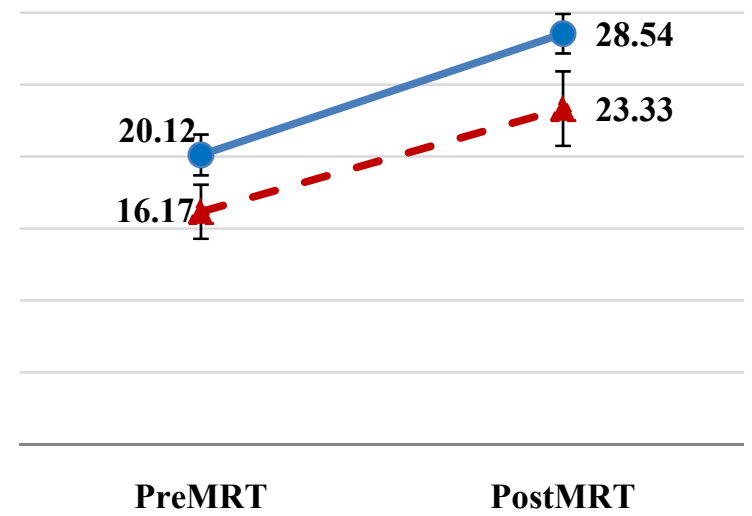

$\longrightarrow$ Hombres $\rightarrow$ Mujeres

Figura 40.- Puntuaciones medias en el pre- y post-test para el grupo Experimental y de Control $(\mathrm{n}=68)$

El análisis realizado encuentra una relación positiva entre el Pre-MRT y el Post-MRT, $F(1,63)=81,13, p<0.001$, no encontrando además diferencias significativas por género $F(1,63)=3,09, p=0,084$. Se encontraron diferencias significativas entre el grupo experimental y el grupo de control, $\quad F(1,63)=16,75, p<0.001$, variando éstas en función de las puntuaciones del Pre-MRT, tal como refleja la interacción significativa Grupo*Pre-MRT, $F(1,63)=5,08, p=0,028$.

El modelo de regresión múltiple obtenido en este análisis se recoge en la Ecuación 3. Se observa que, aunque no es significativo el género, hay una diferencia media de 2,502 puntos a favor de los hombres.

Pos $\widehat{t M R T}=14,297+2,502 *($ sexo $=$ hombre $)-12,826 *($ grupo $=$ control $)+0,577$

$*$ PreMRT $+0,357 *($ grupo $=$ control $) *$ PreMRT

Ecuación 3.-: Modelo de regresión múltiple

La Figura 41 muestra la distribución de los datos de las puntuaciones en el test antes y después del entrenamiento. 


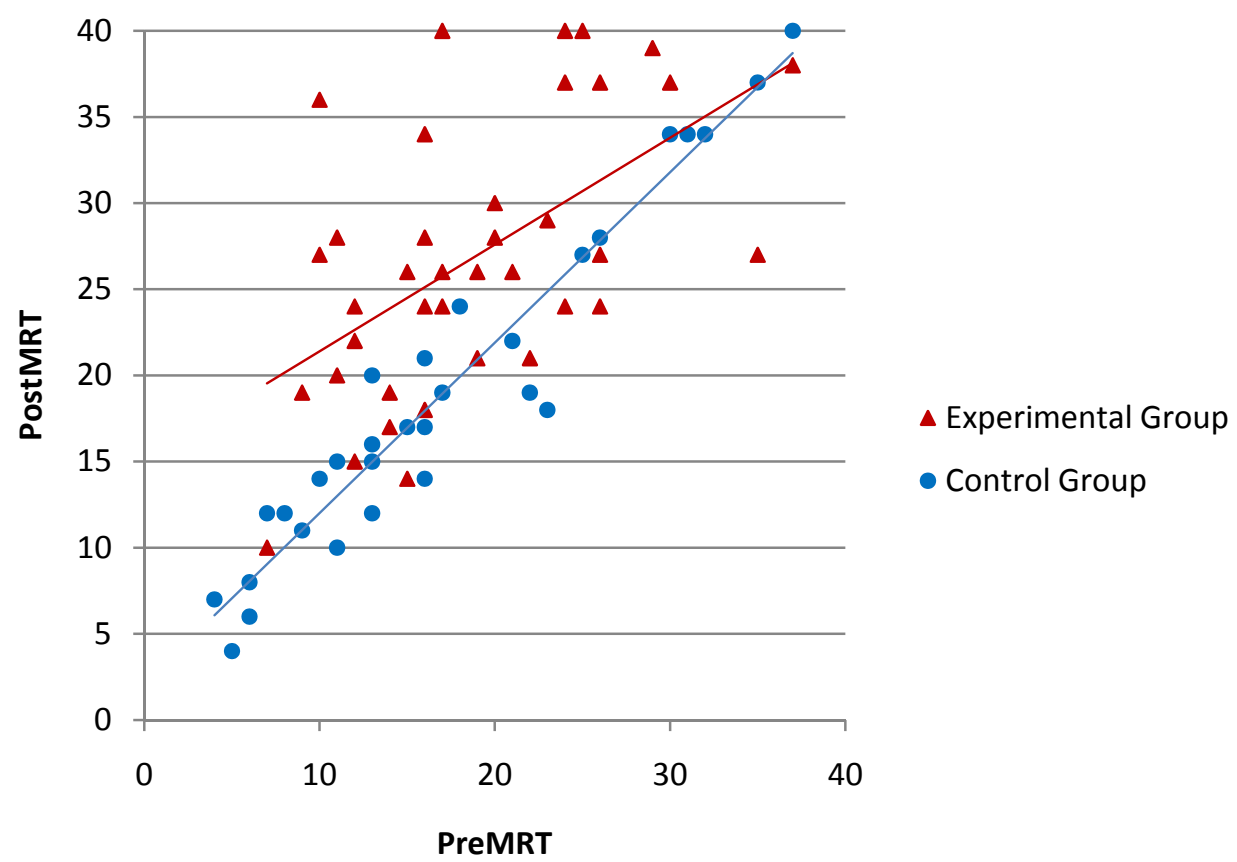

Figura 41.- Puntuaciones en el pre- y post-test para el grupo Experimental y de Control $(\mathrm{n}=68)$

Los datos de las puntuaciones obtenidas por los estudiantes y del análisis estadístico realizado con el software SPSS, en su versión 15, figuran en el Anexo XV y en el Anexo XVI, respectivamente.

\subsubsection{Encuesta de satisfacción de usuarios}

La encuesta de satisfacción de usuarios fue estructurada en dos partes: una primera centrada en la satisfacción con el dispositivo, y una segunda parte que valora la satisfacción general con el curso desarrollado.

La Tabla 15 muestra los resultados de la encuesta donde los usuarios evaluaban su experiencia con el iPod, valorando en una escala de Likert desde muy mala a muy buena ( $1=$ Muy mala, $2=$ Mala, $3=$ No sabe $/$ No contesta, 4= Buena, 5= Muy Buena).

La valoración que los estudiantes realizaron sobre el curso se presenta en la Tabla 16. Se utiliza también una escala de Likert de cinco puntos (1= Totalmente en desacuerdo, $2=$ En desacuerdo, $3=$ No sabe/ No contesta, 4= De acuerdo, $5=$ Totalmente de acuerdo). 
CAPÍTULO IV: LOS CONTENIDOS WEB INTERACTIVOS EN LA MEJORA DE LAS HHEE

Tabla 15.- Respuestas de los estudiantes a la encuesta sobre su experiencia con el iPod ( $\mathrm{n}=38)$

\begin{tabular}{|c|c|c|c|c|c|c|}
\hline \multirow{2}{*}{$\begin{array}{c}\text { Item } \\
\text { no }^{\mathbf{0}}\end{array}$} & \multirow[b]{2}{*}{ Pregunta } & \multicolumn{5}{|c|}{ Grado de satisfacción (\%) } \\
\hline & & $\begin{array}{l}\text { MUY } \\
\text { MALO }\end{array}$ & MALO & INDECISO & BUENO & $\begin{array}{c}\text { MUY } \\
\text { BUENO }\end{array}$ \\
\hline 1 & $\begin{array}{l}\text { ¿Cómo valoras tu experiencia con la pantalla } \\
\text { táctil? }\end{array}$ & o & o & 5,56 & 52,77 & 41,66 \\
\hline 2 & $\begin{array}{l}\text { ¿Cómo valoras tu experiencia con el teclado } \\
\text { táctil? }\end{array}$ & o & 5,57 & 19,44 & 52,78 & 22,21 \\
\hline 3 & ¿Cómo valoras la conexión Wi-Fi del dispositivo? & 2,78 & 13,89 & 30,56 & 44,44 & 8,33 \\
\hline 4 & $\begin{array}{l}\text { ¿Cómo valoras la experiencia de navegación por } \\
\text { internet? }\end{array}$ & o & 2,78 & 25,00 & 61,11 & 11,11 \\
\hline 5 & $\begin{array}{l}\text { En global, ¿Cómo valoras tu satisfacción general } \\
\text { con el aparato? }\end{array}$ & o & o & 8,57 & 62,86 & 28,57 \\
\hline
\end{tabular}


Tabla 16.- Resumen de las respuestas de los estudiantes a la encuesta sobre su experiencia con el curso $(\mathrm{n}=38)$

\begin{tabular}{|c|c|c|c|c|c|c|}
\hline \multirow[b]{2}{*}{$\begin{array}{l}\text { Item } \\
\mathbf{n}^{\mathbf{o}}\end{array}$} & \multirow[b]{2}{*}{ Pregunta } & \multicolumn{5}{|c|}{$\begin{array}{l}\text { Grado de satisfacción (\%) } \\
\end{array}$} \\
\hline & & $\begin{array}{l}\text { COMPLETAMENTE } \\
\text { EN DESACUERDO }\end{array}$ & $\begin{array}{c}\text { EN } \\
\text { DESACUERDO }\end{array}$ & INDECISO & $\begin{array}{c}\text { DE } \\
\text { ACUERDO }\end{array}$ & $\begin{array}{l}\text { COMPLETAMENTE } \\
\text { DE ACUERDO }\end{array}$ \\
\hline 1 & $\begin{array}{l}\text { El material del curso tiene una buena } \\
\text { y cuidada presentación }\end{array}$ & 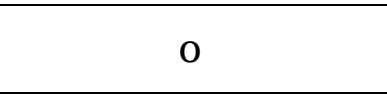 & 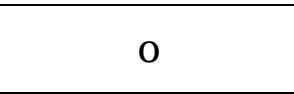 & 2,78 & 66,67 & 30,55 \\
\hline 2 & $\begin{array}{l}\text { La estructura del curso por módulos } \\
\text { y niveles es adecuada }\end{array}$ & o & o & 11,11 & 58,33 & 30,56 \\
\hline 3 & $\begin{array}{l}\text { Me he sentido capaz de resolver los } \\
\text { ejercicios planteados }\end{array}$ & $\mathrm{O}$ & o & 8,33 & 61,11 & 30,56 \\
\hline 4 & $\begin{array}{l}\text { Considero que los videos son una } \\
\text { buena herramienta para asimilar los } \\
\text { contenidos }\end{array}$ & $\mathrm{O}$ & 5,55 & 22,22 & 41,67 & 30,56 \\
\hline 5 & El curso ofrece contenido útil & $\mathrm{O}$ & $\mathrm{O}$ & 5,55 & 77,78 & 16,67 \\
\hline 6 & $\begin{array}{l}\text { Me gustaría disponer de material de } \\
\text { este tipo como apoyo a la docencia } \\
\text { presencial, tanto es esta asignatura } \\
\text { como en otras }\end{array}$ & $\mathrm{O}$ & 2,78 & 19,44 & 41,67 & 33,33 \\
\hline 7 & $\begin{array}{l}\text { Es importante poder acceder a los } \\
\text { contenidos de este curso dónde y } \\
\text { cuándo yo quiera }\end{array}$ & o & 5,56 & 13,89 & 36,11 & 44,44 \\
\hline \multirow[t]{4}{*}{8} & $\begin{array}{l}\text { Si tuviera que elegir entre distintos } \\
\text { formatos para realizar este curso: } \\
\text { ¿Cuál preferirías? }\end{array}$ & & & & & \\
\hline & Lápiz y papel & 17,65 & 26,47 & 29,41 & 20,59 & 5,88 \\
\hline & $\mathrm{PC}$ & $\mathrm{O}$ & 2,86 & 5,71 & 68,57 & 22,86 \\
\hline & $\begin{array}{l}\text { Dispositivos portátiles (consolas, } \\
\text { móviles, etc,) }\end{array}$ & o & o & 20,00 & 51,43 & 28,57 \\
\hline 9 & $\begin{array}{l}\text { Creo que la utilización del iPod, con } \\
\text { su tecnología de pantalla táctil, para } \\
\text { la realización de cursos a distancia } \\
\text { en un buen sistema de aprendizaje }\end{array}$ & $\mathrm{O}$ & $\mathrm{O}$ & 8,33 & 44,45 & 47,22 \\
\hline
\end{tabular}


CAPÍTULO IV: LOS CONTENIDOS WEB INTERACTIVOS EN LA MEJORA DE LAS HHEE

\begin{tabular}{clccccc}
\cline { 3 - 5 } $\begin{array}{c}\text { Item } \\
\mathbf{n}^{\mathbf{0}}\end{array}$ & \multicolumn{1}{c}{ Pregunta } & \multicolumn{5}{c}{ Grado de satisfacción (\%) } \\
\cline { 2 - 5 } & $\begin{array}{c}\text { COMPLETAMENTE } \\
\text { EN DESACUERDO }\end{array}$ & $\begin{array}{c}\text { EN } \\
\text { DESACUERDO }\end{array}$ & INDECISO & $\begin{array}{c}\text { DE } \\
\text { ACUERDO }\end{array}$ & $\begin{array}{c}\text { COMPLETAMENTE } \\
\text { DE ACUERDO }\end{array}$ \\
\hline 10 & $\begin{array}{l}\text { Me hubiera gustado realizar este } \\
\text { curso con asistencia del profesor }\end{array}$ & 13,89 & 36,11 & 44,44 & 5,56 & 0 \\
\hline 11 & $\begin{array}{l}\text { ¿Recomendarías este curso a tus } \\
\text { compañeros? }\end{array}$ & 0 & 0 & 2,78 & 75,00 & 22,22 \\
\hline 12 & $\begin{array}{l}\text { Globalmente, estoy satisfecho con el } \\
\text { curso }\end{array}$ & 0 & 0 & 0 & 75,00 & 25,00 \\
\hline
\end{tabular}




\subsection{Resultados}

\subsubsection{Respecto al entrenamiento espacial}

Este curso web, evaluado sobre dispositivos iPod Touch y desarrollado en un formato de enseñanza a distancia (on-line), ha demostrado, mediante el análisis estadístico detallado en el apartado anterior, que:

- Para los valores iniciales de rotación mental, medidas con el test MRT (PreMRT), las mujeres tienen una puntuación media más baja que los hombres. Este dato coincide con los estudios iniciales de los creadores de este Test y con otros trabajos recogidos en la literatura científica.

- Además, los resultados demuestran que, con un entrenamiento específico, hombres y mujeres alcanzan una ganancia media similar en el test MRT. A pesar de las diferencias iniciales existentes entre hombres y mujeres, ambos logran aumentar entorno a 8 puntos en el Test MRT.

- Que la ganancia media que obtiene el grupo experimental frente al grupo de control, depende del valor del PreMRT. Así, por ejemplo, si la puntuación inicial en el test (PreMRT) de un individuo es igual a 10 puntos, la ganancia media experimentada es de 9,256 puntos superior en el grupo que realiza el entrenamiento frente a los individuos que no realizan entrenamiento espacial (ver Ecuación 3). Si la puntuación obtenida por un individuo en el PreMRT fuera de 30 puntos, la ganancia media se reduce a 2,116 puntos. Esto concuerda con los hallazgos obtenidos en otras investigaciones: los individuos con puntuaciones iniciales altas tienen poco margen para poder experimentar un aumento. Aquellos alumnos que tienen valores iniciales bajos tienen más capacidad de mejora.

El curso está disponible en la web del Grupo de Investigación Dehaes (http://www.degarin.com/moodle).

\subsubsection{Respecto a la satisfacción del usuario con el curso y el dispositivo utilizado}

La satisfacción global con el dispositivo utilizado ha sido valorada por el 91,43\% como Buena o Muy Buena. La pantalla táctil y la navegación por Internet ha sido lo mejor valorado, mientras que la red Wi-Fi ha sido lo 
peor valorado, debido fundamentalmente a problemas encontrados por los estudiantes en los puntos de acceso de las redes Wi-Fi.

Aproximadamente el 90\% puntúa la presentación y la estructura del material didáctico del curso entre 4 y 5 puntos en una escala de Likert de cinco puntos. Además se les ha pedido que indiquen los ejercicios que, en su opinión, presentan mayor dificultad. Consideran que el Nivel 3 del Módulo 1 es uno de los más complicados, seguidos del módulo 4 y 5 . Sin embargo, alrededor del 90\% manifiestan sentirse capaces de resolver las tareas que se le plantean.

El 94,45 \% está de acuerdo en que el curso ofrece un contenido útil y al $75 \%$ le gustaría disponer de material didáctico de este tipo de apoyo a la docencia en las asignaturas de su titulación. El 80,55 está de acuerdo o totalmente de acuerdo en que es importante poder acceder a contenidos de este tipo dónde y cuándo quiera.

Respecto a las preferencias de formato para realizar este curso, destacamos que sólo el 26,47\% estaría de acuerdo o totalmente de acuerdo en realizar este curso en el formato tradicional de lápiz y papel. Entorno al 90\% preferiría hacerlo en ordenador y el 80\% en dispositivos de mano (móviles, consolas, etc.).

Es de destacar que sólo el 5,56\% está de acuerdo en realizar este curso con asistencia del profesor.

El curso ha sido valorado globalmente por los estudiantes considerando el $75 \%$ que están satisfechos con el curso (4 puntos) y el 25\% restante está totalmente satisfechos (5 puntos). Además casi la totalidad de los estudiantes lo recomendarían a sus compañeros.

\subsection{Resumen}

$\mathrm{Al}$ iniciar este trabajo nos planteábamos una serie de preguntas, con el objetivo de poder darle respuesta en este trabajo de investigación:

- ¿Colaboran esta tipología de contenidos y la utilización de nuevos dispositivos de hardware en el desarrollo de las habilidades espaciales?

- ¿Pueden desarrollarse tecnologías con interfaces más amigables para el usuario que las existentes y que ayuden en el desarrollo de esta capacidad? 
Los datos obtenidos de la encuesta de satisfacción de usuarios permiten afirmar que el curso web desarrollado sobre los dispositivos de mano de pantalla táctil fueron atractivos para los estudiantes que participaron en este curso, produciendo un alto grado de satisfacción y la manifestación de que lo recomendarían a sus amigos. Este aspecto es importante en el contexto de un curso de intensificación de participación voluntaria.

El material diseñado para este curso fue agradable para los usuarios, valorando además muy positivamente la navegación mediante de la pantalla táctil del dispositivo (>97\%). Parece destacable su no preferencia por realizar cursos de este tipo con asistencia del profesor, lo que puede indicar que este formato de aprendizaje a distancia y en un contexto no formal les resulta agradable y cercano a las costumbres de ocio habituales de los jóvenes de hoy día: juegos de ordenador o consolas de sobremesa o de mano.

Valoran también positivamente el acceso a los materiales desde cualquier lugar y momento ("Any time, Any place learning") (>80\%) y se muestran poco receptivos a los cursos en papel (menos del $27 \%$ querría hacer el curso en este formato). Además el curso ha demostrado que es una buena opción para desarrollar las HHEE. El análisis estadístico muestra un aumento significativo de entorno a 8 puntos en el Test de Rotación Mental.

Es importante destacar que este curso brinda un nuevo contexto para el desarrollo de las habilidades espaciales: por un lado aporta la utilización de un nuevo dispositivo de hardware, los dispositivos móviles de pantalla táctil, y además ofrece movilidad al proceso de enseñanza-aprendizaje, ofreciendo un curso de aprendizaje a distancia que se puede desarrollar en el metro, en el autobús, en el tranvía o en cualquier otro lugar donde exista un acceso a internet (red Wi-Fi, 3G, GPRS, etc.).

Este trabajo se ha guiado por el interés de desarrollar un material de apoyo para los estudiantes que a su entrada en la Universidad dispongan de niveles más bajos de HHEE. Creemos que es necesario continuar el desarrollo de materiales de este tipo que aporten movilidad a los estudiantes y que abran nuevas posibilidades de adaptar el desarrollo de habilidades a la forma de vida y costumbres de los estudiantes. 

Capítulo V: Diseño, implementación y evaluación de una arquitectura sobre dispositivos móviles de pantalla táctil

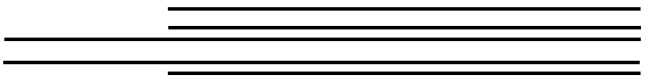





\subsection{Introducción y objetivos}

Estudios recientes han puesto su atención en el potencial pedagógico de los dispositivos móviles (Sánchez, Salinas, \& Sáenz, 2007). Distintas experiencias elaboran herramientas para estos aparatos, indicando que ayudan a apoyar y fortalecer el aprendizaje en áreas tales como: los idiomas (Thornton \& Houser, 2005; Lu, 2008), la ciencia y la historia natural (Facer, Joiner, D., Reid, Hull, \& Kirk, 2004; Sánchez \& Flores, 2006; Sánchez, Salinas, \& Sáenz, 2007); y como herramienta complementaria al aprendizaje tradicional, entre otras aplicaciones (Corlett, Sharples, Bull, \& Chan, 2005; Clough, Jones, McAndrew, \& Scanlon, 2007; Christian Hoff, Wehling, \& Rothkugel, 2008; Chris, 2008).

Unido a esto, el uso de móviles de pantalla táctil (PDAs, Smartphones, etc.) parece ser una de las tendencias más importantes del mercado actual. La mayoría de los fabricantes se han posicionado a favor de la introducción de las mismas en sus nuevos dispositivos. En 2007 el volumen de ventas era de aproximadamente 30 millones de unidades. Según un estudio de IMS Research (Reseach, IMS., 2008), la previsión de ventas para el año 2012 es superior a 230 millones de unidades.

El informe "The Research Agenda for the New Discipline of Engineering Education" (The Steering Committee of the National Engineering Education Research Colloquies, 2006) propone, dentro de la investigación en el area de Engineering Learning Systems, "creating formal or informal learning experiences in a variety of settings (e.g., classrooms, laboratories, exhibits, synchronous and asynchronous online activities) that are more motivating, more engaging, and address the needs of a diverse group of learners" 15 .

El propósito de este trabajo ha sido elaborar una herramienta que utilice la construcción con cubos para el entrenamiento de las habilidades espaciales, con el objetivo de que los usuarios se familiaricen con el entorno 3D y puedan mejorar el entendimiento de la relación 2D-3D, en un contexto de educación no formal. Se ha desarrollado sobre dispositivos móviles de pantalla táctil, que nos permiten una interfaz más intuitiva y natural, cercana a los juegos de construcción tipo Lego@. Este trabajo

${ }^{15} \underline{\mathrm{http}}$ ///asee.org/publications/jee/upload/EERC intro and report.pdf 
plantea la tesis de que la articulación entre juegos y movilidad ofrece oportunidades para desarrollar las habilidades cognitivas, mejorando las condiciones de aprendizaje de los alumnos. Esto se produce porque los juegos de móvil integran características que los hacen adecuados a los estilos de aprendizaje y prácticas habituales de los estudiantes de hoy: desarrollo de tareas simultáneas, rapidez de procesamiento de la información, feedback inmediato, etc. (Prensky, 2001).

El trabajo descrito en este capítulo es fruto de la colaboración entre la investigadora Isabel Sánchez Berriel, del Área de Ciencias de la Computación e Inteligencia Artificial de la ULL, y la autora de esta tesis, del Grupo de Investigación en Habilidades Espaciales (Dehaes) de la ULL, en el seno del proyecto fin de carrera titulado "Construyendo con bloques: Juego 3D para la mejora de las Habilidades Espaciales en Dispositivos Móviles usando J2ME”, realizado por los ingenieros informáticos Miguel Jonás Bravo García y Juan Antonio Hernández Cordovez y leído en el mes de Diciembre del año 2008 (Bravo-García, Hernández-Cordovez, Sánchez-Berriel, 2008). En el Anexo XVII se muestran las actividades realizadas en este proyecto y los participantes implicados en cada una de ellas.

\subsection{Antecedentes de este trabajo}

En otoño de 2007, se lleva a cabo un estudio piloto sobre 47 estudiantes voluntarios de primer curso de la titulación de Ingeniería Técnica de Obras Públicas de la Universidad de La Laguna. Se evaluó su nivel de habilidades espaciales con los test MRT y DAT:SR, antes y después de llevar a cabo el experimento. Se seleccionó aquellos estudiantes que obtuvieron puntuaciones más bajas, con el objetivo de que asistieran a un curso intensivo. Doce estudiantes completaron el curso de forma voluntaria, con edades comprendidas entre 18 y 20 años.

El curso fue realizado en ordenadores de sobremesa Pentium IV $2.80 \mathrm{GHz}$ con 512 MB RAM, bajo sistema operativo Windows XP, en un aula de prácticas de la universidad. Se organizó en dos sesiones de tres horas, desarrolladas en dos semanas. Se utilizaron los applets "Building with 
blocks 16 " and "Building houses with sides"17 del Instituto Freudenthal de Ciencia y Matemáticas de la Universidad de Utrecht (2004), disponibles en su web y elaborados en lenguaje Java. Para desarrollar la segunda sesión, se facilitó además a los estudiantes una colección de ejercicios en papel. La Tabla 17 resume las actividades y programación del curso y las Figuras de las 43 a 51 muestran ejemplos de las actividades desarrolladas. Se describe a continuación cada una de ellas.

Tabla 17.-Tabla resumen de las actividades del curso "Building with Blocks"

\begin{tabular}{|c|c|c|c|c|}
\hline SE & SIOI & JES/ACTIVIDADES & DESCRIPCIÓN & TIEMPO \\
\hline \multirow{6}{*}{$\begin{array}{l}\text { SESIÓN } \\
1\end{array}$} & 1.1 & Copy the building & Copiar el modelo de cubos & \multirow{6}{*}{$\begin{array}{l}3 \text { horas } \\
\text { Semana } 1\end{array}$} \\
\hline & 1.2 & $\begin{array}{l}\text { Building with height } \\
\text { numbers }\end{array}$ & $\begin{array}{l}\text { Construir el modelo de cubos } \\
\text { según la planta numerada }\end{array}$ & \\
\hline & 1.3 & Making height numbers & $\begin{array}{l}\text { Construir el modelo de cubos } \\
\text { por número de cubos }\end{array}$ & \\
\hline & 1.4 & Building with three sides & $\begin{array}{l}\text { Construyendo modelos de cubos } \\
\text { a partir de tres vistas }\end{array}$ & \\
\hline & 1.5 & $\begin{array}{l}\text { Building houses with side } \\
\text { views }\end{array}$ & $\begin{array}{l}\text { Construyendo modelos de cubos } \\
\text { a partir de tres vistas con el } \\
\text { mínimo número de cubos }\end{array}$ & \\
\hline & 1.6 & Extra problems & Ejercicios extra & \\
\hline \multirow{2}{*}{$\begin{array}{l}\text { SESIÓN } \\
2\end{array}$} & 2.1 & $\begin{array}{l}\text { Building freely: del 3D en } \\
\text { papel al } 3 \mathrm{D} \text { en PC }\end{array}$ & $\begin{array}{l}\text { Construyendo modelos de cubos } \\
\text { a partir de perspectivas } \\
\text { modulares facilitadas en papel }\end{array}$ & \multirow{2}{*}{$\begin{array}{c}3 \text { horas } \\
\text { Semana } 2\end{array}$} \\
\hline & & $\begin{array}{l}\text { Building freely: de las vistas } \\
\text { al } 3 \mathrm{D} \text { en PC }\end{array}$ & $\begin{array}{l}\text { Construyendo modelos de cubos } \\
\text { a partir de vistas de piezas } \\
\text { modulares facilitadas en papel. }\end{array}$ & \\
\hline & & & TOTAL & $\begin{array}{l}6 \text { horas } \\
\text { en } 2 \\
\text { semanas } \\
\end{array}$ \\
\hline
\end{tabular}

${ }^{16} \mathrm{http}: / /$ www.fi.uu.nl/toepassingen/o0339/toepassing wisweb.en.html

${ }_{17}$ http://www.fi.uu.nl/toepassingen/02015/toepassing wisweb.en.html 


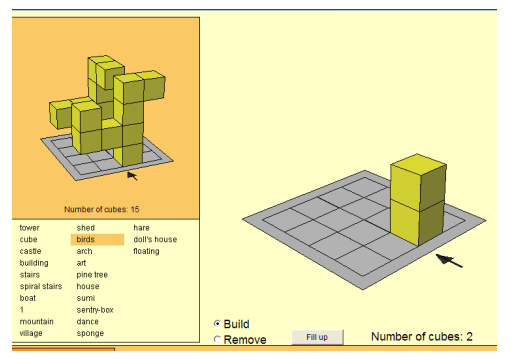

Figura 42.- Actividad 1.1: Copy the building

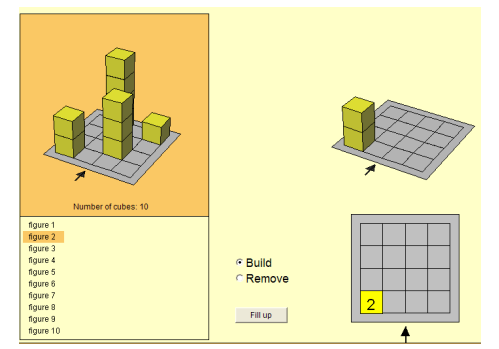

Figura 44.- Actividad 1.3: Making height numbers

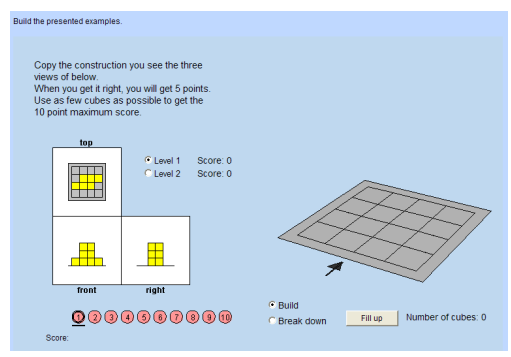

Figura 46.- Actividad 1.5: Building houses with side views

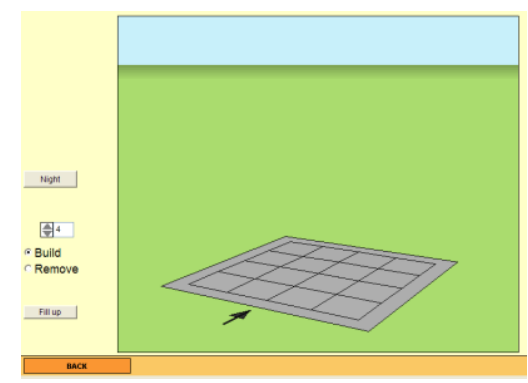

Figura 48.- Sesión 2: Construcción libre

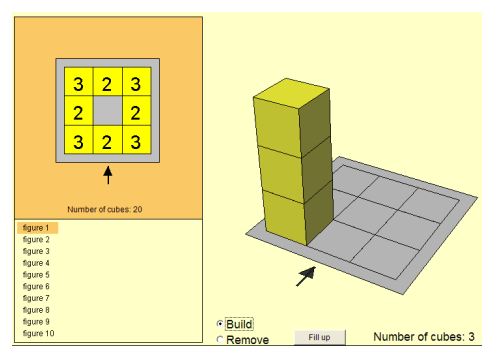

Figura 43.- Actividad 1.2: Building with height numbers

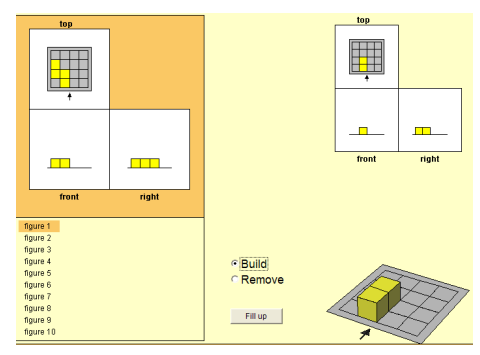

Figura 45.- Actividad 1.4: Building with three sides

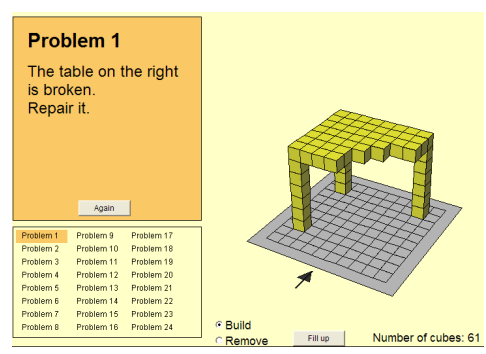

Figura 47.- Actividad 1.6: Extra Problems

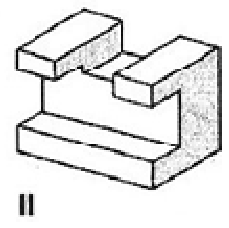

Figura 49.-

Actividad 2.1:

Building freely: del $3^{\mathrm{D}}$ en papel al $3 \mathrm{D}$ en PC

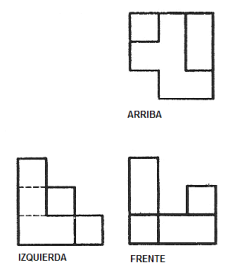

Figura 50.Actividad 2.2: Building freely: de las vistas al 3D en PC 
La Sesión 1, desarrollada en la tercera semana del calendario oficial del curso 2007-08, se centró en los siguientes ejercicios:

1.1 Copy the building: consiste en construir modelos de cubos, copiando uno dado como enunciado (ver Figura 42).

1.2 Building with height numbers: se da como dato una planta en la que se refleja el número de cubos que tendremos que colocar en cada posición. Se trata de construir el modelo de cubos en función de los números dados en la planta (ver Figura 43).

1.3 Making height numbers: se trata del ejercicio contrario al anterior, dado un modelo tridimensional tendremos que copiarlo, pero actuando sobre la planta (ver Figura 44).

1.4 Building with three sides: este ejercicio comienza a ser un poco más difícil. Se trata de construir un modelo de cubos a partir de las vistas dadas de alzado, planta y perfil derecho (Sistema Americano) (ver Figura 45).

1.5. Building houses with side views: consiste en construir un modelo de cubos a partir de las vistas dadas de planta, alzado y perfil derecho, con la dificultad de que se debe hacer con el mínimo número de cubos posibles. Esta actividad tiene dos niveles y se puntúan las respuestas (ver Figura 46).

1.6 Extra Problems: problemas extra que se han utilizado para los estudiantes que han completado el resto de las actividades antes de finalizar la sesión. Se trata de resolver las cuestiones que plantean completar las construcciones de cubos (ver Figura 47).

La Sesión 2 se dedicó a construir modelos de cubos a partir de ejercicios facilitados en papel (ver Figura 48), en dos fases:

2.1 Building freely: del $3 \mathrm{D}$ en papel al $3 \mathrm{D}$ en PC. Se facilitaron perspectivas de piezas modulares para que las construyeran en el entorno tridimensional (ver Figura 49).

2.2 Building freely: de las vistas al $3 \mathrm{D}$ PC. Se facilitaron las vistas ortogonales de piezas modulares para que las construyeran el modelo de cubos en el entorno tridimensional (ver Figura 50).

Es importante aclarar que no se imparte ninguna lección teórica o práctica acerca de los contenidos de vistas ortogonales normalizadas o de los sistemas de representación, sólo se les indica cuál es la dirección de 
visualización de cada una de las vistas y su denominación: vista desde arriba, vista de frente y vista de perfil.

La Tabla 18 y la Figura 51 muestran las puntuaciones obtenidas por los estudiantes antes y después de realizar el curso de intensificación, en los test MRT y DAT-SR (ver Anexo XVIII).

Para el análisis estadístico, se parte de la hipótesis nula (Ho), de que los valores medios de habilidades de visualización espacial no han variado después de someterse al curso de entrenamiento. Se aplica la prueba $\mathrm{T}$ de Student para series emparejadas y se obtienen los p-valores que representan la probabilidad de que dicha hipótesis sea cierta. Se puede comprobar que el nivel de significación no llega en ningún caso al $1 \%$ oo, de hecho se ha de destacar que el p-valor es muy bajo. Es por ello que se rechaza la hipótesis nula en todos los casos y podemos afirmar con un nivel de significación superior al 99,9\% que la variación media del grupo estudiado ha experimentado un aumento. Es decir, que existe un efecto del curso de intensificación sobre el valor medio de las habilidades espaciales medidas por ambos test (MRT y DAT). El efecto obtenido es el de aumentar dichas habilidades en los sujetos sometidos a los cursos. Del análisis estadístico se puede concluir que las habilidades espaciales experimentan un aumento medio de 5,25 puntos en el caso del test MRT y de 7,83 puntos en DAT (ver datos en Anexo XVIII).

Tabla 18.- Puntuaciones medias del MRT (pre y post-test) $(n=12)$

\begin{tabular}{cccccc}
\hline \multicolumn{2}{c}{ MRT } & \multicolumn{2}{c}{ DAT:SR } & \multicolumn{2}{c}{ Ganancia } \\
\hline $\begin{array}{c}\text { Pre MRT } \\
\text { (s.d.) }\end{array}$ & $\begin{array}{c}\text { Post MRT } \\
\text { (s.d.) }\end{array}$ & $\begin{array}{c}\text { Pre DAT } \\
\text { (s.d.) }\end{array}$ & $\begin{array}{c}\text { Post DAT } \\
\text { (s.d.) }\end{array}$ & $\begin{array}{c}\text { MRT } \\
\text { (s.d.) }\end{array}$ & $\begin{array}{c}\text { DAT:SR } \\
\text { (s.d.) }\end{array}$ \\
\hline 10,75 & 16,00 & 31,33 & 39,17 & 5,25 & 7,83 \\
$(3,36)$ & $(4,67)$ & $(11,49)$ & $(12,07)$ & $(4,18)$ & $(6,01)$ \\
\hline
\end{tabular}

s.d. = desviación estándar 


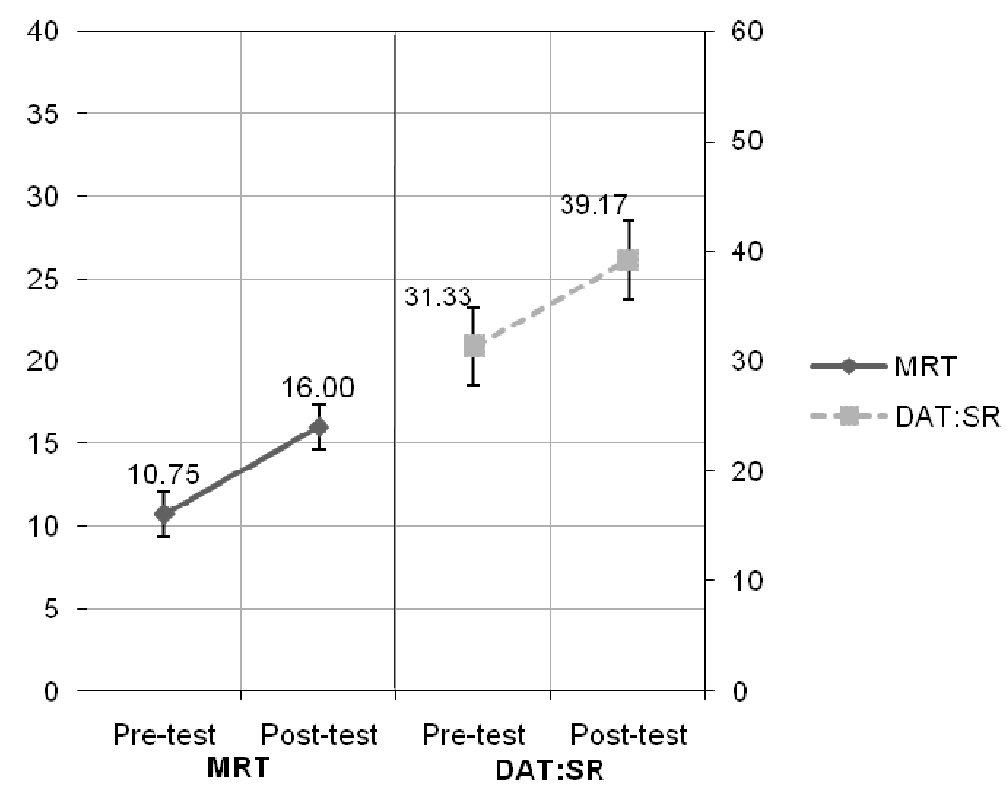

Figura 51.- Puntuaciones medias en el MRT (izquierda) y DAT:SR (derecha) (n=12)

\subsection{Justificación/ Motivación}

Los resultados del estudio piloto descrito en el apartado anterior sentaron las bases para el desarrollo de este proyecto. Se comprobó, por observación directa, que las tareas con un sistema de puntuaciones y feedback inmediato provocaban en los estudiantes un alto grado de motivación. Además, consideramos que este tipo de ejercicios podrían trasladarse a un formato portátil: teléfonos móviles, PDAs, consolas de mano, etc.

Actualmente, el uso de pantallas táctiles parece ser una de las tendencias más importantes en el mercado de los dispositivos móviles. La mayoría de los fabricantes se han posicionado a favor de la introducción de las mismas en sus nuevos dispositivos. En 2007 el número de dispositivos de este tipo vendidos era de aproximadamente 30 millones de unidades. Según un estudio de IMS Research (2008), la previsión de ventas para el año 2012 es superior a 230 millones de unidades. Las previsiones de futuro, sobre todo tras la sorprendente penetración del IPhone en el mercado, hacen que pensemos en desarrollar nuestra aplicación para estos aparatos (PDAs, Smartphones, etc.).

Desde que en Enero de 2007 Apple presentara el iPhone, parece que algo ha cambiado en el mundo de las telecomunicaciones en general y en el de la telefonía móvil en particular (Alcina, 2009). Hasta ese momento 
existían en el mercado Smartphones o PDAs de gama alta que ofrecían pantallas táctiles para manejar con punteros (lápiz), destinadas a un público determinado: hombres de negocios, ejecutivos, etc. La aparición del iPhone ha cambiado el escenario del mercado, marcando una nueva época. De hecho, muchos fabricantes han reaccionado sacando productos similares. Analizando el fenómeno iPhone, parece que aunque el éxito parte de la pantalla táctil del dispositivo, este no es el único factor que distingue al iPhone:

- La pantalla táctil: la pantalla del dispositivo de Apple es multitáctil, es decir, que admite no sólo pulsaciones únicas sobre iconos, sino que entiende el deslizamiento sobre la pantalla.

- El cambio automático de imágenes o videos cuando giramos la pantalla: aunque no fue el primer terminal en sacarlo al mercado-HTC se adelantó unos meses-, la transición en el iPhone está muy bien conseguida.

- El tamaño de la pantalla: su tamaño de 3,5 pulgadas se ha convertido en un referente para la industria. Tanto es así que los modelos que pretenden competir con éste disponen de tamaños similares: 3,2" el Nokia 5800, 3,8" el HTC HD o 3,2" el Samsumg Omnia.

- El teclado: es una novedad importante porque se sustituyen los teclados físicos por teclados virtuales. Estos teclados tienen detractores y defensores.

- Sistema de distribución de contenidos: fundamental ha sido el sistema de distribución de contenidos a través de "Apple Store". Los estudios recientes hablan de un gran volumen de negocio a través de estos sistemas, por lo que se abre una puerta a un nuevo negocio, al que ya se apuntan el resto de competidores.

Para la consultora IDG COMMUNICATIONS ${ }^{18}$, lo más destacado de 2008 ha sido el segmento de los dispositivos móviles convergentes o Smartphones, cuyas ventas crecieron un 22,5 por ciento con respecto a 2007, aventajando claramente al resto del mercado. Los datos publicados por la consultora Gartner ${ }^{19}$, en su informe del último trimestre de 2008, reflejan el aumento de ventas que han experimentado algunas de las empresas de teléfonos, como Samsung o LG Electronics, especialmente debido a los terminales de pantalla táctil. Parece importante el aumento

${ }^{18} \mathrm{http}: / /$ www.idg.es/dealer/actualidad.asp?id=76520

19 http://www.idg.es/dealer/actualidad.asp?id=77653 
de ventas de estos dispositivos, por un precio bastante asequible a gran cantidad de público, provocando una creciente penetración de estos aparatos en los estudiantes que llegan a las Universidades.

\subsection{Estudio previo}

Se llevó a cabo un análisis previo, con el objetivo de determinar los dispositivos sobre los que podríamos desarrollar la herramienta, el formato y lenguaje de programación a utilizar y los ejercicios que se podrían implementar.

\subsubsection{Dispositivos portátiles de pantalla táctil explorados}

\subsubsection{Nintendo DS}

El planteamiento de este proyecto propone explorar los dispositivos de pantalla táctil del mercado. Se trabajó en primer lugar sobre una de las consolas de mayor éxito entre los niños y adolescentes en España actualmente, la Nintendo DS o también conocida por DS o NDS. Es una consola portátil con doble pantalla desarrollada por Nintendo. Entre sus características técnicas se pueden destacar sus dos pantallas LCD de 3 pulgadas con una resolución de 256 x 192 píxeles de las que una es táctil, dos procesadores de la familia Advanced RISC Machine (ARM) a una velocidad de $67 \mathrm{Mhz}$ (CPU principal AMR9) y $33 \mathrm{Mhz}$ (coprocesador $\mathrm{AMR} 7$ ) respectivamente, una GPU para representación en $2 \mathrm{D}$ y $3 \mathrm{D}, 4$ megas de RAM y, por último, conectividad Wi-Fi que permite, entre otros usos, la conexión a Internet. Dispone de un elemento innovador, no presente en ninguna otra consola aparecida hasta el momento de la irrupción de la misma en el mercado, como es la pantalla táctil. Nintendo mantiene un programa de desarrolladores oficial, en el cual las compañías que quieran acceder al mismo deben contar con un grupo de desarrollo especializado en juegos y contar con suficiente experiencia. Dado que el equipo de programación no cuenta con la suficiente experiencia previa y que el proyecto no cuenta con unas dimensiones tales como para plantearse la posibilidad de iniciar los trámites para convertirse en desarrolladores oficiales, se descartó la posibilidad del uso de cualquiera de los recursos oficiales que Nintendo disponga para el desarrollo de aplicaciones. 


\subsubsection{Dispositivos móviles}

Estos hallazgos llevaron a analizar los dispositivos móviles de pantalla táctil disponibles en el mercado en el momento que comienza este proyecto, sus sistemas operativos, especificaciones y sus sistemas de desarrollo de terceros. Muchos de los dispositivos presentes disponen de las características necesarias para abordar el proyecto con éxito. Dentro de estas características se puede destacar la disponibilidad de pantalla táctil de gran tamaño, hardware para permitir conectividad vía Wi-Fi, procesadores con una potencia de cálculo importante o incluso, en según qué modelos, hardware específico para tareas 3D. La gran mayoría de dispositivos del mercado, independientemente del hardware que incluya y del fabricante que lo desarrolle, poseen un denominador común: el sistema operativo del móvil. Este puede ser un sistema operativo propio, desarrollado expresamente para un terminal en concreto, o un sistema operativo desarrollado por terceros, diseñado de forma genérica para ser implantado en diversidad de dispositivos móviles con distintas características de hardware. En las siguientes líneas se detallan estos aspectos.

\subsubsection{Sistemas operativos móviles, lenguajes y sistemas de desarrollo a terceros}

Este apartado valora los sistemas operativos (SSOO) presentes en los dispositivos móviles de pantalla táctil en el mercado actual, en el momento de realizar este estudio: Android, BlackBerry OS 4.7, iPhone OS 3.0, S6o de Nokia, Palm Web OS y Windows Mobile.

\subsubsection{Symbian OS}

Symbian OS es un sistema operativo multitarea para dispositivos móviles basado en eventos. Este sistema operativo fue creado por un grupo de empresas entre las cuales se puede destacar Nokia, Sony Ericcson, Samsung y Motorola. Recientemente Nokia ha adquirido la totalidad de los derechos de dicho sistema operativo. Entre los dispositivos más destacados que utilizan Symbian podemos destacar toda la gama de móviles de Nokia y algunos modelos del resto de empresas citadas 
anteriormente. Estos fabricantes han creado sus propias interfaces gráficas (destacando la S6o para Nokia y la UIQ para Sony Ericcson), ya que el diseño por capas del sistema operativo permite personalizarlo en función de las necesidades del fabricante al que vaya destinado.

El lenguaje de programación para el desarrollo de aplicaciones nativas en Symbian es $\mathrm{C}++$, aunque no se trata de una versión estándar del mismo. Muchas de las plataformas basadas en este sistema operativo disponen de un SDK específico que dispone de documentación, ficheros cabecera y librerías que permiten el desarrollo de aplicaciones. Lamentablemente, la curva de aprendizaje para el desarrollo de de aplicaciones en Symbian es alta ya que requiere técnicas de programación avanzadas lo que implica que el desarrollo de aplicaciones sea más complicado que en otras plataformas, ya que los programadores deben concentrarse más en tareas de bajo nivel que en las rutinas propias de la aplicación. Destacar que, según el tipo de versión de Symbian para la que se desarrolle, concretamente a partir de la versión 9.1 en adelante, se pueden encontrar que para acceder a ciertas funcionalidades del sistema operativo las aplicaciones desarrolladas deben ser firmadas digitalmente por Symbian con el consiguiente coste asociado. Por otro lado, a pesar de que el lenguaje de programación de Symbian es $\mathrm{C}++$, este permite ejecutar aplicaciones desarrolladas en otros lenguajes de programación como pueden ser Python, Visual Basic, Perl o J2ME gracias a la integración de maquinas virtual e intérpretes de dichos lenguajes.

\subsubsection{Windows Mobile}

Windows Mobile es un sistema operativo para dispositivos móviles creado por Microsoft y basado en la API Win32. Este sistema operativo fue diseñado para ser similar en características y estética a las versiones de escritorio de Windows. Existen diferentes ediciones de Windows Mobile dentro de una misma versión que están diseñadas en función del dispositivo al que va dirigido. Así, la versión de Windows Mobile para SmartPhone se denomina Windows Mobile SP y la versión para PocketPC se denomina Windows Mobile PPC, siendo sus aplicaciones incompatibles entre sí. Microsoft permite el desarrollo de aplicaciones por terceros y para ello dispone de múltiples opciones como por ejemplo escribir código nativo con Visual $\mathrm{C}++\mathrm{o}$ escribir código para ser interpretado en el Framework .NET Compact. Generalmente, Microsoft provee de kits de desarrollo para cada versión de Windows Mobile que trabajan en conjunto con el entorno de desarrollo Visual Studio. Estos SDKs incluyen 
emuladores para que los desarrolladores puedan probar y depurar sus aplicaciones en el momento que la están desarrollando. Aunque Windows Mobile no da soporte a otros lenguajes, gracias al desarrollo de diversos intérpretes por parte de grupos de desarrolladores independientes, se pueden ejecutar aplicaciones desarrolladas en lenguaje no nativo, como el J2ME.

\subsubsection{3 iPhone OS}

iPhone OS es el sistema operativo desarrollado por Apple a partir de Mac OS X, optimizado para procesadores ARM y destinada en concreto para los dispositivos iPhone e iPod. Está diseñado en cuatro capas: la capa OS $\mathrm{X}$ Kernel, destinada al control del sistema de archivos, gestión de energía, TCP/IP etc.; la capa Core Services, destinada al control de threads, conectividad, almacenamiento de datos, etc; la capa Media destinada al tratamiento de imágenes, gráficos en $3 \mathrm{D}$, audio, etc., y por último la capa CoCoa Touch encargada del tratamiento de eventos de pantalla táctil, las funciones de la cámara, el acelerómetro, etc.

Para el desarrollo de aplicaciones, Apple distribuye el SDK de iPhone OS que da la posibilidad de crear aplicaciones en el lenguaje nativo del mismo, Objective-C. Este SDK está disponible de forma totalmente gratuita aunque sólo se puede ejecutar bajo la plataforma Mac. En el mismo se pueden encontrar el entorno de desarrollo Xcode y un emulador para iPhone. Sin embargo, la carga de las aplicaciones únicamente es posible una vez se haya entrado en el programa de desarrolladores de iPhone, previo pago (99 dólares) y bajo aprobación de Apple. Una vez se consigue superar este escollo, las aplicaciones estarán disponibles en la tienda Apple para su venta al precio que estimen conveniente los desarrolladores. La cantidad económica se reparte en una proporción del 30\% para Apple y un 70\% para los desarrolladores. Estos últimos pueden poner sus aplicaciones en la tienda Apple a coste cero, aunque compensarán la parte económica de Apple en base a lo pagado por la suscripción. De esta forma, Apple controla quien desarrolla aplicaciones y qué tipo de aplicaciones realiza. Destacar que cada aplicación disponible en la tienda de Apple está firmada digitalmente para identificar a los creadores de la misma, garantizar que la aplicación provenga de un sitio de confianza, evitar modificaciones del código y evitar el intercambio ilegal de software entre usuarios. Con este control sobre los desarrolladores, Apple gana, además de por el terminal y por parte de las compañías que quieren utilizarlo, por parte de los desarrolladores que 
crean aplicaciones para sus productos. Por último destacar que la única vía de desarrollo de aplicaciones para iPhone OS pasa por el uso del SDK de Apple, ya que iPhone no permite ejecutar aplicaciones creadas en otro lenguaje de programación o que no hayan pasado el cauce oficial de Apple. En Septiembre de 2008 Apple lanza su Programa Universitario del Desarrollador del iPhone (iPhone Developer University Program), que permite, de forma gratuita y a las instituciones académicas acreditadas, desarrollar, probar, depurar y distribuir aplicaciones a través de la App Store.

\subsubsection{BlackBerry OS}

BlackBerry OS es un sistema operativo propietario multitarea desarrollado por Research In Motion (RIM) para sus dispositivos BlackBerry orientado al mundo de los negocios. Para desarrollar aplicaciones para BlackBerry se pueden utilizar dos alternativas: por un lado las APIs de J2ME basadas en la versión MIDP 2.0 y CLDC 1.1, que permiten la reutilización de código entre aplicaciones creadas para la misma versión, y por otro lado unas APIs propias de BlackBerry, basadas en Java, que ofrecen servicios básicos de acceso a redes, interfaz de usuario y otros más avanzados sobre criptografía, sincronización y mensajería que proveen de la apariencia característica de las aplicaciones desarrolladas para BlackBerry. Cabe destacar que para utilizar algunos de los servicios avanzados proporcionados por las APIs de BlackBerry se debe firmar digitalmente la aplicación desarrollada lo que implica un coste aproximado de 100 dólares. Para el desarrollo de aplicaciones, BlackBerry proporciona un entorno de desarrollo de forma gratuita, denominado BlackBerry Java Develoment Enviroment o BlackBerry JDE, que permite desarrollar aplicaciones tanto con las APIs de J2ME como las APIs de BlackBerry e incorpora herramientas para simular y depurar el código desarrollado.

\subsubsection{Android}

Android es una plataforma de software y un sistema operativo para dispositivos móviles basado en el núcleo de Linux. Inicialmente desarrollado por Google y luego por la Open Handset Alliance. Android permite a los desarrolladores escribir código gestionado en el lenguaje de programación Java y controlar los dispositivos por medio de bibliotecas desarrolladas o adaptadas por Google. Aplicaciones escritas en $\mathrm{C} \mathrm{u}$ otros 
lenguajes pueden ser compiladas a código nativo de ARM y ser ejecutadas. La presentación de la plataforma Android se realizó el 5 de noviembre de 2007, por lo que también es una plataforma joven. El primer dispositivo en el que se incorpora Android es el T-Mobile G1 o HTC Dream. El 18 de febrero de 2009 se presentó el HTC Magic, una versión evolucionada del HTC Dream sin teclado Qwerty.

\subsubsection{Palm webOS}

Palm webOS es un sistema operativo empotrado desarrollado por Palm, Inc. para smartphones, es el sistema más joven hasta el momento, presentado al público el 8 de enero de 2009. Palm webOS está diseñado para ser usado a través de una interfaz de usuario basada en pantalla táctil. El Palm Pre, cuya comercialización está prevista para la primera mitad de 2009, es el primer dispositivo que incorpora este sistema operativo. Palm webOS tendrá un catálogo de aplicaciones de serie, un entorno de desarrollo denominado Mojo (que estará disponible a desarrolladores) y APIs para extender JavaScript para poder acceder al hardware del dispositivo. WebOS es un sistema operativo basado en Linux. El SDK de Mojo estará limitado respecto a la utilización del hardware del Palm Pre, complicando el desarrollo de cierto tipo de aplicaciones, como pueden ser complejos videojuegos en $3 \mathrm{D}$.

Una de las grandes diferencias en la experiencia del interfaz reside en el tipo de pantalla: Capacitiva o Resistiva. Las capacitivas son la nueva alternativa, en especial porque no requieren de objetos externos (como un stylus) para funcionar. Los nuevos dispositivos de Nokia ya incorporan este tipo de pantallas.

\subsubsection{La Pantalla Táctil}

El uso de la pantalla táctil libera del uso de los periféricos clásicos de entrada, habilitando un mecanismo más intuitivo que facilita la interacción entre el dispositivo y el usuario. Además, la interacción puede llevarse a cabo mediante herramientas destinadas a ello, como puede ser el "stylus" o lápiz, o simplemente con la mano. Existen dos tipos principales de pantallas táctiles en los móviles, que se distinguen fundamentalmente por la sensación del usuario: 
- Pantallas resistivas: se manejan con el stylus (lápiz) o con el dedo, pero al requerir presión para que funcionen la experiencia del usuario es menos agradable, más lenta y parece menos intuitiva.

- Pantallas capacitivas: son las que se deben manejar con el dedo, no admiten stylus, no requieren presión, admiten varias pulsaciones simultáneas. La experiencia del usuario con estas pantallas es muy buena.

El uso de pantallas táctiles, tanto en dispositivos móviles como en otros entornos, presenta una serie de ventajas e inconvenientes. Entre las ventajas se pueden enumerar:

- Directo: Al contrario que puede pasar con un ratón, un teclado o un joystick, el funcionamiento de la pantalla táctil, de cara al usuario, se basa simplemente en tocar sobre la pantalla. No hay necesidad de recordar una sintaxis compleja, buscar una herramienta de entrada, apartar el foco visual de los objetos que interesen o presionar múltiples teclas para mover el cursor. Además, no existe la necesidad para los usuarios de sincronizar el movimiento de su mano con el movimiento del cursor como pasa con un ratón tradicional.

- Velocidad: Los usuarios no necesitan una herramienta de entrada en el momento de interactuar con la pantalla. Simplemente tocan en la posición deseada como si pichasen con el cursor en dicha posición.

- Facilidad de aprendizaje: Una vez que el usuario se da cuenta de que simplemente debe tocar en la pantalla para interactuar, pueden realizar acciones como pulsar botones o arrastrar objetos de forma rápida y sencilla.

- Flexibilidad: Las pantallas táctiles ofrecen flexibilidad a la hora de mostrar contenidos. Estas se pueden adaptar a cualquier tarea específica en función de lo que se desee hacer, mostrando, por ejemplo, un teclado en el momento que se solicite introducir datos personales, o una serie de botones cuando debemos realizar una determinada selección.

- Menos espacio y tamaño: Las pantallas táctiles liberan de la necesidad de tener periféricos adicionales para la entrada de datos en aplicaciones y dispositivos donde estos aspectos son críticos. 
Por el contrario debemos tener cuidado con diversos aspectos que pueden afectar considerablemente en el desarrollo y en el uso de una aplicación en un dispositivo de este tipo:

- Deslumbramientos y manchas: La existencia de fuentes de luz intensa cerca de la pantalla táctil puede producir deslumbramientos o reflejos que limitan la visibilidad de la pantalla. Por otro lado, las huellas ensucian y oscurecen la pantalla lo que provoca la necesidad de limpiar la pantalla regularmente o utilizar accesorios como lápices o stylus para interactuar con ellas.

- Ocultación de la pantalla: El hecho de que los usuarios deban utilizar la pantalla con la mano, provoca que la misma oculte parte del contenido mostrado en la pantalla o provoque la aparición de sombras limitando la visibilidad. Un diseño cuidado de la interfaz gráfica puede reducir este problema.

- Feedback táctil limitado: El feedback táctil es importante cuando se realizan pulsaciones rápidas de botones sin tener que mirar la pantalla. En un teclado convencional la forma de las teclas puede indicar, en mayor o menor medida, que tecla se está pulsado y si realmente se ha pulsado. En una pantalla táctil este feedback no es posible. Además, por el modo de funcionamiento de un botón tradicional, cuando se pulsa sobre uno de ellos se sabe realmente que se ha pulsado. Al pulsar sobre un botón de una pantalla táctil no hay ningún indicativo físico que indique que realmente se ha pulsado.

- Pulsaciones no deseadas: El uso de estas pantallas con las manos puede provocar que, al tratar de pulsar un determinado botón, se pulse accidentalmente otros botones. La presencia de múltiples pulsaciones sobre la pantalla en un mismo instante de tiempo puede provocar que a pantalla no responda correctamente. Las pantallas que puedan reconocer varias pulsaciones al mismo tiempo pueden solucionar este problema.

- Tamaño limitado: Si el tamaño de la pantalla táctil es reducido, la pulsación de un determinado botón mostrado en pantalla puede resultar complicado, ya sea porque el botón es muy pequeño o el dedo muy grande. 


\subsubsection{Gráficos 3D en dispositivos móviles}

Existen dos grandes estándares de referencia para el desarrollo de gráficos y aplicaciones 3D para dispositivos móviles: OpenGL ES y M3G.

\subsubsection{OpenGLES}

OpenGL ES (OpenGL for Embedded Systems) es una variante simplificada de la API gráfica OpenGL diseñada para teléfonos móviles, PDAs, etc., que actúa como una interfaz entre la capa de software de bajo nivel y el hardware gráfica. Hay que destacar que OpenGL ES, en sus diferentes versiones, ha sido elegida como la API $3 \mathrm{D}$ oficial por muchos fabricantes: Symbian OS, Android platform, iPhone SDK. Además, Sony ha elegido a OpenGL ES como una de las APIs gráficas para su Playstation 3. A la vista de la elección de OpenGL ES por parte de la mayoría de fabricantes se puede decir que este se ha convertido en el estándar gráfico de facto para aplicaciones programadas en $\mathrm{C}$.

J2ME dispone de una API denominada Java Binding for OpenGL ES (JSR 239) que permite el uso de OpenGL ES. La API JSR 239 no es actualmente soportada por un gran número de dispositivos, lo que puede ser un gran hándicap a la hora de decantarse por el uso de OpenGL ES junto con el lenguaje de programación J2ME.

\subsubsection{M3G}

La API Mobile 3D Graphics (M3G) es una especificación de una API Java destinada a generar gráficos $3 \mathrm{D}$ en dispositivos móviles. Actualmente la versión disponible de $\mathrm{M}_{3} \mathrm{G}$ es la 1.1 aunque ya se encuentra en desarrollo la versión 2.0 (JSR 297). M3G fue creada para cubrir las necesidades de representación en $3 \mathrm{D}$ de este tipo de dispositivos, teniendo en cuenta las limitaciones tanto de memoria como de capacidad de procesamiento, además de la ausencia de elementos hardware necesarios para dicha representación, como pueden ser unidades dedicadas para punto flotante o para gráficos en $3 \mathrm{D}$. $\mathrm{M} 3 \mathrm{G}$ es una librería de alto nivel diseñada para ser compatible con OpenGL ES, que puede trabajar sobre ella y que no pretende ser un competidor sino un complemento. OpenGL ES requiere de muchas líneas de código para construir una simple escena 3D, mientras que con M3G minimiza el código a utilizar en las aplicaciones gráficas, aumentando el rendimiento de las aplicaciones y mejorando la productividad de los desarrolladores. 
Los gráficos $3 \mathrm{D}$ en los dispositivos móviles dependen del hardware disponible en el aparato. Hasta hace poco tiempo sólo los teléfonos de gama alta disponían de buenas capacidades gráficas, pero está situación está cambiando, sobre todo porque los precios de esos aparatos ya son más asequibles a todos los públicos.

La Tabla 19 refleja un resumen de las características más importantes de los sistemas operativos descritos en los párrafos precedentes. Es de destacar que los sistemas operativos S6o y Windows Mobile disponen de los núcleos más maduros y estables, disponiendo de buena adaptabilidad. El núcleo del Iphone proviene de Unix, uno de los sistemas operativos más poderosos del mundo de la informática. Palm Web OS y Android son los sistemas más jóvenes, pero parece que con buena proyección en el mercado. Respecto a la interfaz de usuario, destaca el iPhone por la posibilidad de realizar cambios con simples desplazamientos de los dedos sobre la pantalla. Los movimientos en Android son difíciles de aprender, lo que puede ser un inconveniente para su penetración en el mercado. Por otro lado, Windows Mobile y BlackBerry OS tienen que usar dispositivos físicos, como el stylus o la conocida rueda de RIM. Los S6o están abriéndose camino con el nuevo Nokia 5800, aunque todavía tienen que mejorar. 
CAPÍTULO V: DISEÑO, IMPLEMENTACIÓN Y EVALUACIÓN DE UNA ARQUITECTURA..

Tabla 19.- Sistemas Operativos Móviles y sus características (Andrade, 2009)

\begin{tabular}{|c|c|c|c|c|c|c|c|}
\hline & & $\begin{array}{l}\text { Android } \\
\text { Cupcake }\end{array}$ & $\begin{array}{c}\text { BlackBerry } \\
\text { OS } 4.7\end{array}$ & $\begin{array}{c}\text { iPhone } \\
\text { OS 3.1 } \\
\end{array}$ & $\begin{array}{c}\text { S6o } \\
\text { 5th Edition }\end{array}$ & $\begin{array}{l}\text { Palm Web } \\
\text { OS }\end{array}$ & $\begin{array}{l}\text { Windows } \\
\text { Mobile } 6.5\end{array}$ \\
\hline \multirow{4}{*}{$\sum_{\substack{1 \\
0}}^{0}$} & $\begin{array}{l}\text { Tipo de núcleo } \\
\text { (kernel) }\end{array}$ & Linux & Propietario & $\begin{array}{c}\text { OS X } \\
\text { Variante Unix } \\
\end{array}$ & Symbian & Linux & Windows CE \\
\hline & Adaptabilidad & Excelente & Buena & Mala & Excelente & Excelente & Excelente \\
\hline & $\begin{array}{l}\text { Edad de la } \\
\text { plataforma }\end{array}$ & Joven & Madura & Adolescente & Madura & Joven & Madura \\
\hline & $\begin{array}{l}\text { Tecnologías } \\
\text { inalámbricas }\end{array}$ & GSM, Wi-Fi & GSM, CDMA, Wi-Fi & GSM, Wi-Fi & GSM, Wi-Fi & $\begin{array}{l}\text { GSM, CDMA, } \\
\text { Wi-Fi }\end{array}$ & $\begin{array}{l}\text { GSM, CDMA, } \\
\text { Wi-Fi }\end{array}$ \\
\hline \multirow{4}{*}{ 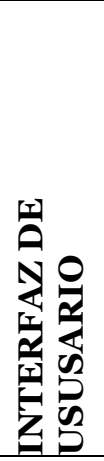 } & Gestos & Sí & Sí & Sí & Limitado & Sí & Limitado \\
\hline & $\begin{array}{l}\text { Tecnología de la } \\
\text { pantalla }\end{array}$ & Capacitiva & Capacitiva & Capacitiva & $\begin{array}{l}\text { Resistiva / } \\
\text { Capacitiva }\end{array}$ & Capacitiva & Resistiva \\
\hline & Multitáctil & Sí (no oficial) & Sí & Sí & No & Sí & No \\
\hline & Teclado & $\begin{array}{l}\text { Teclado virtual, } \\
\text { teclado físico }\end{array}$ & Teclado virtual & Teclado virtual & $\begin{array}{l}\text { Teclado virtual, T9 } \\
\text { y triple clic; } \\
\text { reconoce } \\
\text { caracteres; teclado } \\
\text { físico }\end{array}$ & Teclado físico & $\begin{array}{c}\text { Teclado virtual; } \\
\text { reconoce } \\
\text { caracteres; } \\
\text { teclado físico }\end{array}$ \\
\hline \multirow{5}{*}{ 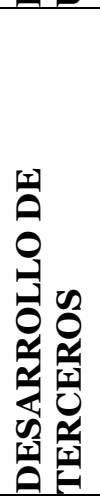 } & $\begin{array}{l}\text { Disponibilidad de } \\
\text { SDK / Soporte }\end{array}$ & Sí & Sí & Sí & Sí & Sí & Sí \\
\hline & $\begin{array}{l}\text { Tienda de } \\
\text { aplicaciones }\end{array}$ & Sí & Próximamente & Sí & $\begin{array}{l}\text { Próximamente } \\
\text { Ovi store }\end{array}$ & Sí & Sí \\
\hline & $\begin{array}{l}\text { Disponibilidad de } \\
\text { aplicaciones }\end{array}$ & Mediana & Mediana & Alta & Mediana & Baja & Alta \\
\hline & $\begin{array}{l}\text { Aplicaciones } \\
\text { nativas }\end{array}$ & No & No & Sí & Sí & No & Sí \\
\hline & $\begin{array}{l}\text { Administración } \\
\text { local de } \\
\text { aplicaciones }\end{array}$ & Excelente & Buena & Excelente & Buena & Excelente & Buena \\
\hline
\end{tabular}




\subsubsection{Selección de las especificaciones para este proyecto}

Las aplicaciones desarrolladas para dispositivos móviles presentan, en general, dificultad para poder ejecutarse en una amplia variedad de aparatos. Esto es debido a los distintos SSOO y sus lenguajes nativos, el grado de personalización del dispositivo (posibilidad de instalar software, modificar hardware, etc.), la pantalla (interacción y tamaño) y el teclado, entre otras. Es por ello que en este proyecto se planteó elegir un dispositivo móvil, atendiendo lo descrito en los apartados anteriores en cuanto a SSOO y lenguajes soportados y teniendo en cuenta la tendencia del mercado hacia los dispositivos táctiles con pantallas de gran tamaño $(2,8$ " a 3,5 "), que mejora sustancialmente la experiencia de los usuarios.

Se detalla a continuación los elementos de hardware, software y lenguajes, utilizados en el desarrollo de la aplicación móvil:

\subsubsection{Sistema Operativo}

Según los últimos datos ${ }^{20}$, los sistemas operativos con mayor presencia en los dispositivos móviles son el Symbian (47,1\%), el RIM BlackBerry (19,5\%), el Windows Mobile (12,4\%) y el iPhone Os (10,7\%), ocupando entre los cuatro el 89,7\% del mercado actual. Sin embargo, decantarse por uno de ellos para desarrollar una aplicación significa perder un espectro importante de mercado. Por otro lado, 3 de los 4 sistemas operativos analizados permiten la ejecución de aplicaciones desarrolladas en Java Micro Edition (J2ME), ocupando el 79\% del mercado (ver Figura 52). Cuando se comienza este proyecto el iPhone no se comercializa todavía en España y no existe el sistema de desarrollo para universidades ${ }^{21}$. El sistema operativo Symbian estaba disponible en muy pocos teléfonos táctiles. Por todo ello se utiliza Windows Mobile, el sistema operativo disponible en muchas PDAs, smartphones y teléfonos de gama alta.

\section{J2ME (Java Micro Edition)}

Java Micro Edition, también conocido como Java ME o J2ME es una especificación de un subconjunto de la plataforma Java de Sun dirigida al desarrollo de software para dispositivos de recursos limitados y sistemas

${ }^{20} \mathrm{http}: / /$ en.wikipedia.org/wiki/Smartphone

${ }^{21}$ http://developer.apple.com/iphone/program/university.html 
embebidos como pueden ser teléfonos móviles, PDAs, dispositivos para televisión digital, etc. La arquitectura J2ME se sustenta sobre dos cubos principales, las configuraciones y los perfiles (I), y otro bloque secundario formador por una serie de paquetes opcionales (II). Una configuración se define como el grupo de APIs mínimo necesarios para un grupo de dispositivos que tienen características similares en cuanto a memoria y capacidad de procesamiento. Una configuración está compuesta de una máquina virtual y un conjunto mínimo de clases que soporta ese grupo de dispositivos. Por otro lado, un perfil extiende una configuración y completa las necesidades específicas para una cierta familia de dispositivos.

En el momento de iniciar este proyecto, comienzan a introducirse en España los nuevos dispositivos móviles táctiles, que mejoran la experiencia del usuario con la pantalla, introducen pantallas más grandes y mejoran las velocidades del procesador y la memoria RAM, que permiten desarrollar aplicaciones $3 \mathrm{D}$ en buenas condiciones. Hay que destacar que en el actualmente la gama de dispositivos con estas características es bastante más amplio y asequible a muchos usuarios: Nokia 5800, LG, Samsung Omnia, etc.

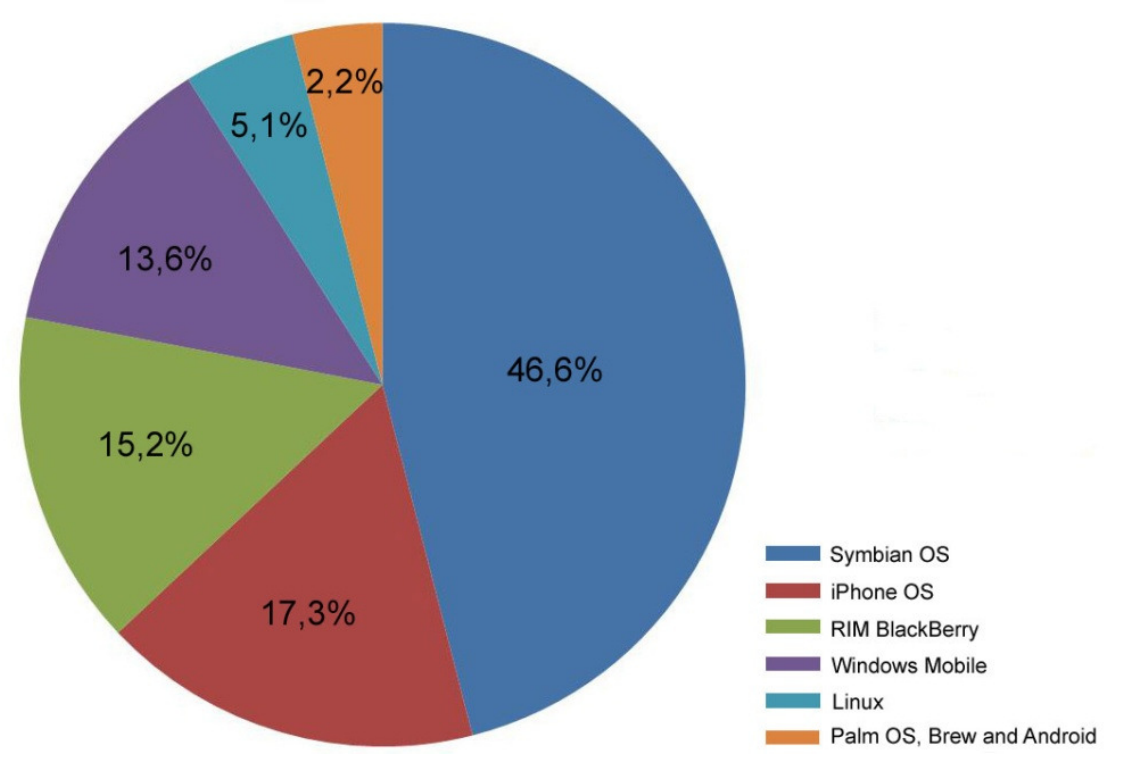

Figura 52.- Presencia de los SSOO para DDMM en el mercado (Noviembre 2008) 


\subsubsection{Dispositivo}

Se utilizó un dispositivo táctil HTC Touch para realizar la implementación de la aplicación, que tiene las características reflejadas en la Tabla 20.

Tabla 20.- Características del HTC Touch

$\begin{array}{ll}\text { Dispositivo móvil } & \text { Procesador TI OMAP }{ }^{\mathrm{TM}} 850,201 \text { Mhz, } 128 \\ & \text { ROM, 64 MB SDRAM DDR } \\ & \text { Windows Mobile 6.0 } \\ & \text { Pantalla táctil, 2,8”, 240 x } 320 \\ & \text { Máquina virtual Jbed Smertec }\end{array}$

\subsubsection{Elección del estándar 3D}

A la hora de decantarse por la API gráfica a utilizar en el proyecto, inicialmente la decisión era clara: OpenGL ES era el candidato ideal, tanto por el conocimiento previo que se tenía de su predecesor OpenGL, como de su extensión y utilización por parte de la mayoría de fabricantes del mercado. Sin embargo, como el lenguaje de programación sobre el que se desarrollaría el proyecto era J2ME, la API a utilizar debería ser la JSR 239, Java bindings for OpenGL ES. Después de una serie de pruebas iniciales para una primera toma de contacto con la API gráfica, y como ya indicaban las primeras advertencias del poco soporte que disponen los dispositivos móviles de la JSR 239, se pone de manifiesto que la API no es soportada por la mayoría de los dispositivos móviles. En esta situación no cabe más solución que tratar de abordar el proyecto con la API alternativa, M3G. Igualmente se trató de realizar unas pruebas de toma de contacto para comprobar el soporte de dicha API, que esta vez sí resultaron exitosas y permitieron la representación de elementos $3 \mathrm{D}$.

\subsubsection{Máquina virtual}

A pesar de que J2ME puede ser ejecutado en múltiples sistemas operativos, Sun no proporciona de manera oficial una máquina virtual para las aplicaciones móviles, como hace en las versiones de Java para escritorio y servidores, con la excepción de la KVM para MIDP 1.o. Es por ello que cada fabricante debe realizar su implementación del estándar como crea conveniente. Esto provoca que la portabilidad de J2ME no sea 
tal, encontrándose problemas e incompatibilidades al ejecutar una misma aplicación en diferentes dispositivos móviles e, incluso entre los resultados ofrecidos por el emulador proporcionado por Sun para J2ME y los resultados obtenidos al ejecutar la misma aplicación en un dispositivo móvil real. Entre los problemas más comunes se pueden destacar la falta de implementación de algunas de las APIs de J2ME o el ignorar ciertas propiedades de elementos gráficos.

Se experimentó con algunas de ellas, entre las que cabe destacar la Esmetek Jeodek, la Tao Intent Midlet Manager o la Esmertec Jbed, que presenta muy buenos resultados ejecutando aplicaciones desarrolladas en J2ME. Presenta problemas con ciertas propiedades de algunos objetos a la hora de mostrarlos en la interfaz gráfica, que aún no han sido corregidos en las últimas versiones. A diferencia del resto de máquinas virtuales, esta última, permite ejecutar prácticamente cualquier tipo de API de J2ME, incluyendo la JSR 184 Mobile 3D Graphics.

En definitiva, se ha utilizado en este proyecto el SO Windows Mobile, el lenguaje J2ME y la Máquina Virtual Jbed Smertec que interpreta el código java (ver Figura 53).

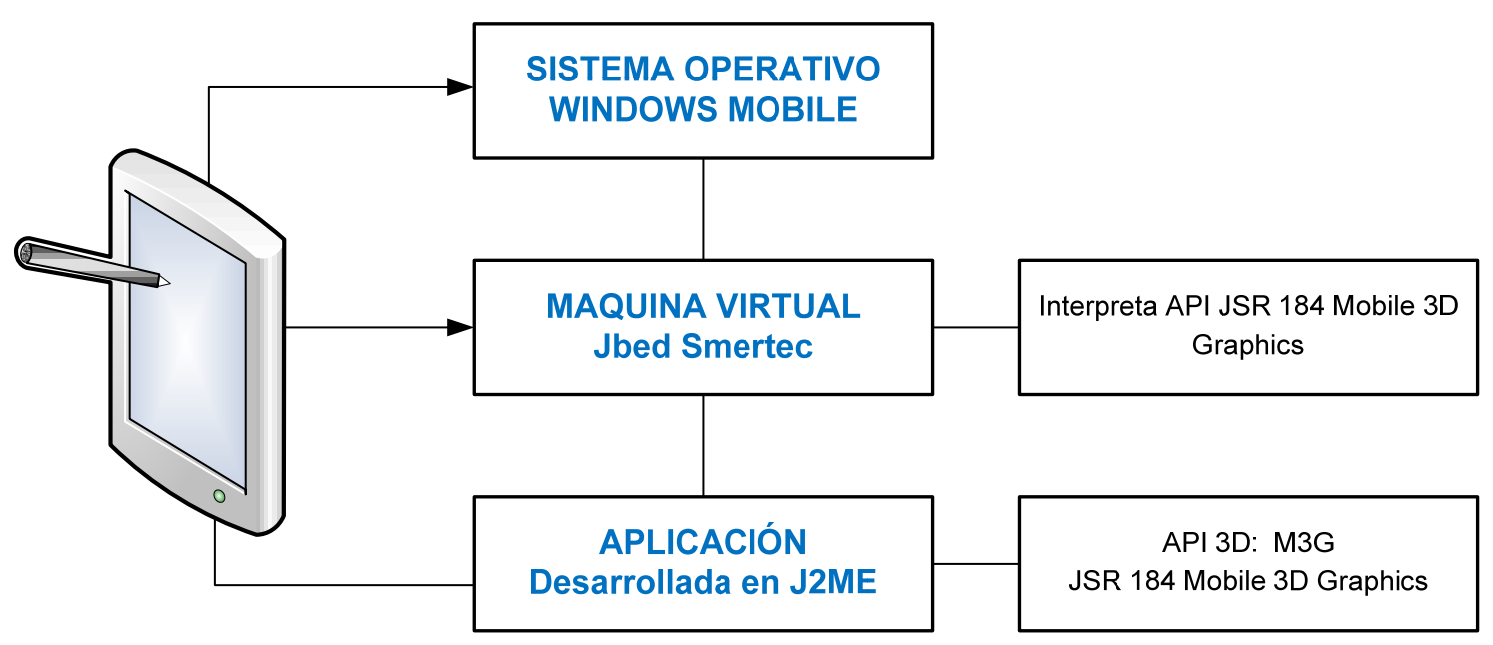

Figura 53.- Arquitectura de la aplicación móvil 


\subsection{Arquitectura e implementación del sistema diseñado}

La arquitectura diseñada incluye:

- una aplicación de escritorio,

- un aplicación 3D para dispositivo móvil de pantalla táctil,

- una aplicación de servidor y,

- una base de datos.

La Figura 54 presenta un esquema resumido del sistema diseñado y en las siguientes líneas se describe de forma breve su funcionamiento. El juego de móvil consiste en una aplicación, desarrollada para dispositivos de pantalla táctil, donde el estudiante desarrolla una colección de ejercicios creados por el profesor. Los ejercicios tratan de la construcción de modelos de cubos en un entorno 3D. Se establecen dos modos de juego: Entrenamiento y Competición. Los ejercicios de Entrenamiento están destinados a que el usuario se familiarice con el entorno del juego y están disponibles de forma local en el dispositivo móvil. Las Competiciones son colecciones de ejercicios, establecidas por el profesor o administrador y que el usuario tiene que descargar, accediendo al sistema mediante un nombre de usuario y una contraseña. Los usuarios sólo pueden realizar cada competición una vez. Luego podrán acceder a otras competiciones que el profesor o administrador del sistema tenga activas. Los resultados de las Competiciones se envían al servidor, con los datos de los tiempos y puntuaciones obtenidas. La aplicación de PC permite al profesor o administrador del sistema dar de alta a los nuevos usuarios, crear ejercicios, crear competiciones y activarlas para que estén disponibles para descargar.

Este proyecto ha utilizado la plataforma de desarrollo de código abierto (Open Source) NetBeans 6.0.1 para la programación de todas las aplicaciones. Además se utilizó Sun Java Wireless Toolkit 2.5.2 para la emulación de la aplicación móvil.

La aplicación móvil se desarrolla en J2ME (Java Micro Edition), bajo la configuración CLDC 1.1 y el perfil MIDP 2.o. El desarrollo de la aplicación de escritorio se realizó también utilizando Java, en su versión para escritorio. Además de los beneficios que ofrece Java en cuanto a portabilidad, nos ha permitido, en nuestro caso, la reutilización de parte del código en la aplicación móvil. EL servidor se implementó con Java 2 Platform, Enterprise Edition (J2EE). Se utilizó el servidor libre Tomcat y 
MySQL como sistema gestor de la base de datos. Para facilitar las tareas de diseño y creación se utilizó la herramienta MySQL Workbench y para la administración con interfaz gráfica phpMyadmin integrado en el paquete WAMPServer.

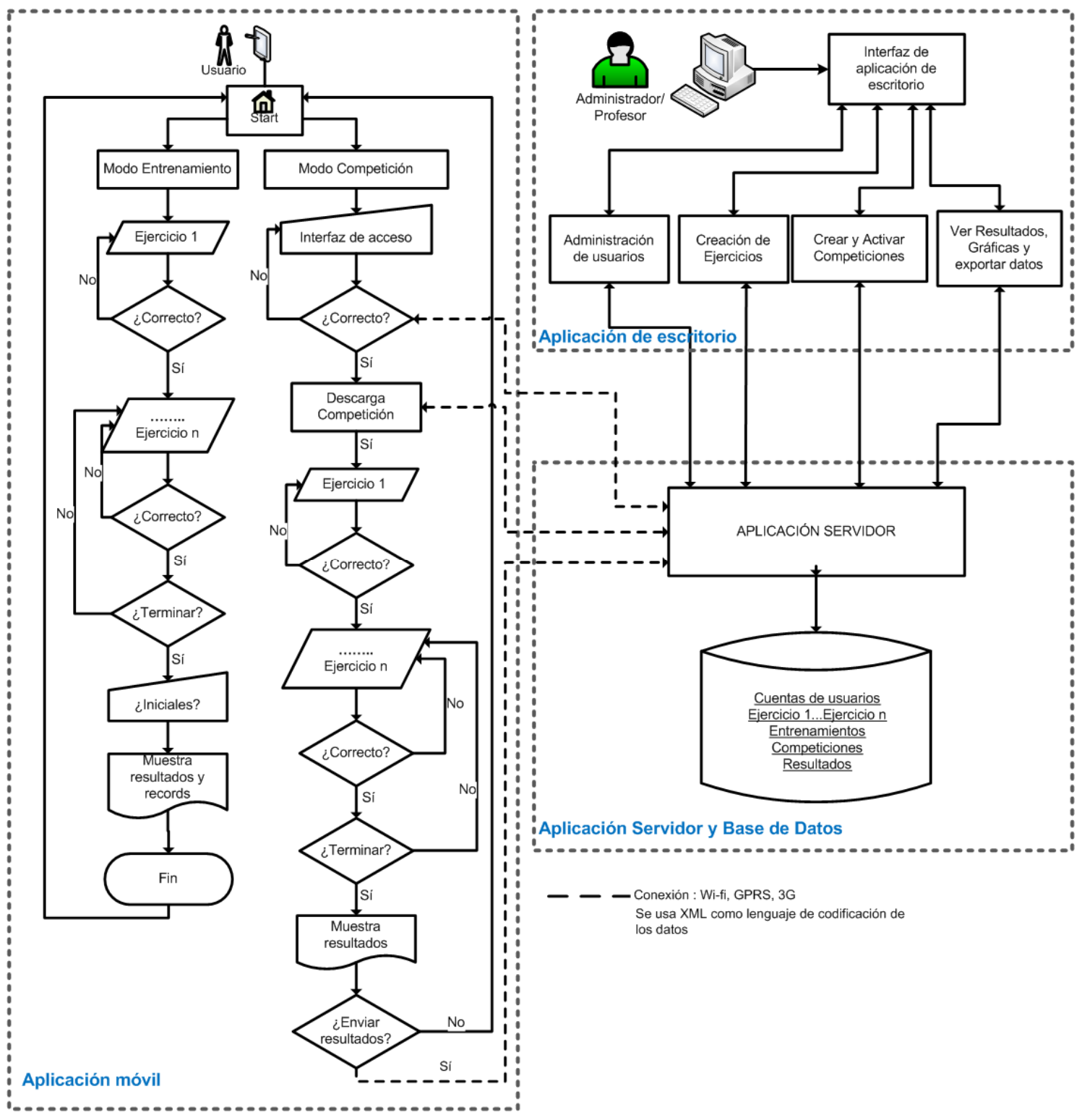

Figura 54.- Arquitectura del sistema

El intercambio de información entre los componentes de este sistema se ha llevado a cabo mediante la implementación de conexiones HTTP (HttpConnection). Esto nos permite la interconexión entre los componentes de este sistema utilizando distintas tecnologías: cable, WiFi, GPRS, 3G, etc., necesarias en este diseño. Se utiliza el formato XML para la transferencia, con el objetivo de estructurar los datos y que 
puedan ser tratados de forma más cómoda por las aplicaciones implicadas.

\subsubsection{Aplicación de escritorio}

La aplicación de escritorio permite al administrador o profesor gestionar las siguientes operaciones:

- Consultar, crear, modificar y borrar usuarios. Gestiona los datos personales (nombre, edad, sexo, etc.), los resultados de las competiciones y las fechas de las mismas (ver Figura 55).

- Consultar, crear, modificar y borrar ejercicios (ver Figura 56). Los ejercicios son creados por el profesor en un entorno $3 \mathrm{D}$ interactivo en la aplicación de escritorio, de tal manera que facilite la labor de gestión de los mismos.

- Consultar, crear, modificar y borrar competiciones (ver Figura 57). El profesor podrá gestionar la información de las competiciones y ejercicios en un entorno $3 \mathrm{D}$.

- Visualizar en los gráficos de los resultados de las competiciones (Figura 58). La aplicación de escritorio permite generar gráficos mostrando los resultados de calificación $\mathrm{y}$ tiempo, para una competición dada.

- Exportar los datos. Se permite exportar los resultados de las competiciones (calificaciones y tiempos) de los usuarios en formato txt para que posteriormente puedan ser tratados en una hoja de cálculo o software estadístico. Además las gráficas generadas por la aplicación pueden ser guardadas en formato "jpg" o "pdf".

- Configurar parámetros de conexión: IP y puerto del servidor, en el caso de que fuera necesario.

La Figura 55 muestra la interfaz de la aplicación de PC, donde el profesor o administrador del sistema puede crear nuevos ejercicios en un entorno 3D interactivo o utilizar la colección de ejercicios existente en la base de datos. Se han desarrollado dos tipos de ejercicios, que consisten fundamentalmente en la construcción de modelos de cubos (Figura 56).

Se deben agrupar los ejercicios en Competiciones y activar la que se quiera que esté disponible para que pueda ser descargada por la aplicación móvil (ver Figura 57). Los usuarios autorizados para descargar las colecciones de ejercicios (Competiciones) deben haber sido dados de alta en la aplicación por el profesor. La aplicación de PC permite consultar 
en formato gráfico las estadísticas de los usuarios (calificaciones y tiempos) y ver y exportar los datos en formato "txt" para poder ser tratados en una hoja de cálculo o software estadístico (Figura 58).

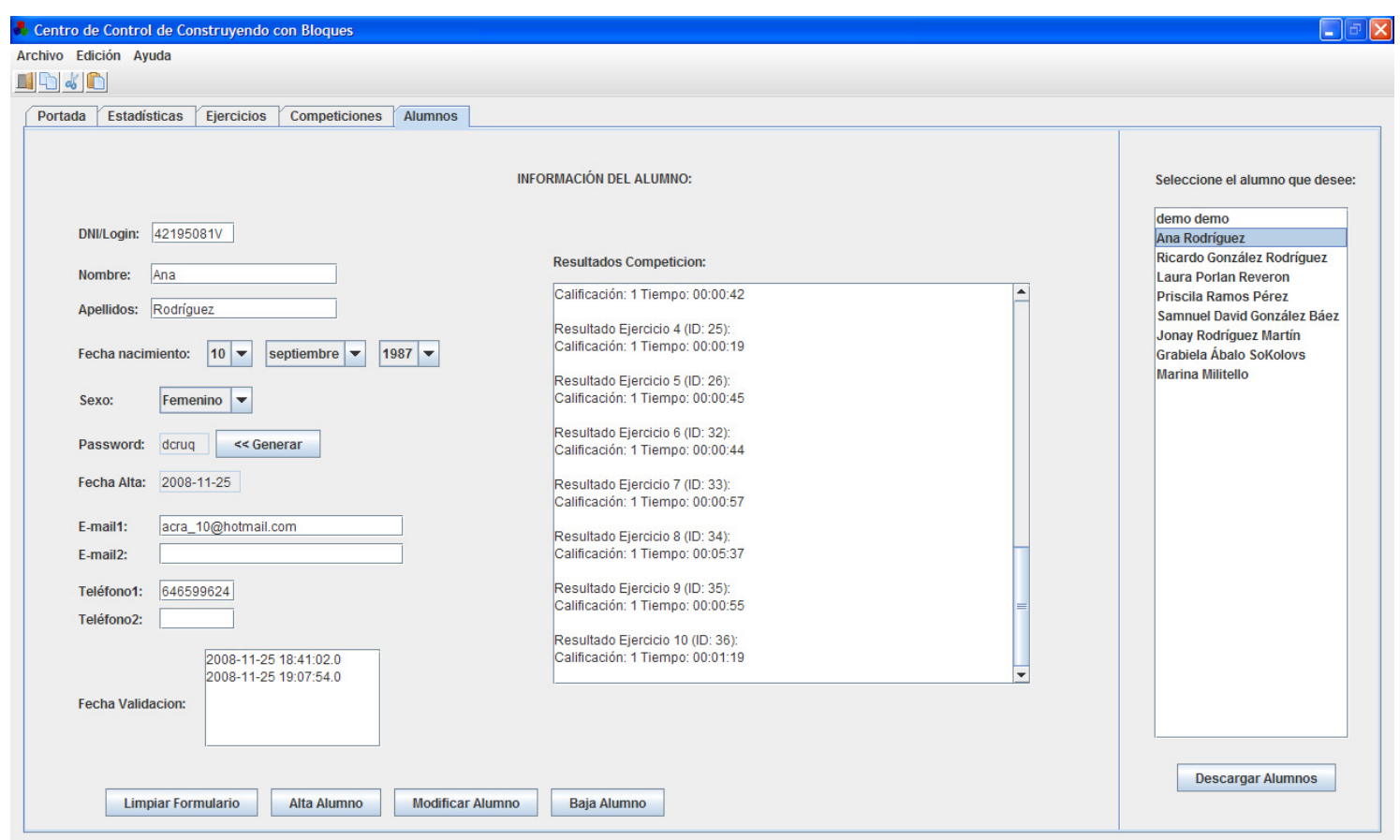

Figura 55.- Interfaz de de la aplicación de escritorio: gestión de usuarios

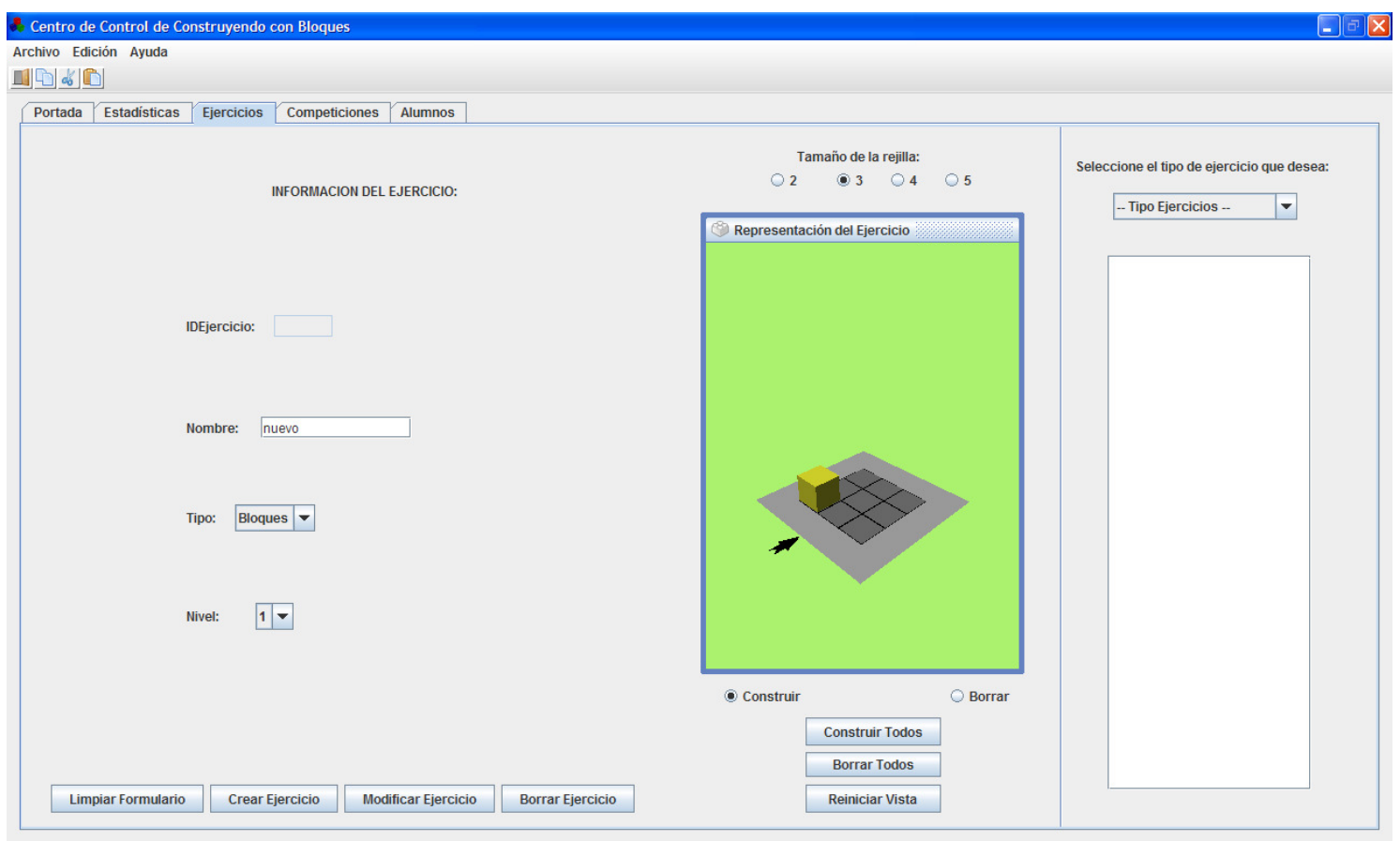

Figura 56.- Interfaz de de la aplicación de escritorio: creación de ejercicios 


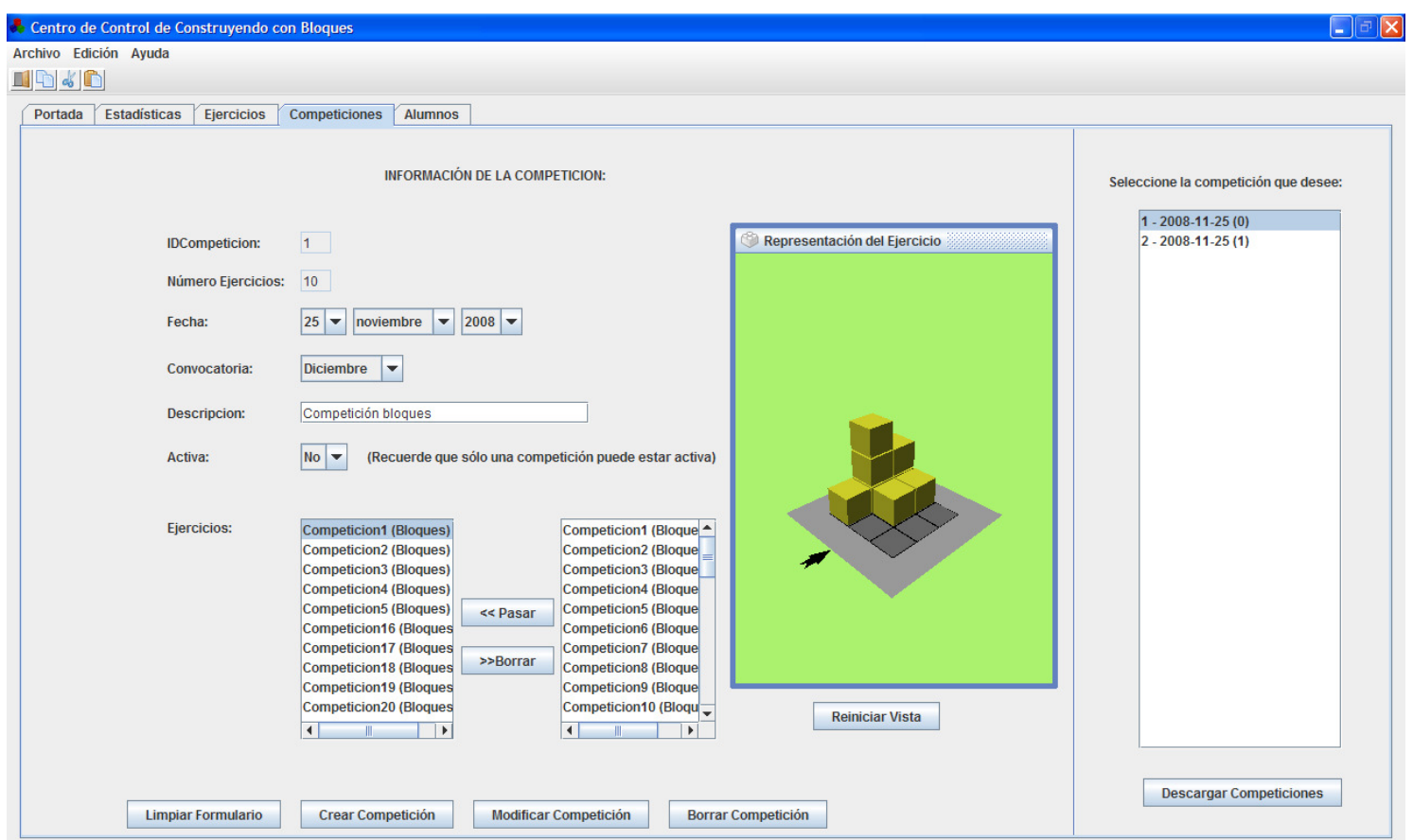

Figura 57.- Interfaz de de la aplicación de escritorio: creación de competiciones

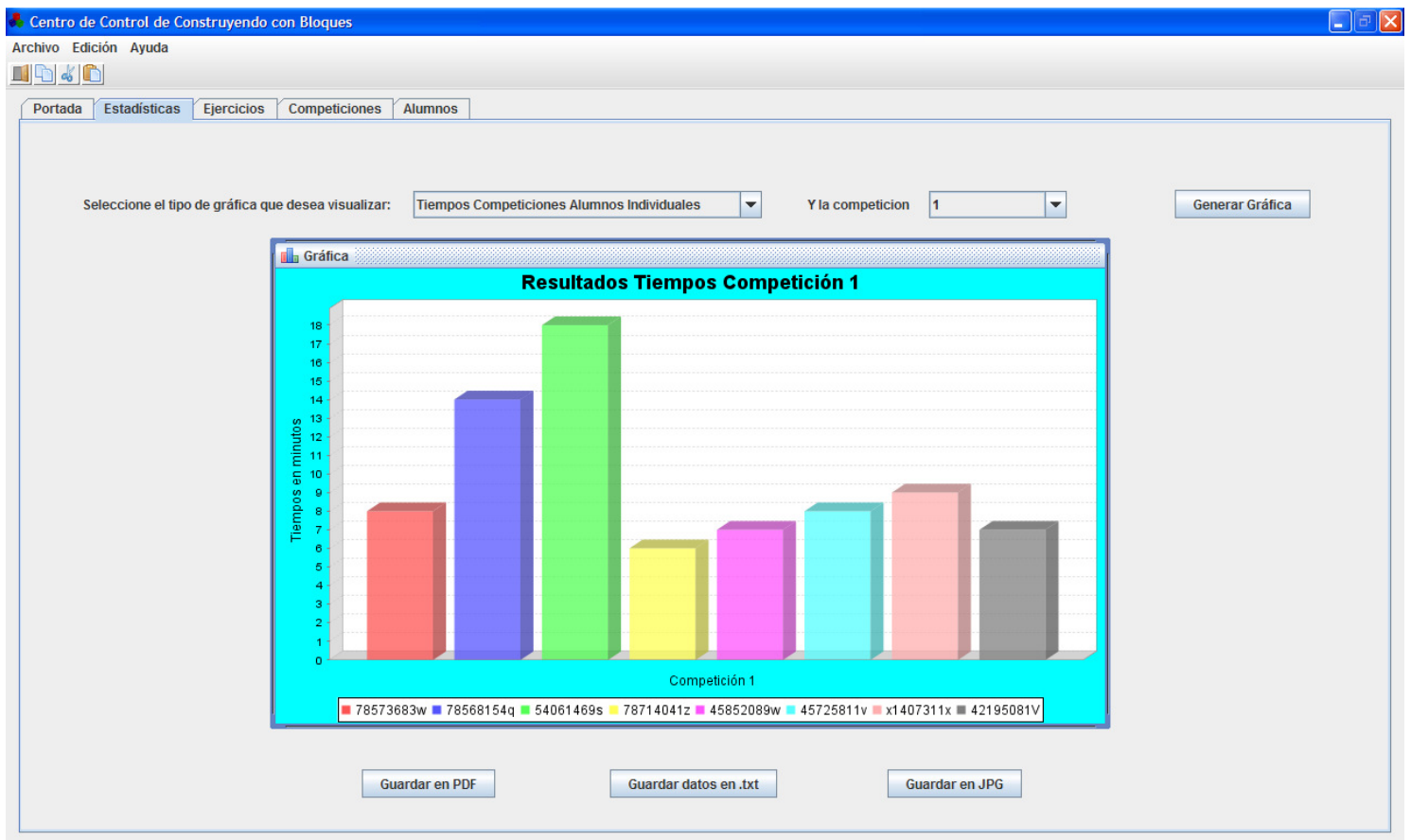

Figura 58.- Interfaz de de la aplicación de escritorio: estadísticas 


\subsubsection{Tipología de ejercicios}

El usuario debe resolver una serie de ejercicios, que consisten en la construcción de un modelo de cubos. Cada ejercicio lleva asociada una puntuación (un punto si es correcto y cero si es incorrecto) y el tiempo que ha empleado en completar la actividad. Se diseñaron dos tipos de ejercicios: copiar un modelo $3 \mathrm{~d}$ (tipo 1) y construir un modelo $3 \mathrm{~d}$ a partir de tres vistas ortogonales (tipo 2).

- Tipo 1: "Bloques": consiste en reproducir el modelo de cubos propuesto (Figura 59).

- Tipo 2: "Vistas": consiste en construir un modelo 3D usando tres vistas ortogonales: vista de frente, vista superior y vista derecha (Figura 60).

El desarrollo de este proyecto usó el Sistema Europeo de Proyección, o del primer diedro (Figura 61).

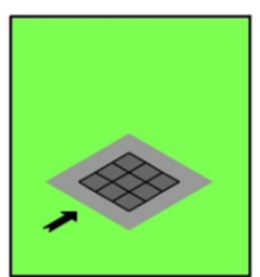

a)

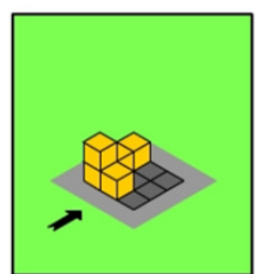

b)

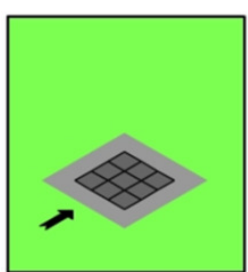

a)

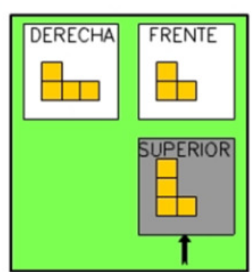

b)

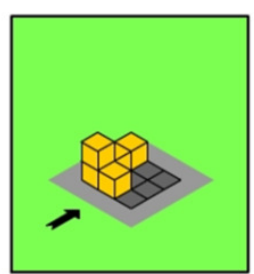

c)
Figura 59.-. Ejercicio Tipo 1: Bloques

(a) Pantalla 1: construye el modelo 3D.

(b) Pantalla 2: ejercicio propuesto.
Figura 60.-. Ejercicio Tipo 2: Vistas.

(a) Pantalla 1: construye el modelo 3D

(b) Pantalla 2: ejercicio propuesto.

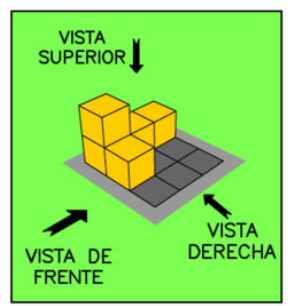

Figura 61.- Ayuda sobre vistas ortogonales normalizadas.

\subsubsection{Juego de móvil.}

El usuario del juego de móvil podrá realizar las siguientes operaciones:

- Realizar los ejercicios de entrenamiento presentes en el dispositivo. La aplicación dispone de forma local de una serie de ejercicios con el 
objetivo de practicar los tipos de ejercicios que tendrán que resolver en las competiciones.

- Descargar y realizar una competición. Para ello debe disponer de un usuario y contraseña que le permita validarse en el sistema. Sólo podrá realizar la misma competición una vez.

- Descargar nuevos ejercicios de entrenamiento si los hubiera.

- Enviar los resultados de una competición. Esta acción puede llevarse a cabo justo al finalizar la competición o posteriormente, en el caso de que se produjeran fallos de conexión o que el usuario decidiera enviar los resultados en otra sesión.

- Consultar la ayuda de la aplicación.

La Figura 62a muestra la pantalla inicial de la aplicación para móvil. La aplicación dispone de un acceso a la ayuda para conocer el funcionamiento del juego (ver Figura 62b). Los usuarios pueden realizar los ejercicios de entrenamiento disponibles localmente en la aplicación, con el objetivo de practicar los tipos de tareas que tendrán que resolver en las Competiciones (ver Figura 62c, d, e y f). Disponiendo de un usuario y contraseña que le permita validarse en el sistema pueden descargar y realizar Competiciones (ver Figura $62 \mathrm{~g} \mathrm{y} \mathrm{h}$ ). Cada ejercicio es evaluado cuando el usuario pulsa "siguiente", informando de si es correcto ó no: un punto si es correcto y cero si es incorrecto (ver Figura 62i y Figura 63j). El ejercicio lleva asociado una puntuación y el tiempo que se ha empleado en completar la actividad. Cuando finaliza la colección de ejercicios y, si existe una conexión activa, los resultados se envían al servidor (ver Figura $63 \mathrm{k} \mathrm{y} \mathrm{l),} \mathrm{donde} \mathrm{son} \mathrm{almacenados} \mathrm{en} \mathrm{la} \mathrm{base} \mathrm{de} \mathrm{datos} \mathrm{y} \mathrm{pueden} \mathrm{ser}$ consultados por el profesor.

Las especificaciones de hardware y software son enumeradas en la Tabla 21. Se utilizó un dispositivo HTC Touch para realizar las pruebas de la aplicación móvil.

Tabla 21.- Especificaciones del hardware y software

\begin{tabular}{ll}
\hline Aplicación & Especificaciones \\
\hline Dispositivo móvil & Procesador TI OMAP ${ }^{\mathrm{TM}}$ 850, 201 Mhz, 128 \\
& ROM, 64 MB SDRAM DDR \\
& Windows Mobile 6.0 \\
& Pantalla táctil, 2,8”, 240 x 320; \\
& Máquina virtual Jbed Smertec \\
\hline Aplicación de escritorio & Windows XP; 2.00GHz; 1 GB RAM; \\
& Máquina virtual Java; Máquina virtual Java 3D \\
\hline Servidor y base de datos & MySQL y Apache Tomcat \\
\hline
\end{tabular}


Z Construyendo con Bit \& $\& Y_{X}$ 标 $X$

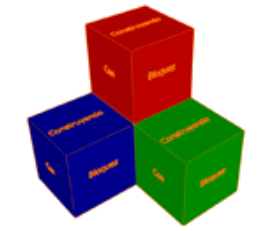

Construye modelos de bloques

A.ccede a ENTRENAMIENTO para practicar

Accede a COMPETICIÓN cuando estés preparado

LA TECLA CENTRRAL DEL TELÉFONO

te permite ver el modelo

Competición Menu

(a) Pantalla inicial

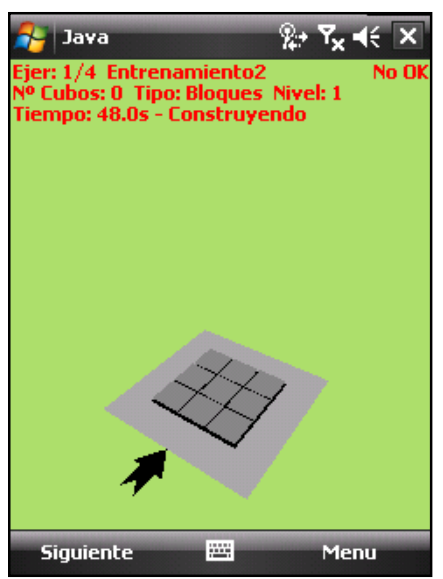

(d) Escena $3 D$ donde se resuelve el ejercicio

Z Validación $\quad \&+T_{x} \sqrt{x}$

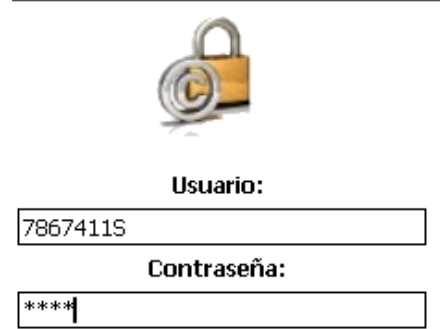

OK Atrás

(g) Interfaz de acceso

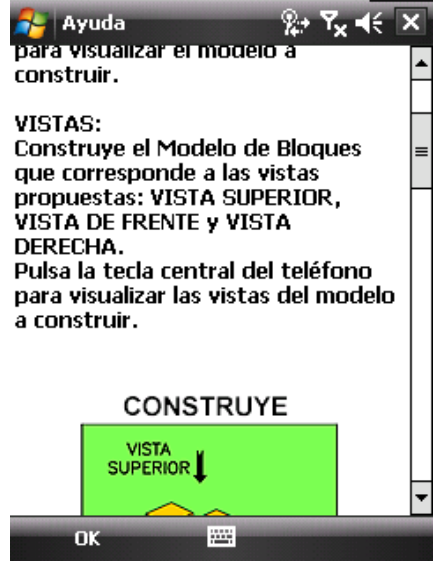

(b) Pantalla de Ayuda

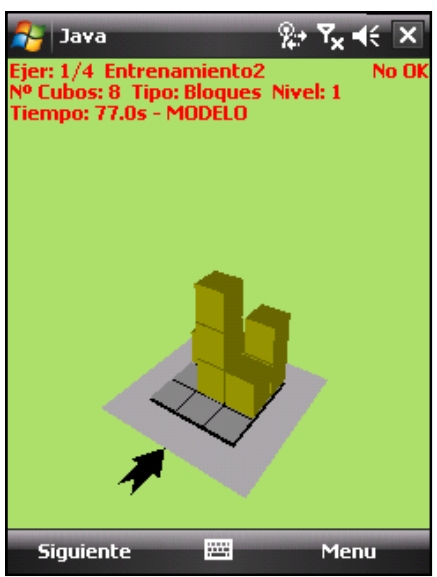

(e) Ejemplo de ejercicio Tipo 1

Z Modo competición \& $P_{x} \sqrt{x}$

Descargando ejercicio de competicion $6 / 10$

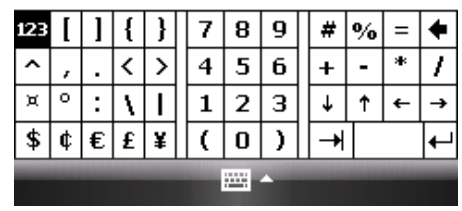

(h) Descarga de competición

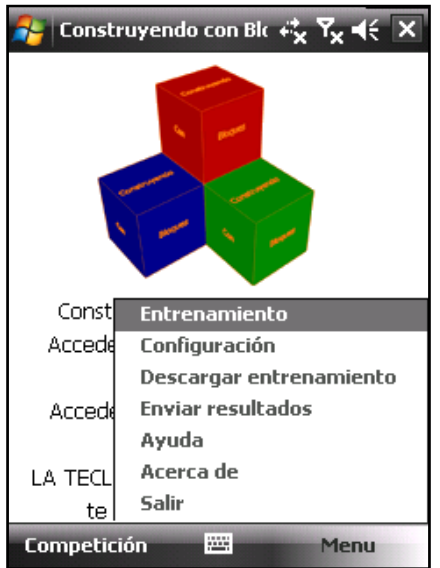

(c) Menú inicial

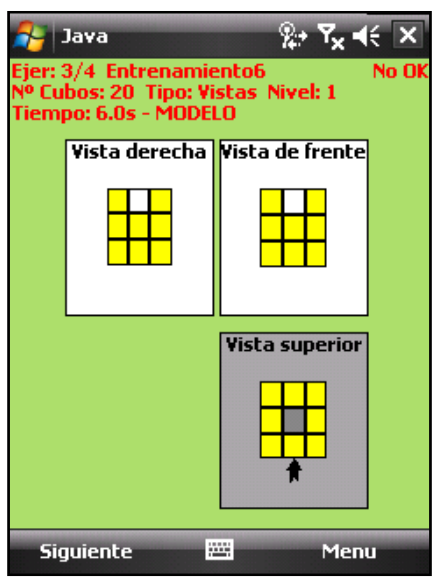

(f) Ejemplo de ejercicio Tipo 2

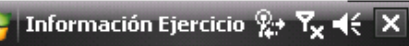

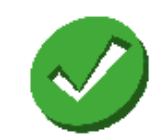

iGenial, Lo has hecho muy bien!

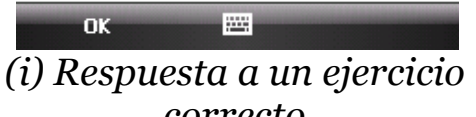

correcto

Figura 62.- Interfaz de la aplicación para móvil (I) 


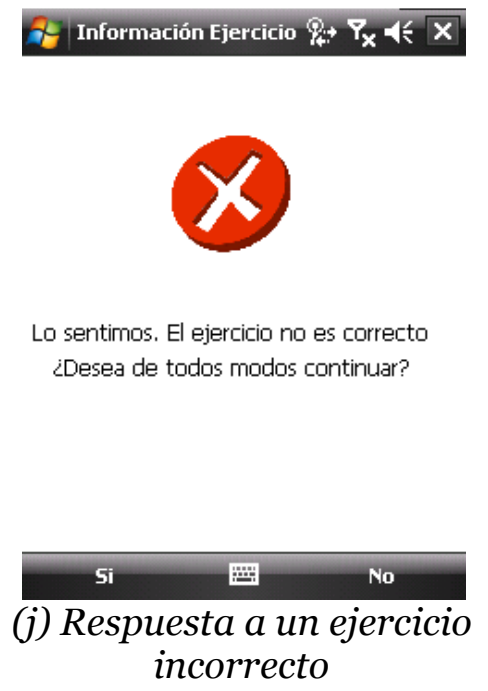

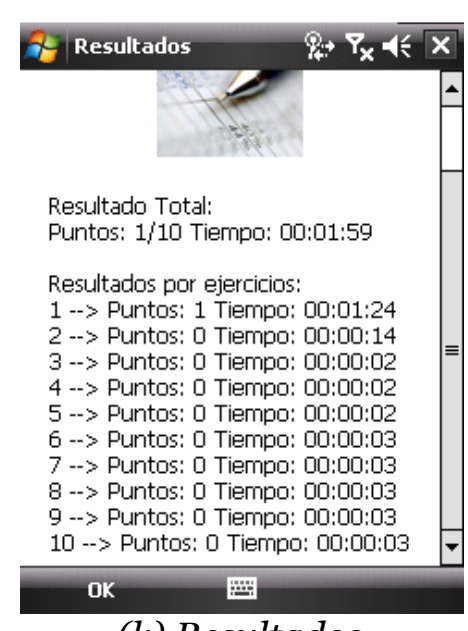

(k) Resultados

Figura 63.- Interfaz de la aplicación para móvil (II)

\section{Q Enviar resultados $\quad \& Y_{x} \Vdash x$}

1 competición enviada con éxito

\section{ok 甜}

(l) Respuesta a un envío de resultados exitoso

\subsubsection{Aplicación de servidor y base de datos}

Las aplicaciones tanto de móvil como de escritorio necesitan acceder a la base de datos (BD) para leer/escribir información en ella. Por motivos de seguridad y con el objetivo de evitar accesos indeseados a los datos, se ha desarrollado una aplicación servidor que hace de intermediario entre la base de datos y los clientes, atendiendo las peticiones y enviando las respuestas adecuadas. El flujo de información entre las aplicaciones se muestra en la Figura 64.

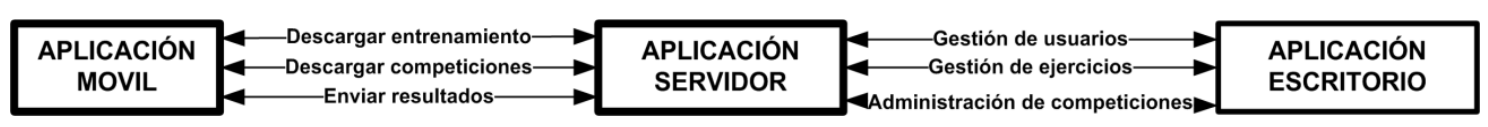

Figura 64.- Flujo de datos desde las aplicaciones al servidor.

En este proyecto la base de datos juega un papel importante debido a que controlar el flujo de información es un punto vital para un funcionamiento del óptimo. El sistema gestor de base de datos debe ser estable y garantizar la consistencia de los datos. Además debe permitir la concurrencia de acceso a los datos, de tal forma que permita varios accesos en el mismo instante de tiempo. La BD recogerá información de datos personales de los usuarios, ejercicios, entrenamientos, competiciones, resultados de las competiciones (fecha, calificación, tiempo, etc.). 
Todos los archivos de las aplicaciones, manuales de instalación y ayuda están disponibles en la web del Grupo de Investigación Dehaes ${ }^{22}$.

\subsection{Satisfacción de los usuarios con la aplicación para móvil}

\subsubsection{Introducción y objetivos}

El estudio de usabilidad permite obtener información objetiva y subjetiva del usuario, y comprobar si la aplicación evaluada resulta usable.

En este estado de desarrollo interesa conocer la experiencia de los usuarios con el juego, con el objetivo de detectar si es necesario invertir más recursos en la mejora de la aplicación. Se utilizaron distintas técnicas de medición de la usabilidad:

- los test con usuarios,

- los cuestionarios y,

- la grabación del uso (Logging).

De esta manera se analiza la aplicación y se explican los problemas de usabilidad que se derivan de las diferentes técnicas utilizadas.

Los objetivos de este proyecto son básicamente dos:

- Mejorar la experiencia del usuario con la aplicación.

- Detectar los problemas y errores de la aplicación y poder mejorarlos en futuras versiones.

\subsubsection{Materiales}

En el proceso de medición de la experiencia de los usuarios con la aplicación móvil se emplearon los siguientes materiales:

- Encuestas de perfil de usuarios, que se detalla en el Anexo XIX.

- Consentimiento informado, que se detalla en el Anexo XX.

- Instrucciones a los observadores, que se detalla en el Anexo XXI.

- Instrucciones a los usuarios, que se detalla en el Anexo XXII.

${ }^{22}$ http://www.degarin.com/moodle 
- Encuestas de satisfacción de usuarios, que se detalla en el Anexo XXIII.

- Laboratorio de usabilidad: Se utilizó una sala del Departamento de Expresión Gráfica en Arquitectura e Ingeniería como laboratorio para las pruebas, en la que se montó un ordenador portátil para monitorizar el uso de la aplicación y una cámara de video que grababa la sesión. El dispositivo móvil utilizado fue un HTC Touch y hay un "observador" que facilita los datos necesarios al usuario. La Figura 65 muestra un momento de la ejecución de los test. El Ordenador portátil graba la sesión de lo que ocurre en el dispositivo móvil, mediante la aplicación MyMobile23. Además la cámara de video graba la sesión, no sólo la interacción con la aplicación, sino las expresiones pronunciadas por el usuario. Esto nos permite recoger los datos de satisfacción, duda, frustración, etc., y utilizarlos para mejorar la aplicación.

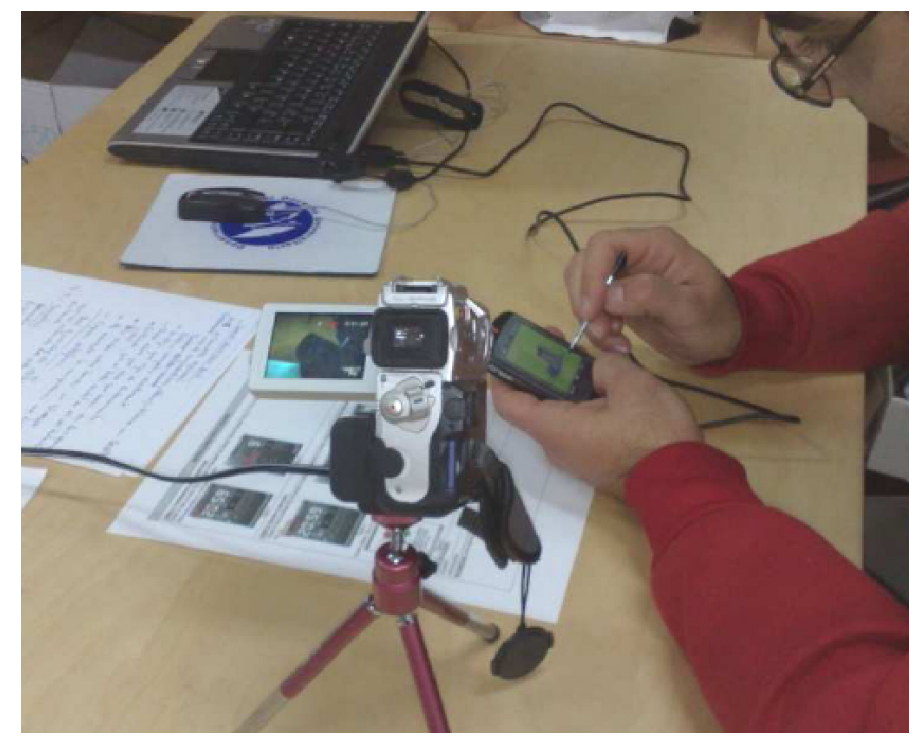

Figura 65.- Un usuario realizando el test de usabilidad

\subsubsection{Metodología de medición de la Usabilidad}

La metodología de medición de la usabilidad en este proyecto se ha llevado a cabo en distintas etapas (ver Figura 66):

${ }^{23}$ http://www.mtux.com/ 
ETAPA 1: Se establecieron los objetivos del proyecto, se montó el laboratorio de usabilidad y se decidieron las tareas a realizar por los usuarios.

ETAPA 2: Se administraron las encuestas de Perfil de Usuarios. En el Anexo XIX se reflejan las preguntas realizadas. Esta encuesta nos permite tener un datos del perfile de los usuarios (género, edad, titulación, uso de juegos, si ha cursado asignaturas de dibujo, etc).

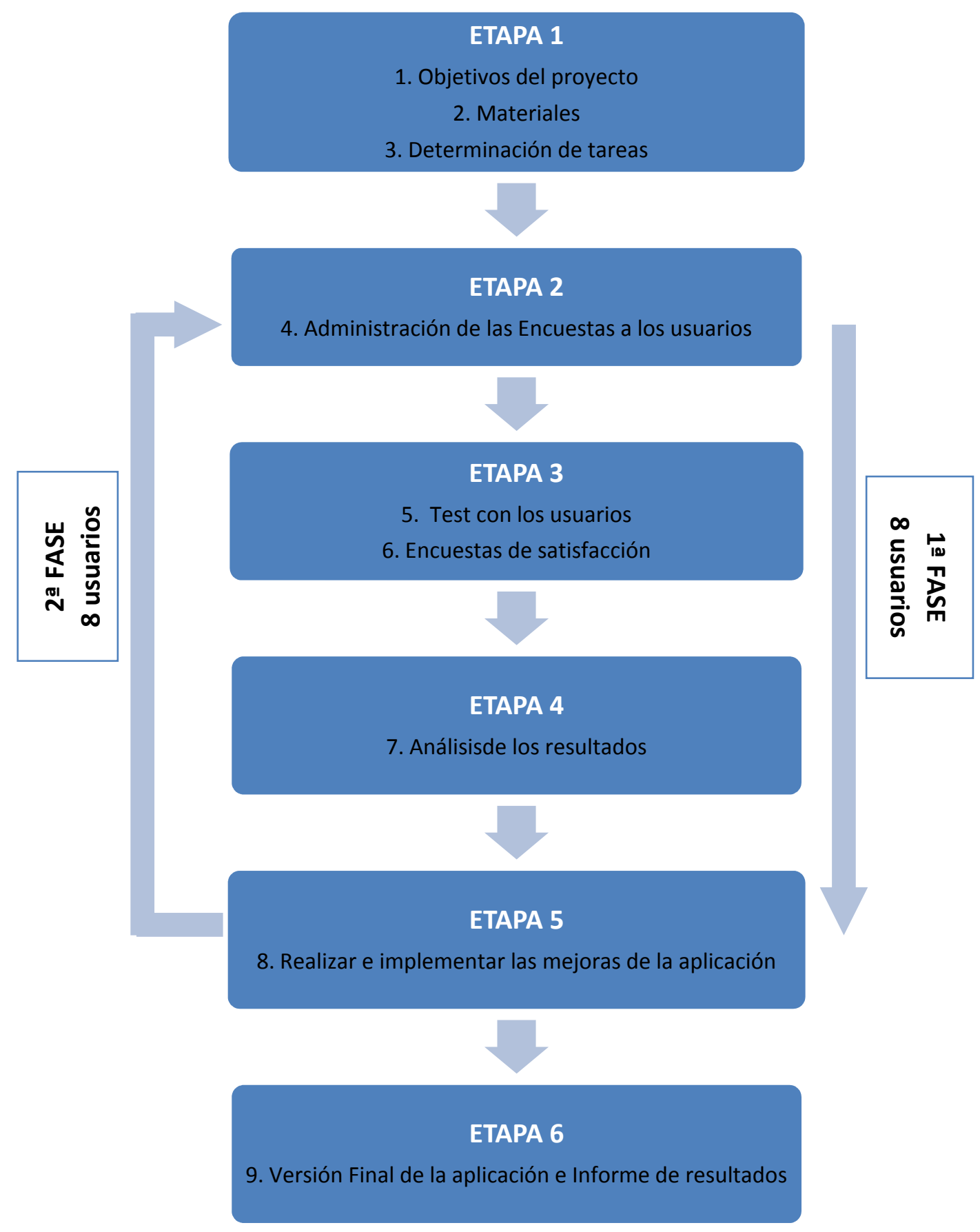

Figura 66.- Esquema de las etapas y fases del estudio de usabilidad 
ETAPA 3: Test de usabilidad. Se llevan a cabo los test de usabilidad con usuarios en el laboratorio, recogiendo los datos de monitorización de las tareas, la grabación de la sesión y la administración de las encuestas de satisfacción.

ETAPA 4: Análisis de resultados. Se realiza un análisis de los datos obtenidos de la etapa anterior, realizando un resumen de los problemas encontrados y proponiendo soluciones.

ETAPA 5: Mejoras de la aplicación. Se programan e implementan las soluciones propuestas en la etapa anterior.

ETAPA 6: Versión Final. Con las mejoras implementadas se obtiene una versión final de la aplicación.

\subsubsection{Fases de la evaluación}

La evaluación se desarrolló en dos fases: $1^{\mathrm{a}}$ y $2^{\mathrm{a}}$ fase (ver Figura 66). Cada fase de la evaluación involucró 8 estudiantes universitarios de titulaciones técnicas, con edades comprendidas entre 20-25 años. Se les administró una encuesta de datos, respecto al género, edad, titulación, uso de juegos, si ha cursado asignaturas de dibujo, etc. (ver Anexo XIX). Se elabora una primera versión de prueba que es evaluada por 8 usuarios. Con los errores detectados y las sugerencias realizadas, se elaboró una segunda versión, que de nuevo es evaluada por 8 usuarios. En la evaluación se utilizó un dispositivo HTC Touch (Tabla 20).

Los test con usuarios se han realizado en la última semana del mes de Noviembre de 2008. Los usuarios participaban en un seminario de libre elección de esta Universidad titulado "Uso y aplicaciones de los dispositivos móviles en Ingeniería Gráfica”, ofrecido en el curso 20082009 por el Departamento de Expresión Gráfica en Arquitectura e Ingeniería y reconocido con un crédito en su curriculum. Tuvieron una duración aproximada de una hora y media.

Para llevar a cabo este test se siguió el protocolo reflejado en el Anexo XXI. Se informa a los usuarios de los objetivos de este proyecto. Se les deja claro que se trata de evaluar la aplicación, que no se les está haciendo un test a ellos. Se les informa de que se va a grabar la sesión y que para darnos su aprobación, y si están de acuerdo, deben leer y después firmar el "Consentimiento Informado", que figura en el Anexo XX. 
Una vez que se comprueba han comprendido las instrucciones dadas, se les entrega el dispositivo HTC Touch y una hoja con las "Instrucciones para los Usuarios", que figuran en el Anexo XXII. Se les comunica además que es necesario que comenten en voz alta las sensaciones, dudas que vayan experimentando en el desarrollo de la sesión y con la interacción con la aplicación, que la sesión será grabada y que los datos serán utilizados para mejorar la aplicación. Se les avisa de que pueden realizar las preguntas que quieran, aunque no todas ellas podrán tener respuesta de forma inmediata porque pueden influir en el estudio, aunque se les sugiere que no duden en realizarlas.

Las instrucciones a los usuarios constan de dos tareas:

- TAREA 1: Se trata de familiarizarse con la pantalla táctil. Se le pide que accede al Navegador "Internet Explorer" y que vaya a la web de google (http://www.google.es ) y realice una búsqueda de un periódico y accedan a alguna de sus noticias.

- TAREA 2: Consiste en acceder a la aplicación. Desde el menú de Inicio accede a la aplicación Jbed y luego la aplicación "Construyendo con bloques".

La evaluación cuenta con un observador que graba la sesión, da de alta a los usuarios, activa las competiciones, anota las manifestaciones relevantes que emite el usuario y soluciona los problemas que surgieran si fuera necesario (Figura 65). Una vez acceden a la aplicación, interesa comprobar la reacción del usuario, sus dudas, la interacción con la aplicación, etc., por lo que el observador no da ninguna instrucción más a los usuarios sobre el uso de la aplicación móvil. Los usuarios deben realizar los cuatro ejercicios de entrenamiento disponibles en el dispositivo y dos competiciones (10 ejercicios tipo I y 10 ejercicios tipo II).

\subsubsection{Resultados}

\subsubsection{Primera fase (primera versión de la aplicación)}

Los usuarios rellenan el cuestionario de usabilidad, basado en el QUIS Questionnaire (Chin, Diehl, \& Norman, 1988), que utiliza una escala de 10 puntos (de o a 9). La Figura 67 presenta un resumen de los resultados de la encuesta, incluyendo la primera y la segunda versión de la aplicación. 
Los resultados de la primera fase permitieron detectar errores y mejorar la interfaz de la aplicación. Las puntuaciones más bajas se obtuvieron en los siguientes ítems:

- “Ayuda" (Figura 67, factor 9): los usuarios tienen indecisión al iniciar el juego. Nos parece importante destacar que aunque puedan tener dificultad para saber cómo funciona el juego, en general, no acceden al menú de Ayuda al iniciar la aplicación.

- "Facilidad de aprendizaje" (Figura 67, factor 10): los usuarios, en general, consideran que es un juego que no se podría utilizar sin instrucciones.

- "Velocidad del sistema" (Figura 67, factor 9): los usuarios estiman que el tiempo de paso de un ejercicio al siguiente debería ser más rápido y que el juego no les informa suficientemente de qué operación está realizando cuando terminan un ejercicio.

Con los datos obtenidos de esta primera prueba y después de analizar las grabaciones, las notas tomadas durante las sesiones, y las encuestas de usabilidad, se llevó a cabo una reunión del equipo de trabajo y se acordó tomar las medidas que se reflejan en la Tabla 22.

\subsubsection{Segunda fase (segunda versión de la aplicación)}

Se tarda aproximadamente tres semanas en implementar las mejoras propuestas para la aplicación móvil. Pasado este período comienza la segunda fase de sesiones con los últimos 8 usuarios.

Las mejoras de la aplicación provocan un aumento importante en la valoración del sistema de ayuda, de la facilidad de aprendizaje (aumenta 1,3 puntos) y de la velocidad de la aplicación (aumenta 2,5 puntos). La valoración global de la aplicación es de 7,3 sobre 9 puntos máximos. La Figura 67 muestra gráficamente estos datos.

En la encuesta de satisfacción, los usuarios valoraron positivamente tres aspectos fundamentalmente:

- El buen aspecto visual y la facilidad para interactuar con la aplicación mediante la pantalla táctil y el puntero (8,3 de 9).

- Lo consideran un juego entretenido. El nivel de entusiasmo con el que lo recomendarías a sus compañeros fue de 4,9 de 5 puntos en una escala de Likert.

- Respecto al entrenamiento espacial, estiman que puede ser un buen sistema para la mejora de la capacidad espacial, obteniendo 7,95 
puntos de media en la valoración del ítem $\mathrm{n}^{0} 4$ (Interesante: bajo-alto) de la encuesta de satisfacción. Hay que hacer notar que esto es una apreciación subjetiva de los usuarios.

Los aspectos negativos que destacaron iban orientados a la posibilidad de la utilización de botones gráficos, en lugar de los accesos por menús.

Tabla 22.- Problemas encontrados en la $1^{\text {a }}$ Fase y medidas a adoptar

\begin{tabular}{|c|c|}
\hline PROBLEMA & MEDIDAS A ADOPTAR \\
\hline $\begin{array}{l}\text { Los usuarios parecían tener } \\
\text { indecisión al iniciar el juego. No } \\
\text { suelen acceder a la Ayuda, por lo que } \\
\text { parece complicado que sepan los } \\
\text { modos de juego. La mayoría tiene } \\
\text { dificultad para encontrar el botón } \\
\text { central del teléfono. }\end{array}$ & $\begin{array}{l}\text { Mejorar la AYUDA de la aplicación. } \\
\text { En la pantalla inicial se colocan } \\
\text { instrucciones básicas: } \\
\text { Accede al Modo Entrenamiento para } \\
\text { practicar } \\
\text { Accede al Modo Competición para } \\
\text { comenzar } \\
\text { Pulsa la tecla central del teléfono para } \\
\text { ver el modelo } \\
\text { Accede al menú para ver Ayuda }\end{array}$ \\
\hline $\begin{array}{l}\text { Normalmente los usuarios no van al } \\
\text { menú Comprobar, sino que pasan al } \\
\text { siguiente ejercicio. Entienden que la } \\
\text { aplicación les debería decir si el } \\
\text { ejercicio está bien o mal. } \\
\text { Los usuarios piensan que el paso de } \\
\text { un ejercicio a otro es un poco lento y } \\
\text { que no les informa por ejemplo con } \\
\text { un cartel que diga cargando. }\end{array}$ & $\begin{array}{l}\text { La actitud de los usuarios respecto a } \\
\text { estos dos aspectos nos hizo replantear } \\
\text { la forma de pasar de un ejercicio a } \\
\text { otro. Se decidió que cuando el usuario } \\
\text { pasara al siguiente ejercicio, la } \\
\text { aplicación comprobara si el ejercicio } \\
\text { era correcto. Si es correcto le informa } \\
\text { al usuario de que el ejercicio es } \\
\text { correcto. Si no es correcto, le pregunta } \\
\text { al usuario si quiere continuar. }\end{array}$ \\
\hline $\begin{array}{l}\text { El tiempo comienza a contar antes de } \\
\text { que se cargue el ejercicio. }\end{array}$ & $\begin{array}{l}\text { Se soluciona modificando el código de } \\
\text { la aplicación. }\end{array}$ \\
\hline $\begin{array}{l}\text { Los conceptos de Alzado, Planta y } \\
\text { Perfil no son familiares para los } \\
\text { usuarios de titulaciones no técnicas. }\end{array}$ & $\begin{array}{l}\text { Se modifica la denominación de las } \\
\text { vistas, cambiándolas a Vista de Frente, } \\
\text { Vista de Arriba y Vista Derecha. }\end{array}$ \\
\hline
\end{tabular}


CAPÍTULO V: DISEÑO, IMPLEMENTACIÓN Y EVALUACIÓN DE UNA ARQUITECTURA..

\section{MEDIDA DE LA SATISFACCIÓN DEL USUARIO CON LA APLICACION MOVIL}

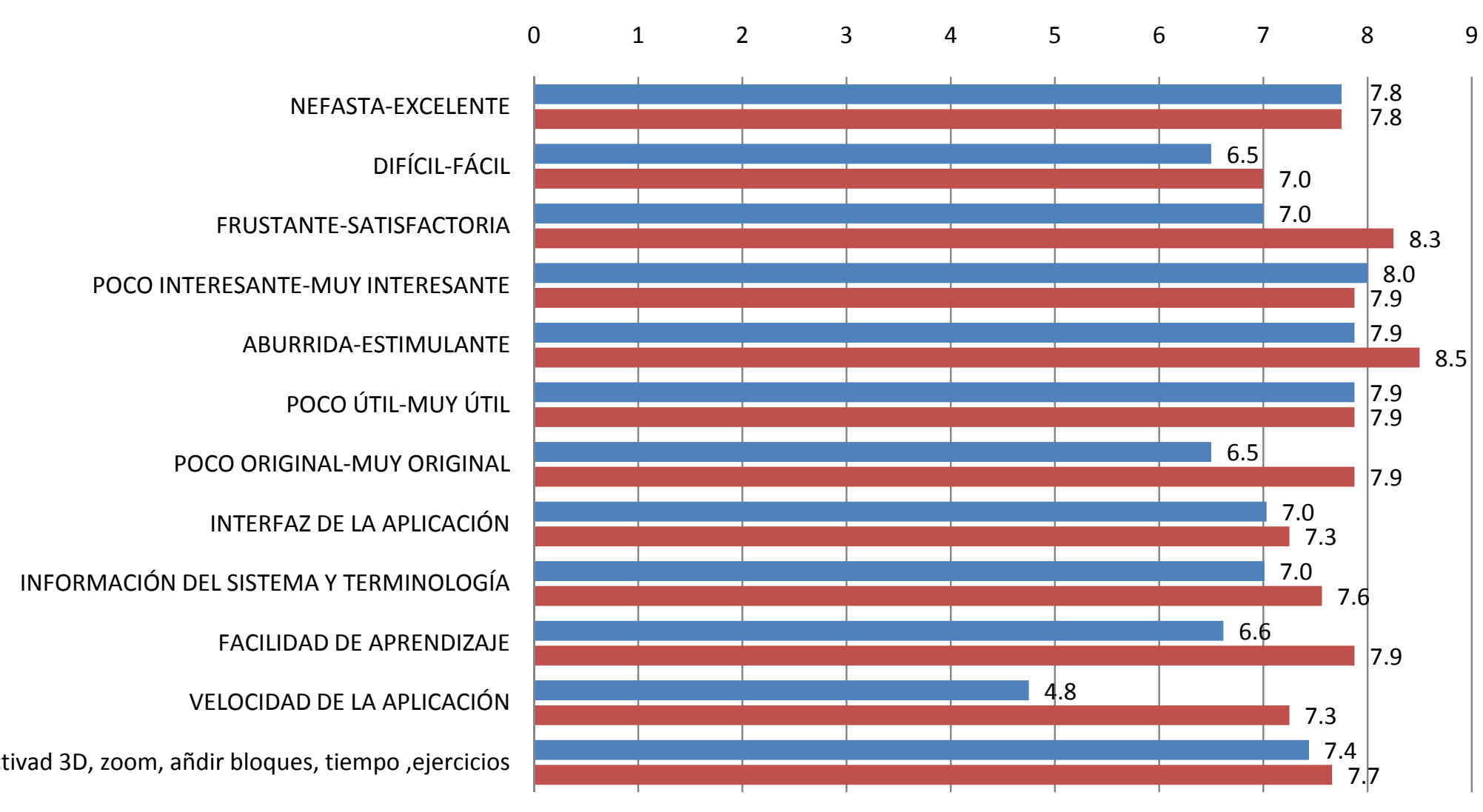

च 1ㄹ PRUEBA DE USABILIDAD $n=8$ 2a PRUEBA DE USABILIDAD $n=8$

Figura 67.- Medida de la satisfacción de usuarios 


\subsection{Estudio preliminar del efecto de la aplicación desarrollada sobre la mejora de las HHEE}

\subsubsection{Introducción}

A continuación se detalla el trabajo de campo llevado a cabo al inicio del curso 2009 con la aplicación descrita en los apartados anteriores y con el objetivo de explorar su efecto sobre las habilidades espaciales.

Se plantea como un estudio preliminar porque la tipología de ejercicios disponibles (sólo 2 tipos: tipo vistas y tipo bloques) no permite realizar un curso intensivo con la suficiente duración para que pueda aproximarse a los "entrenamientos de corta duración" (de 6 a 8 horas) que habitualmente se realizan.

Los objetivos concretos de esta investigación son los siguientes:

1. Explorar los efectos que sobre las habilidades espaciales tiene la instrucción realizada con la aplicación "Construyendo con bloques".

2. Valorar la satisfacción de los usuarios con la aplicación.

\subsubsection{Materiales}

En el estudio de campo se utilizaron dispositivos HTC Touch Cruise, con las características detalladas en la Tabla 23. La Figura 68 presenta el aspecto de la aplicación ejecutándose en el dispositivo.

Tabla 23.- Características del hardware del HTC Touch Cruise y del software instalado

Procesador Qualcomm MSM 7225, 528

Mhz, 512 ROM

256 RAM

Windows Mobile 6.1

Pantalla táctil, 2,8”

Resolución QVGA 240 x 320

Máquina virtual Jbed Smertec, versión WM 6.1

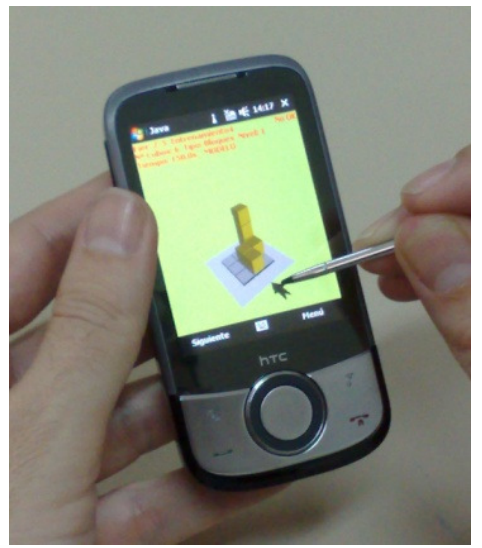

Figura 68.- La aplicación ejecutándose en un dispositivo HTC Touch Cruise 


\subsubsection{Procedimiento}

En la primera semana del curso 2009-2010 se administran el test MRT (pre-test) a 289 estudiantes de las titulaciones de Ingeniería Técnica de Obras Públicas, Ingeniería Técnica Industrial Mecánica y Electrónica de la Universidad de La Laguna.

Se selecciona un grupo de estudiantes de entre los que presentan puntuaciones bajas en el test, concretamente los que están cercanos a la media de la población menos una desviación típica.

Este estudio utilizó dos grupos de trabajo: un grupo experimental y un grupo de control. El grupo experimental lo forman 26 estudiantes (17 hombres y 9 mujeres), que voluntariamente realizan el programa de entrenamiento. El grupo de control, formado por 21 estudiantes (11 hombres y 9 mujeres), no se somete al programa de entrenamiento durante la semana que dura este estudio. Los participantes tienen una media de edad de 18,46 años y 1,45 de desviación típica.

El Grupo experimental, dividido en dos subgrupos, lleva a cabo el entrenamiento durante la segunda y tercera semana del curso, según el programa de actividades detallado en la Tabla 22. El programa de entrenamiento se ha desarrollado en formato no presencial, durante una semana. Cada día se programó una competición, cuatro en total durante cuatro días. El último día El Grupo Experimental rellena la encuesta de satisfacción. La cuarta semana se administra el post-test sólo al Grupo Experimental y al Grupo de Control.

\subsubsection{Ejercicios}

Se han programado cuatro competiciones, de 10 ejercicios cada una. Dos competiciones tipo bloques y dos competiciones tipo vistas. Tras la respuesta a cada ejercicio el usuario recibe un feedback inmediato de la precisión de su respuesta (acierto/error). Si la respuesta no es correcta el usuario puede optar por solucionar correctamente la tarea. La tabla 2 muestra detalladamente las actividades desarrolladas en la semana del entrenamiento. 
Tabla 24.- Sumario de actividades realizadas en este estudio

\begin{tabular}{|c|c|c|}
\hline Semana & Día & Actividades \\
\hline \multirow[t]{2}{*}{1} & Lunes & Inicio del curso \\
\hline & & $\begin{array}{l}\text { Pre-test y Encuesta de perfil de usuarios (grupo } \\
\text { experimental) }\end{array}$ \\
\hline \multirow[t]{7}{*}{2 y 3} & Lunes & $\begin{array}{l}\text { Entrega de los dispositivos y explicación de la } \\
\text { programación del curso (grupo experimental) }\end{array}$ \\
\hline & & Competición 1: tipo bloques \\
\hline & Martes & Competición 2: tipo bloques \\
\hline & Miércoles & Competición 3: tipo vistas \\
\hline & Jueves & Competición 4: tipo vistas \\
\hline & Viernes & Entrega de los dispositivos \\
\hline & & $\begin{array}{l}\text { Encuesta de satisfacción de usuarios (grupo } \\
\text { experimental) }\end{array}$ \\
\hline 4 & $\begin{array}{l}\text { Lunes y } \\
\text { Martes }\end{array}$ & Post-test (grupo experimental) \\
\hline
\end{tabular}

El tiempo medio dedicado al entrenamiento con la aplicación fue de 1,5 horas, distribuidos en cuatro días. Este tiempo recoge la suma de las cuatro competiciones programadas, almacenada en la base de datos.

\subsubsection{Resultados}

La Tabla 25 muestra las puntuaciones medias obtenidas por los 289 estudiantes testeados a principio del curso (pre-test). La puntuación media de la población estudiada fue de 19,98 (s.d.= 8,18) en el MRT. Además se reflejan las puntuaciones en el test MRT, antes y después del entrenamiento para el Grupo Experimental y de Control.

Tabla 25.- Resumen descriptivo de las variables

\begin{tabular}{lcccc}
\hline & & \multicolumn{3}{c}{ MRT } \\
\cline { 3 - 5 } & & $\begin{array}{c}\text { Pre-MRT } \\
\text { (s.d.) }\end{array}$ & $\begin{array}{c}\text { Post-MRT } \\
\text { (s.d.) }\end{array}$ & $\begin{array}{c}\text { Ganancia } \\
\text { MRT } \\
\text { (s.d.) }\end{array}$ \\
\hline Población total 2009 & $\mathrm{n}=289$ & $\begin{array}{c}19,98 \\
(8,18)\end{array}$ & - & - \\
Grupo Experimental & $\mathrm{n}=26$ & $\begin{array}{c}11,12 \\
(2,90)\end{array}$ & $\begin{array}{c}19,12 \\
(6,45)\end{array}$ & $\begin{array}{c}8,00 \\
(5,80)\end{array}$ \\
\cline { 2 - 5 } Grupo de Control & $\mathrm{n}=18$ & $\begin{array}{c}11,28 \\
(5,42)\end{array}$ & $\begin{array}{c}14,67 \\
(5,40)\end{array}$ & $\begin{array}{c}3,39 \\
(3,57)\end{array}$ \\
\cline { 2 - 5 } & & & &
\end{tabular}

Con el objetivo de evaluar si existen diferencias entre los participantes en este estudio, por grupos (experimental vs control) en los niveles de habilidades espaciales, medidos con el MRT, se realiza una T-Student de 
series independientes (con aproximación de Welch). Para el pre-MRT se encuentra que no existen diferencias significativas entre los grupos de entrenamiento (experimental vs control), $\mathrm{T}(21,24)=0,037, \mathrm{p}-$ valor $<0,971$. Esto permite comparar los grupos de estudio.

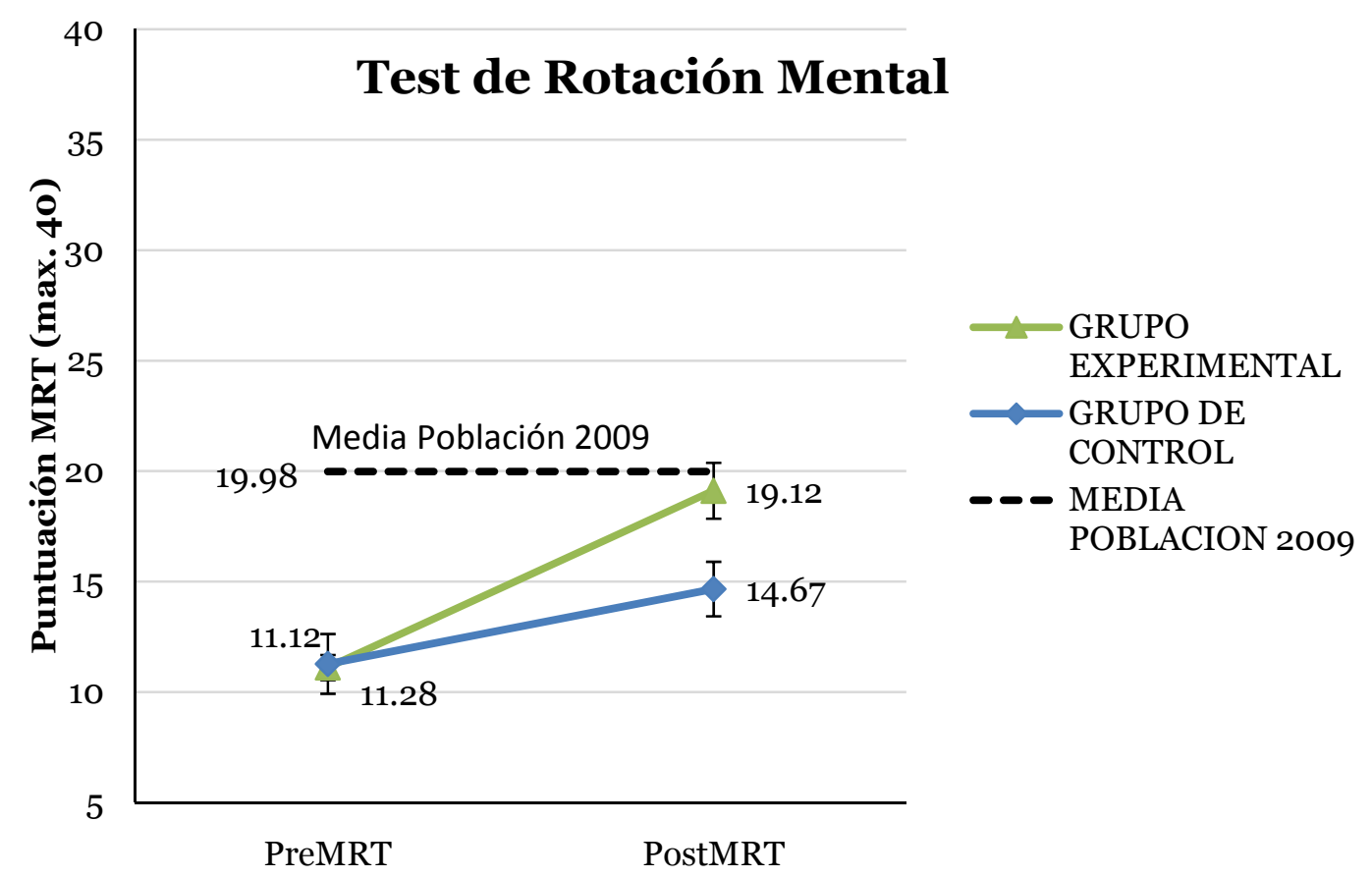

Figura 69.- Puntuaciones medias del pre- y post-test para el grupo Experimental y de Control $(n=44)$

La Figura 69 muestra las puntuaciones medias obtenidas en el pre-test por el Grupo Experimental y de Control.

Con el objetivo de evaluar si existe un aumento significativo en los niveles de HHEE del grupo Experimental respecto del grupo de Control, se lleva a cabo igualmente una T-Student de series independientes. Se encuentran diferencias significativas entre los grupos (experimental vs control), T(41) $=2,908$, p-valor $=0,006$. La ganancia media del Grupo Experimental es significativamente distinta a la del Grupo de Control.

\subsubsection{Evaluación de la Satisfacción de los usuarios}

Al finalizar el entrenamiento se administró una encuesta con el objetivo de que se valorara la experiencia de los participantes con el 
entrenamiento. Una selección de las preguntas se muestran a continuación. La encuesta completa se puede consultar en el Anexo XXIV.

El 80\% valora como Buena o Excelente su experiencia con el teclado y la pantalla táctil. En cambio entorno al 40\% valora como Regular o Mala la red Wi-Fi del dispositivo (ver Figura 70).

En su gran mayoría, los participantes consideran que la aplicación puede ser una buena herramienta para la mejora de las HHEE. El 100\% recomendaría el curso a sus compañeros (ver Figura 71).

Respecto a los contenidos del curso y su dificultad, los usuarios valoran el contenido como claro, entendible y de resolución asequible (ver Figura 72).

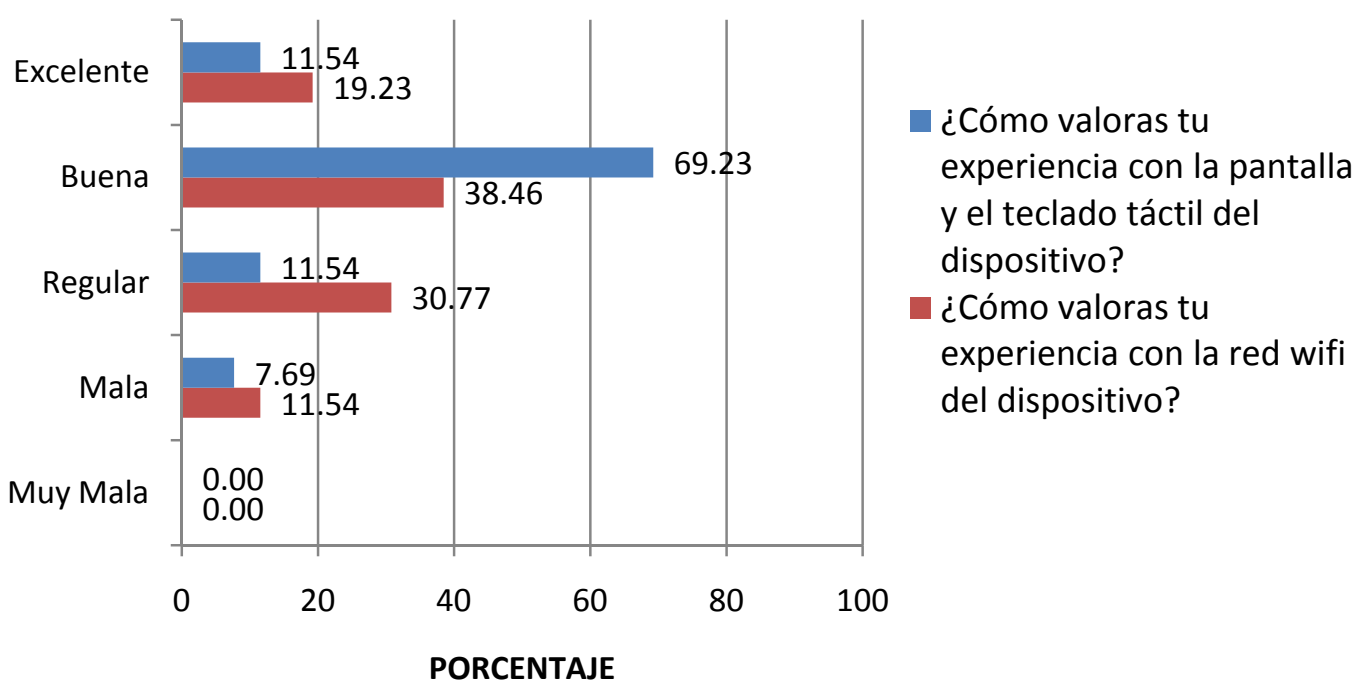

Figura 70.- Valoración de los participantes de la experiencia con el aparato

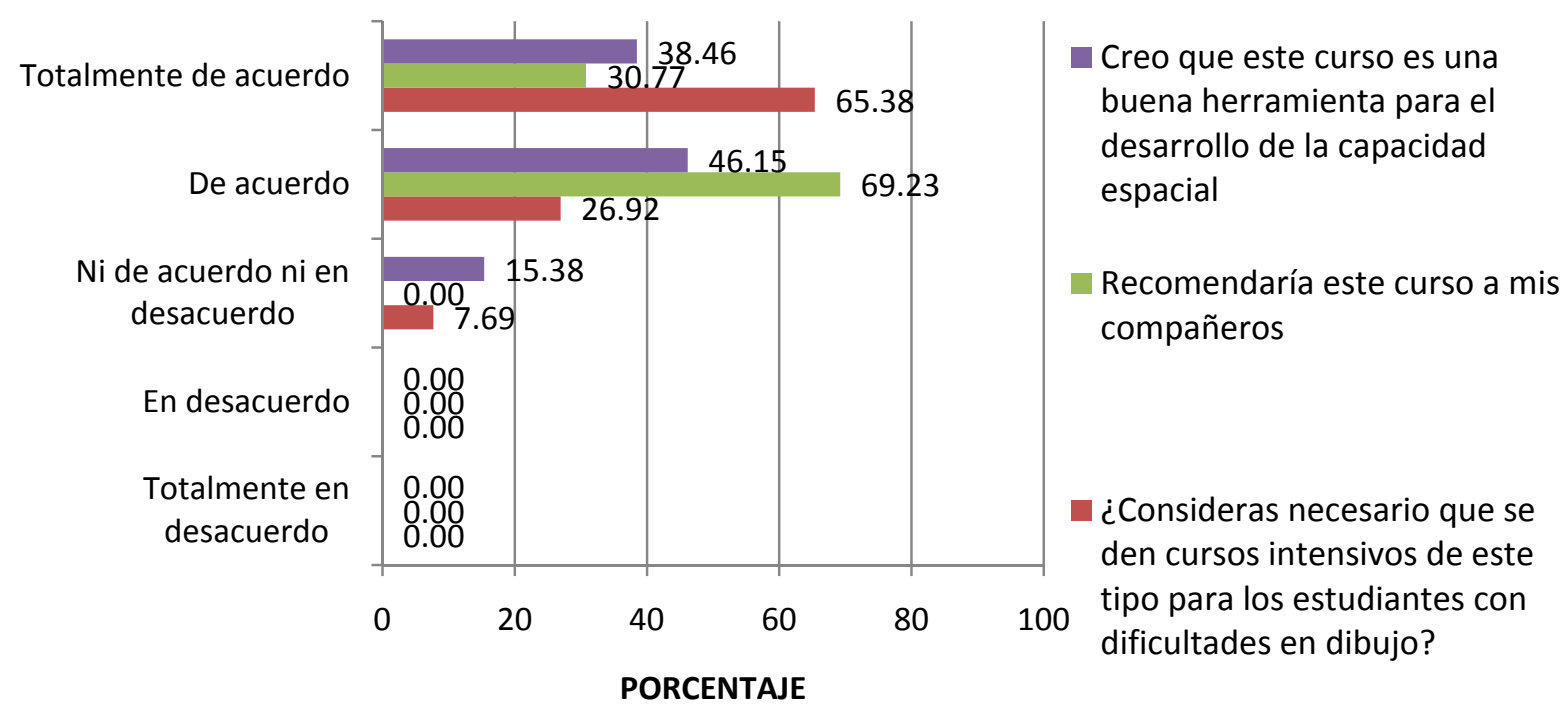

Figura 71.- Valoración de los participantes del contenido del curso (I) 


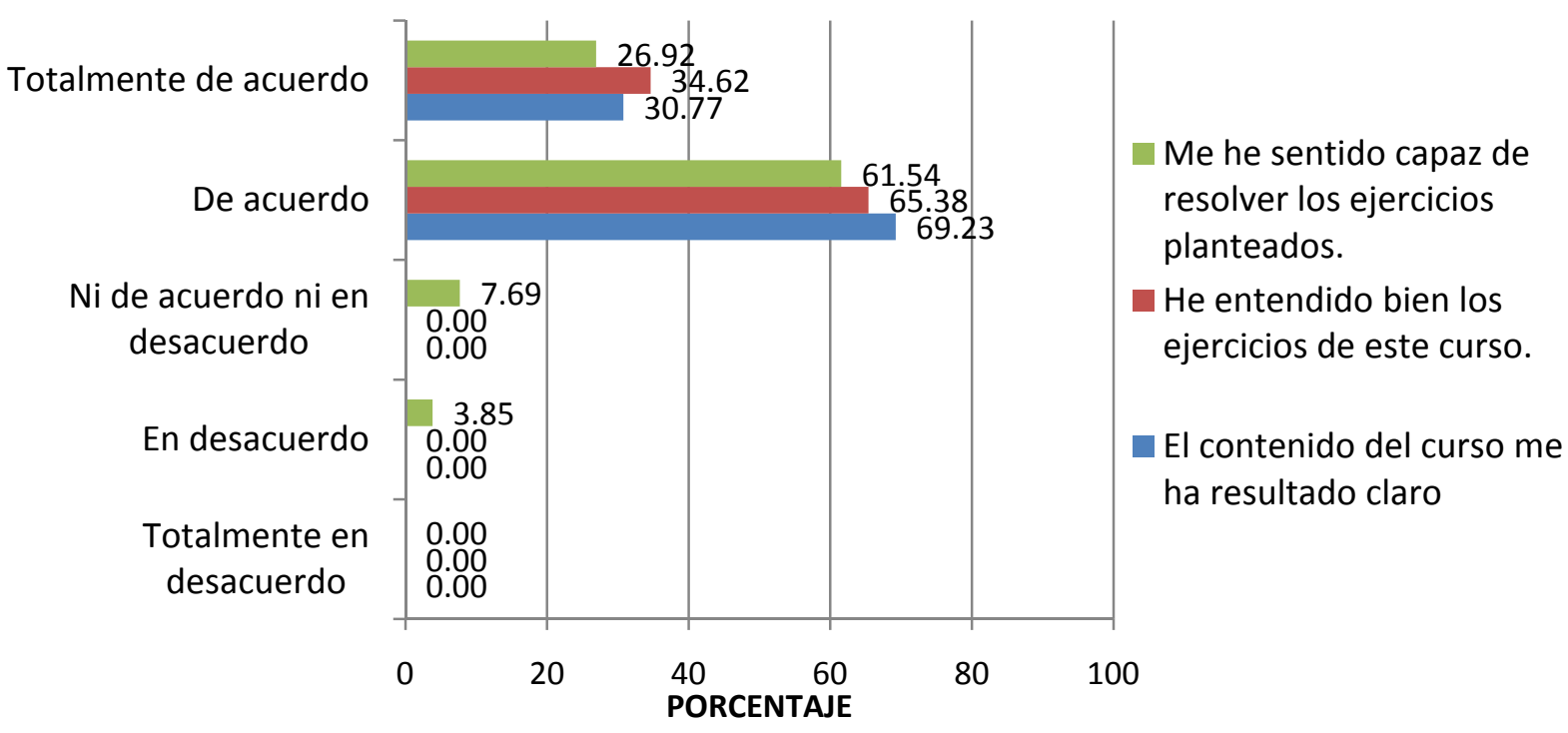

Figura 72.- Valoración de los participantes del contenido del curso (II)

La interacción con el entorno $3 \mathrm{D}$, la ayuda y la interfaz ha sido valorada por aproximadamente el $70 \%$ con tres o cuatro puntos (de Confusa $=0$ a Clara $=4)$ (ver Figura 73).

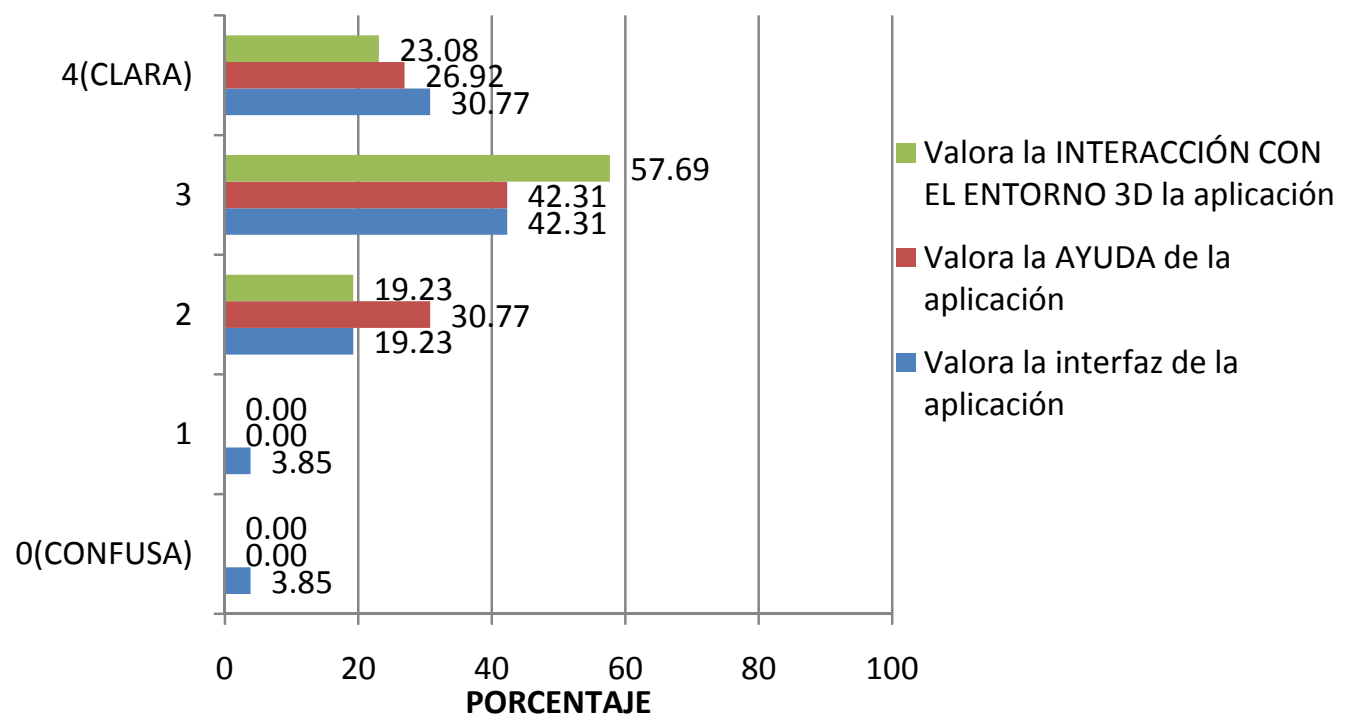

Figura 73.- Valoración de los participantes de su experiencia con la aplicación 
Se les ha preguntado respecto del formato en el que preferirían realizar este curso. Sólo el 3,85\% considera los ejercicios en papel. Hay que destacar que se les pregunta por un curso cómo el que están desarrollando, por lo que parece probable esta respuesta.

Respecto a su preferencia por un curso a distancia o presencial, aproximadamente el 10\% prefiere el formato presencial (ver Figura 74).

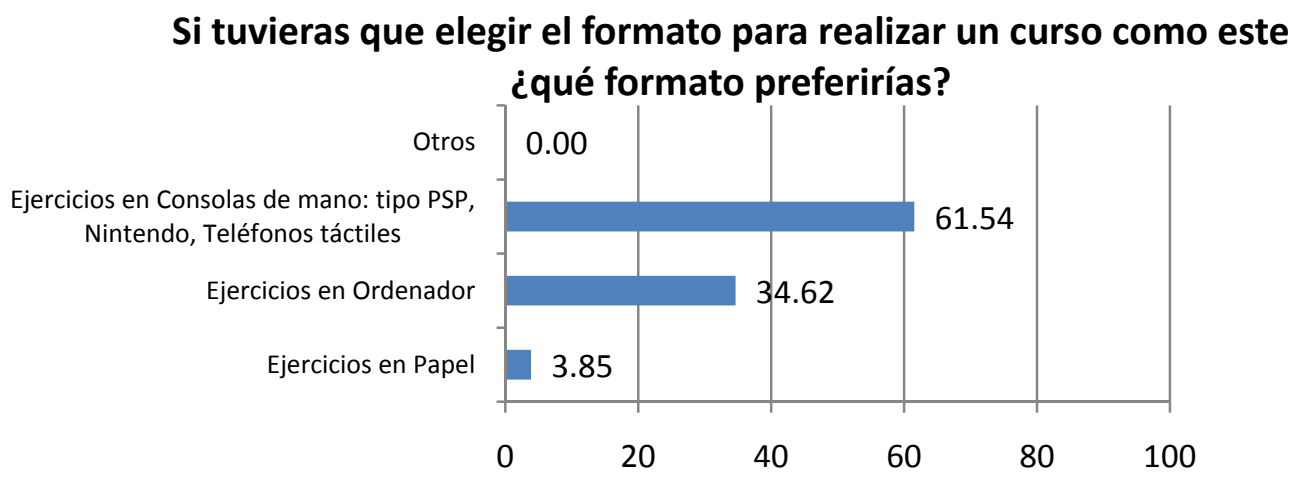

Me hubiera gustado realizar este curso con asistencia del profesor.

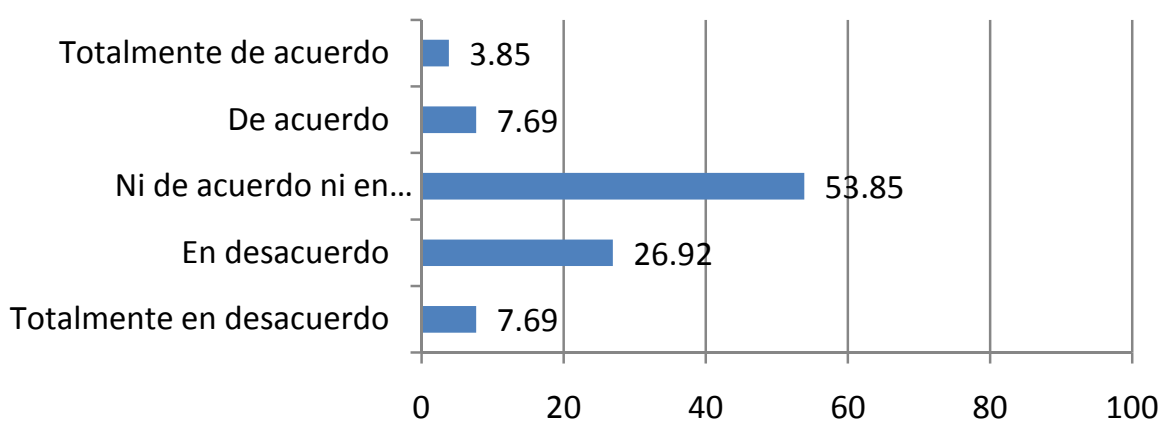

Figura 74.- Valoración de los participantes del formato del curso

Se les pidió que valoraran globalmente la aplicación y el curso desarrollado, en una escala de o a 4 puntos, en distintos aspectos. La Figura siguiente muestra los datos. En todos los ítems preguntados más del 70\% de los usuarios valoran con una puntuación de 3 ó 4 puntos (ver Figura 75). 


\section{VALORACION GLOBAL}

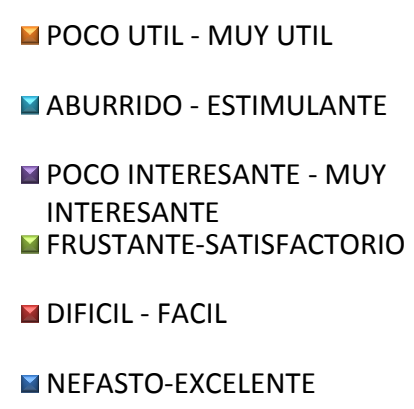

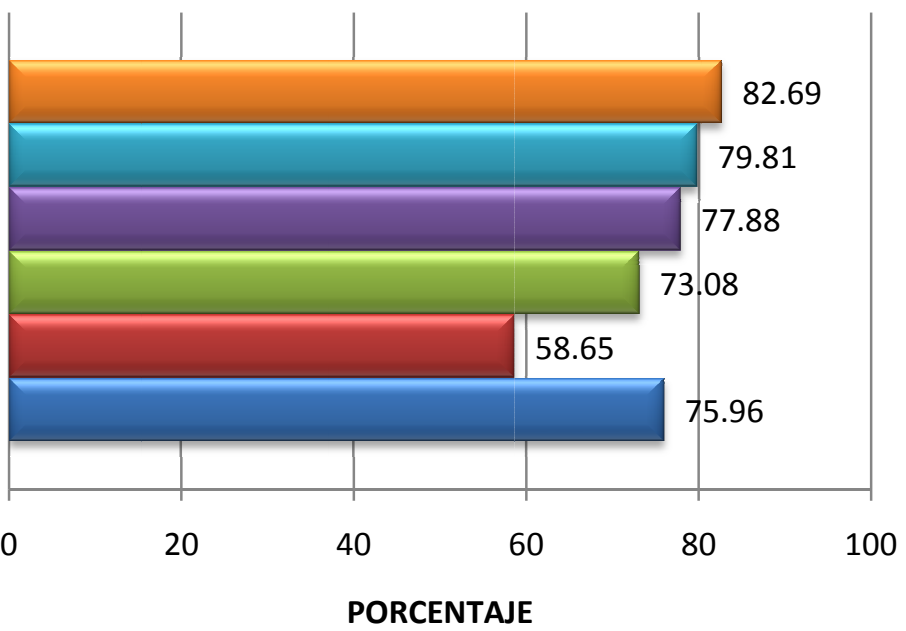

Figura 75.- valoración global del curso

La Figura 76 muestra los tiempos medios dedicados a cada competición.

\section{TIEMPOS MEDIOS EN LAS COMPETICIONES}

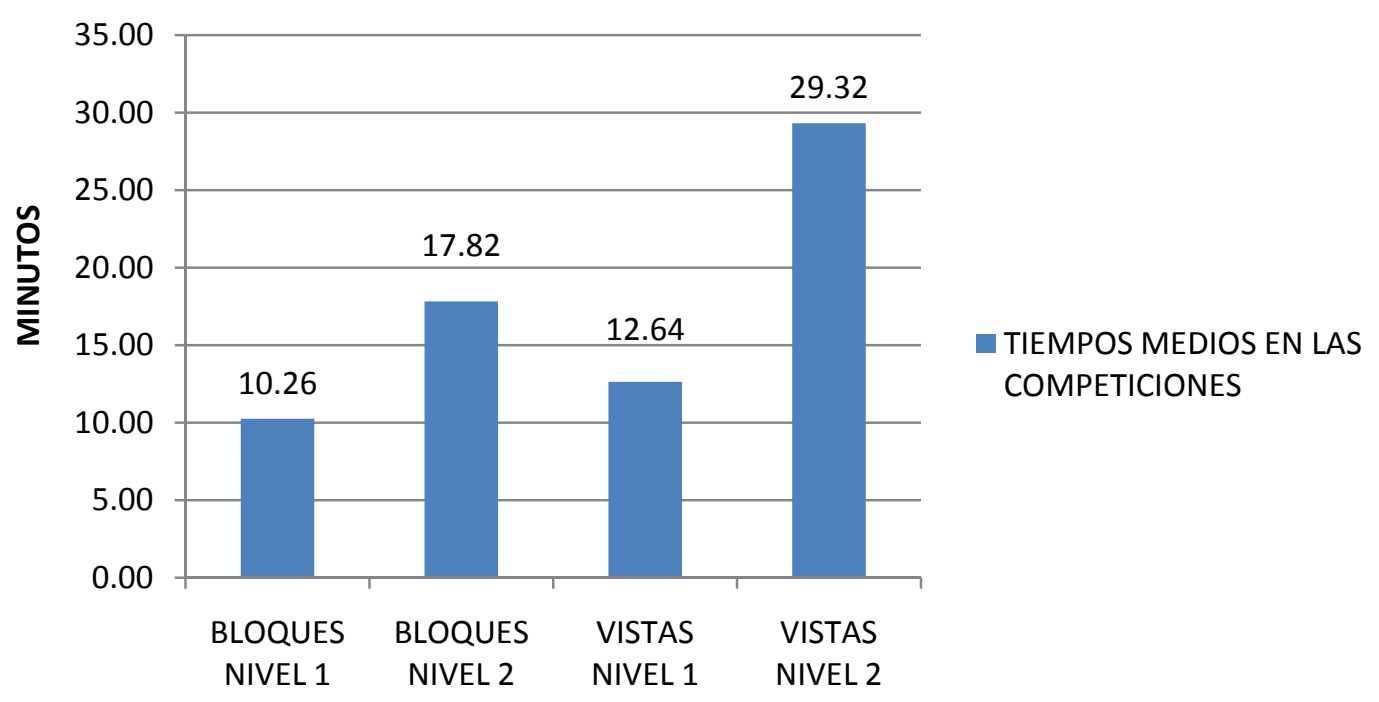

Figura 76.- Tiempos medios de cada Competición 


\subsubsection{Conclusiones}

El análisis estadístico indica que la aplicación tiene un efecto positivo en la mejora de las HHEE, lo que sienta las bases para poder abordar en futuros trabajos la programación de nuevas tipologías de ejercicios que permitan llevar a cabo un estudio de campo que valide la herramienta.

La valoración global de los usuarios fue positiva. Consideran mayoritariamente que los dispositivos móviles y los cursos a distancia son un buen formato para realizar este tipo de entrenamiento, lo que anima a continuar en el desarrollo de materiales en este ámbito.

Como se ha comentado en la introducción, este trabajo aborda un estudio preliminar debido a que la limitación de las tipologías de ejercicios y de la duración del curso no permiten obtener resultados comparables con otros "cursos intensivos de corta duración”.

\subsection{Resumen}

El trabajo descrito en el Capítulo $\mathrm{V}$ de esta tesis, aborda el diseño y la implementación de la arquitectura de un sistema para la instrucción de las habilidades espaciales formado por 4 componentes: (1) una aplicación de escritorio, (2) una aplicación 3D para dispositivos móviles de pantalla táctil, (3) una aplicación servidor y (4) una base de datos. Además se realiza la evaluación de dos versiones de prueba de la aplicación móvil. La novedad de este sistema es que se ha diseñado y testeado una aplicación para teléfonos móviles de pantalla táctil, que nos permite la construcción de modelos de cubos en un entorno tridimensional, y que ha sido desarrollada para el sistema operativo Windows Mobile. Finalmente, se realiza un estudio de campo que permite obtener conclusiones preliminares que apuntan en la dirección de que esta aplicación mejora las habilidades espaciales de los estudiantes sometidos a un entrenamiento específico.

Teniendo en cuenta estas consideraciones y las respuestas dadas por los usuarios en las encuestas de satisfacción, se puede concluir lo siguiente:

- La aplicación para dispositivos móviles fue agradable para los usuarios, provocando satisfacción y la manifestación de que la recomendarían a sus compañeros. La aplicación móvil recibe una 
valoración global de 7,3 puntos sobre 9. Se valora positivamente la interacción con el escenario $3 \mathrm{D}$ a través de la pantalla táctil $(8,3$ sobre 9). Preguntados específicamente sobre el grado de entusiasmo con el que la recomendarían a sus compañeros, valoran este apartado con 4,9 puntos sobre 5 en una escala de Likert.

- El 90\% de los usuarios que participan en esta prueba reconocen que esta aplicación puede servir para la mejora de las habilidades espaciales en estudiantes de carreras técnicas.

- El desarrollo de este tipo de aplicaciones puede ayudar a desarrollar capacidades en un contexto de aprendizaje no formal, que tiene las ventajas de no estar limitado a lugares o tiempos específicos y de permitir mayor flexibilidad.

A partir del trabajo realizado en las sesiones presenciales grabadas y de las respuestas dadas por los usuarios en las encuestas de satisfacción, podemos realizar una serie de recomendaciones respecto al diseño de este tipo de juegos educativos:

- Claridad: Los ejercicios que el usuario deba realizar deben ser claramente explicados al comienzo, con ejemplos prácticos. En nuestro proyecto hemos dedicado mucho tiempo a la mejora del sistema de ayuda y hemos visto que es un punto importante que puede llevar al éxito o al fracaso a una herramienta de este tipo. La utilización del modo entrenamiento se ha mostrado como un sistema adecuado para aliviar el proceso de familiarizarse con el juego.

- Retroalimentación (feedback): Que el usuario disponga de un feedback inmediato en las tareas que realiza, ha sido una mejora que se ha introducido en la segunda versión de este juego y que ha sido valorada muy positivamente por los usuarios.

- Nivel de dificultad: los niveles de dificultad deben cambiar de acuerdo con el aumento en el nivel de habilidad del jugador. Todos los usuarios han considerado que la distribución de los ejercicios estaban de acuerdo a su nivel de dificultad. La gráficas que muestran los tiempos dedicados por los usuarios en cada una de las tareas nos permiten poder realizar una distribución de los ejercicios de menor a mayor grado de dificultad.

- Sistema de puntuaciones (records): La utilización de un sistema de puntuaciones (records) parece crear un cierto nivel de competitividad. En las sesiones realizadas, todos los usuarios 
preguntaban acerca del ranking mostrado por la aplicación en el modo entrenamiento.

Es importante destacar que las pruebas con usuarios han demostrado que nuestro sistema es fiable (estable), puesto que no se han presentado errores, ni en el trabajo con las aplicaciones de móvil o de PC, ni en las conexiones con el servidor.

Finalmente, el estudio preliminar llevado a cabo en el ámbito de la mejora de las habilidades espaciales indica que la aplicación tiene un efecto positivo. La valoración global de los usuarios fue positiva.

Este trabajo abre nuevos retos para futuras investigaciones ligadas al sistema creado:

- Elaborar una batería amplia de ejercicios con los que realizar una programación competiciones.

- Evaluar y valorar la sobrecarga de los usuarios respecto al número de ejercicios y grado de dificultad de las competiciones.

- Elaborar nuevos tipos de ejercicios.

- Tomar una muestra amplia de estudiantes para comprobar mediante los test (MRT and DAT:SR) si la aplicación mejora las habilidades espaciales.

- Realizar pruebas de usabilidad con estudiantes de secundaria.

- Abordar la implantación de la aplicación móvil en otros sistemas operativos, como el iPhone OS, el Symbian o el Android. 

Capítulo VI: Conclusiones y futuros trabajos

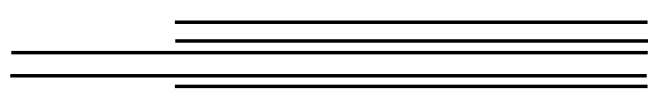





\subsection{Introducción}

Al iniciar esta tesis nos planteábamos una serie de objetivos generales, con el propósito de responderlos con el trabajo de investigación realizado. Aprovechamos esta introducción para recordarlos y así poder evaluar mejor las conclusiones obtenidas:

- Elaborar nuevas herramientas que puedan contribuir al desarrollo de las habilidades espaciales.

- Proponer estas herramientas en forma de "cursos intensivos de corta duración" o "cursos cero" a los estudiantes en los que se detecte niveles más bajos de habilidades espaciales.

- Aportar nuevos formatos e interfaces de usuario (dispositivos móviles de pantalla táctil) con la finalidad de utilizarlos como un instrumento motivador

- Explorar la utilización de la educación a distancia para los cursos de mejora de las habilidades espaciales.

Teniendo en cuenta esto, se han estructurado las conclusiones en el siguiente apartado.

\subsection{Conclusiones}

\subsubsection{Conclusiones sobre la utilización del modelado 3D como herramienta de mejora de las HHEE}

Desde la experiencia en el diseño y la evaluación del curso intensivo para la mejora de las habilidades espaciales mediante modelado 3D, descrito en el Capítulo III de esta tesis, se puede concluir que:

- El desarrollo de las habilidades espaciales se puede mejorar con un programa de entrenamiento específico. El programa de actividades detallado en este estudio, utilizando el software SketchUp, ha demostrado ser una buena opción, según los resultados obtenidos y el análisis realizado.

- Los cursos intensivos de mejora de las habilidades espaciales, de 6 a 12 horas de duración, pueden proporcionar un importante aumento de los niveles de capacidad de visión espacial. La ganancia media en el curso intensivo con SkecchUp fue de alrededor de 5 puntos en el MRT y de 8 puntos en el DAT-SR, que se puede comparar con los 8 puntos 
en el MRT y 9 puntos en el DAT-SR alcanzados al final de un cuatrimestre, tras cursar una asignatura de Expresión Gráfica.

- Con un entrenamiento específico, como el que aquí describimos, tanto hombre como mujeres tienen un aumento medio similar en ambos test.

Podemos concluir que esta investigación demostró que el curso descrito en este trabajo es una opción válida para poner en marcha un curso de mejora de las habilidades espaciales, en forma de "Curso Intensivo" o "Curso Cero". Esto permitiría elevar el nivel medio de habilidades espaciales a los estudiantes con mayores dificultades a su entrada en la Universidad.

Además, se abren nuevas expectativas para la utilización de estas herramientas, en estudiantes más jóvenes, de etapas educativas previas a la Universidad, como en la Enseñanza Secundaria Obligatoria (ESO), Bachiller, módulos profesionales, etc.

\subsubsection{Conclusiones sobre la utilización de los contenidos Web interactivos sobre dispositivos móviles de pantalla táctil como herramienta de la mejora de las HHEE.}

Desde la experiencia en el diseño y la evaluación de un curso web, optimizado para dispositivos de pantalla táctil, y utilizado en la mejora de las habilidades espaciales, descrito en el Capítulo IV de esta tesis, se puede concluir que:

\section{Respecto a la mejora de las HHEE:}

Este curso web, diseñado y evaluado sobre dispositivos iPod Touch, y desarrollado en un formato de enseñanza a distancia (on-line), ha demostrado, mediante el análisis estadístico detallado en el apartado anterior, que:

- Para los valores iniciales de HHEE, medidos con el test MRT (PreMRT), las mujeres tienen una puntuación media más baja que los hombres. Este dato coincide con los estudios iniciales de los creadores de este Test y con otros trabajos recogidos en la literatura científica.

- Además, los resultados demuestran que, con un entrenamiento específico, hombres y mujeres alcanzan una ganancia media similar en 
el test MRT. A pesar de las diferencias iniciales existentes entre hombres y mujeres, ambos logran aumentar entorno a 8 puntos en el Test MRT.

- Que la ganancia media que obtiene el grupo experimental frente al grupo de control, depende del valor del PreMRT. Así, por ejemplo, si la puntuación inicial en el test (PreMRT) de un individuo es igual a 10 puntos, la ganancia media experimentada es de 9,256 puntos superior en el grupo que realiza el entrenamiento frente a los individuos que no realizan entrenamiento espacial (ver Ecuación 3). Si la puntuación obtenida por un individuo en el PreMRT fuera de 30 puntos, la ganancia media se reduce a 2,116 puntos. Esto concuerda con los hallazgos obtenidos en otras investigaciones: los individuos con puntuaciones iniciales altas tienen poco margen para poder experimentar un aumento. Aquellos alumnos que tienen valores iniciales bajos tienen más capacidad de mejora.

\section{Respecto a la satisfacción del usuario con el dispositivo utilizado}

- La satisfacción global con el dispositivo utilizado ha sido valorada por el 91,43\% como BUENA o MUY BUENA. La pantalla táctil y la navegación por Internet ha sido lo mejor valorado, mientras que la red Wi-Fi ha sido lo peor valorado, debido fundamentalmente a problemas encontrados por los estudiantes en los puntos de acceso de las redes domésticas.

\section{Respecto a la satisfacción global del usuario con el curso web desarrollado}

- El curso ha sido valorado globalmente por los estudiantes considerando, el 75\% que están satisfechos con el curso (4 puntos) y el $25 \%$ restante está totalmente satisfechos (5 puntos), en una escala de Likert de cinco puntos.

- Además casi la totalidad de los estudiantes lo recomendarían a sus compañeros.

- Aproximadamente el 90\% puntúa la presentación y la estructura del material didáctico del curso entre 4 y 5 puntos. A pesar de que valoran algunos módulos cómo los que presentan mayor dificultad, el $90 \%$ manifiestan sentirse capaces de resolver las tareas que se le plantean. 
- El 94,45\% está de acuerdo en que el curso ofrece un contenido útil y al $75 \%$ le gustaría disponer de material didáctico de este tipo de apoyo a la docencia en las asignaturas de su titulación.

\section{Respecto a las preferencias de formato para realizar el curso web desarrollado}

- Respecto a las preferencias de formato para realizar este curso, destacamos que sólo el 26,47\% estaría de acuerdo o totalmente de acuerdo en realizar este curso en el formato de lápiz y papel. Entorno al 90\% preferiría hacerlo en ordenador y el $80 \%$ en dispositivos de mano (móviles, consolas, etc.).

\section{Respecto a las preferencias del usuario con la accesibilidad del curso web desarrollado}

- El 80,55\% está de acuerdo o totalmente de acuerdo en que es importante poder acceder a contenidos de este tipo dónde y cuándo quiera.

- Es de destacar que sólo el 5,56\% está de acuerdo en realizar este curso con asistencia del profesor.

\subsubsection{Conclusiones sobre el diseño, implementación y evaluación de la arquitectura de un sistema para el entrenamiento espacial.}

El trabajo descrito en el Capítulo V de esta tesis, aborda el diseño y la implementación de la arquitectura de un sistema para el entrenamiento espacial formado por 4 componentes: (1) una aplicación de escritorio, (2) una aplicación 3D para dispositivos móviles de pantalla táctil, (3) una aplicación servidor y (4) una base de datos. Además se realiza la evaluación de dos versiones de prueba de la aplicación móvil. La novedad de este sistema es que se ha diseñado y testeado una aplicación que utiliza un entorno tridimensional y la construcción con cubos sobre dispositivos móviles de pantalla táctil, un formato novedoso en el campo de la mejora de las HHEE. 
A partir del trabajo realizado en las sesiones presenciales grabadas y de las respuestas dadas por los usuarios en las encuestas de satisfacción, podemos realizar una serie de recomendaciones respecto al diseño de este tipo de juegos educativos:

- Claridad: Los ejercicios que el usuario deba realizar deben ser claramente explicados al comienzo, con ejemplos prácticos. En nuestro proyecto hemos dedicado mucho tiempo a la mejora del sistema de ayuda y hemos visto que es un punto importante que puede llevar al éxito o al fracaso a una herramienta de este tipo. La utilización del modo entrenamiento se ha mostrado como un sistema adecuado para aliviar el proceso de familiarizarse con el juego.

- Retroalimentación (feedback): Que el usuario disponga de un feedback inmediato en las tareas que realiza, ha sido una mejora que se ha introducido en la segunda versión de este juego y que ha sido valorada muy positivamente por los usuarios.

- Nivel de dificultad: los niveles de dificultad deben cambiar de acuerdo con el aumento en el nivel de habilidad del jugador. Todos los usuarios han considerado que la distribución de los ejercicios estaban de acuerdo a su nivel de dificultad. La gráficas que muestran los tiempos dedicados por los usuarios en cada una de las tareas nos permiten poder realizar una distribución de los ejercicios de menor a mayor grado de dificultad.

- Sistema de puntuaciones (records): La utilización de un sistema de puntuaciones (records) parece crear un cierto nivel de competitividad. En las sesiones realizadas, todos los usuarios preguntaban acerca del ranking mostrado por la aplicación en el modo entrenamiento.

Es importante destacar que las pruebas con usuarios han demostrado que nuestro sistema es fiable (estable), puesto que no se han presentado errores, ni en el trabajo con las aplicaciones de móvil o de PC, ni en las conexiones con el servidor.

El estudio preliminar realizado al comienzo del curso académico 20092010, apunta en la dirección de que esta aplicación mejora las habilidades espaciales de los estudiantes de ingeniería. La valoración global de los usuarios fue positiva. Consideran mayoritariamente que los dispositivos móviles y los cursos a distancia son un buen formato para realizar este tipo de entrenamiento, lo que anima a continuar en el desarrollo de materiales en este ámbito. 


\subsection{Futuros trabajos}

Después de realizar esta tesis, aparecen en el horizonte nuevas líneas de investigación que complementarían los resultados obtenidos en este trabajo, pero que quedan fuera del objeto de ella. Se enumeran estructuran estas futuras líneas de investigación en tres campos:

\section{Diseño de cursos intensivos de corta duración:}

La experiencia descrita en el Capítulo III de esta tesis permite plantear nuevos ámbitos de trabajo:

- Elaborar un estudio de la satisfacción de los estudiantes con los cursos intensivos de corta duración desarrollados, valorando qué tipología de cursos gusta más a los estudiantes.

- Diseñar de nuevos cursos en ordenador que utilicen otras tecnologías, como por ejemplo la Realidad Aumentada.

- El curso intensivo desarrollado ha demostrado que, tanto el modelado $3^{\mathrm{D}}$ de piezas físicas como la realización de ejercicios más tradicionales (construcción de modelos a partir de una perspectiva en papel o a partir de las vistas diédricas), mejora las habilidades espaciales. En este sentido, parece interesante plantear un análisis de cuáles de estos ejercicios son más efectivos en el proceso de desarrollo de las habilidades espaciales.

\section{Utilización de las tecnologías móviles para el desarrollo de las HHEE:}

- Creemos que el desarrollo de material didáctico optimizado para dispositivos móviles con propósitos educativos es gratificante y estimulante. Creemos que es necesario continuar el desarrollo de materiales de este tipo que aporten movilidad a los estudiantes y que abran nuevas posibilidades de adaptar el aprendizaje a la forma de ser de los estudiantes.

- En el ámbito del desarrollo de aplicaciones con gráficos 3D en dispositivos móviles, se presentan distintos campos de trabajo, como continuación del trabajo descrito en el Capítulo V de esta tesis: 
$\checkmark$ Abordar la implantación de la aplicación móvil en otros sistemas operativos, como el Symbian, el Android o el iPhone OS.

$\checkmark$ Elaborar nuevos tipos de ejercicios.

$\checkmark$ Elaborar una batería amplia de ejercicios con los que realizar una programación competiciones con la aplicación desarrollada.

$\checkmark$ Evaluar y valorar la sobrecarga de los usuarios respecto al número de ejercicios y grado de dificultad de las competiciones.

$\checkmark$ Realizar pruebas con estudiantes de niveles educativos previos a la Universidad.

$\checkmark$ Evaluar la aplicación de escritorio desarrollada. 

Referencias

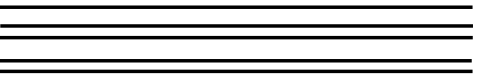



Adobe. (2009). Adobe. Recuperado en Mayo de 2009, de http://www.adobe.com/products/creativesuite/

Alcina, M. W. (Ed.). (Febrero de 2009). Impacto del Apple iPhone entre sus competidores. Connect , 20-23.

Alexeev, V. (2001-2009). Impossible world. Obtenido de http://im-possible.info/english/

Alias, M., Black, T., \& Gray, D. E. (2002). Effect of instruction on Spatial Visualization Ability in civil Engineering Students. International Education Journal , 3 (1), 1-12.

Alias, M., Gray, D., \& Black, T. R. (2002). Attitudes towards sketching and drawing and the relationship with spatial visualization ability in engineering students. International Education Journal , 3 (3), 165-175.

Amory, A., Naicker, K., Vincent, J., \& Adams, C. (1999). The Use of Computer Games as an Educational Tool: Identification of Appropriate Game Types and Game Elements. British Journal of Educational Technology , 30 (4), 311-321.

Andrade, J. (2009). Engadget en español. Recuperado en Junio de 2009, de http://es.engadget.com/2009/03/19/la-gran-comparacion-de-lossistemas-operativos-moviles/

Andrés Pueyo, A. (2001). Manual de psicología diferencial. Madrid: McGraw Hill.

Andrés Pueyo, A., \& Jayme Zaro, M. (1998). La inteligencia de los hombres y las mujeres. Mundo científico (196), 63-77.

Apple. (2008). QuickTime Pro. Recuperado en Mayo 2009, de http://www.apple.com/es/quicktime/download/.

Attewell, J. (2003). Mobile Learning. Literacy Today , 14.

Ault, H. (2003). A comparison of solid modelling curriculum approaches. Proceedings of the 2003 American Society for Engineering Education Annual Conference \& Exposition. American Society for Engineering Education.

Autodesk Corporation. (2009). Autodesk. Recuperado en May de 2009, de http://usa.autodesk.com/adsk/servlet/index?siteID=123112\&id $=2704278$. 
Barr, R., \& Juricic, D. (1994). From drafting to modern design representation: The evolution of engineering design graphics. Journal of Engineering Education, 81 (1), 26-29.

Basham, K. L. (2007). The Effects of 3-Dimensional CADD Modeling Software on the development of spatial ability of ninth grade technology discovery students. Mississippi.

Ben-Chaim, D., Lappan, G., \& Hougang, R. (1998). The effect of instruction on spatial visualization skills of middle school boys and girls. American Educational Research Journal , 25, 51-71.

Bennett, G., Seashore, H., \& Wesman, A. (2000). DAT 5: Tests de aptitudes diferenciales. Madrid: TEA Ediciones.

Boytchev, P., Chehlarova, T., \& Sendova, E. (2007). Enhancing Spatial Imagination of Young Students by Activities in $3 \mathrm{D}$ Elica Applications. 36th Spring Conference of the Union of Bulgarian Mathematicians, (págs. 109-119). Varna, Bulgaria.

Bravo-García, M., Hernández-Cordovez, J., Sánchez-Berriel, I. (2008). Construyendo con bloques: Juego 3D para la mejora de las Habilidades Espaciales en Dispositivos Móviles usando J2ME (Proyecto fin de carrera).

Burnet, S., \& Lane, D. (1980). Effects of academic instruction on spatial visualization. Intelligence , 4, 233-242.

Carrol, J. (1993). Human cognitive abilities: A survey of factor-analytic studies. New York: Cambridge University Press.

Chen, C., \& Chung, C. (2008). Personalized mobile English vocabulary learning system based on item response theory and learning memory cycle. Computers \& Educations , 51 (2), 624-645.

Chester, I.R. (2006). Delineating and developing expertise en three dimensional computer aided design. Master Thesis, Universidad de Newcastle.

Chin, J., Diehl, V., \& Norman, K. (1988). Development of an Instrument Measuring User Satisfaction of the Human-Computer Interface. Proceedings of the SIGCHI Conference on Human Factors in Computing Systems, 213-218.

Chris, E. (2008). The effectiveness of m-learning in the form of podcast revision lectures in higher education. Computers \& Education , 50 (2), 491-498. 
Christian Hoff, C., Wehling, U., \& Rothkugel, S. (2008). From Paper-andPen Annotations to Artefact-based Mobile Learning. Journal of Computer Assisted Learning .

Christou, C., Jones, K., Pitta-Pantazi, D., Pittalis, M., Mousoulides, N., Matos, J., y otros. (2007a). Developing student spatial ability with $3 \mathrm{D}$ software applications. 5th Congress of the European Society for Research in Mathematics Education (CERME). 22-26 Feb. Larnaca, Cyprus,.

Christou, C., Pittalis, M., Mousoulides, N., Pitta, D., Jones, K., Sendova, E., y otros. (2007b). Developing an Active Learning Environment for the Learning of Stereometry. 8th International Conference onTechnology in Mathematics Teaching (ICTMT8), July 1-4. Hradec Králové, Czech Republic.

Clements, D., \& Battista, M. (1992). Geometry and Spatial Reasoning. In A. E. Kelly, \& R. A. Lesh, Handbook of Research on Mathematics Teaching and Learning (pp. 420-464). New York: Macmillan Publishing Company.

Clough, G., Jones, A., McAndrew, P., \& Scanlon, E. (2007). Informal Learning with PDAs and Smartphones. Journal of Computer Assisted Learning , 24, 359-371.

Connolly, P., \& Maicher, K. (2005). The developing and testing of an interactive Web-based Tutorial for Ortographic Drawing instruction and Visualization Enhancement. 2005 ASEE Annual conference \& Exposition.

Contero, M., Company, P., Saorin, J., \& Naya, F. (2006). Learning Support Tools for Developing Spatial Abilities in Engineering Design. International Journal of Engineering Education , 22 (3), 470-477.

Contero, M., Naya, F., Company, P., Saorin, J., \& Conesa, J. (2005). Improving visualization skills in engineering education. IEEE Computer Graphics and Applications , 25 (5), 24-31.

Contreras, M. J., Colom, R., Hernandez, J. M., \& Santacreu, J. (July de 2003). Is static spatial performance distinguishable from dynamic spatial performance? A latent-variable analysis. Journal of General Psychology .

Corlett, D., Sharples, M., Bull, S., \& Chan, T. (2005). Evaluation of a mobile learning organiser for university students. Journal of Computer Assisted Learning , 21 (3), 162-170. 
Crown, S. W. (2001). Improving Visualization Skills of Sngineering Graphics Students Using simple JavaScript Web Based Games. Journal of Engineering Education, Jul, 347-355.

Cuadrado, J. A. (Julio de 2009). "Vistas: Aplicación multimedia de mejora de la visión espacial”. Recuperado en Mayo de 2009, de http://palmera.pntic.mec.es/ jcuadr2/personal/index3.htm.

Dehaes. (2009). Dehaes: grupo de investigación en el desarrollo de habilidades espaciales. Recuperado en Mayo de 2009, de http://degarin.com/dehaes.

Devon, R., Engle, R., Foster, R., Sathianathan, D., \& Turner, G. (1994). The effect of solid modelling software on $3 \mathrm{D}$ visualization skills. Engineering Design Graphics Journal , 58 (2), 4-11.

Dominguez Posada, R. J. (1994). Influencia de las asignaturas gráficas sobre el desarrollo de la vision espacial en los alumnos de las escuelas técnicias superiores. (ETSI caminos de Madrid). Tesis doctoral de la Escuela Tecnica Superior de Ingenieros de Canales y Puertos. Madrid: Universidad Politécnica de Madrid.

Dpto. Expresión Gráfica. Universidad de Burgos. (2007). Taller de Visión Espacial. Recuperado en Mayo de 2009, de http://www2.ubu.es/expgraf/expgrain/visualizacion3d/

Duesbury, R., \& O'Neil, H. (1996). Effect of Practice in a Computer-Aided Design Environment in Visualizing Three-Dimensional Objects from Two-Dimensional Orthographic Projections. Journal of Applied Psychology , 81 (3), 249-260.

Ekstrom, R., French, J., Harman, H., \& Dermen, D. (1976). Kit of FactorReferenced Cognitive Tests. Princeton NJ: Educational Testing Service.

Eliot, J., \& Smith, I. (1983). An International Dictionary of Spatial Tests. Windsor, United Kingdom: The NFER-Nelson Publishing Company, LTD.

Facer, K., Joiner, R., D., S., Reid, J., Hull, R., \& Kirk, D. (2004). Savannah: mobile gaming and learning? Journal of Computer Assisted Learning , 20 (6), 399-409.

Faux, F., McFarlane, A., Roche, N., \& Facer, K. (2006). Learning with handheld technologies. Futurelab.

Feng, J., Spence, I., \& Pratt, J. (2007). Playing an Action Video Game Reduces Gender Differences in Spatial Cognition. Psychological Science, 18 (10), 850-855. 
Ferguson, E. S. (1992). Engineering and the Mind's Eye. MIT Press.

Fernández-Salinero, C. (2006). Las competencias en el marco de la convergencia europea: Un nuevo concepto para el diseño de programas educativos. Encounters on Education , 7, 131-153.

Frey, G., \& Baird, D. (2000). Does Rapid Prototyping Improve Students Visualization Skills. Journal of Industrial Technology (4), 1-6.

Gardner, R. (1957). Field-independence as a determinant of susceptibility to certain illusions. American Psychologist , 12, 397.

Gaughran, W. (2002). Cognitive modelling for engineers. Proceedings of the 2002 American Society for Engineering education Annual Conference and Exposition. American Society for Engineering Education.

Gerson, H., Sheryl, S., Wisocki, A., \& Baartmans, B. (2001). The Development and Assessment of Multimedia Software for Improving 3-D Spatial Visualization Skills. Computer Applications in Engineering Education , 9 (2), 105-113.

Gillespie, W. H. (1995). Using solid modelling tutorials to enhance visualization skills. Dissertation Abstracts International , 56.

Godfrey, G. S. (1999). Three-dimensional visualization using solid-model methods: A comparative study of engineering and technology students((Doctoral dissertation, Northern Illinois University, 1999). Dissertation Abstracts International , 6o, 4390.

Gross, K. (1901). The play of man. New York: Appleton.

Guay, R. (1976). Purdue Spatial Visualization test - Visualization of Rotacions. Purdue Research Fundation.

Guilford, J., \& Zimmerman, W. S. (1948). The Guilford-Zimmerman aptitude survey. Journal of Applied Psychology , 32 (1), 24-34.

Guilford, J., \& Zimmerman, W. (1947). Some A.A.F. findings concerning aptitude factors. Occupations , 26, 154-159.

Halpern, D. F. (1986). Sex Differences in Cognitive Abilities. Hilsdale, New Jersey: Lawrence Erlbaum Associates, Inc.

Harman, K., Humphrey, G., \& Goodale, M. (1999). Active manual control of object views facilitates visual recognition. Current Biology , 9, 13151318.

Hegarty, M., \& Waller, D. (2004). A dissociation between mental rotation and perspective-taking spatial abilities. Intelligence , 32, 175-191. 
Hollyday-Darr, K., Blasko, D. G., \& Dwyer, C. (2000). Improving Cognitive Visualization with a Web Based Interactive assessment and Training Program. Engineering Design Graphics Journal , 64 (1), 4-9.

IAML (The International Association for Mobile Learning). (2009). The International Association for Mobile Learning. Recuperado en Mayo de 2009 de, http://mlearning.noe-kaleidoscope.org/.

Informe Horizon (2008). Universitat Oberta de Catalunya; The New Media Consortium. Stanford, California: The New Media Consortium. Recuperado en Septiembre 2009 de, http://www.nmc.org/pdf/2009Horizon-Report-es.pdf.

Kelley, T. (1928). Crossroads in the mind of man. CA: Standford University Press.

Leach, J. (1992). Utilization of solid modeling in engineering graphics courses. Engineering Design Graphics Journal , 56 (2), 5-10.

Likert, R., \& Quasha, W. (c.1995, 1970). Revised Minnesota paper form board test. Quasha. San Antonio, TX: Psychological Corp.

Linn, M., \& Petersen, A. (1986). A meta-analysis of gender differences in spatial ability: Implications for mathematics and science achievement. En

$\mathrm{Lu}, \mathrm{M}$. (2008). Effectiveness of vocabulary learning via mobile phone. Journal of Computer Assisted Learning , 24 (6), 515-525.

Maccoby, E., \& Jacklin, C. (1974). The Psychology of sex differences. Stanford, CA: Stanford University Press.

Mafalda, R. (2000). Efeitos do uso de diferentes métodos de representaçao gráfica no desenvolvimento da habilidade de visualizaçao espacial. Tesis Doctoral. Sao Paolo.

Martín-Lafuente, D. (2009). Universal iPhone UI Kit. Recuperado el May de 2009, de http://code.google.com/p/iphone-universal/

McGee, M. (1979). Human spatial abilities: Psychometric studies and environmental, genetic, hormonal, and neurological influences. Psychological Bulletin, 86, 889-918.

Miller, C. (1996). A Historical review of applied and theoretical spatial visualization publications in engineering graphics. Engineering Design Graphics Journal , 60 (3), 12-33. 
Miller, C. (1992). Enhancing Visual Literacy of Engineering Students Through the Use of Real and Computer Generated Models. Engineering Design Graphics Journal , 56 (1), 27-38.

Mohler, J. L. (2008). A review of spatial ability research. Design Graphics Journal , 78 (3).

Morán, S., Rubio, R., Gallego, R., Suárez, J., \& Martín, S. (2008). Proposal of interactive applications to enhance student's spatial perception. Computers \& Education , 50 (3), 772-786.

Olkun, S. (2003). Making connections: Improving spatial abilities with engineering drawing activities. April: 1-10. International Journal for Mathematics Teaching and Learning , April, 1-10.

Pak, R. (2001). A further examination of the influence of spatial abilities on computer task performance in younger and older adults. Proceedings of the Humen Factors and Ergonomics Society 45th Annual Meeting, October, págs. 1551-1555. Minneapolis, MN.

Pellegrino, J., Alderton, D., \& Shute, V. (1984). Understanding spatial ability. Educational Psychologist , 19 (3), 239-253.

Pérez, T., \& Serrano, M. (1998). Ejercicios para el desarrollo de la percepción espacial. Alicante: Editorial Club Universitario.

Piaget, J. (1951). Play, dreams and imitation in childhood. New York: W. W. Norton \& Company.

Piaget, J., \& Inhelder, B. (1971). Mental imagery in the child. (F. Langdon, \& T. J.L. Lunzer, Edits.) New York: Basic Books.

Prensky, M. (2001). Digital game based learning. New York: McGrawHill.

Provost, J. (1990). Work, play and type: Achieving balance in your life. Palo Alto, CA: Consulting Psychologist Press.

Rafi, A., \& Samsudin, K. (2009). Practising mental rotation using interactive Desktop Mental Rotation Trainer (iDeMRT). British Journal of Educational Technology , 40 (5), 889-900.

Rafi, A., Samsudin, K. A., \& Ismail, A. (2006). On Improving Spatial Ability Through Computer-Mediated Engineering Drawing Instruction. Educational Technology \& Society , 9 (3), 149-159.

Regeo. (2009). Regeo Research Group. Recuperado el May de 2009, de http://regeo.upv.es. 
Reseach, IMS. (1 de July de 2008). Reseach, IMS. Recuperado en Enero de 2009, de http://www.imsresearch.com/news.html\&press id=39.

Rosas, R., Nussbaum, M., Cumsille, P., Marianov, V., Correa, M., Flores, P., et al. (2003). Beyond Nintendo: design and assessment of educational video games for first and second grade students. Computers \& Education, 40 (1), 71-94.

Sánchez Carlessi, H., \& Reyes Romero, C. (2003). Psicología del aprendizaje y la educación superior. Santa Patricia: Visión Universitaria.

Sánchez, J., \& Flores. (2006). Aprendizaje Móvil de Ciencias para Ciegos. Nuevas Ideas en Informática Educativa , 2, 215.

Sánchez, J., Salinas, A., \& Sáenz, M. (2007). Mobile Game-Based Methodology for Science Learning. Human-Computer Interaction. HCI Applications and Services. LNCS , 4553, 322-331.

Saorín, J. (2006). Estudio del efecto de la aplicación de tecnologías multimedia y del modelado basado en bocetos en el desarrollo de las habilidades espaciales. Tesis Doctoral inédita. Valencia: Universidad Politécnica de Valencia. Recuperado en Septiembre de 2009, de http://webpages.ull.es/users/dehaes/documentos/Tesis\%20Completa\%2 odefinitiva\%20jose\%2oluis.pdf

Sarlé, P., \& Rosas, R. (2005). Juegos de construcción y construcción del conocimiento. Argentina: Miño y Dávila.

Seppala, P., \& Alamaki, H. (2003). Mobile Learning in Teacher Training. Journal of Computer Assisted Learning , 19, 330-335.

Sexton, T. J. (1992). Effect on spatial visualization: Introducing basic engineering graphics concepts using $\mathrm{CAD}$ technology. Engineering Design Graphics Journa , 56 (3), 36-43.

Sharples, M. (2006). Big Issues in Mobile Learning. University of Nottinghan.

Sharples, M. (2000). The Design of Personal Mobile Technologies for Lifelong Learning. Computers \& Education , 34, 177-193.

Smart Lite Software. (2009). Smart Lite Software. WebQuiz XP.

Recuperado en Mayo de 2009, de

http://eng.smartlite.it/en2/products/webquiz/index.asp.

Smith, I. (1964). Spatial ability: Its educational and social significance. London: The University of London Press. 
Sorby, S.A., \& Baartmans, B. J. (2000). The Development and Assessment of a Course for Enhancing the 3-D Spatial Visualization Skills of First Year Engineering Students. Journal of Engineering Education , 89 (3), 301307.

Sorby, S. (1999). Spatial Abilities and Their Relationship to Computer Aided Design Instruction. 1999 ASEE Annual Conference \& Exposition. Charlotte, NC.

Sorby, S., \& Baartmans, B. (1996). A course for development of 3-D spatial visualization skills. Engineering Design Graphics Journal , 60 (1), 13-20.

Sorby, S., Drummer, T., Hungwe, K., \& Charslesworth, P. (2005). Developing 3-D Spatial Visualization Skills for no-Engineering Students. Proceedings of the 2005 ASEE Annual conference \& Exposition.

Sorby, Wysocky, \& Baartmans. (2003). Introduction to $3 D$ Spatial Visualization: An active approach. Thomson: Delmar Learnig.

Spearman, C. (1927). The abilities of man. New York: Mac-Millan.

Suministros Maditeg. (1997). Material didáctico de Técnicas de Expresión Gráfica. Maletín M2: "Modelos de tres vistas y cortes" . Santander: Suministros MADITEG.

The Freudenthal Institute for Science and Mathematics Education. (2004). Wis web. Obtenido de http://www.fi.uu.nl/wisweb/en/.

The Steering Committee of the National Engineering Education Research Colloquies. (2006). The National Engineering Education Research Colloquies (Special Report). Journal of Engineering Education , 95 (4), 257-258.

Thorndike, E. (1921). On the organization of the intellect. Psychological Review , 28, 141-151.

Thornton, P., \& Houser, C. (2005). Using mobile phones in English education in Japan. Journal of Computer Assisted Learning , 21 (3), 217228.

Thurstone, L. (1938). Primary mental abilities. Chicago: University of Chicago Press.

Trindade, J., Fiolhais, C., \& Almeida, L. (2002). Science learning in virtual environments. British Journal of Educational Technology . 
Ulloa Reyes, L. (2008). Estrategia didáctica para la utilización de una colección de juegos por computadora en el primer grado de la educación primaria (Tesis doctoral leida 2006) (Vol. ISBN 9789591608116 ). Cuba: Editorial Universitaria.

Vanderberg, S., \& Kuse, A. (1978). Mental Rotation, a group test of three dimensional spatial visualization. Perceptual and motor Skills , 47, 599604.

Voyer, D., Voyer, S., \& Bryden, M. (1995). Magnitudes of sex differences in spatial abilities: A meta-analysis and consideration of critical variables. Psychological Bulletin , 117 (2), 250-270.

Wiley, S. (1990). Computer graphics and the development of visual perception in engineering graphics curricula. Engineering Design Graphics Journal , 54 (3), 30-35.

Witkin, H. (1950). Individual differences in ease of perception of embedded figures. Journal of Personality , 19, 1-15.

Yue, J., \& Chen, D. (2001). Does CAD improve spatial visualization ability? Proceedings of the 2001 American Society for Engineering Education Annual Conference \& Exposition. 
Anexos $\overline{\overline{ }}$ 



\section{Anexo I.- Encuesta previa realizada a los participantes del curso de SketchUp}

1.) ¿Qué franja de edad tienes?

No \%

menos de 20 años: $\quad 29 \quad 72.5$

entre 20 y 25 años: 80

entre 25 y 30 años: $\quad 1 \quad 2.5$

más de 30 años: $\quad 2 \quad 5$

2.) Sexo

No \%

Varón: $\quad 25 \quad \mathbf{6 2 . 5}$

Mujer: $\quad 15 \quad \mathbf{3 7 . 5}$

3.) ¿Trabajas?

No \%

Sí: $\quad 5 \quad \mathbf{1 2 . 5}$

No: $\quad 35 \quad \mathbf{8 7 . 5}$

4.) ¿Eres repetidor?

No $\%$

Sí: $\quad 2 \quad 5$

No: $\quad 38 \quad 95$

5.) Entras en la universidad vía:

No \%

Bachiller: $\quad 32 \quad 80$

F.P.: $\quad 4 \quad 10$

Otra carrera universitaria: $\quad 3 \quad 7.5$

Otros: $\quad 1 \quad \mathbf{2 . 5}$

6.) ¿Has estudiado alguna asignatura de dibujo técnico con anterioridad? (Bachiller, FP..)

No $\%$

Sí: $\quad 17 \quad \mathbf{4 2 . 5}$

No: $\quad 23 \quad \mathbf{5 7 . 5}$

7.) ¿Conoces y manejas alguna aplicación CAD?

No \%

Sí: $\quad 14 \quad 35$

8.) ¿Crees que tienes facilidad para el dibujo y la visión

No: espacial?

Sí, nunca he tenido problemas en esas áreas:

No \%

No mucha, pero la suficiente para aprobar:

$11 \quad 27 \cdot 5$

No, siempre tengo dificultades con esta materia:

9.) ¿Te gusta dibujar a mano alzada?

$20 \quad 50$

$9 \quad \mathbf{2 2 . 5}$

No \%

Sí: $\quad 29 \quad \mathbf{7 2 . 5}$

No: $\quad 11 \quad \mathbf{2 7 . 5}$

No $\%$

10.) ¿Qué mano utilizas para dibujar?

$\begin{array}{rrr}\text { Derecha: } & 40 & 100 \\ \text { Izquierda: } & 0 & \text { o } \\ & N^{0} & \%\end{array}$

11.) ¿Tienes ordenador en casa?

$\begin{array}{rrr}\text { Sí, con conexión a internet: } & 35 & \mathbf{8 7 . 5} \\ \text { Sí, sin conexión a internet: } & 5 & \mathbf{1 2 . 5} \\ \text { No: } & 0 & \text { o }\end{array}$

12.) La conexión a internet es de banda ancha

No \%

$\begin{array}{rrr}\text { Sí: } & 30 & \mathbf{7 5} \\ \text { No: } & 8 & \mathbf{2 0} \\ & \text { No }^{\mathbf{2}} & \%\end{array}$

13.) ¿Eres usuario habitual de los videojuegos?

$\begin{array}{cc}\text { Sí: } & 14 \\ \text { No: } & 26\end{array}$


Anexo II.- Guía de referencia rápida de SketchUp

SketchUP Guía de referencia rápida

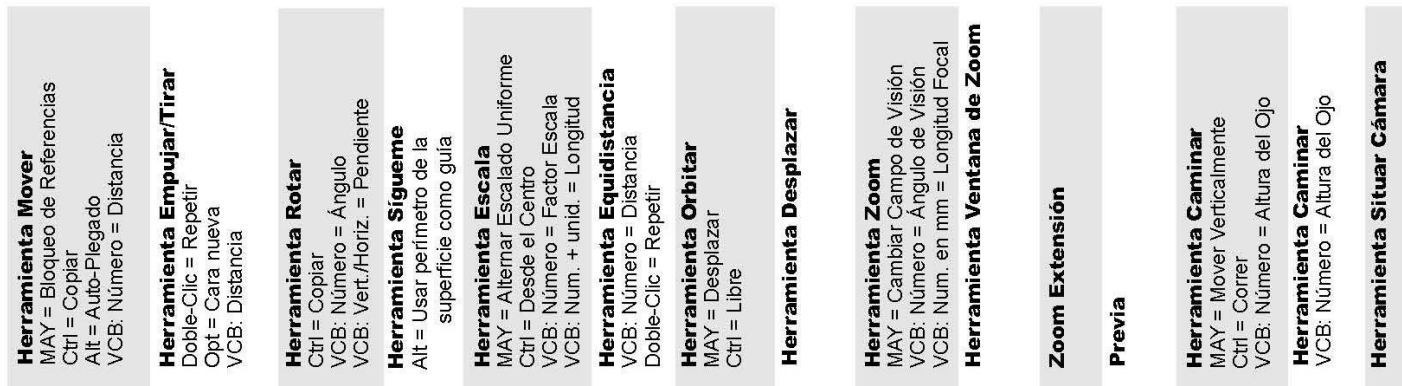

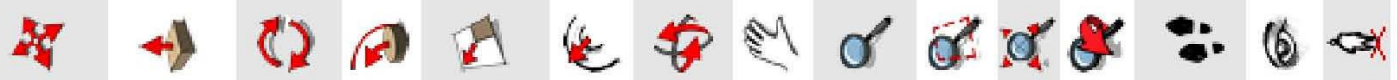
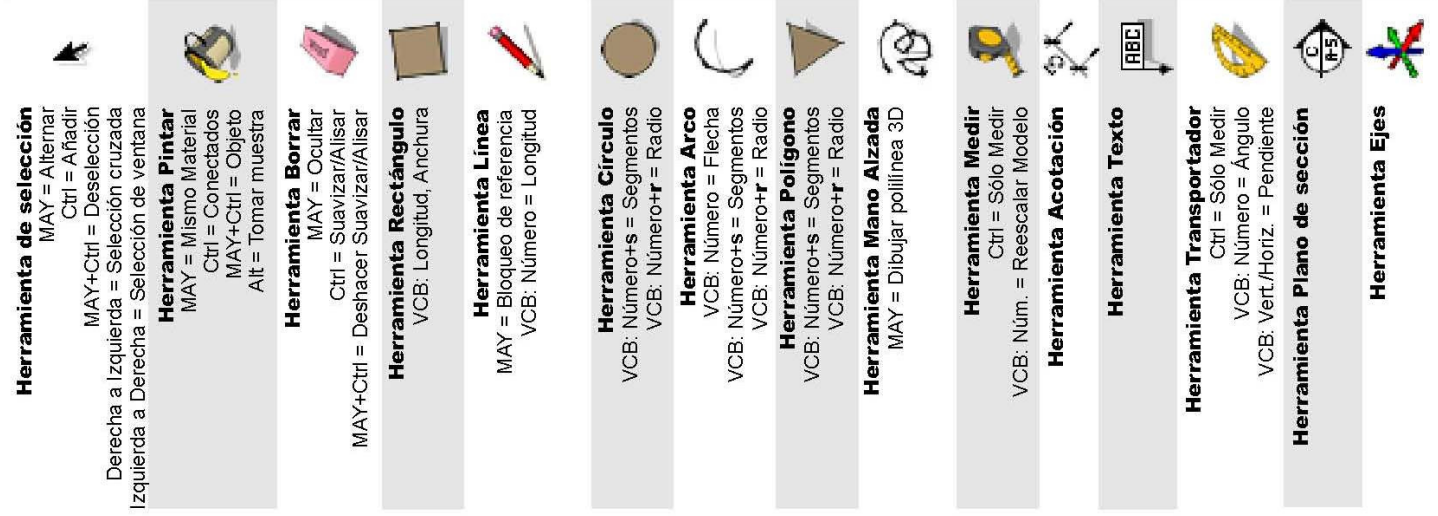


\section{Anexo III.- Instrucciones del Test de Rotación Mental}

Este test mide la capacidad de realizar rotaciones mentales en el espacio 3 D. Está compuesto de 20 ejercicios compuestos cada uno de ellos de cinco figuras. La primera es la que tomamos como referencia y el objetivo es localizar dentro de las otras cuatro, las dos que corresponden a la de figura de referencia después de haber girado alrededor de uno o dos de sus ejes.

\section{Ejemplos propuestos:}
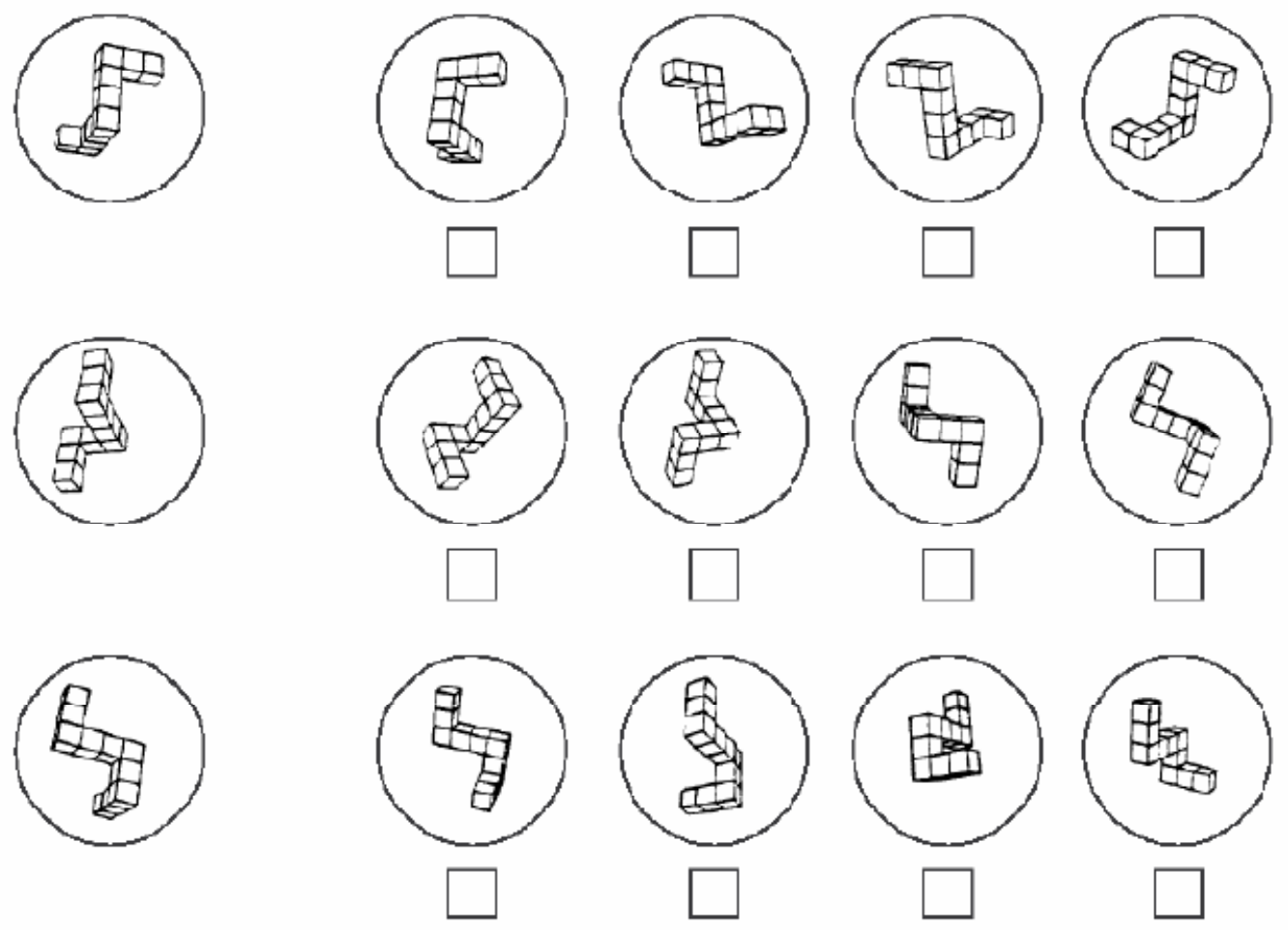

Respuestas correctas:

1.- Dibujos primero y segundo

2.- Dibujos primero y tercero

3.- Dibujos segundo y tercero

\section{Tiempo:}

El tiempo límite es de 6 minutos.

Se divide en dos periodos de 3 minutos. El alumno tiene 3 minutos para realizar 10 items.

\section{Puntuación:}

2 puntos por cada línea de figuras correctamente resueltas

1 punto si sólo se localiza una de las rotaciones por línea y no se marca ninguna otra figura.

o puntos si alguna de las marcas es incorrecta. 


\section{Anexo IV.- Instrucciones del Test de DAT-SR}

El test DAT-SR pertenece a la batería DAT (Differential Attitude Test), elaborada con el objeto de proporcionar un instrumento científico tipificado para la apreciación de aptitudes de los estudiantes. Este test consta de 60 items en su primera versión y de 50 la versión denominada DAT-5. Cada pregunta se presenta un modelo o patrón que es el desarrollo en superficie de un modelo en tres dimensiones. A continuación aparecen cuatro figuras. Una de ellas se ha formado doblando el modelo. La tarea consiste en averiguar cuál es la figura correcta. El modelo siempre representa la parte exterior de la figura.

\section{Ejemplos propuestos:}

\section{Ejemplo X:}

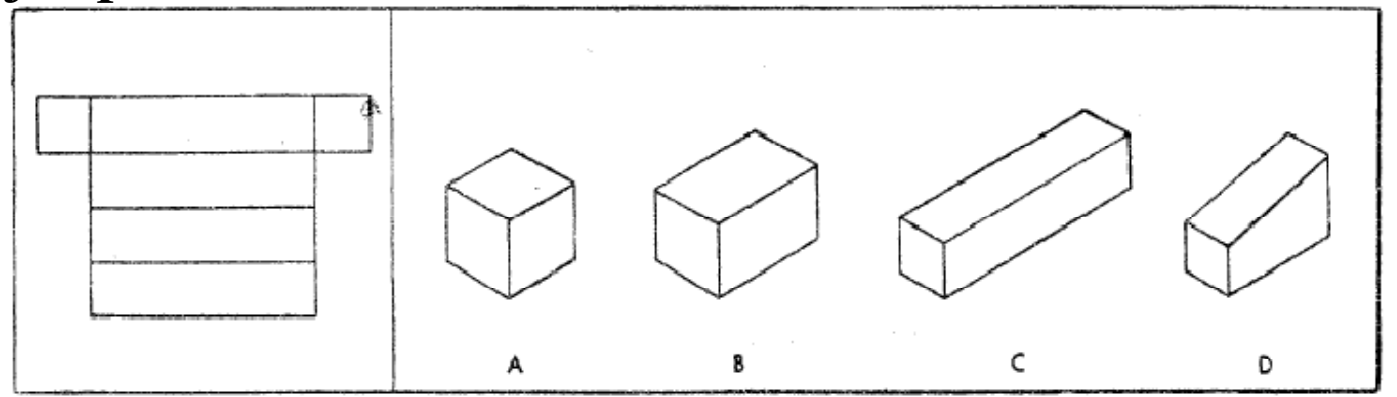

¿Cuál de estas figuras, A, B, C o D puede construirse a partir del modelo $\mathrm{X}$ ? Evidentemente sólo la $\mathrm{C}$, porque las otras son de forma y tamaño diferentes. Compruébelo.

En la hoja de respuestas marcaremos la letra $\mathrm{C}$ como correcta. En cada problema hay siempre cuatro figuras a continuación del modelo. De ellas sólo una está correctamente construida a partir de él.

\section{Ejemplo Y:}

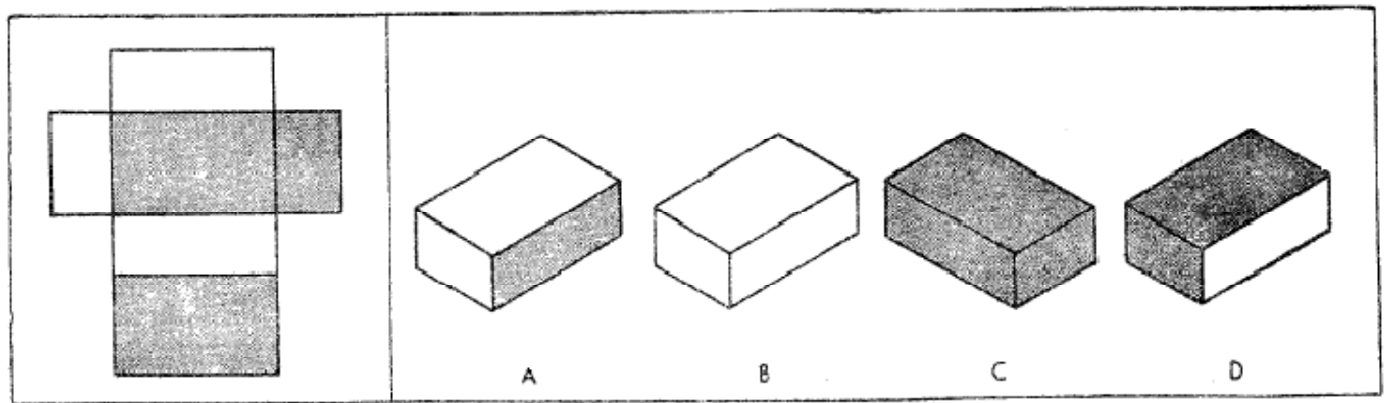

En el ejemplo Y, el modelo puede doblarse formando una caja. Las dos caras mayores y una de las pequeñas deberán ser oscuras. La figura que resulta ha de tener esas tres caras oscuras, aunque alguna no aparezca a la vista debido a la colocación de la caja.

Observe: las cuatro figuras son correctas en cuanto a la forma, pero las caras que se ven son diferentes. Sólo una de estas figuras puede construirse a partir del modelo. Fíjese en las cuatro posibilidades de elección: 
- La figura A está mal; tiene un lateral oscuro y la superficie superior blanca; en el modelo los dos laterales son blancos y las dos superficies mayores oscuras.

- La figura B es igualmente incorrecta porque la superficie superior debería ser oscura.

- La figura $\mathrm{C}$ es igualmente incorrecta porque tiene oscuro uno de los laterales a diferencia del modelo.

- La figura D está bien: todas las caras que aparecen a la vista concuerdan con las del modelo.

Así, pues, aunque todas las figuras son correctas en cuanto a la forma, sólo en la D aparecen correctamente las superficies oscuras. Por eso, en la reproducción de la Hoja de Respuestas se ha marcado la letra D, en la fila correspondiente al ejemplo Y.

HOJA DE RESPUESTAS

\begin{tabular}{|c|c|c|c|c|}
\hline & A & B & C & D \\
\hline & A & B & C. & D \\
\hline Ejemplo Y. & & & & \\
\hline
\end{tabular}

Recuerde que la superficie que usted ve en el modelo representa siempre la parte exterior de la figura.

$\mathrm{Al}$ realizar su ejercicio:

- Estudie el modelo.

- Elija la figura que puede construirse a partir de él

- Dé su contestación marcando, en la Hoja de Respuestas, la letra que coincida con la que está debajo de la figura elegida.

Dispone de 25 minutos.

Trabaje lo más rápida y exactamente que pueda. Si no está seguro de una contestación, marque la que crea mejor.

\section{Tiempo:}

El tiempo límite es de 25 minutos para la versión de 60 items y de 20 minutos para la versión de 50 items.

\section{Puntuación:}

1 punto por problema correctamente resuelto.

o puntos si alguna de las marcas es incorrecta. 
Anexo V.- Instrucciones del Material didáctico de Técnicas de Expresión Gráfica de MAGITEG

Folleio llustrativo: $\mathrm{M} 2$

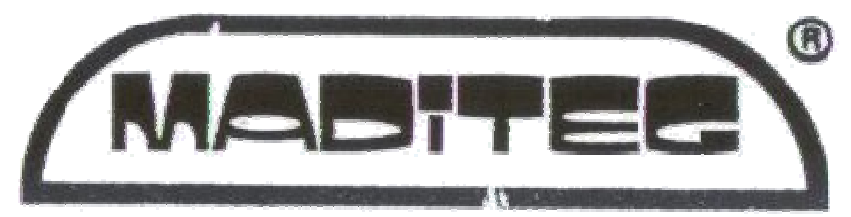

MATERIAL DIDACTICO: TECNICAS DE EXPRESION GRAFICA

MALETIN: M 2

"Modelos de tres vistas y cortes:

橉

"SOLUCIONARIO"

Distribución y venta:

"Suministros MADITEGn - Aptdo. 53 - LAREDO (Santander)

Tho. (942) 605804. 
M 2-A *15 Modelos para dibujarles Tres Vistas.

Estos modelos estân especialmente diseñados para que el alumno al croquizarlos dibuje las tres vistas en orden a una correcta interpretación.

La variedad de los modelos hace que el protesor pueda disponer en cada momento el que considere necesario.

Es muy conveniente que el profesor exija a sus alumnos, que dibuje todas las lineas ocultas para que se acostumbren a imaginar los interiores.

M 2-A

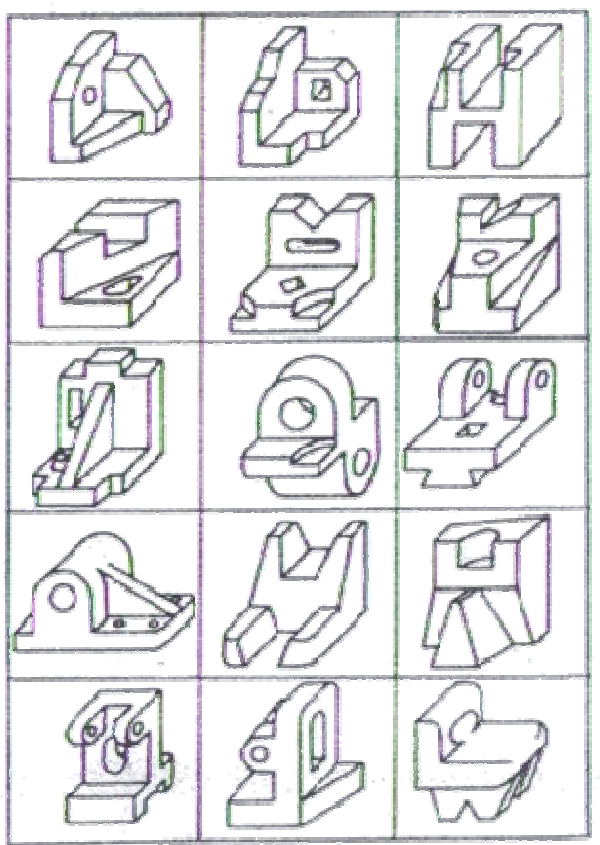

"TRES VISTAS
M 2-B

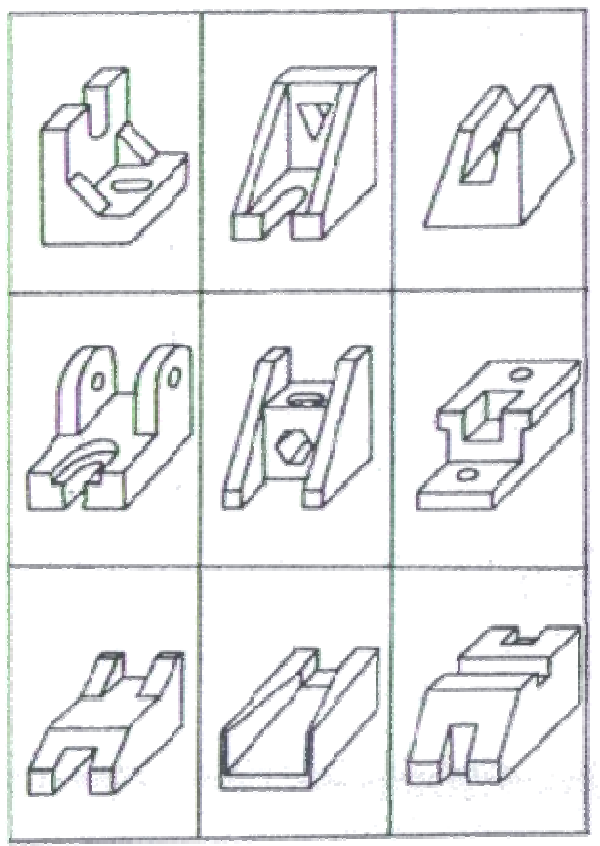

«CORTES

M 2-B: "9 Modelos para dibujarles Cortes".

Estos modelos están especialmente diseñados para que el alumno con la ayuda del profesor, se inicie en los cortes y adquiera de esta forma una práctica fundamental.

Estos modelos complementan los anteriores haciendo que el juego completo, de 24, sea insustituible en el aula de Dibujo.

Las superficies van pintadas de verde, tipo smartelair". 


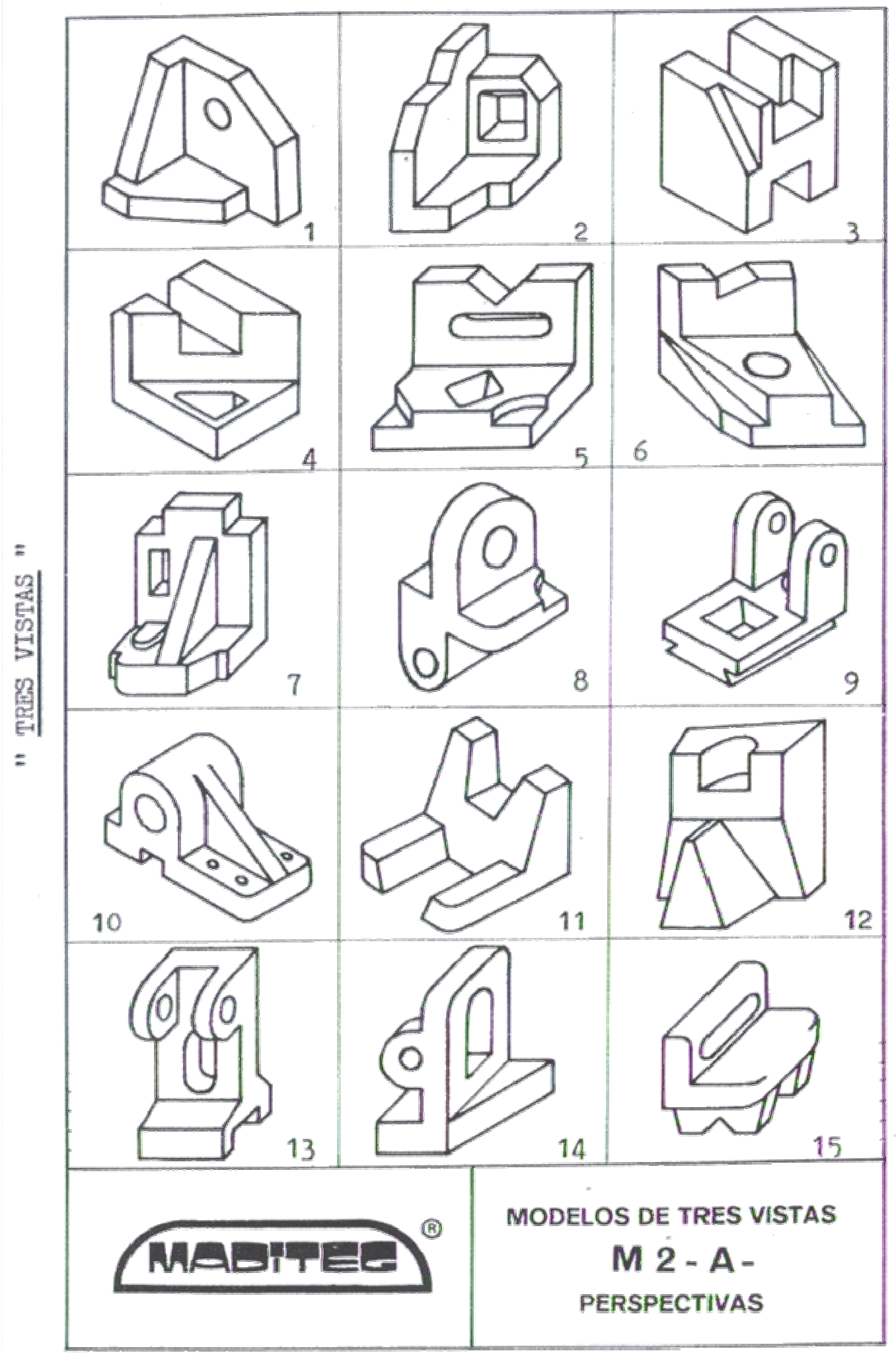




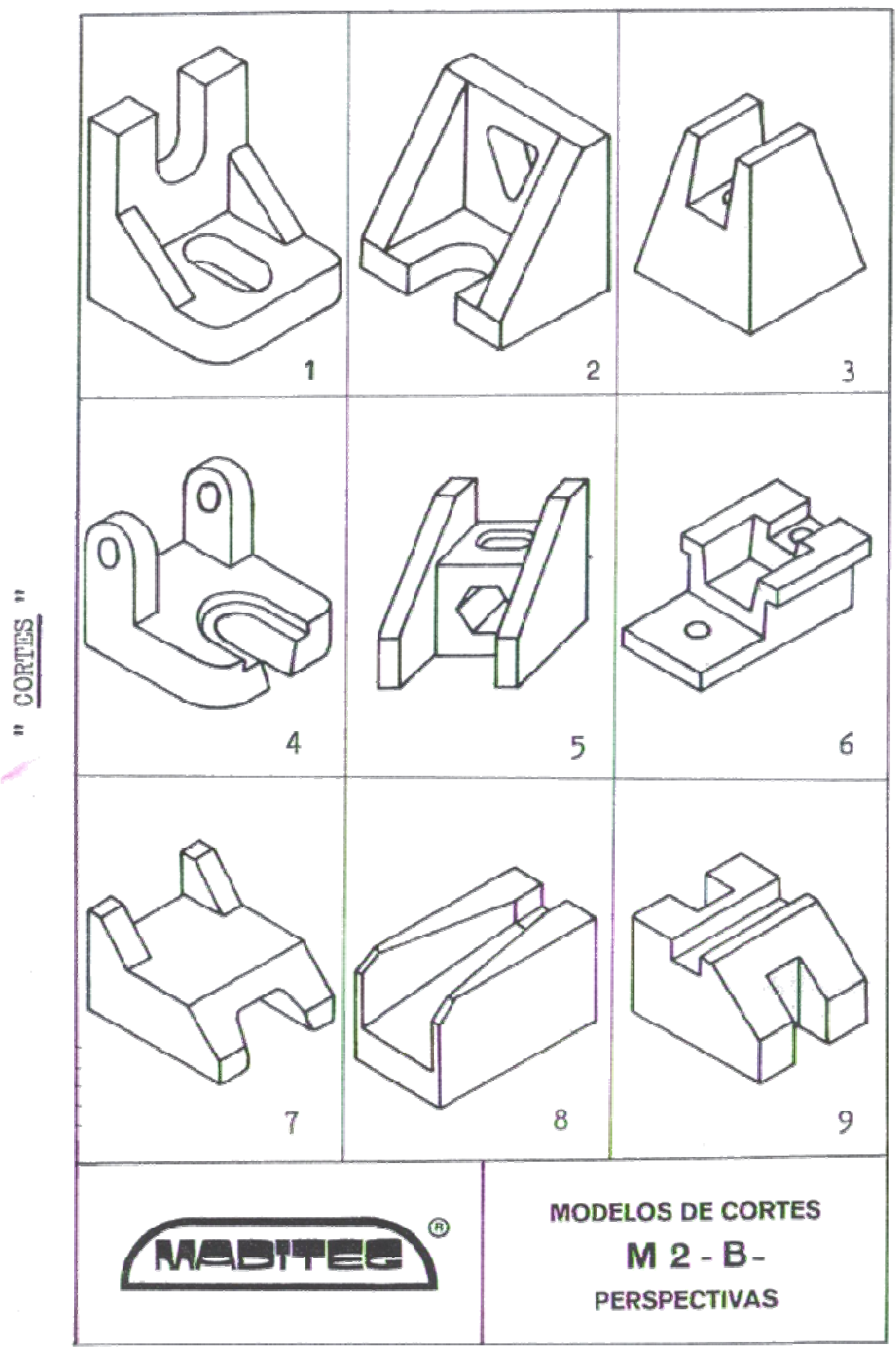




\section{Anexo VI.- Ejercicios en papel dados a los participantes en la $2^{a}$ fase}

\section{Enunciado del ejercicio:}

Realizar el modelo sólido de de las siguientes figuras en SketchUp. Medirlas en la hoja y realizarlas a la misma escala. Unidades en milímetros.
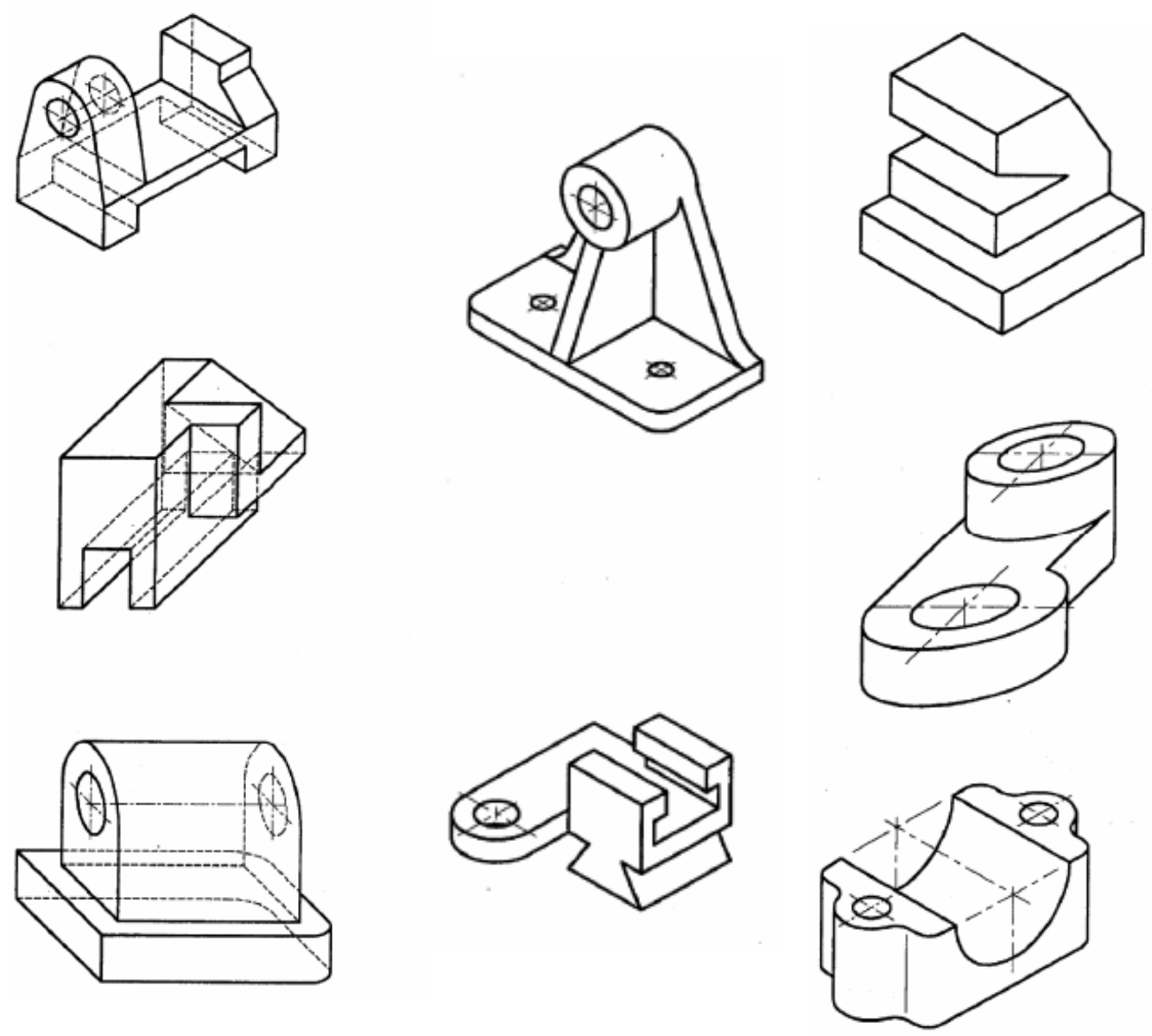


\section{Enunciado del ejercicio:}

Realizar el modelo sólido de de las siguientes figuras en SketchUp. Medirlas en la hoja y realizarlas a la misma escala. Unidades en milímetros.
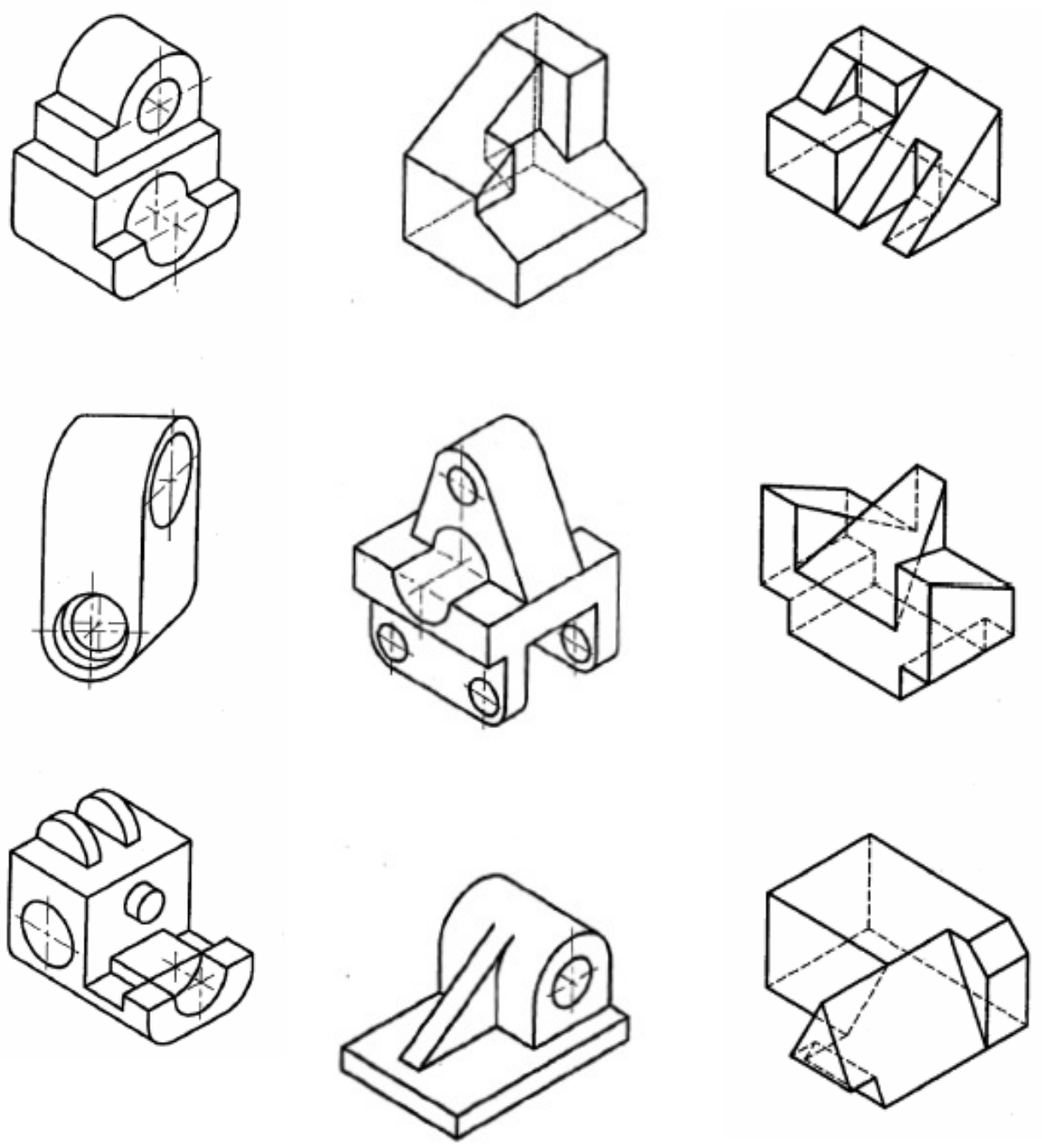


\section{Anexo VII.- Ejercicios realizados por los participantes en la $1^{\text {a }}$ fase en el aula.}

Realizar el modelo sólido de de las piezas dadas en SketchUp.

Medirlas y realizarlas a la misma escala. Unidades en milímetros.

Los ejercicios de la derecha son los realizados por los estudiantes. Pueden contener errores.
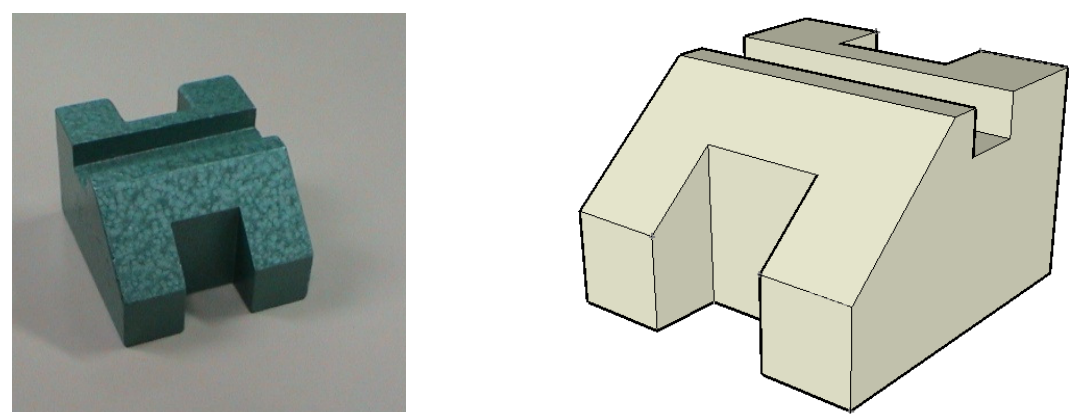

R. O. Aramburu Pino
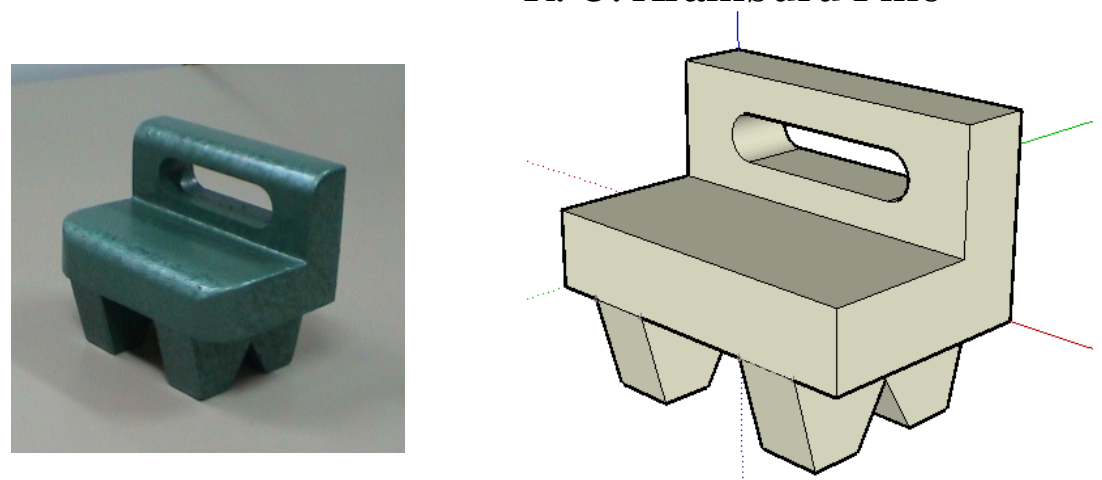

J. Afonso Palma
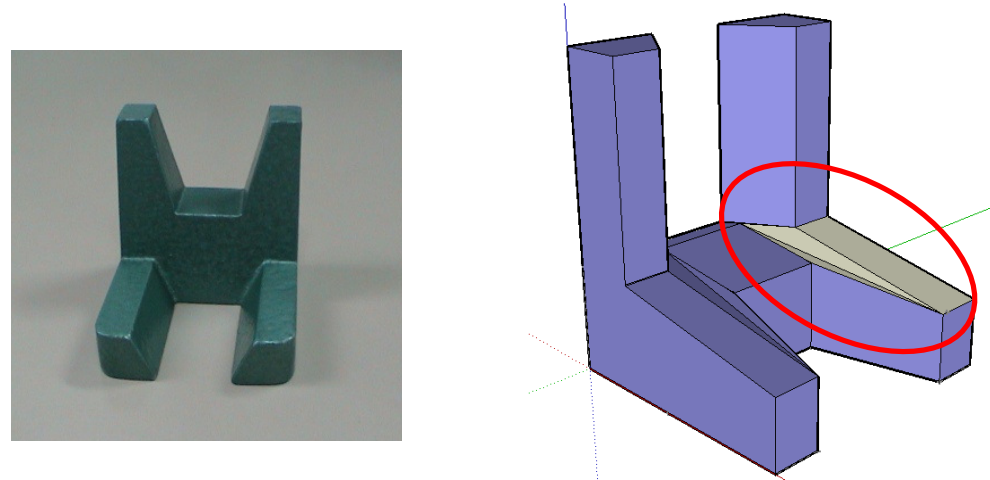

I. Álvarez Jiménez 

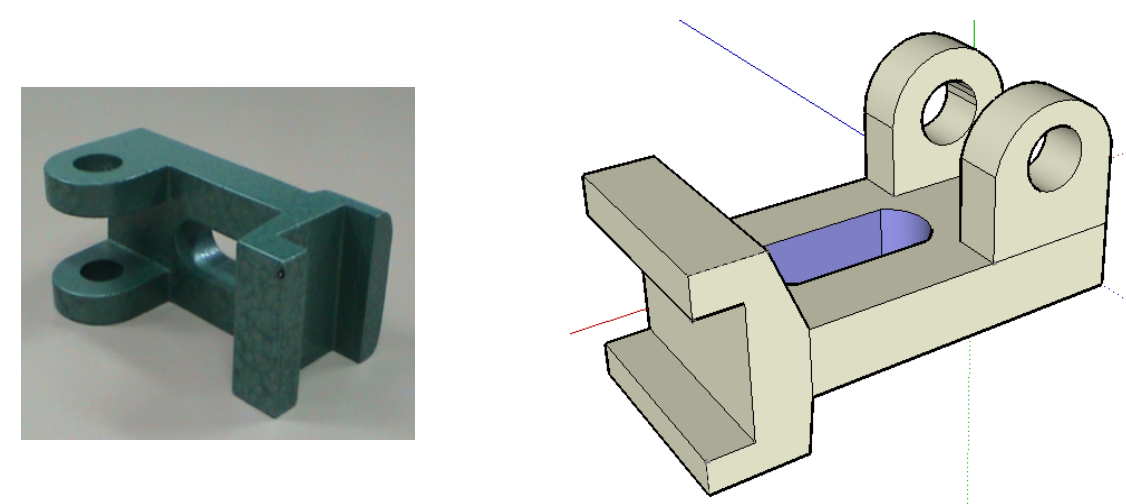

M. Arias Soto
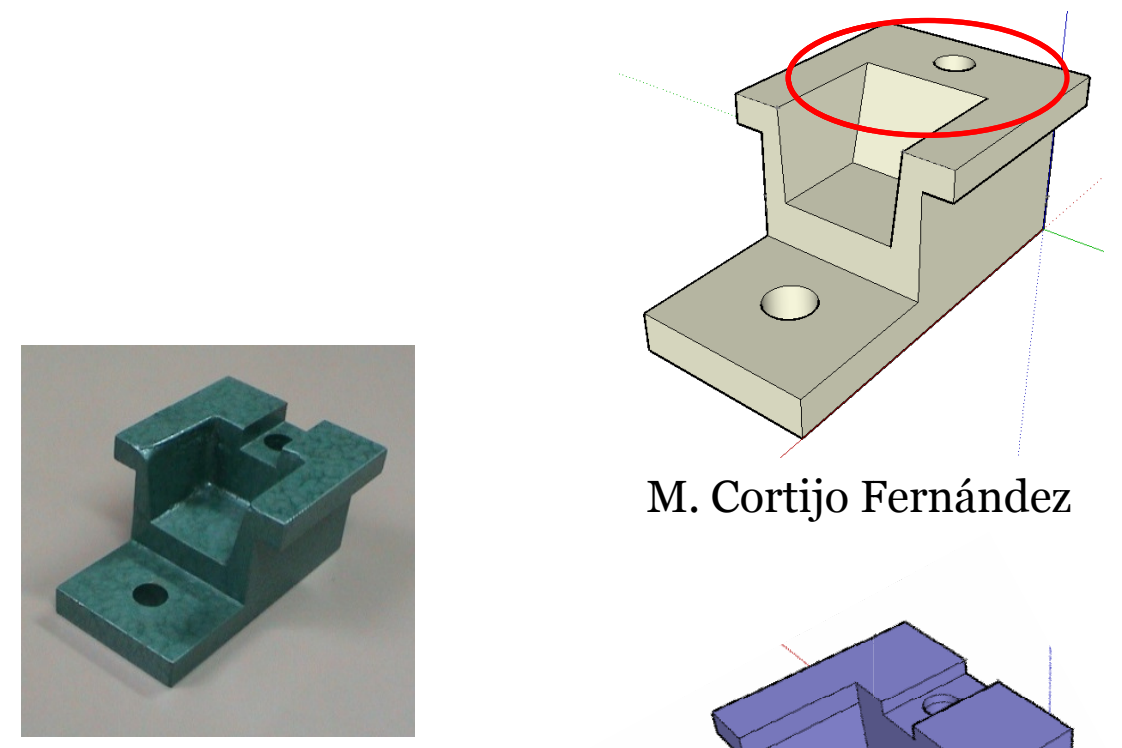

M. Cortijo Fernández
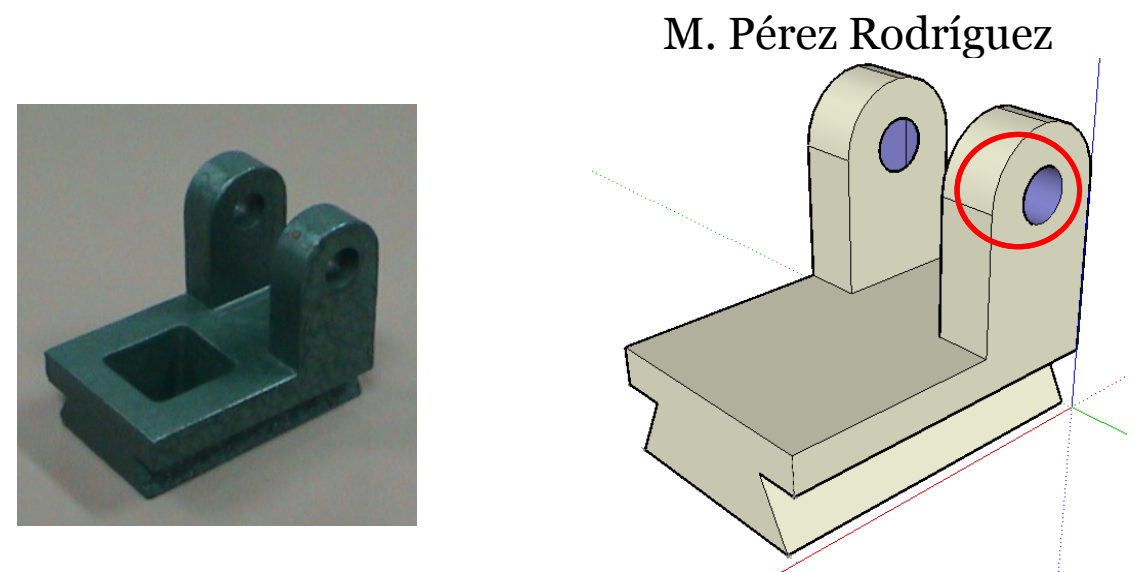

M. Cortijo Fernández 

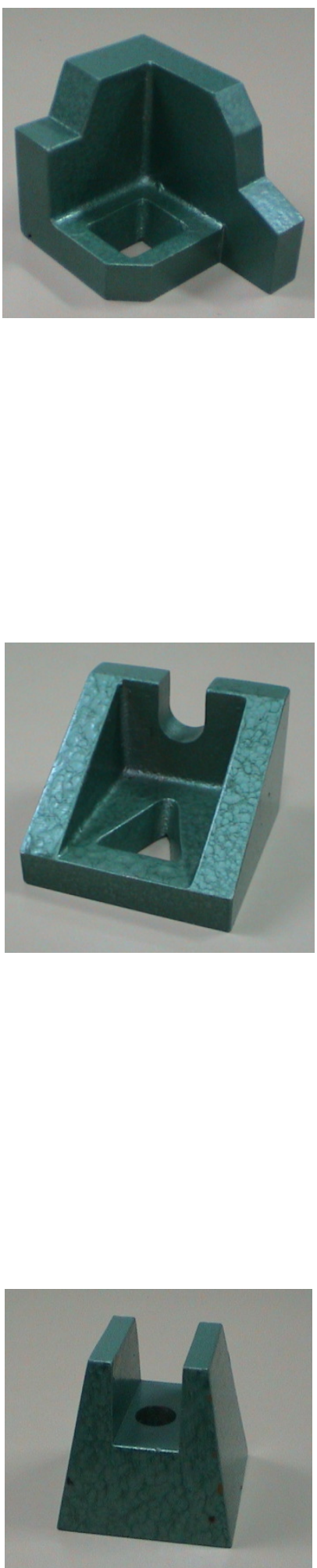

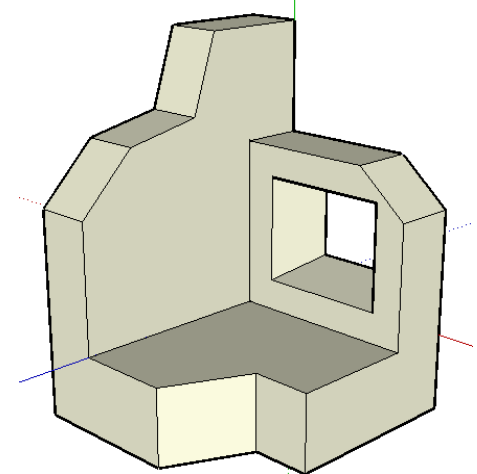

J. D. Delgado Delgado

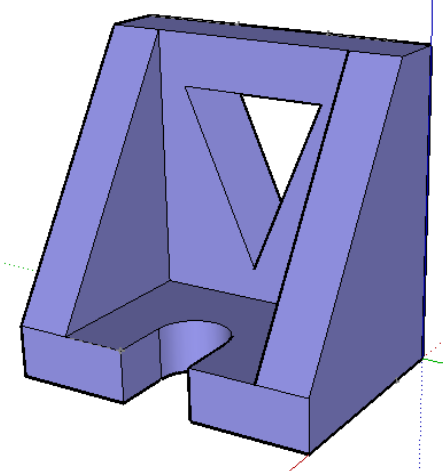

A. Delgado Hernández

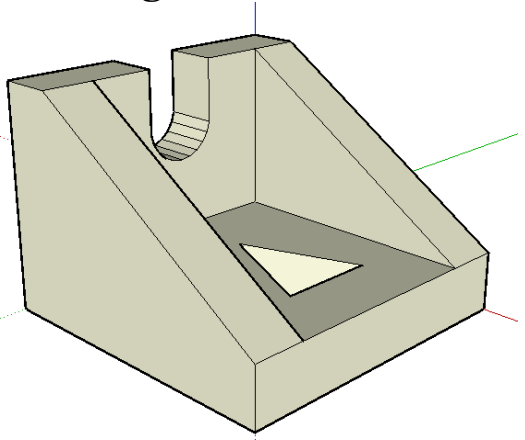

R. Gutiérrez Vargas

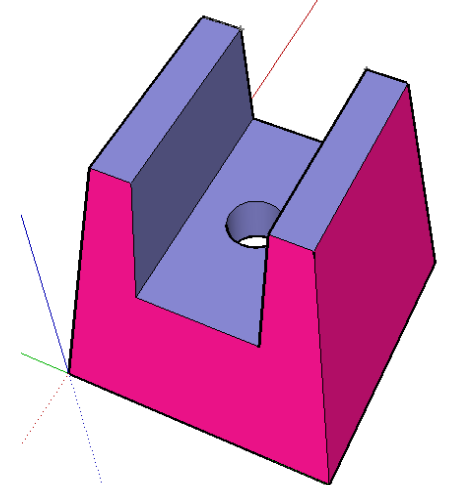

A. Delgado Hernández 

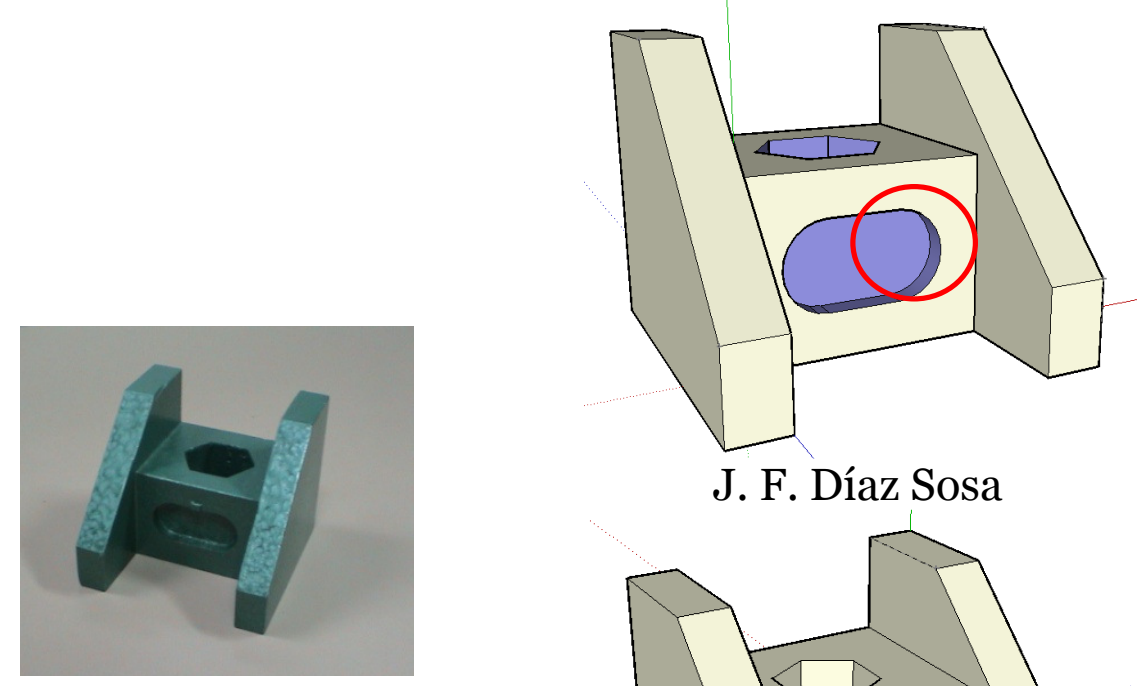

J. F. Díaz Sosa

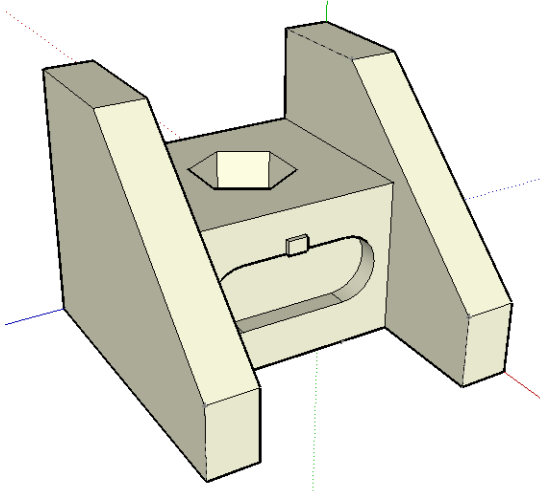

M. Gerster acosta
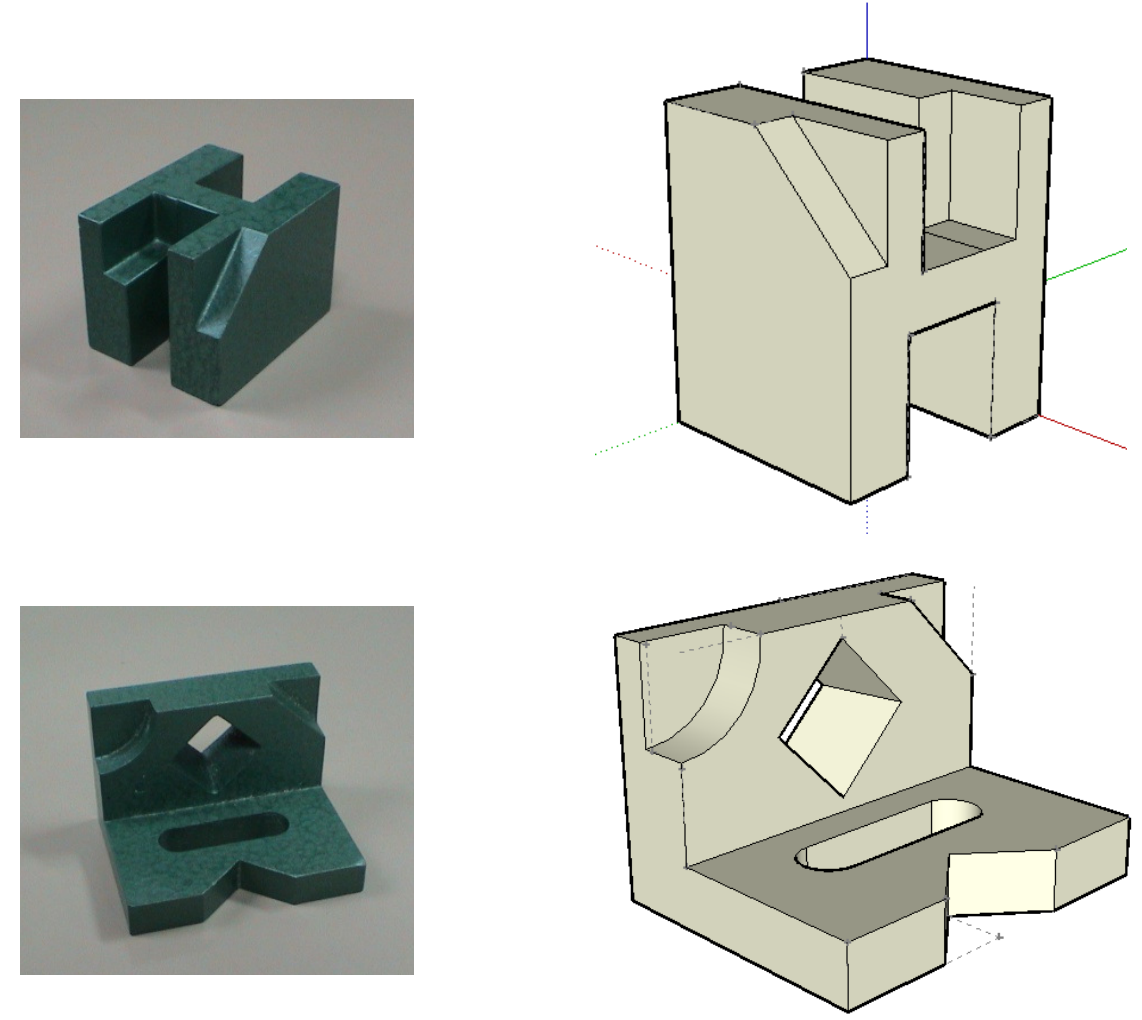

T. Fuentes Berriel 

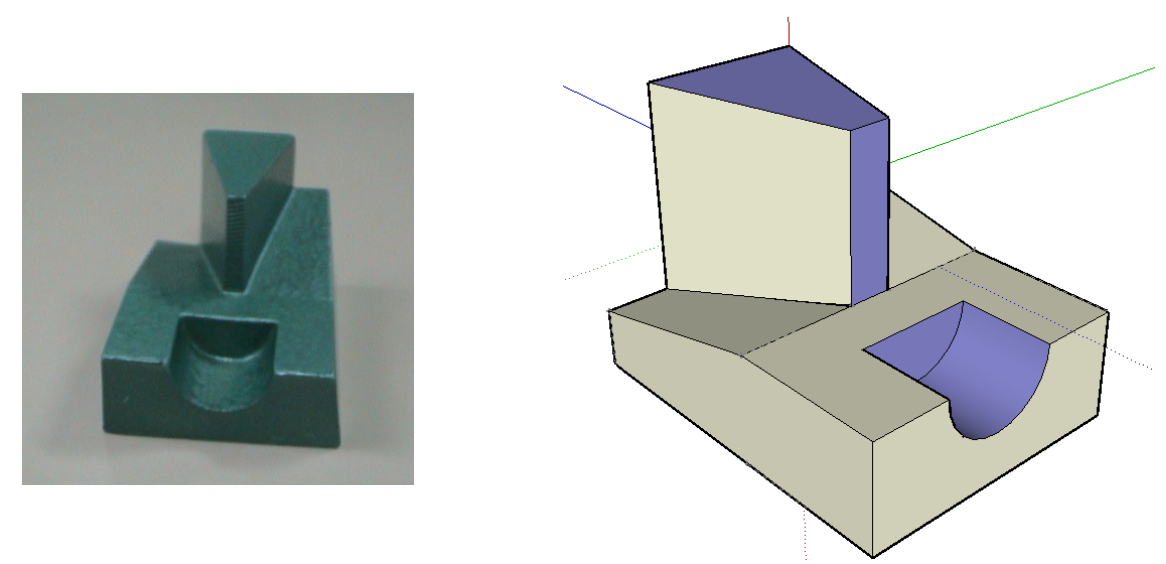

S.D. García Perdomo
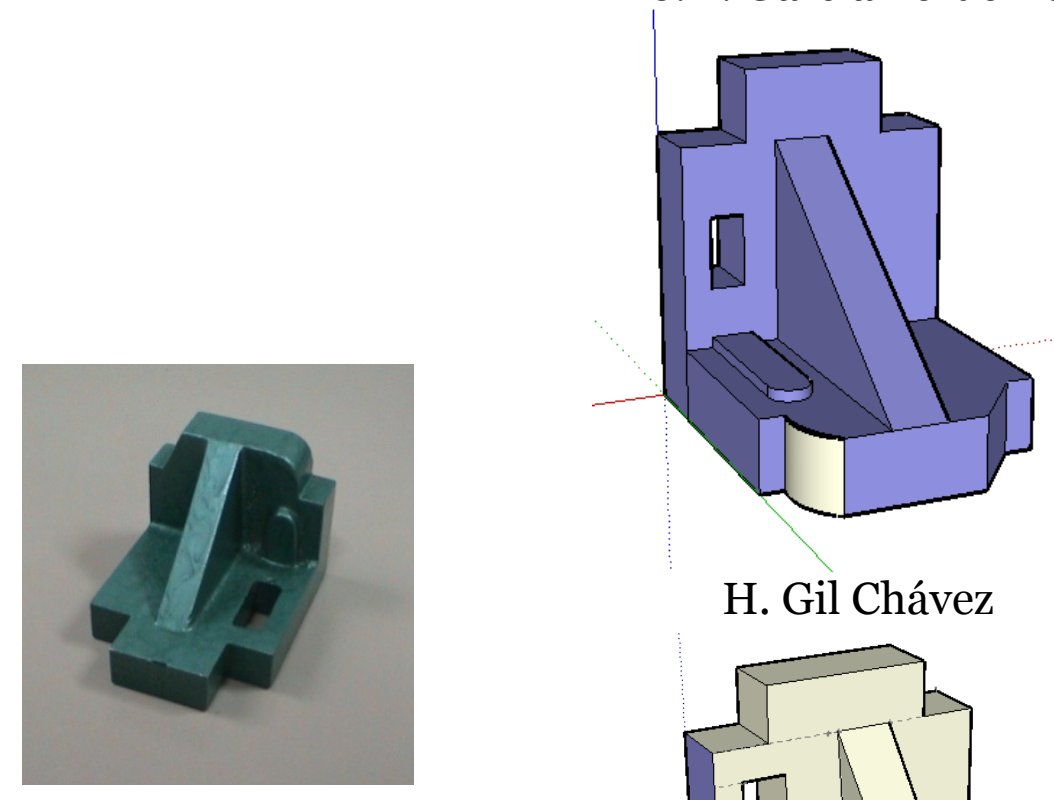

H. Gil Chávez

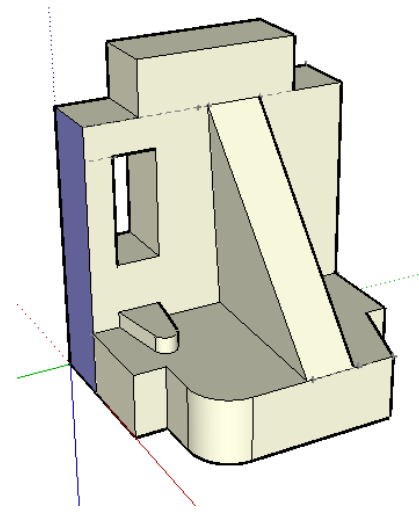

E. Guttenberger Calderón
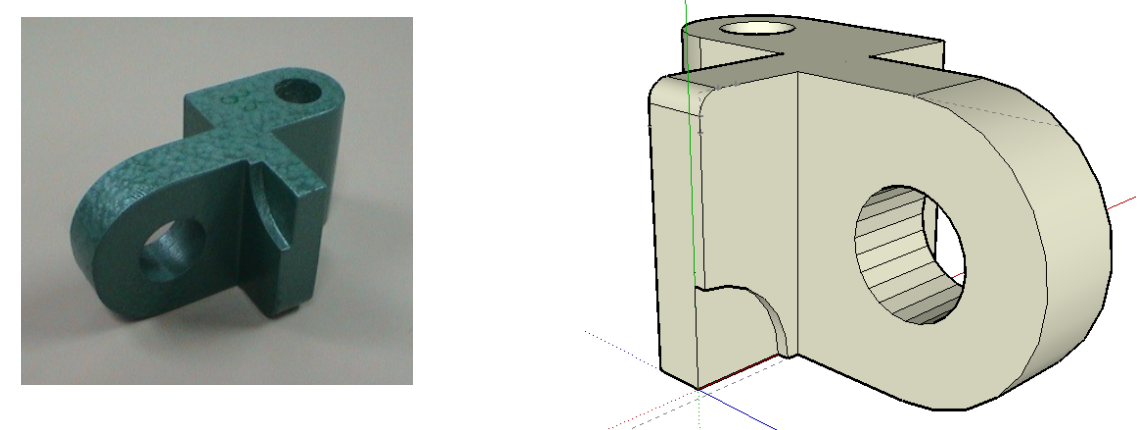

S. Hernández Fumero 

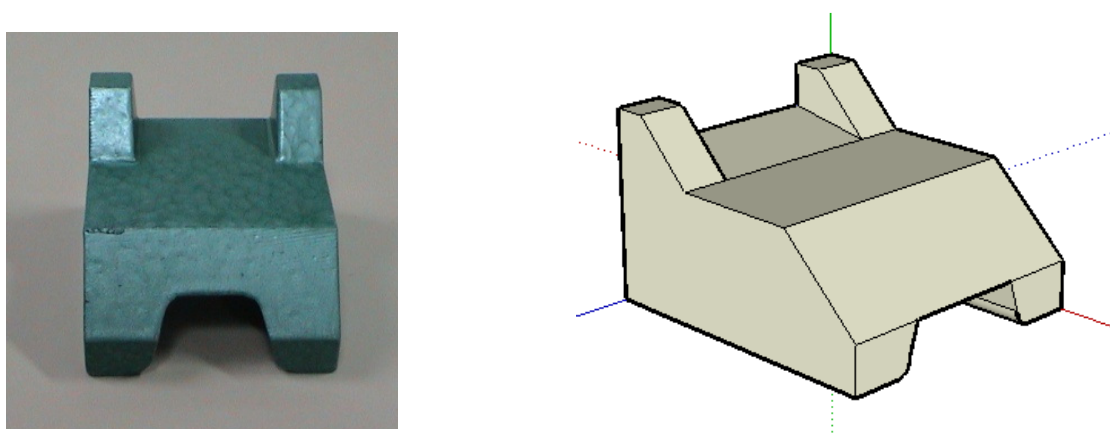

C. Y. Jorge Ramos
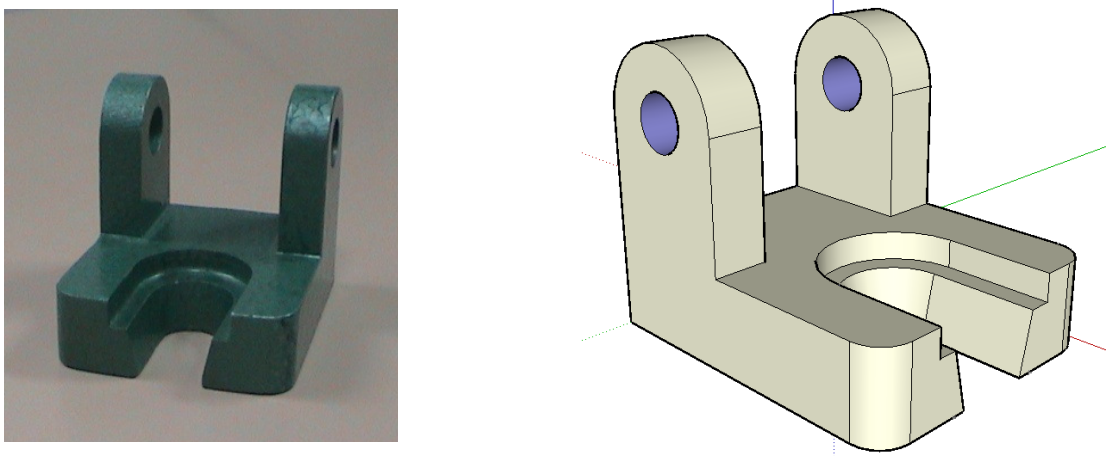

G. J. Lorenzo Díaz
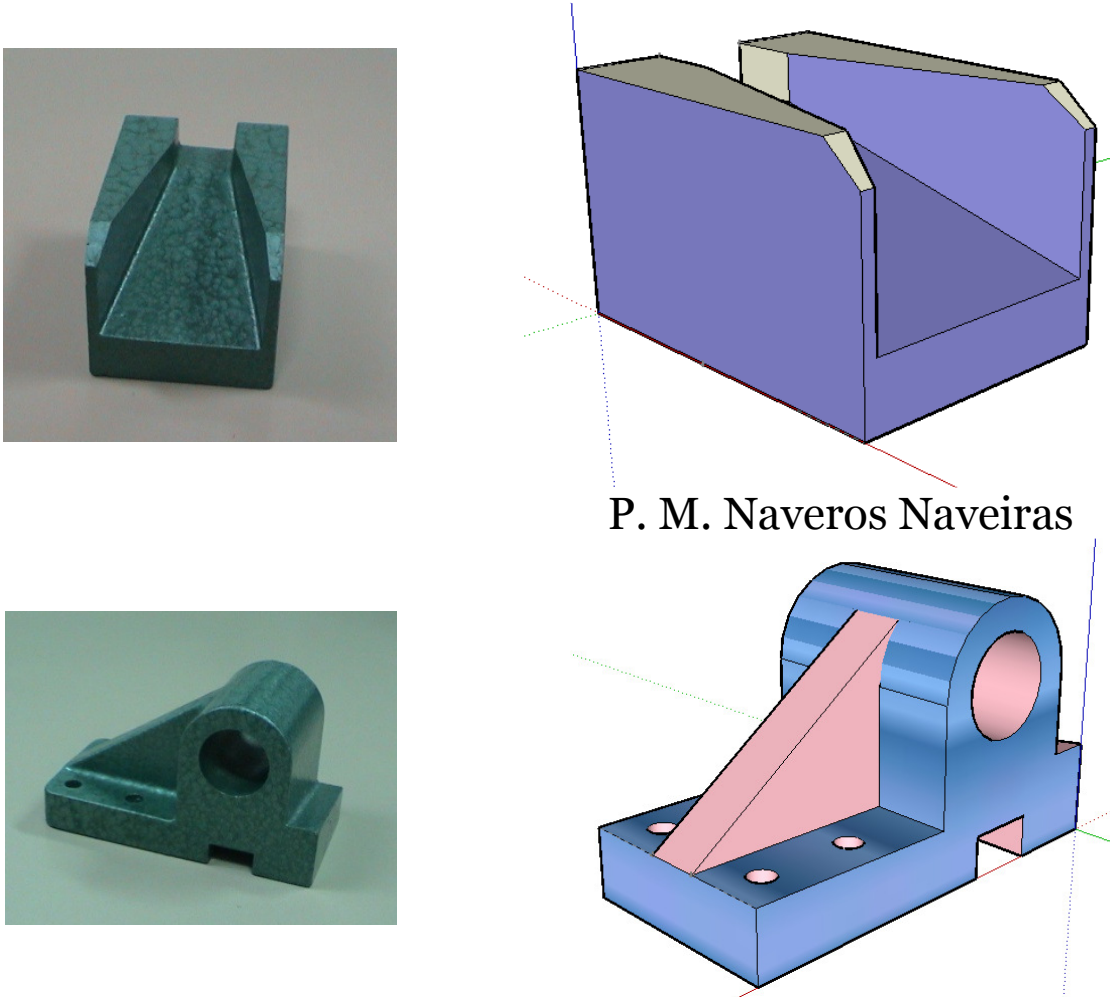

L. Rolo Pérez 


\section{Anexo VIII.- Ejercicios realizados por los participantes en la $1^{\text {a }}$ fase (trabajo en casa).}

\section{Enunciado del ejercicio:}

Realizar el modelo sólido en SketchUp de un objeto cotidiano. Los ejercicios son los realizados por los estudiantes. Pueden contener errores

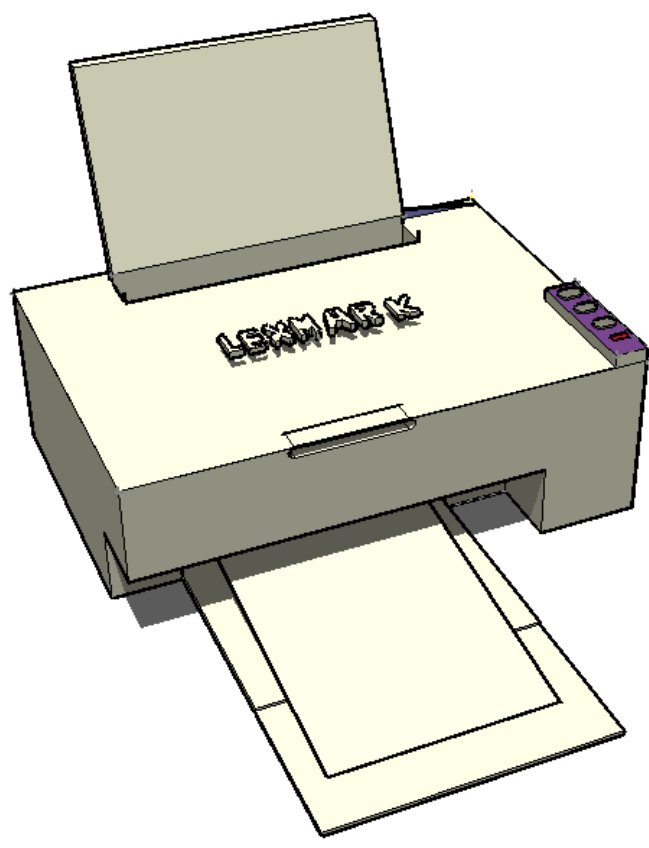

Impresora - J. Afonso Palma

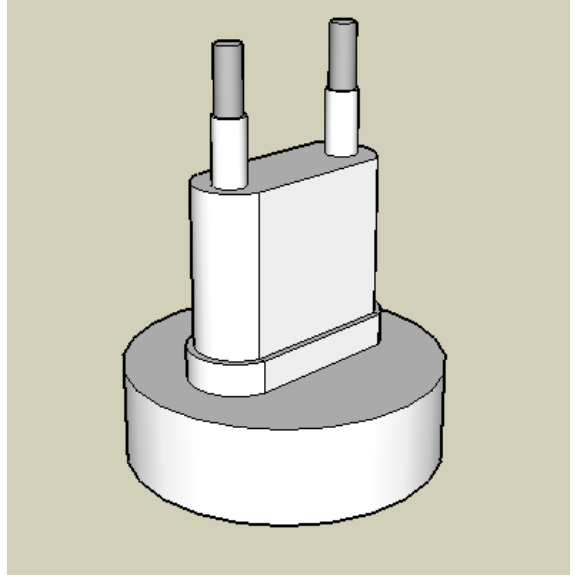

Adaptador - M. Arias Soto 


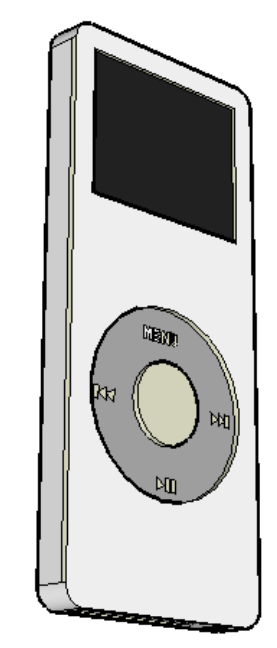

$$
\text { Ipod - F. J. Caballo Llopis }
$$

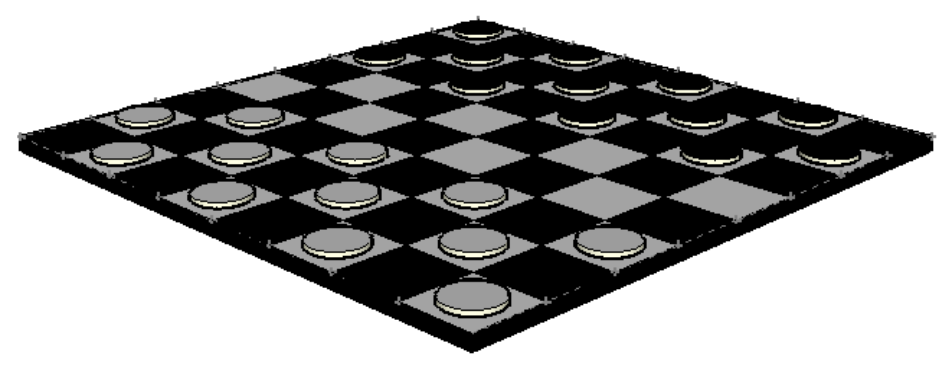

Tablero de damas- J. J. Cabrera Hernández

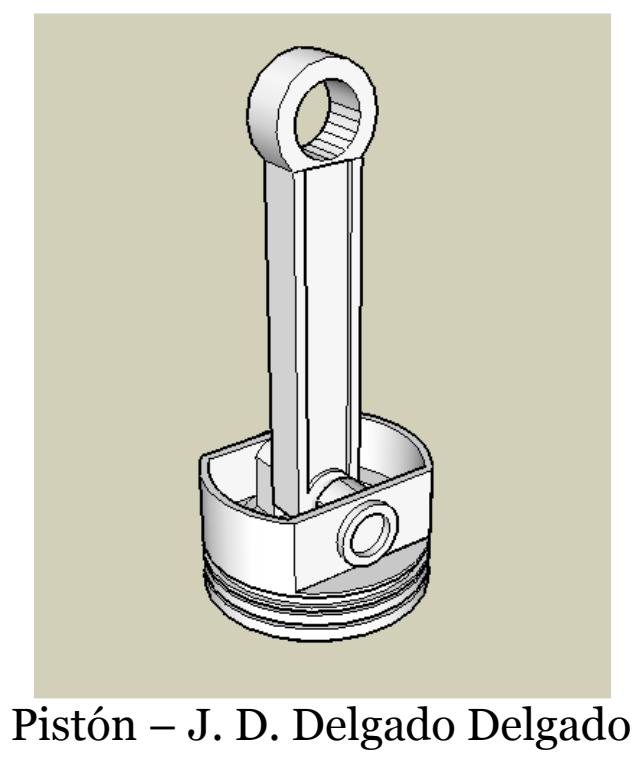




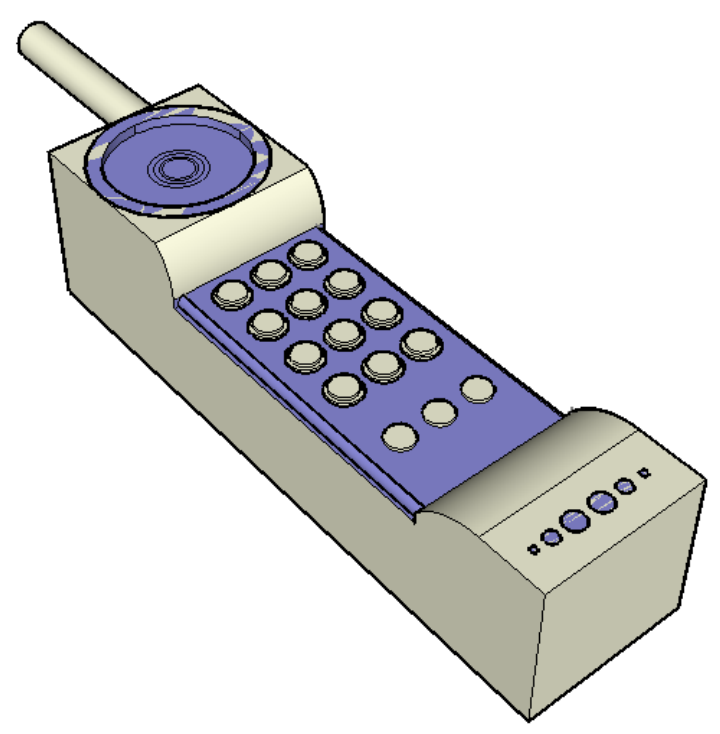

Teléfono - A. Delgado Hernández

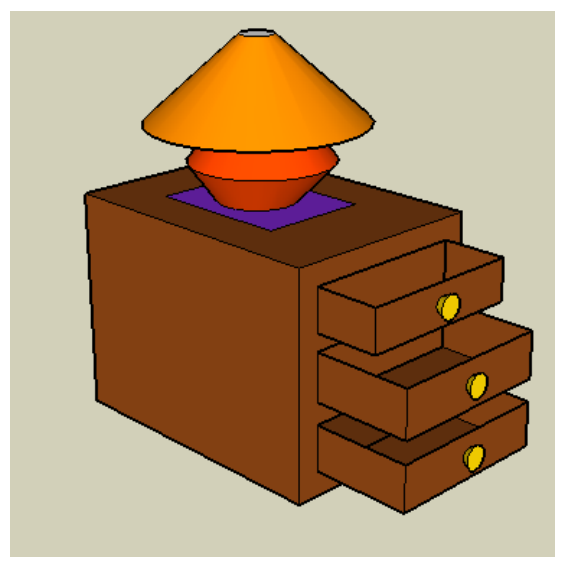

Mesa de noche - J. E. Díaz Rodríguez

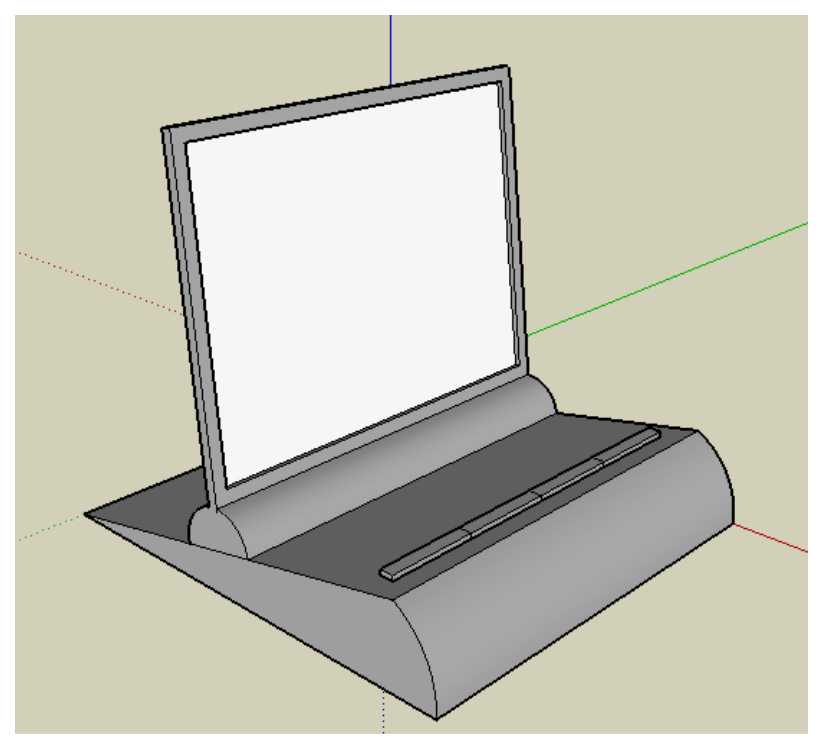

Reloj - G. J. Lorenzo Díaz. 

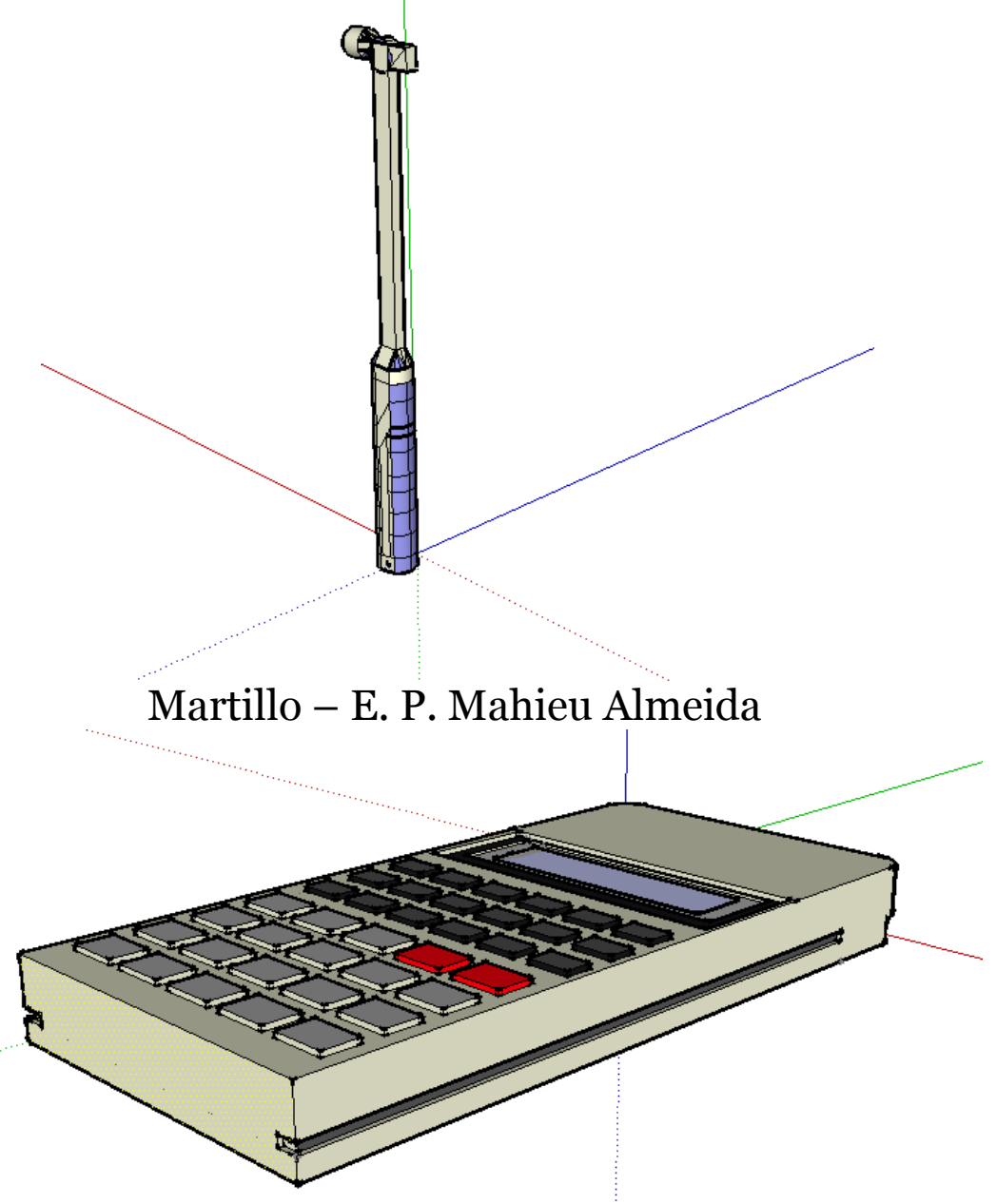

Calculadora - J. Melián Pérez

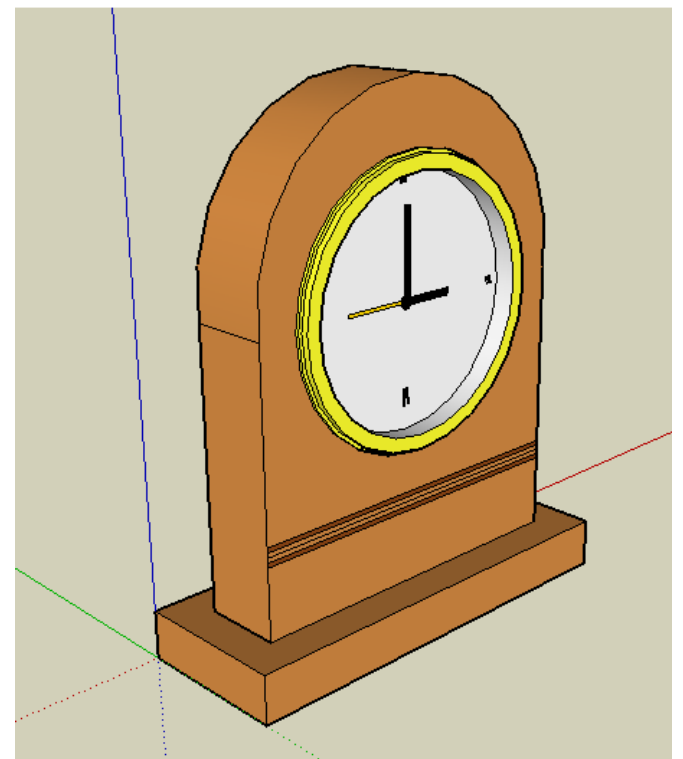

Reloj - F. J. Méndez Acosta 


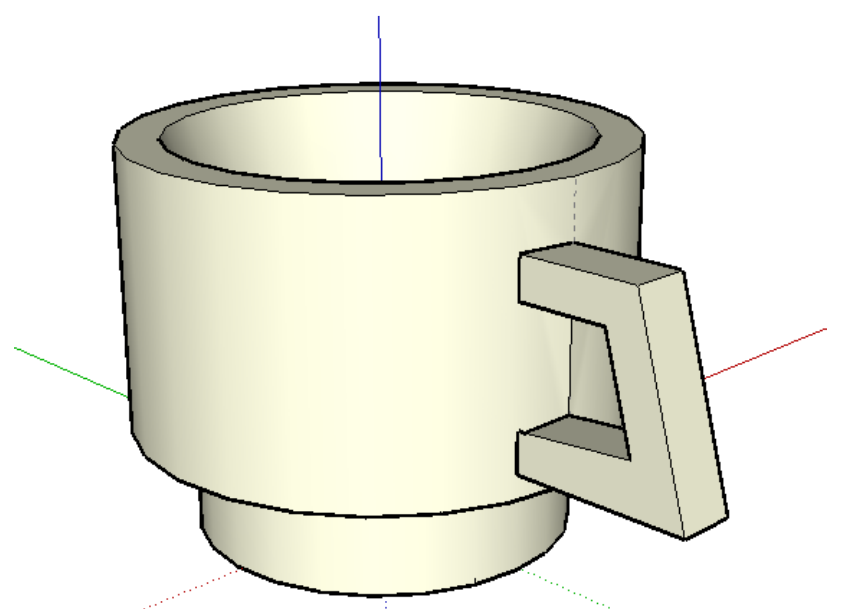

Taza - M. Méndez Palenzuela

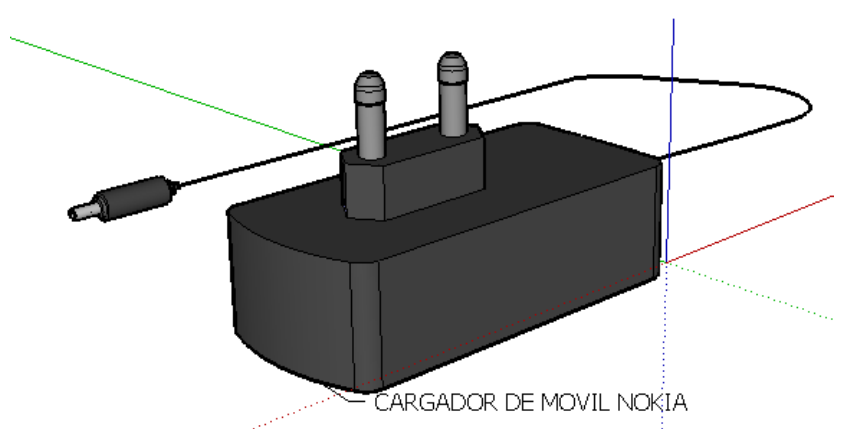

Cargador de móvil - I. Padilla Herrera

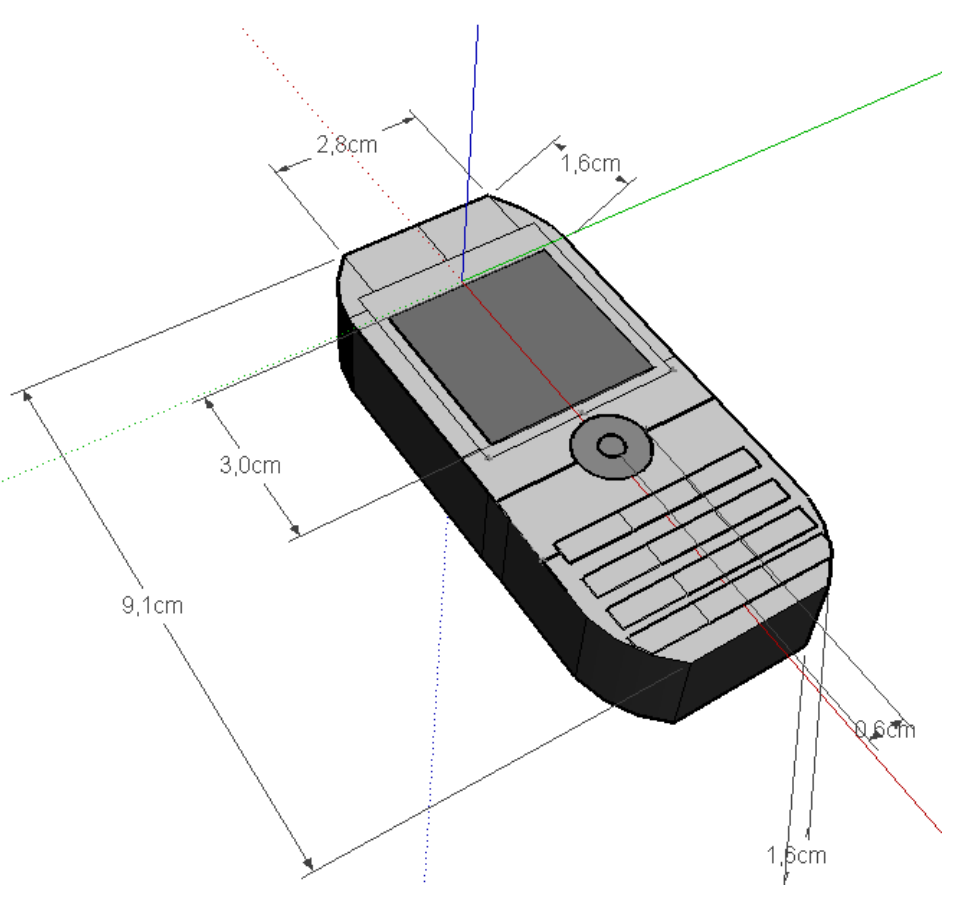

Móvil - M. Pérez Rodríguez 


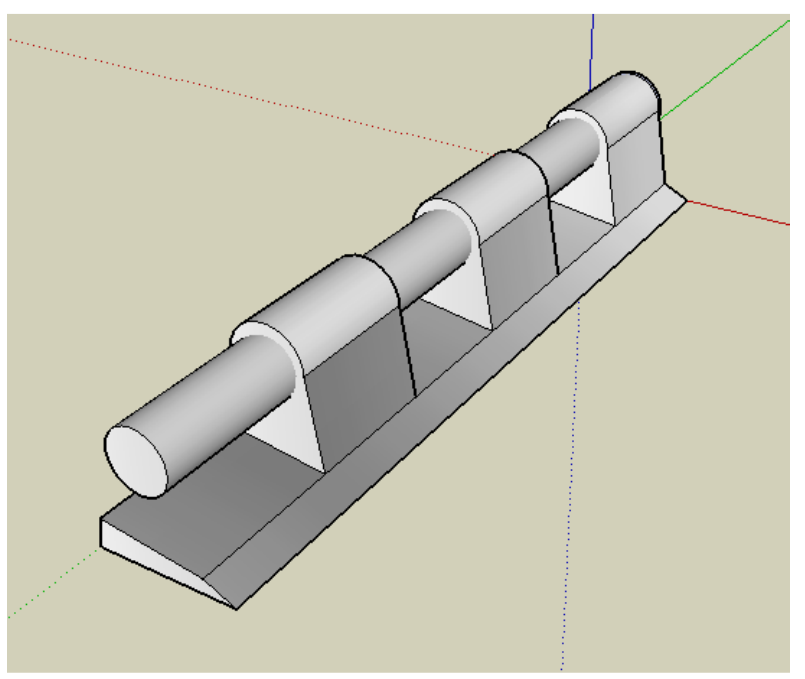

Bisagra - V. J. Rodríguez Pérez

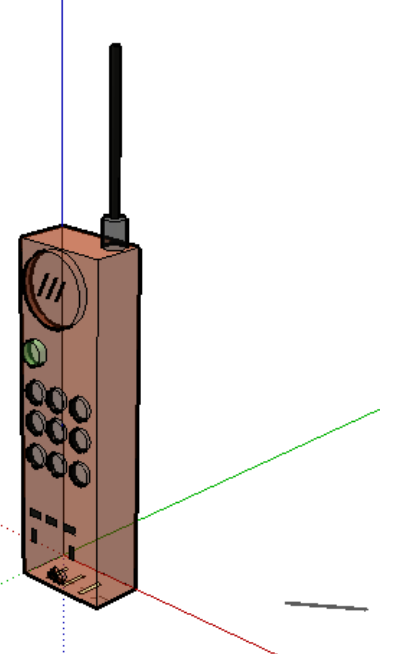

Teléfono - M. Taxonera Rodríguez

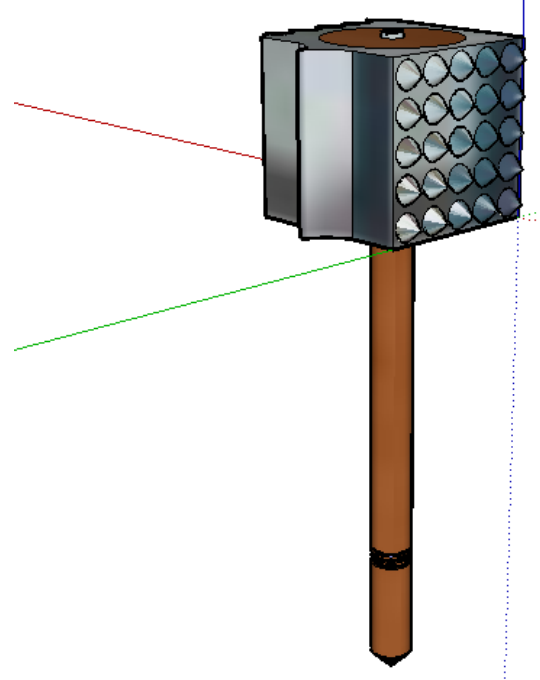

Mazo - M. Yanes Gutiérrez 


\section{Anexo IX.- Ejercicios realizados por los participantes en la segunda fase.}

Los ejercicios mostrados son los realizados por los estudiantes. Pueden contener errores.
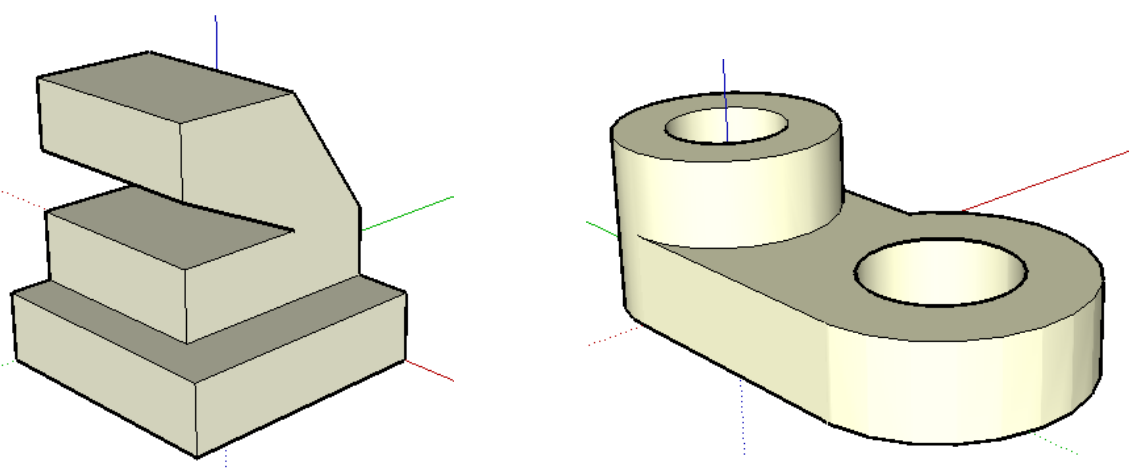

J. Almenara Vera
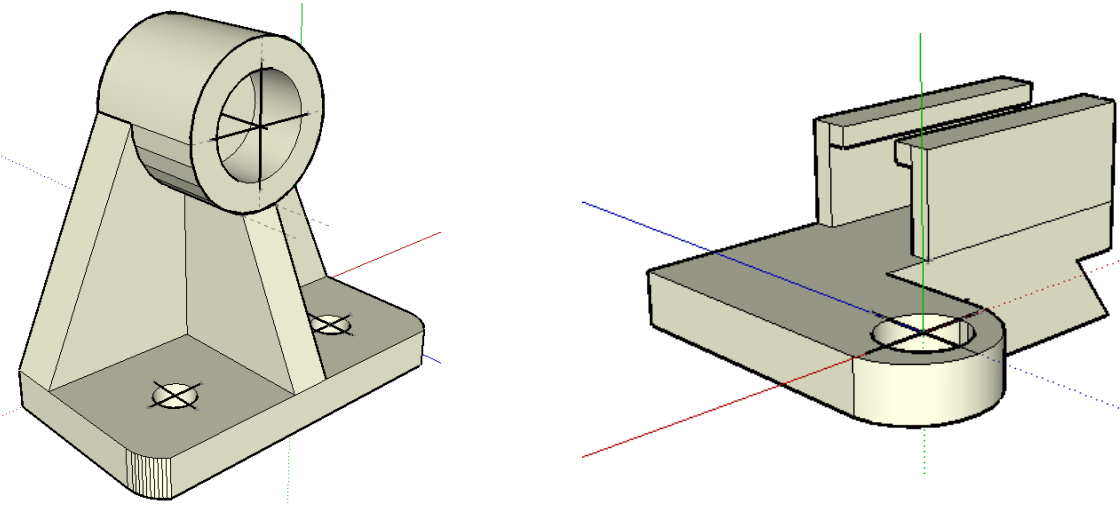

M. Arias Soto
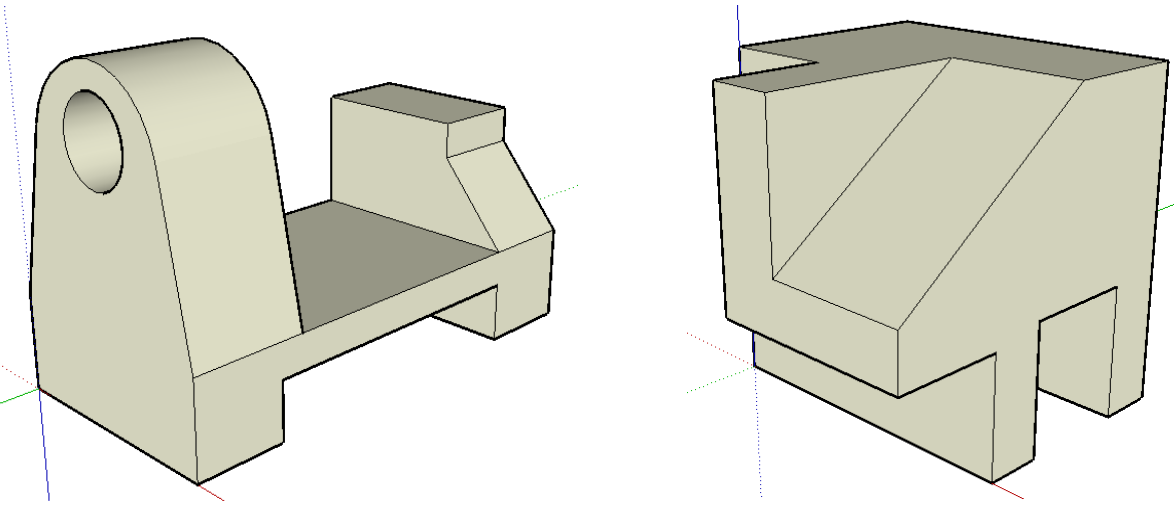

J. Cabrera Hernández 

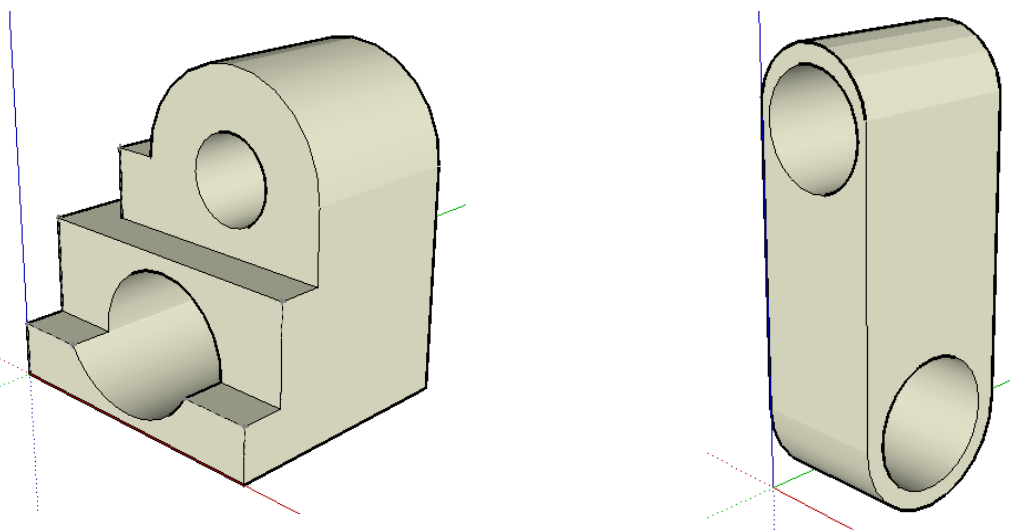

O. J. Casanova Melchor

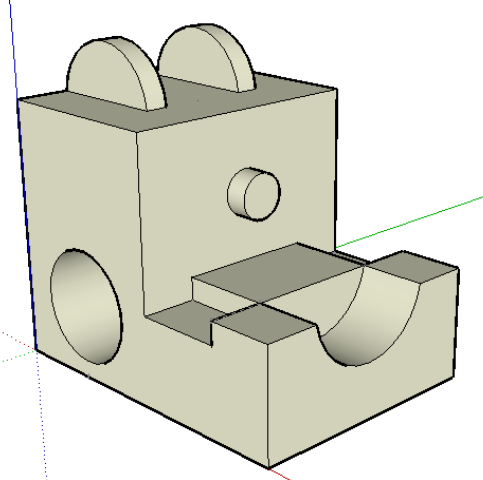

O. J. Casanova Melchor

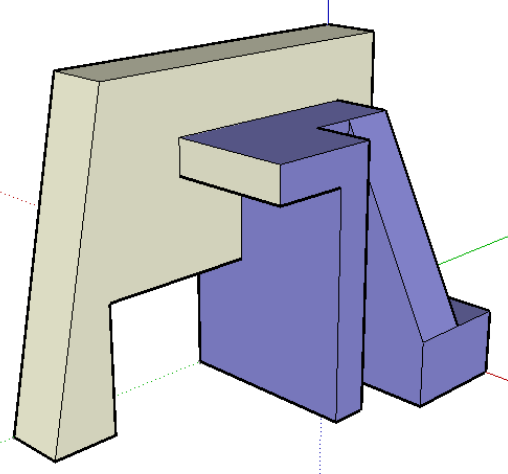

J. D. Delgado Delgado

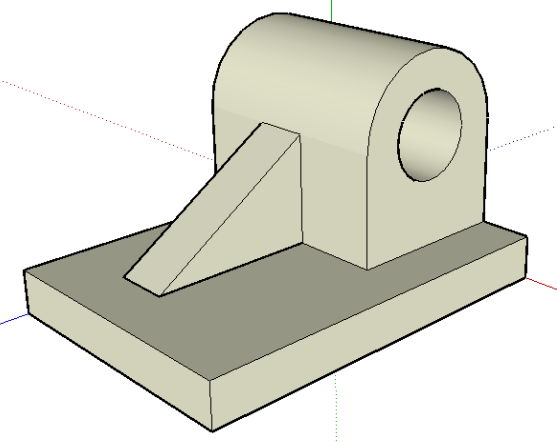

M. Gerster Acosta

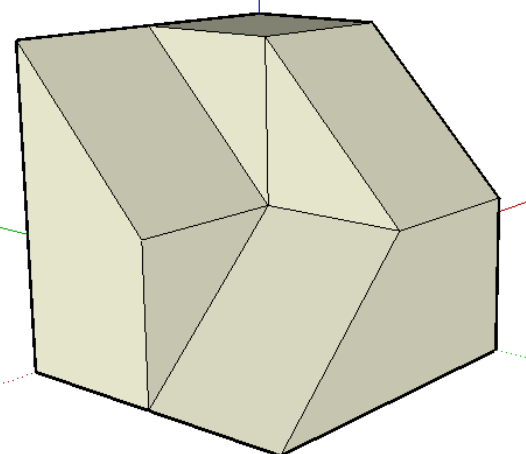

D. Curbelo Barreto

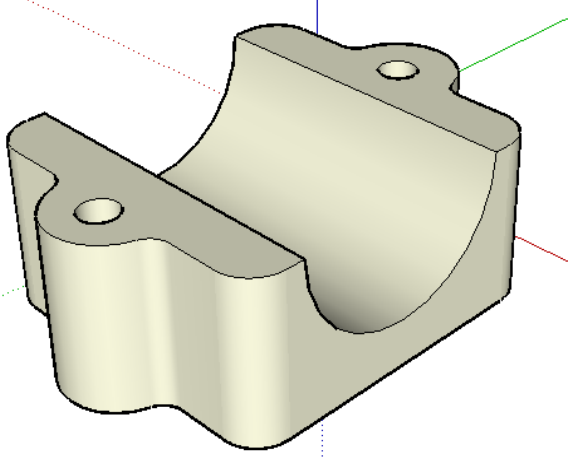

J. F. Díaz Sosa

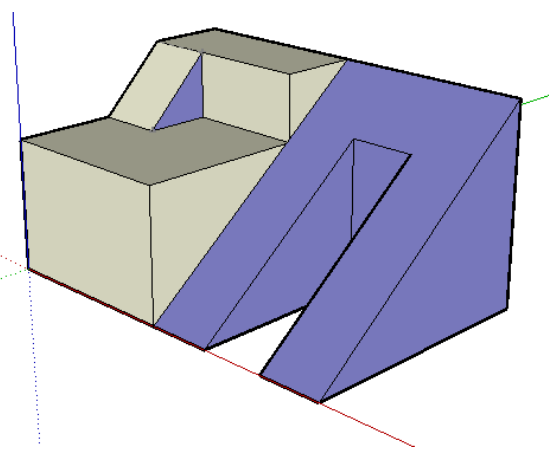

H. Gil Chávez 

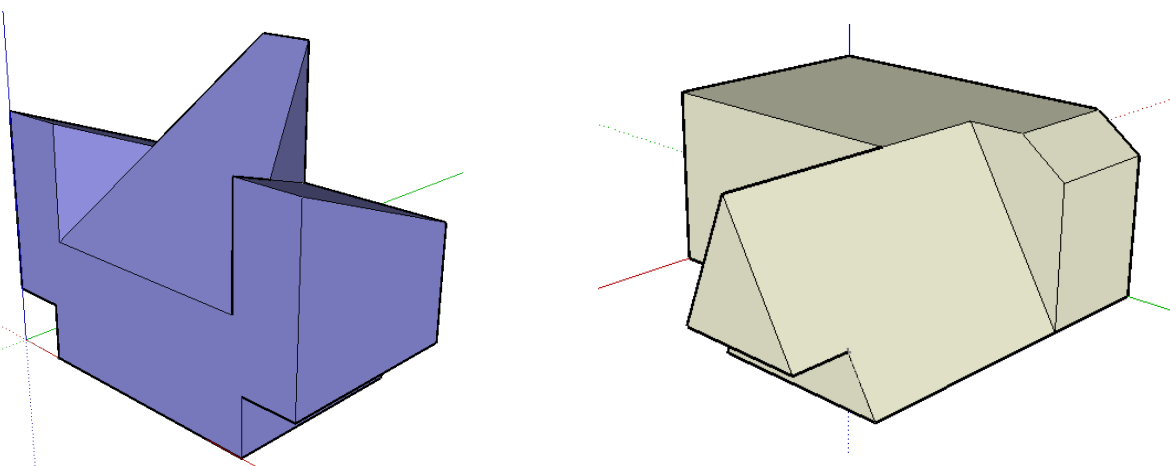

H. Gil Chávez

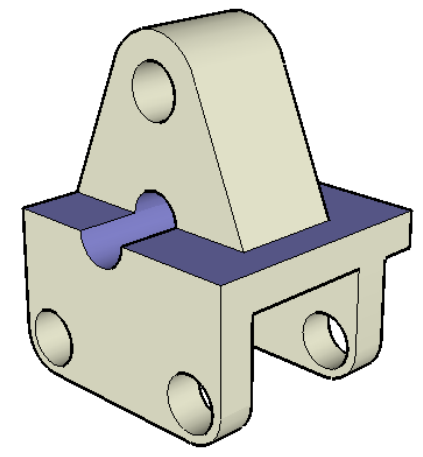

S. Hernández Fumero

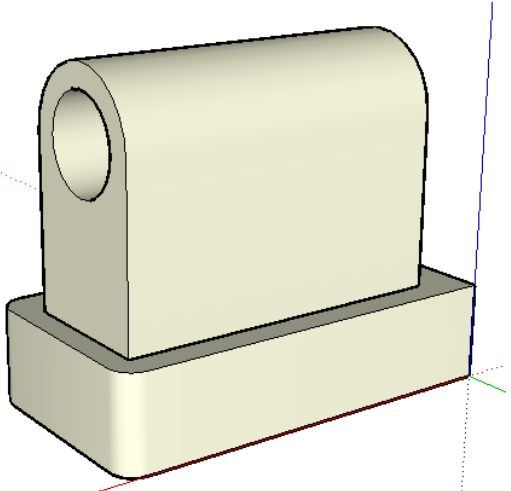

G. J. Lorenzo Díaz 


\section{Anexo X.- Ejercicios realizados por los participantes en la $3^{\mathrm{a}}$ fase (trabajo en grupo).}

Enunciado del ejercicio: Realizar en grupo el modelo sólido en

SketchUp de las siguientes piezas dadas por sus vistas diédricas.

Croquizar además la tercera vista de la pieza. Medirlas y realizarlas a la misma escala. Unidades en milímetros.

Los ejercicios de la derecha son los realizados por los estudiantes. Pueden contener errores.
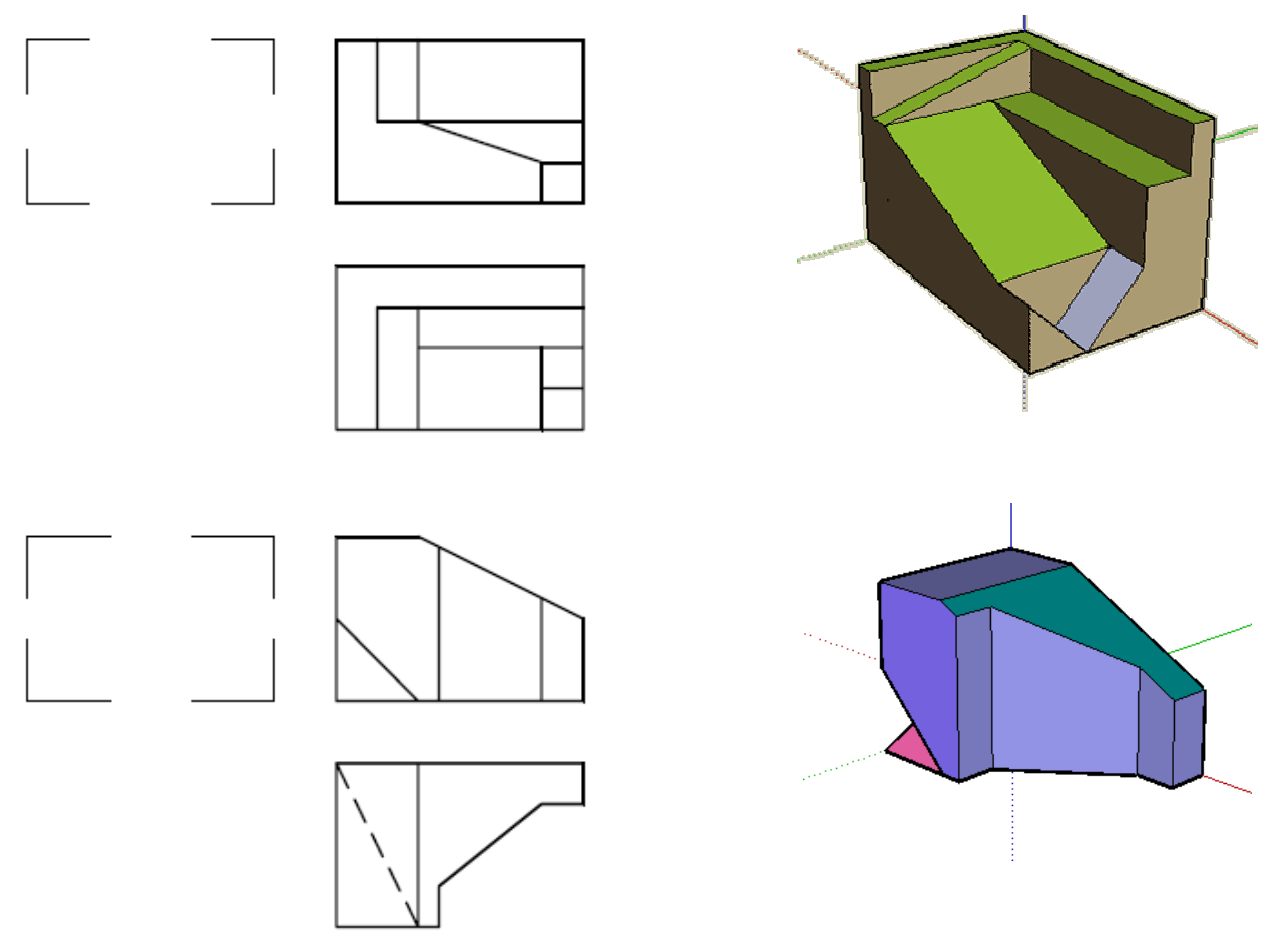

Grupo Po2

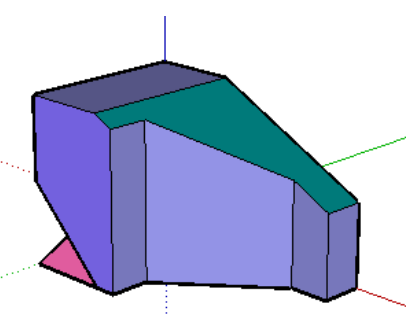



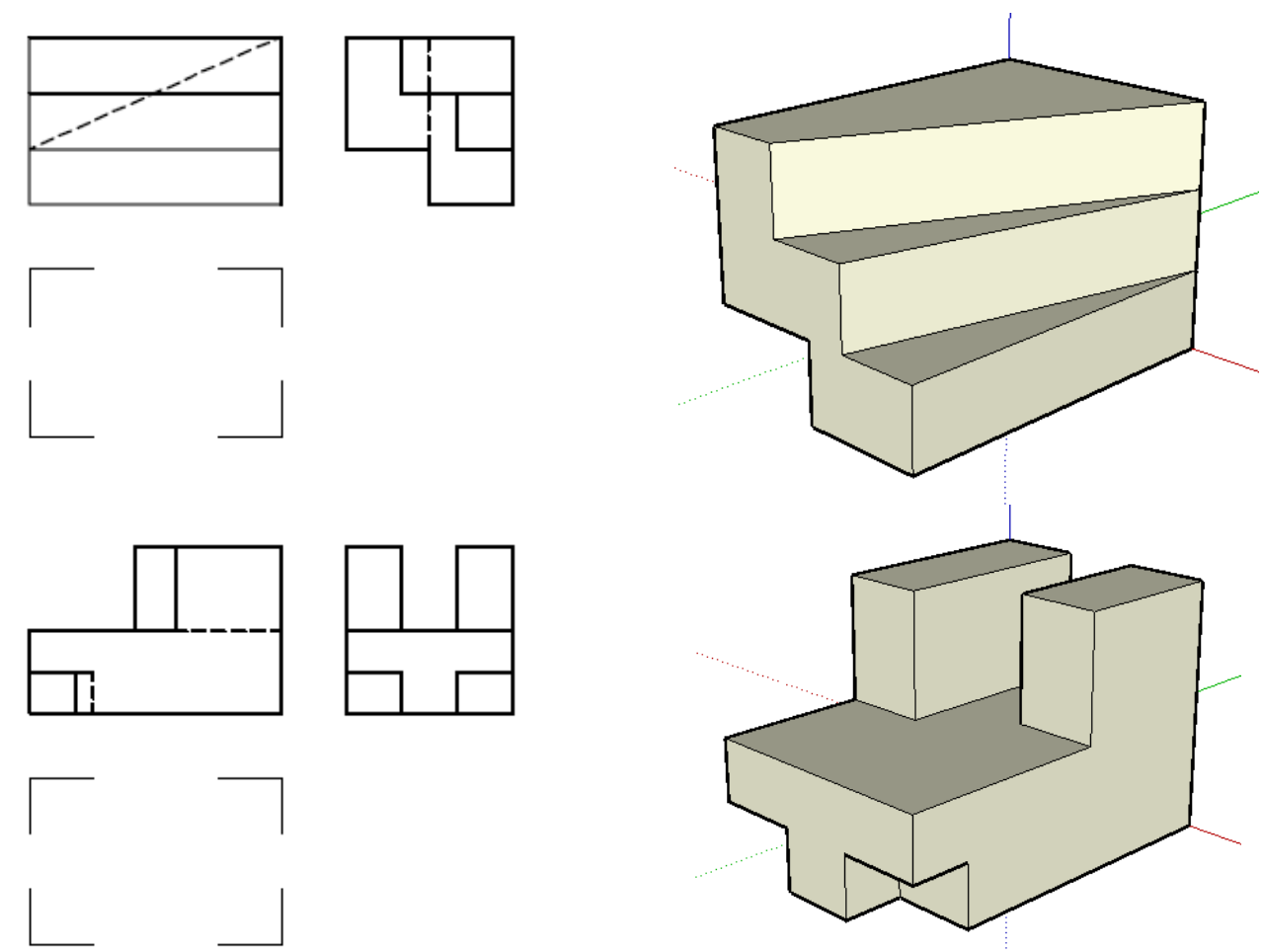

Grupo Po3
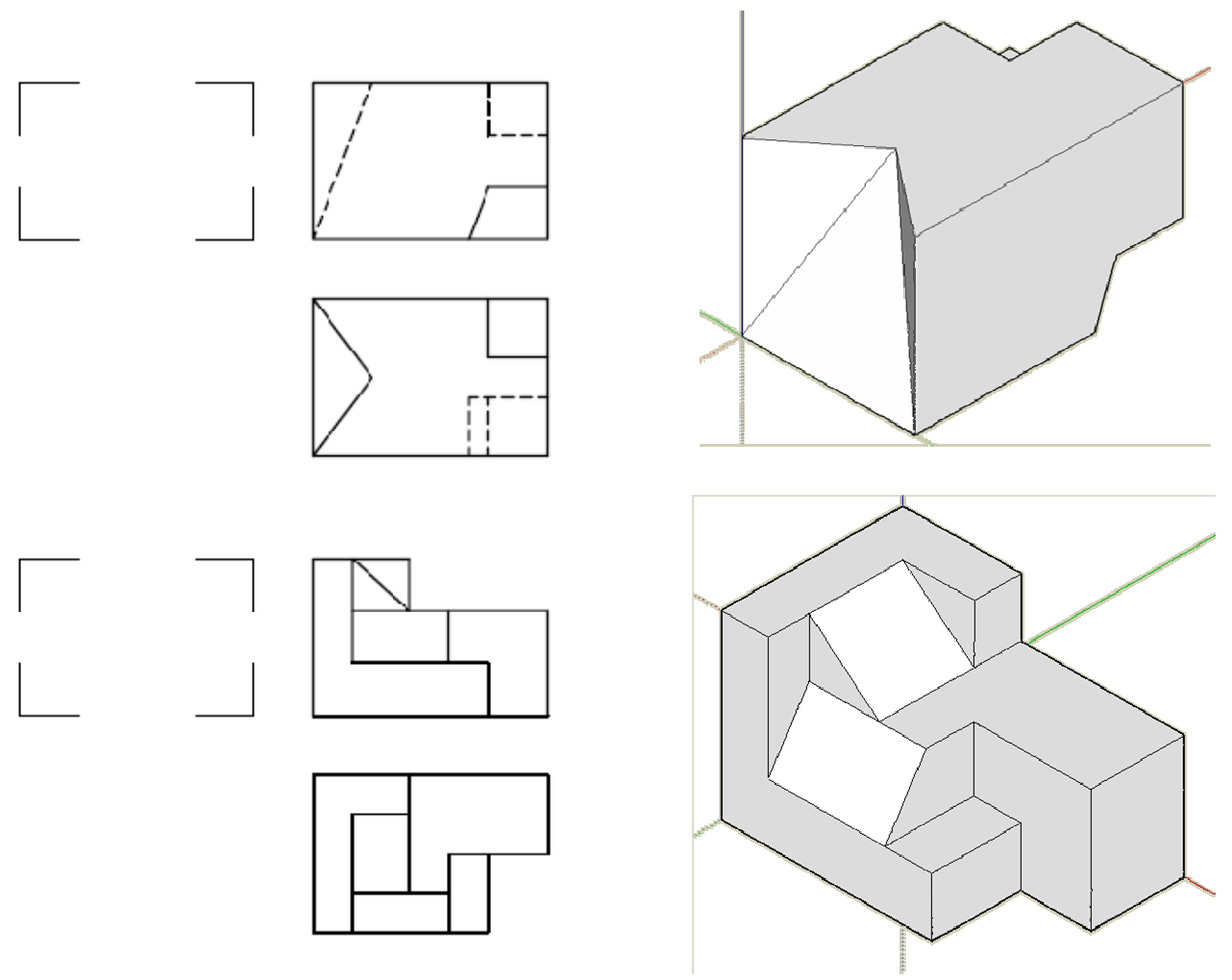

Grupo Po4 


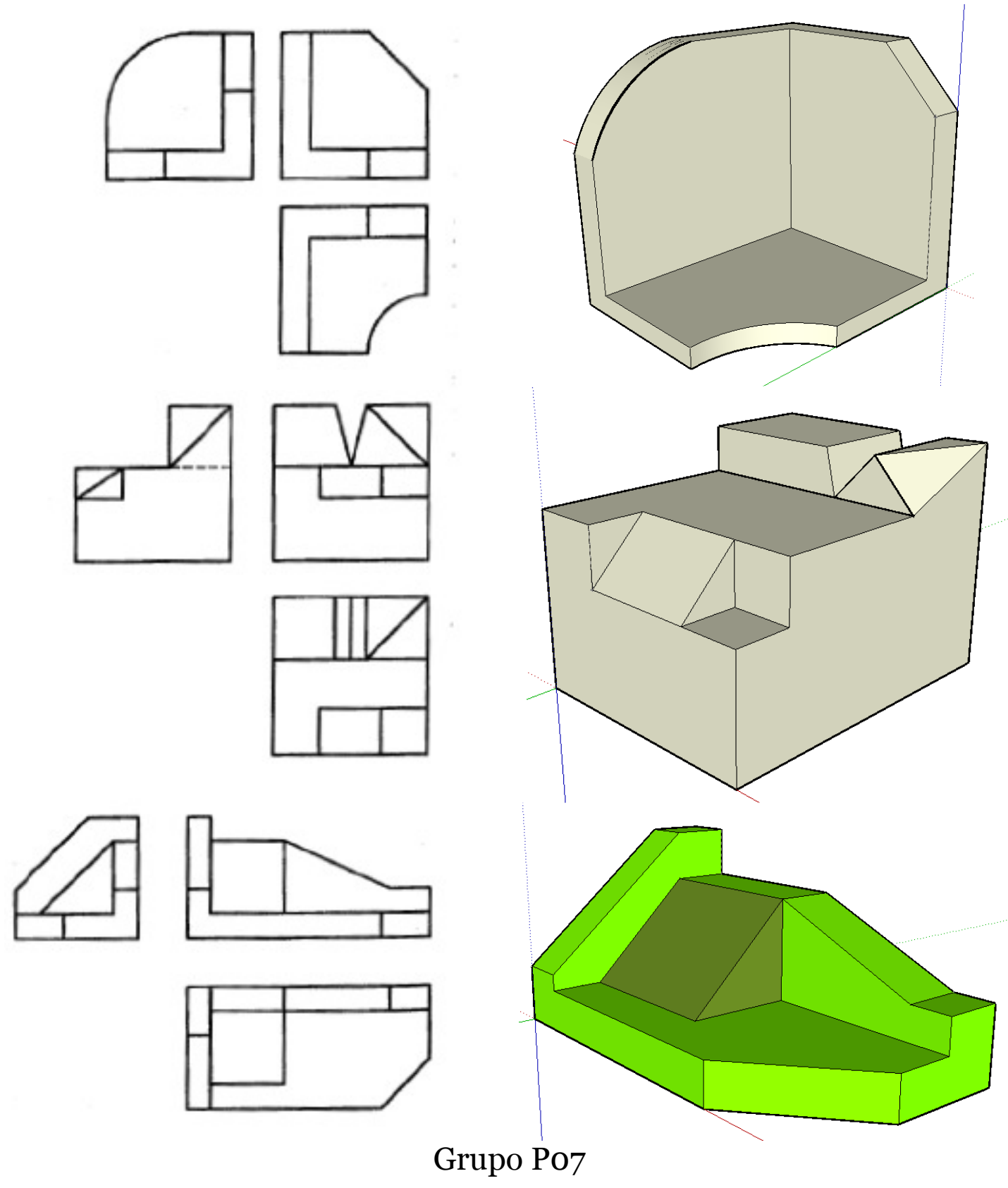



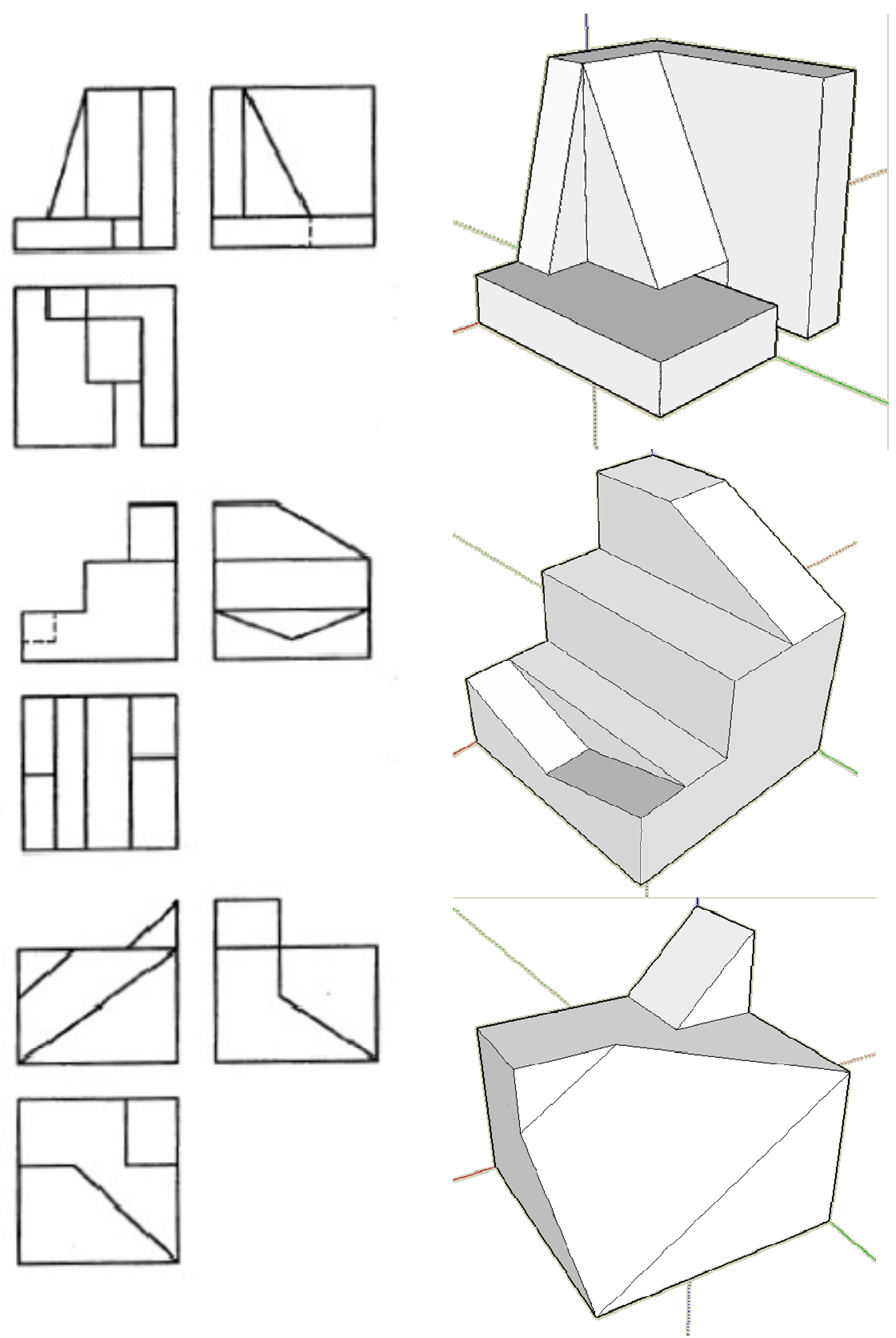

Grupo Po8 y P12 


\section{Anexo XI.- Puntuaciones obtenidas en el curso de SketchUp}

\begin{tabular}{|c|c|c|c|c|}
\hline & MRT & MRT & DAT & DAT \\
\hline Estudiante & Pre-Test & Post-Test & Pre-Test & Post-Test \\
\hline 1 & 27 & 22 & 37 & 39 \\
\hline 2 & 25 & 28 & 50 & 45 \\
\hline 3 & 7 & 8 & 32 & 43 \\
\hline 4 & 7 & 12 & 25 & 38 \\
\hline 5 & 15 & 14 & 37 & 52 \\
\hline 6 & 33 & 34 & 49 & 55 \\
\hline 7 & 8 & 10 & 31 & 47 \\
\hline 8 & 32 & 38 & 52 & 56 \\
\hline 9 & 17 & 25 & 37 & 35 \\
\hline 10 & 17 & 25 & 23 & 51 \\
\hline 11 & 27 & 40 & 57 & 60 \\
\hline 12 & 22 & 19 & 35 & 48 \\
\hline 13 & 18 & 22 & 27 & 51 \\
\hline 14 & 21 & 32 & 49 & 52 \\
\hline 15 & 28 & 22 & 55 & 57 \\
\hline 16 & 11 & 34 & 35 & 42 \\
\hline 17 & 14 & 18 & 20 & 37 \\
\hline 18 & 20 & 32 & 59 & 59 \\
\hline 19 & 22 & 31 & 42 & 54 \\
\hline 20 & 20 & 28 & 57 & 60 \\
\hline 21 & 23 & 34 & 55 & 58 \\
\hline 22 & 13 & 13 & 48 & 55 \\
\hline 23 & 17 & 27 & 48 & 51 \\
\hline 24 & 28 & 32 & 40 & 48 \\
\hline 25 & 20 & 25 & 49 & 59 \\
\hline 26 & 14 & 24 & 35 & 45 \\
\hline 27 & 19 & 29 & 47 & 54 \\
\hline 28 & 4 & 8 & 37 & 40 \\
\hline 29 & 8 & 21 & 28 & 37 \\
\hline 30 & 21 & 30 & 44 & 58 \\
\hline 31 & 19 & 24 & 33 & 50 \\
\hline 32 & 28 & 26 & 36 & 50 \\
\hline 33 & 24 & 32 & 49 & 51 \\
\hline 34 & 29 & 28 & 48 & 55 \\
\hline 35 & 16 & 18 & 45 & 54 \\
\hline 36 & 32 & 40 & 57 & 60 \\
\hline 37 & 21 & 26 & 49 & 55 \\
\hline 38 & 8 & 18 & 35 & 43 \\
\hline 39 & 12 & 13 & 31 & 37 \\
\hline 40 & 14 & 18 & 40 & 54 \\
\hline
\end{tabular}




\section{Anexo XII.- Análisis estadístico del curso con SketchUp \\ Curso Sketchup $\mathbf{N}=\mathbf{4 0}$}

Resumen descriptivo de las variables utilizadas.

\begin{tabular}{|ll|r|r|r|r|r|r|}
\hline \multirow{2}{*}{ Sexo } & & PreMRT & PostMRT & $\begin{array}{r}\text { Ganancia } \\
\text { MRT }\end{array}$ & PreDAT & PostDAT & $\begin{array}{c}\text { Ganancia } \\
\text { DAT }\end{array}$ \\
\hline hombre & N & 25 & 25 & 25 & 25 & 25 & 25 \\
& Media & 21,28 & 27,24 & 5,96 & 42,36 & 50,52 & 8,16 \\
& Desv. típ. & 7,249 & 7,721 & 4,198 & 11,049 & 7,223 & 7,771 \\
& Error típ. de la & 1,450 & 1,544 &, 840 & 2,210 & 1,445 & 1,554 \\
& media & 15 & 15 & 15 & 15 & 15 & 15 \\
mujer & N & 15,27 & 19,93 & 4,67 & 40,27 & 48,80 & 8,53 \\
& Media & 6,829 & 7,950 & 7,603 & 9,246 & 8,002 & 4,764 \\
& Desv. típ. & 1,763 & 2,053 & 1,963 & 2,387 & 2,066 & 1,230 \\
& Error típ. de la & 40 & 40 & 40 & 40 & 40 & 40 \\
media & N & 19,03 & 24,50 & 5,48 & 41,58 & 49,88 & 8,30 \\
& Media & 7,601 & 8,497 & 5,657 & 10,338 & 7,470 & 6,734 \\
& Desv. típ. & 1,202 & 1,344 &, 894 & 1,635 & 1,181 & 1,065 \\
\hline
\end{tabular}

\section{Prueba T, Muestras relacionadas}

Estadísticos de muestras relacionadas

\begin{tabular}{|ll|r|r|r|r|}
\hline & Media & $\mathrm{N}$ & \multicolumn{1}{c|}{$\begin{array}{c}\text { Desviación } \\
\text { típ. }\end{array}$} & $\begin{array}{c}\text { Error típ. de } \\
\text { la media }\end{array}$ \\
\hline Par 1 & PreMRT & 19,03 & 40 & 7,601 & 1,202 \\
& PostMRT & 24,50 & 40 & 8,497 & 1,344 \\
Par 2 & PreDAT & 41,58 & 40 & 10,338 & 1,635 \\
& PostDAT & 49,88 & 40 & 7,470 & 1,181 \\
\hline
\end{tabular}

Correlaciones de muestras relacionadas

\begin{tabular}{|ll|r|r|r|}
\hline & & N & Correlación & \multicolumn{1}{c|}{ Sig. } \\
\hline Par 1 & PreMRT y PostMRT & 40 &, 758 &, 0000000143 \\
Par 2 & PreDAT y PostDAT & 40 &, 760 &, 0000000132 \\
\hline
\end{tabular}




\section{Prueba de muestras relacionadas}

\begin{tabular}{|c|c|c|c|c|c|c|c|c|c|}
\hline & & \multicolumn{5}{|c|}{ Diferencias relacionadas } & \multirow{3}{*}{$\begin{array}{c}\mathrm{t} \\
\text { Media } \\
\text { Superior }\end{array}$} & \multirow{3}{*}{$\begin{array}{c}\text { gl } \\
\begin{array}{c}\text { Desviación } \\
\text { típ. }\end{array} \\
\text { Inferior }\end{array}$} & \multirow{3}{*}{$\begin{array}{c}\text { Sig. } \\
\text { (bilateral) } \\
\text { Error típ. } \\
\text { de la } \\
\text { media } \\
\\
\text { Superior }\end{array}$} \\
\hline & & \multirow{2}{*}{$\begin{array}{l}\text { Media } \\
\text { Inferior }\end{array}$} & \multirow{2}{*}{$\begin{array}{c}\text { Desviación } \\
\text { típ. } \\
\text { Superior }\end{array}$} & \multirow{2}{*}{$\begin{array}{c}\text { Error típ. de } \\
\text { la media } \\
\text { Inferior }\end{array}$} & \multicolumn{2}{|c|}{$\begin{array}{c}95 \% \text { Intervalo de } \\
\text { confianza para la } \\
\text { diferencia }\end{array}$} & & & \\
\hline & & & & & Superior & Inferior & & & \\
\hline & $\begin{array}{l}\text { PreMRT } \\
\text { PostMRT }\end{array}$ & $-5,475$ & 5,657 & ,894 & $-7,284$ & $-3,666$ & $-6,121$ & 39 & $\begin{array}{r}, 00000035 \\
1\end{array}$ \\
\hline Par 2 & $\begin{array}{l}\text { PreDAT } \\
\text { PostDAT }\end{array}$ & $-8,300$ & 6,734 & 1,065 & $-10,454$ & $-6,146$ & $-7,796$ & 39 & $\begin{array}{r}, 00000000 \\
18\end{array}$ \\
\hline
\end{tabular}

\section{Prueba T, Muestras independientes comparación por sexo}

Estadísticos de grupo

\begin{tabular}{|ll|r|r|r|r|}
\hline & Sexo & $\mathrm{N}$ & Media & $\begin{array}{c}\text { Desviación } \\
\text { típ. }\end{array}$ & $\begin{array}{c}\text { Error típ. de } \\
\text { la media }\end{array}$ \\
\hline GananciaMRT & mujer & 15 & 4,67 & 7,603 & 1,963 \\
& hombre & 25 & 5,96 & 4,198 &, 840 \\
GananciaDAT & mujer & 15 & 8,53 & 4,764 & 1,230 \\
& hombre & 25 & 8,16 & 7,771 & 1,554 \\
\hline
\end{tabular}

Prueba de muestras independientes

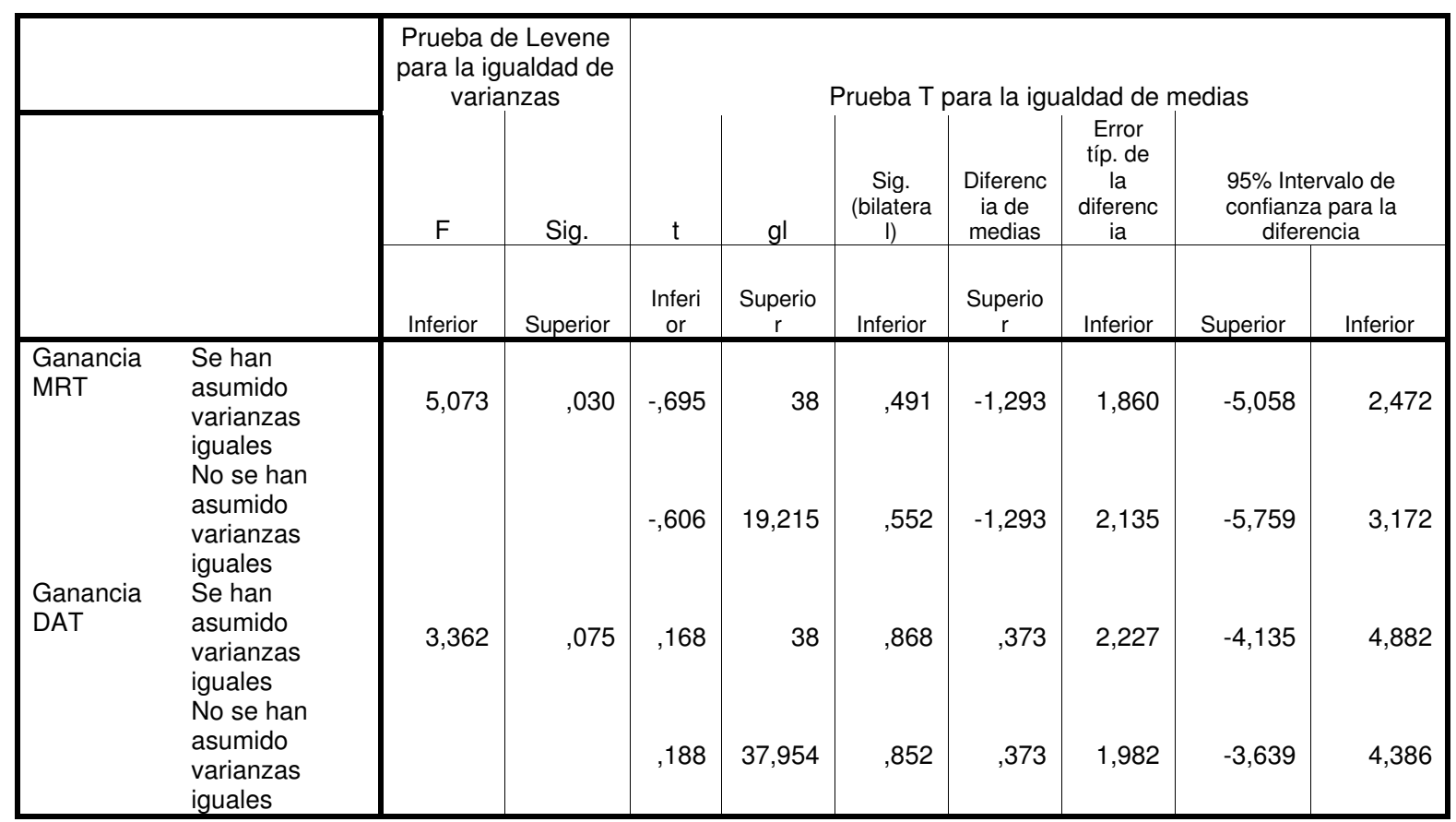


Ecuación de regresión del Post-test MRT vs. Pre-test MRT

Resumen del modelo

\begin{tabular}{|r|r|r|r|}
\hline $\mathrm{R}$ & $\mathrm{R}$ cuadrado & $\begin{array}{c}\text { R cuadrado } \\
\text { corregida }\end{array}$ & $\begin{array}{c}\text { Error típico de } \\
\text { la estimación }\end{array}$ \\
\hline, 758 &, 575 &, 564 & 5,610 \\
\hline
\end{tabular}

La variable independiente esPreMRT.

ANOVA

\begin{tabular}{|l|r|r|r|r|r|}
\hline & \multicolumn{1}{|c|}{$\begin{array}{c}\text { Suma de } \\
\text { cuadrados }\end{array}$} & gl & $\begin{array}{c}\text { Media } \\
\text { cuadrática }\end{array}$ & \multicolumn{1}{c|}{ F } & \multicolumn{1}{c|}{ Sig. } \\
\hline Regresión & 1620,085 & 1 & 1620,085 & 51,478 &, 000 \\
Residual & 1195,915 & 38 & 31,471 & & \\
Total & 2816,000 & 39 & & & \\
\hline
\end{tabular}

La variable independiente esPreMRT.

\section{Coeficientes}

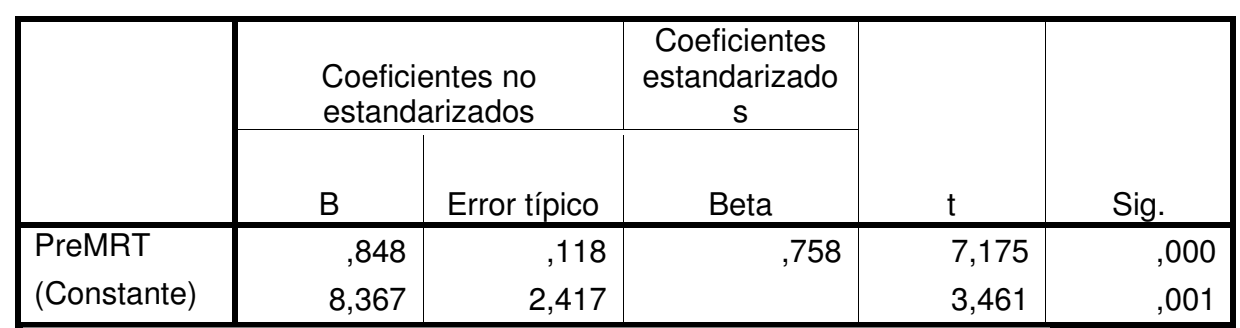

\section{PostMRT}

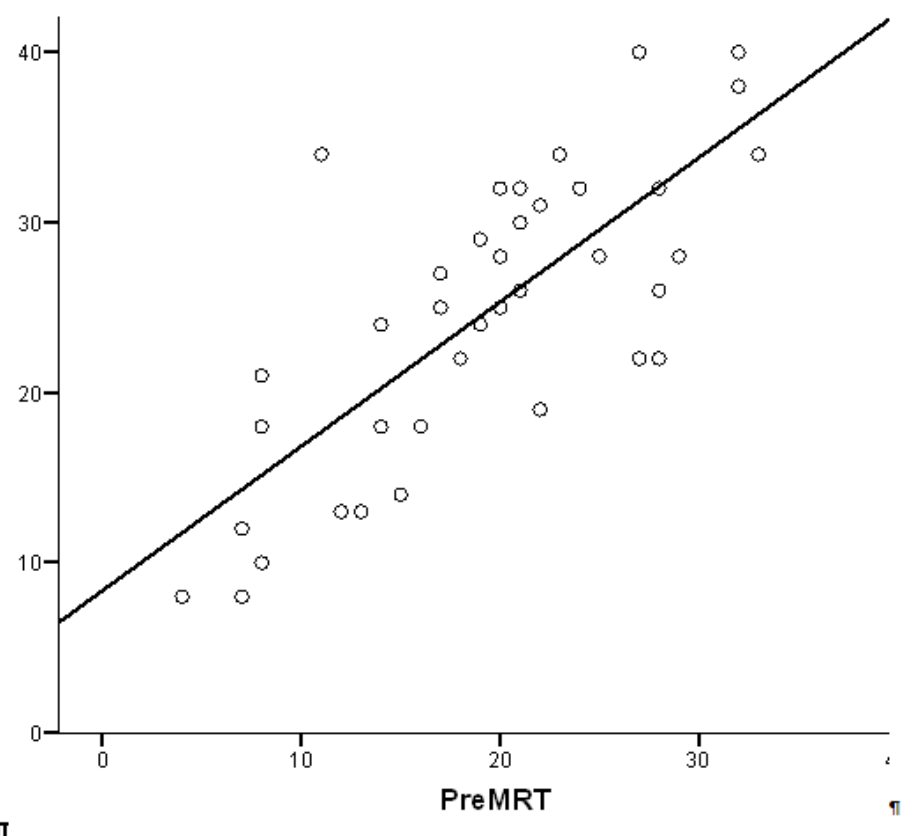


Ecuación de regresión del Post-test MRT vs. Pre-test MRT

Resumen del modelo

\begin{tabular}{|r|r|r|r|}
\hline \multicolumn{1}{|c|}{$\mathrm{R}$} & $\mathrm{R}$ cuadrado & $\begin{array}{c}\text { R cuadrado } \\
\text { corregida }\end{array}$ & $\begin{array}{c}\text { Error típico de } \\
\text { la estimación }\end{array}$ \\
\hline, 760 &, 577 &, 566 & 4,922 \\
\hline
\end{tabular}

La variable independiente esPreDAT.

ANOVA

\begin{tabular}{|l|r|r|r|r|r|}
\hline & \multicolumn{1}{|c|}{$\begin{array}{c}\text { Suma de } \\
\text { cuadrados }\end{array}$} & gl & $\begin{array}{c}\text { Media } \\
\text { cuadrática }\end{array}$ & \multicolumn{1}{c|}{ F } & \multicolumn{1}{c|}{ Sig. } \\
\hline Regresión & 1255,915 & 1 & 1255,915 & 51,849 &, 000 \\
Residual & 920,460 & 38 & 24,223 & & \\
Total & 2176,375 & 39 & & & \\
\hline
\end{tabular}

La variable independiente esPreDAT.

\section{Coeficientes}

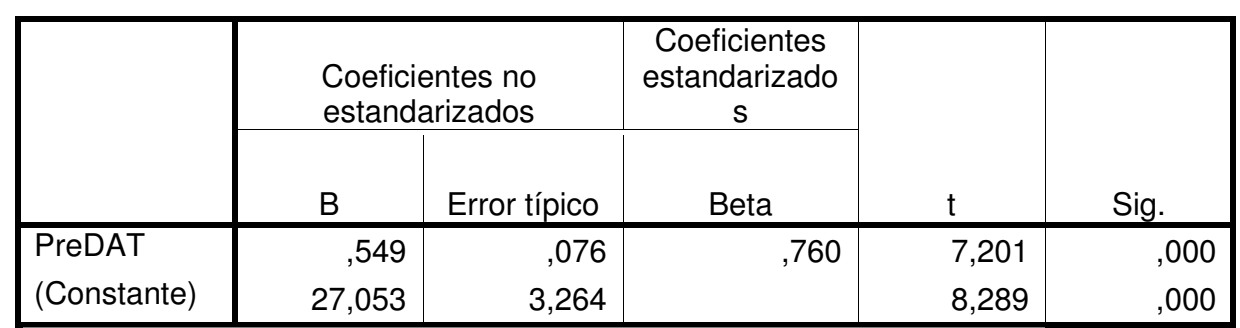

PostDAT

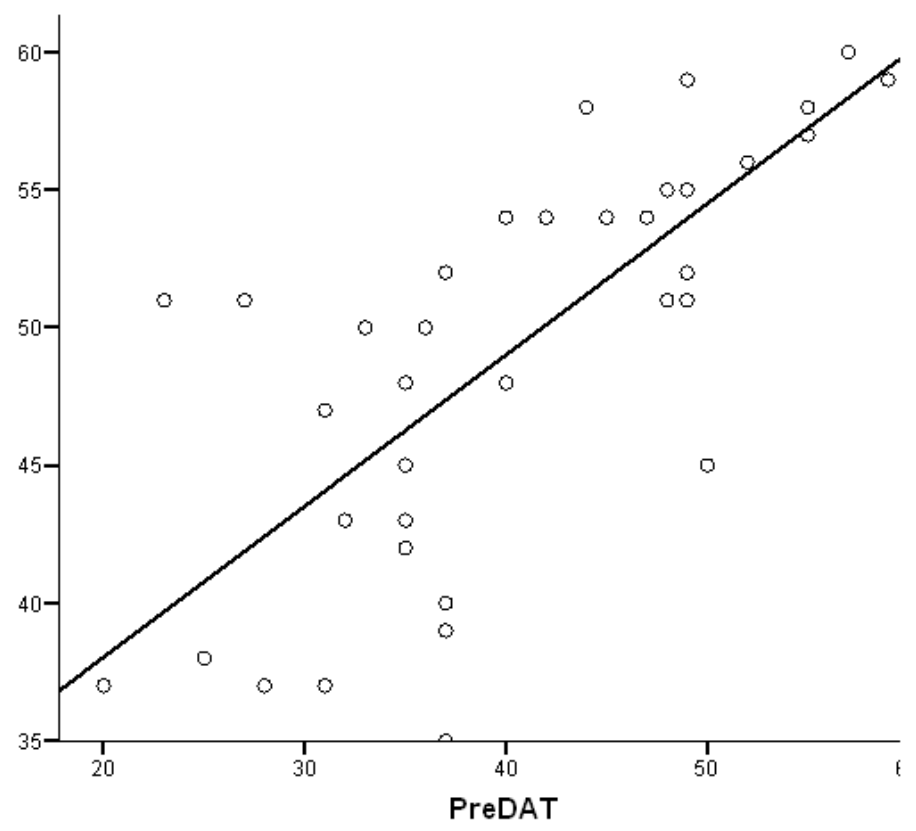




\section{Comparación de la Ganancia de los Test MRT y DAT entre los 4 grupos: Papel, Web, E-cigro y SketchUp}

\section{ANOVA de un factor}

Prueba de homogeneidad de varianzas

\begin{tabular}{|l|r|r|r|r|}
\hline & $\begin{array}{l}\text { Estadístico } \\
\text { de Levene }\end{array}$ & gl1 & \multicolumn{1}{|c|}{ gl2 } & \multicolumn{1}{c|}{ Sig. } \\
\hline Ganancia MRT &, 447 & 3 & 60 &, 721 \\
Ganancia DAT &, 744 & 3 & 60 &, 530 \\
\hline
\end{tabular}

ANOVA

\begin{tabular}{|ll|r|r|r|r|r|}
\hline & \multicolumn{1}{c|}{$\begin{array}{c}\text { Suma de } \\
\text { cuadrados }\end{array}$} & gl & $\begin{array}{c}\text { Media } \\
\text { cuadrática }\end{array}$ & \multicolumn{1}{c|}{ F } & \multicolumn{1}{c|}{ Sig. } \\
\hline Ganancia & Inter-grupos & 68,009 & 3 & 22,670 &, 830 &, 483 \\
MRT & Intra-grupos & 1638,548 & 60 & 27,309 & & \\
& Total & 1706,558 & 63 & & & \\
\hline Ganancia & Inter-grupos & 471,270 & 3 & 157,090 & 4,353 &, 008 \\
DAT & Intra-grupos & 2165,215 & 60 & 36,087 & & \\
& Total & 2636,484 & 63 & & & \\
\hline
\end{tabular}

\section{Pruebas post hoc}

\section{Subconjuntos homogéneos}

\section{DifDAT}

HSD de Tukey ${ }^{\mathrm{a}, \mathrm{b}}$

\begin{tabular}{|l|r|r|r|}
\hline \multirow{2}{*}{ GRUPO } & & \multicolumn{2}{|c|}{$\begin{array}{r}\text { Subconjunto para alfa } \\
=.05\end{array}$} \\
\cline { 3 - 4 } & $\mathrm{N}$ & 1 & \multicolumn{1}{c|}{2} \\
\hline Web & 15 & 5,13 & \\
E-Cigro & 20 & 7,40 & 7,40 \\
Papel & 17 & & 10,88 \\
SketchUp & 12 & & 12,42 \\
Sig. & &, 722 &, 105 \\
\hline
\end{tabular}

Se muestran las medias para los grupos en los subconjuntos homogéneos.

a. Usa el tamaño muestral de la media armónica = 15,455 .

b. Los tamaños de los grupos no son iguales. Se utilizará la media armónica de los tamaños de los grupos. Los niveles de error de tipo I no están garantizados. 


\section{Anexo XIII.- Clasificación de ejercicios para la mejora de las habilidades espaciales}

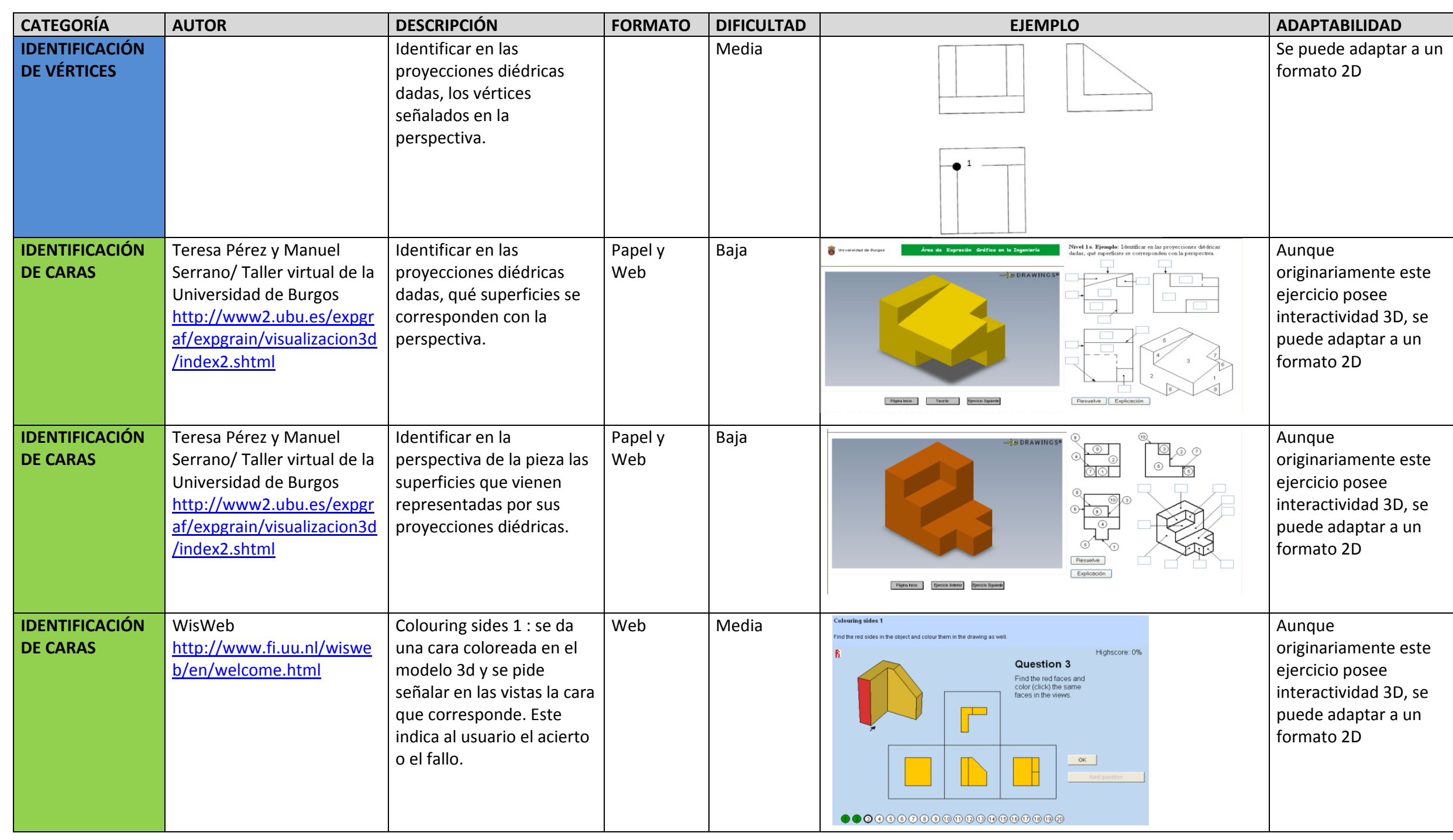




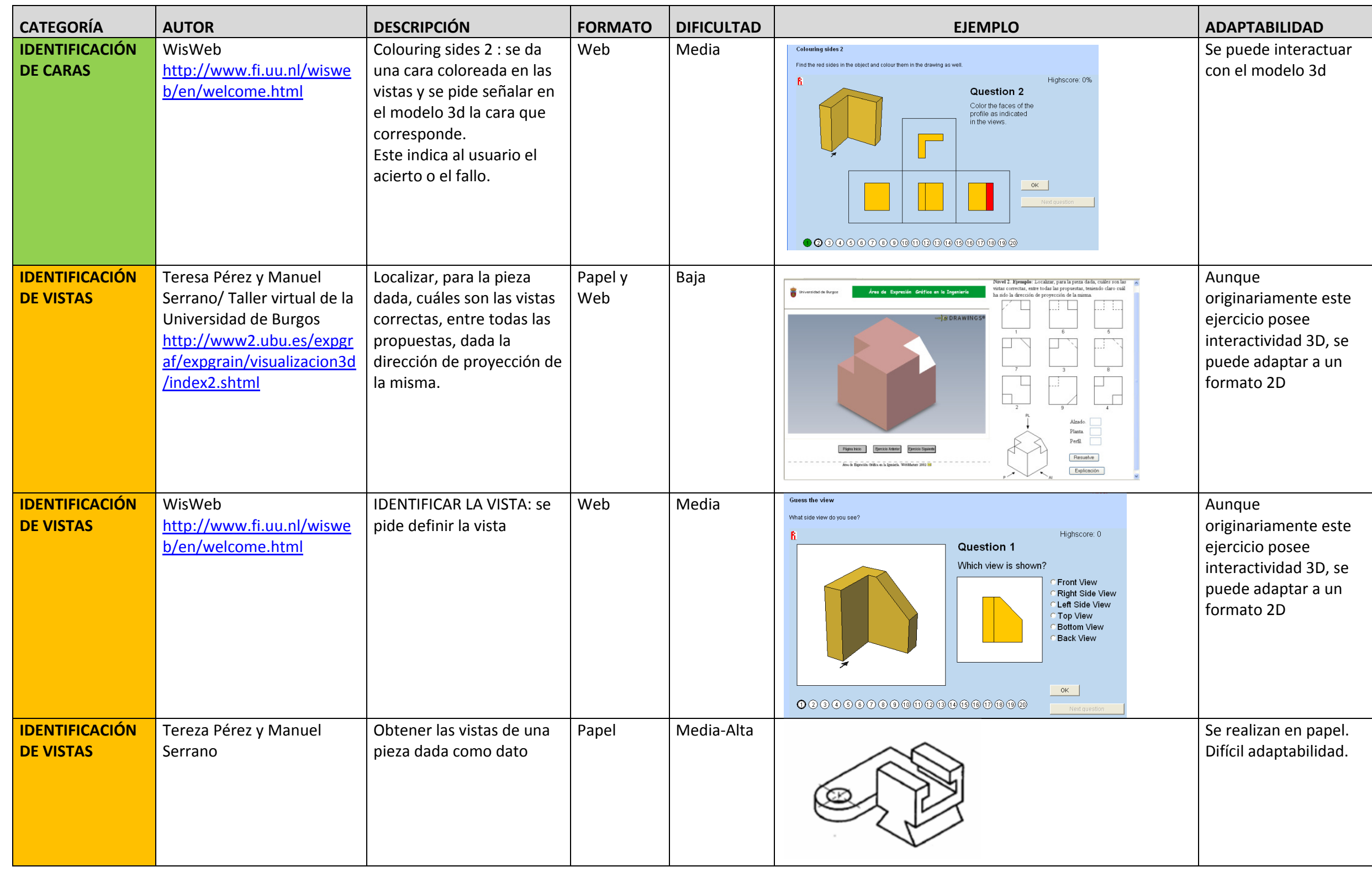




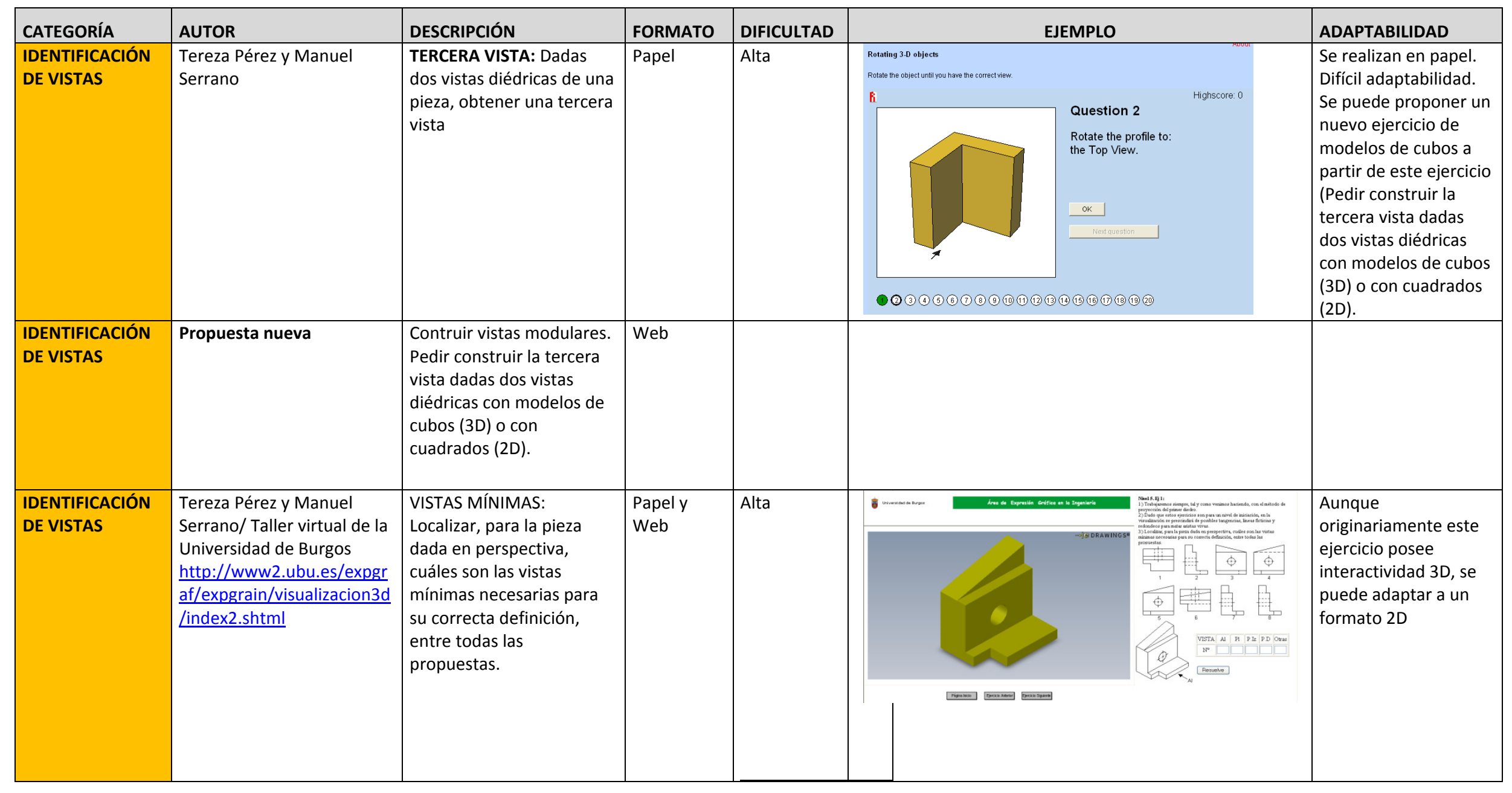




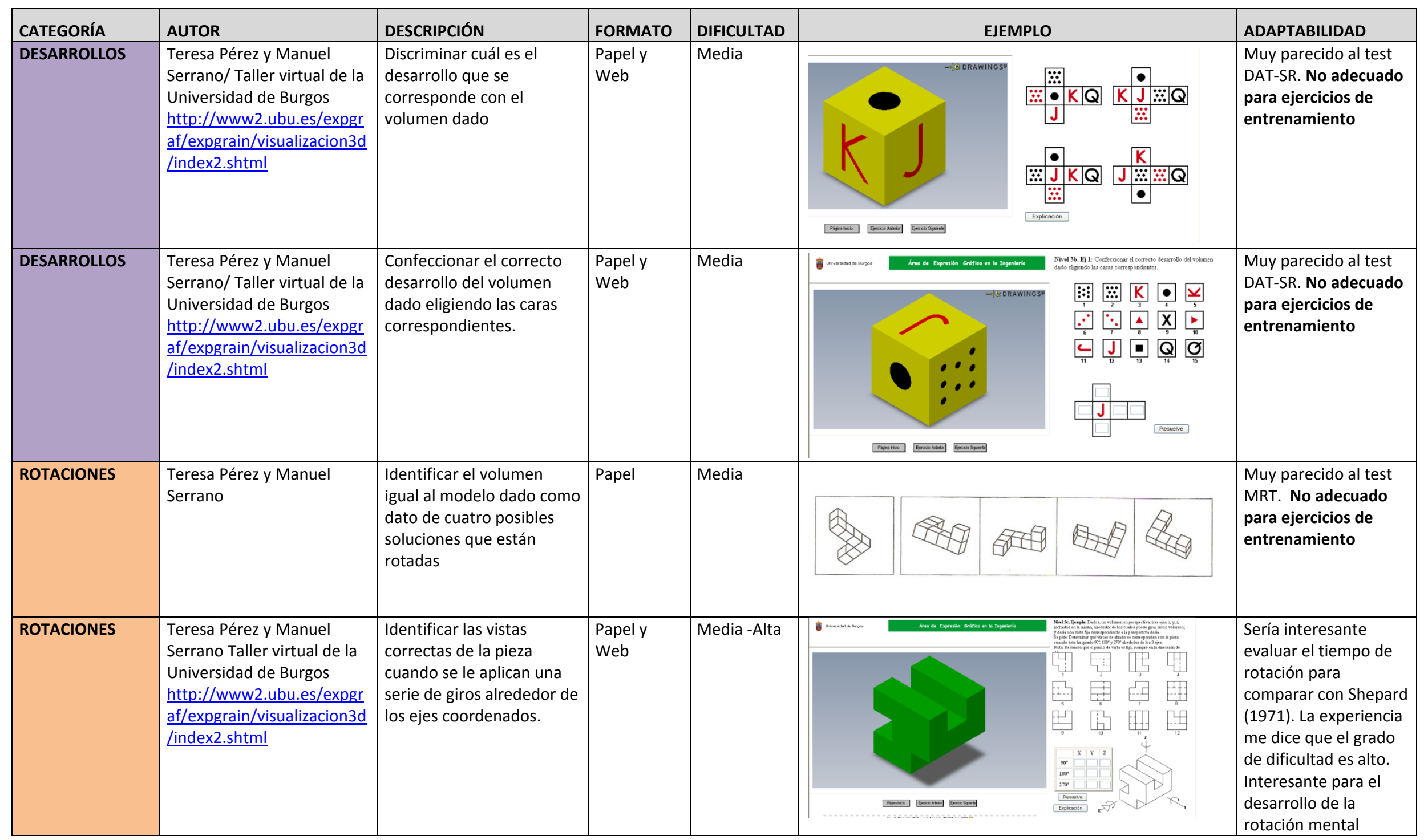




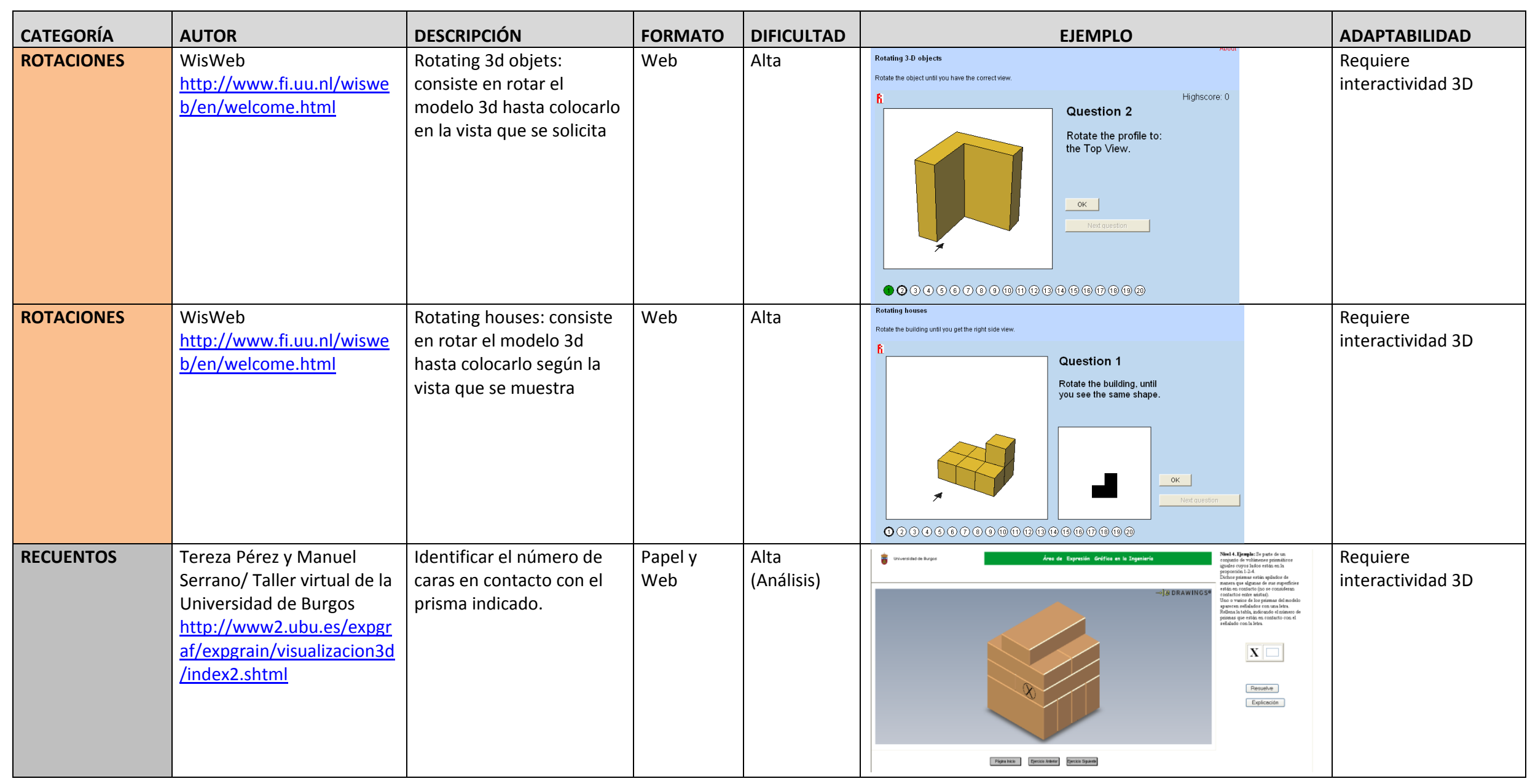




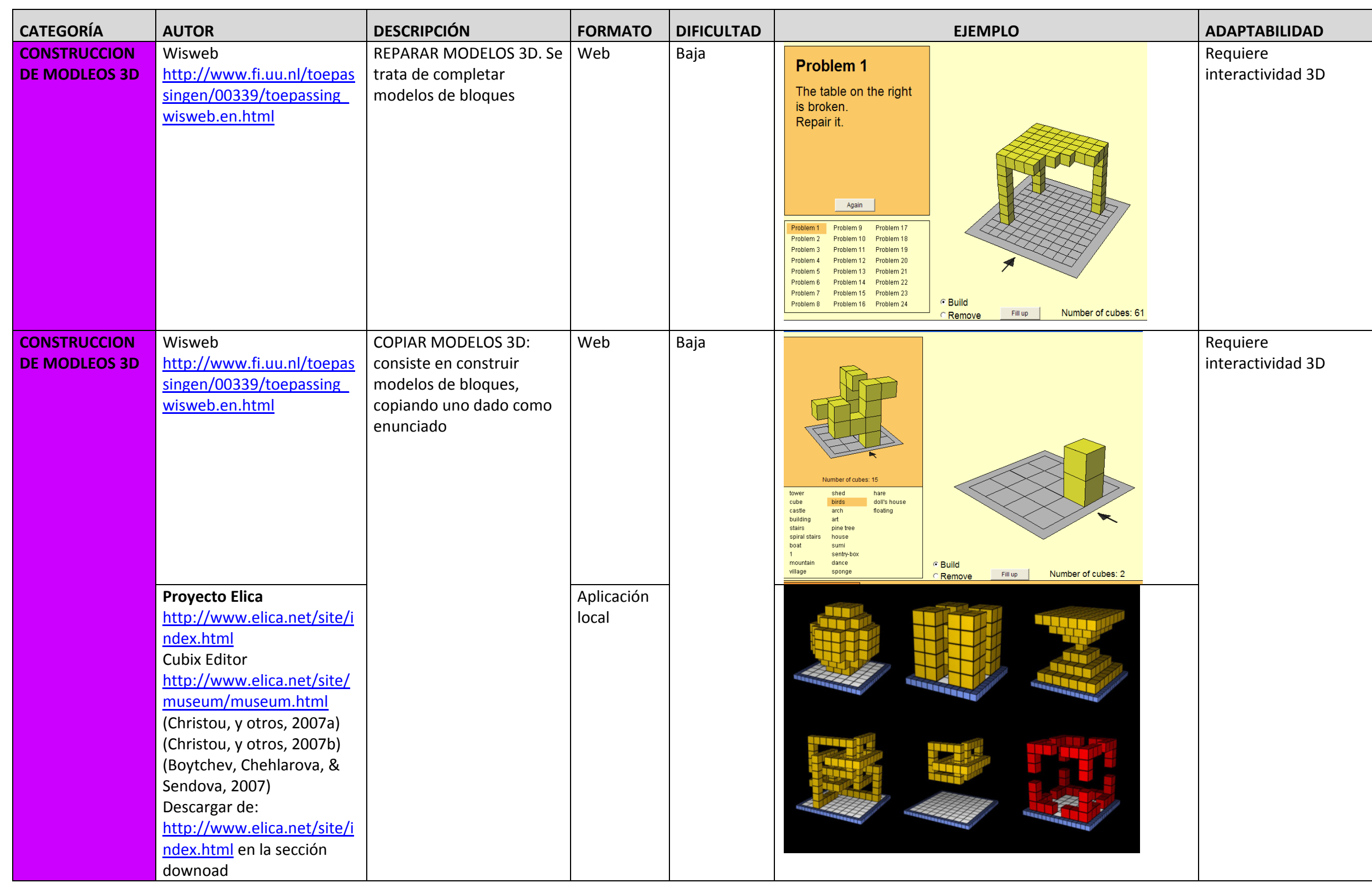




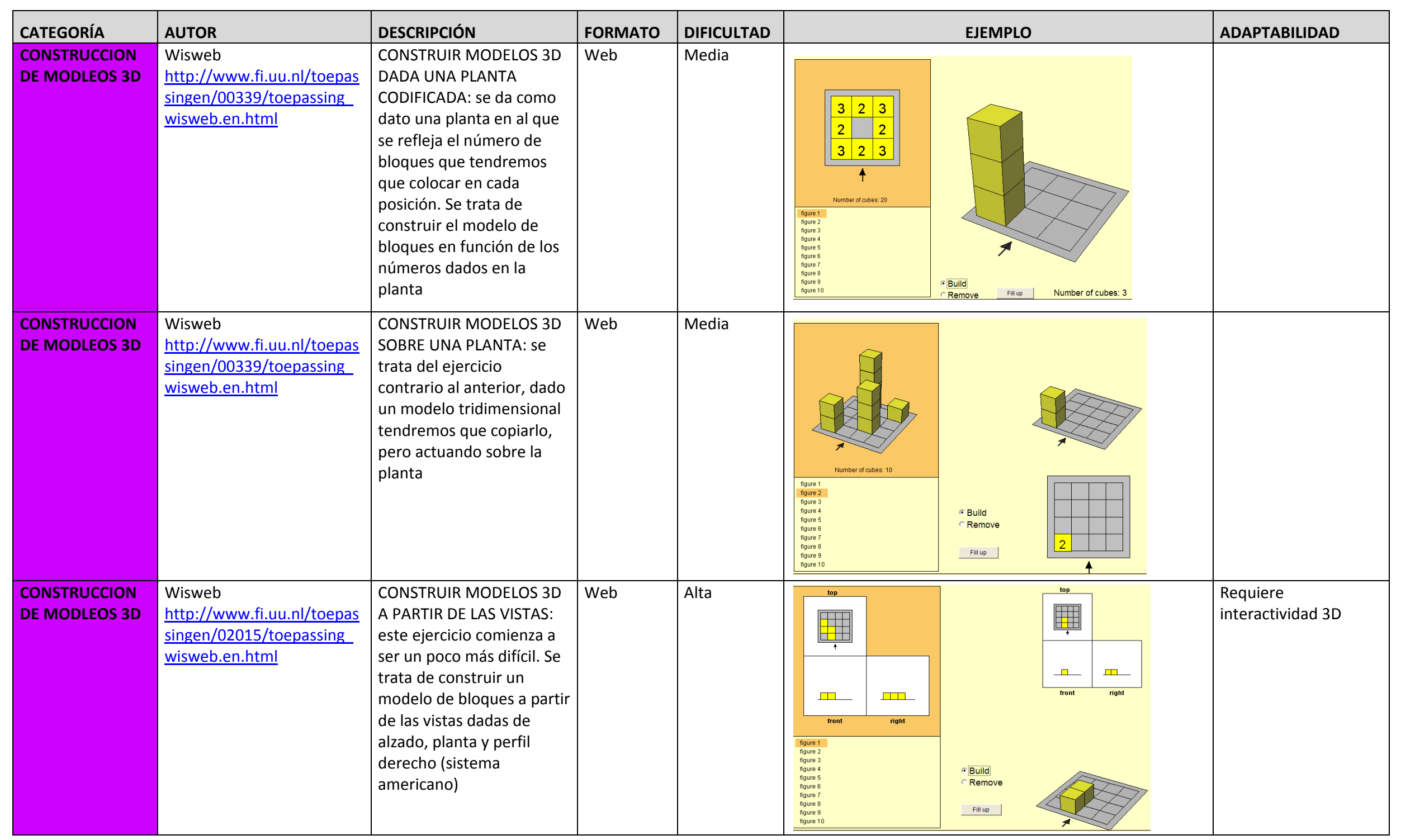




\begin{tabular}{|c|c|c|c|c|c|c|}
\hline CATEGORÍA & AUTOR & DESCRIPCIÓN & FORMATO & DIFICULTAD & EJEMPLO & ADAPTABILIDAD \\
\hline $\begin{array}{l}\text { CONSTRUCCION } \\
\text { DE MODLEOS 3D }\end{array}$ & $\begin{array}{l}\text { Proyecto Elica } \\
\text { http://www.elica.net/site/i } \\
\text { ndex.html } \\
\text { Cubix Editor } \\
\text { http://www.elica.net/site/ } \\
\text { museum/museum.html } \\
\text { Descargar de: } \\
\text { http://www.elica.net/site/i } \\
\text { ndex.html en la sección } \\
\text { downoad }\end{array}$ & $\begin{array}{l}\text { CONSTRUIR MODELOS 3D } \\
\text { A PARTIR DE LAS VISTAS: } \\
\text { Se trata de construir un } \\
\text { modelo de bloques a partir } \\
\text { de las vistas dadas en } \\
\text { forma de lo que llaman } \\
\text { "sombras" en las caras del } \\
\text { cubo que envuelve la } \\
\text { figura. }\end{array}$ & $\begin{array}{l}\text { Aplicación } \\
\text { local }\end{array}$ & Alta & & \begin{tabular}{|l|} 
Requiere \\
interactividad 3D
\end{tabular} \\
\hline $\begin{array}{l}\text { CONSTRUCCION } \\
\text { DE MODLEOS 3D }\end{array}$ & $\begin{array}{l}\text { Wisweb } \\
\text { http://www.fi.uu.nl/toepas } \\
\text { singen/00339/toepassing } \\
\text { wisweb.en.html }\end{array}$ & $\begin{array}{l}\text { CONSTRUIR MODELOS 3D } \\
\text { A PARTIR DE LAS VISTAS: } \\
\text { consiste en construir un } \\
\text { modelo de bloques a partir } \\
\text { de las vistas dadas de } \\
\text { planta, alzado y perfil } \\
\text { derecho, con la dificultad } \\
\text { de que se debe hacer con } \\
\text { el mínimo número de } \\
\text { bloques posibles. Esta } \\
\text { actividad tiene dos niveles } \\
\text { y se puntúan las } \\
\text { respuestas } \\
\end{array}$ & Web & Alta & 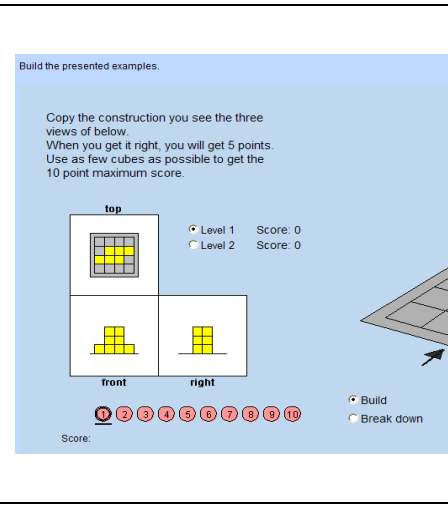 & \begin{tabular}{|l} 
Requiere \\
interactividad 3D
\end{tabular} \\
\hline
\end{tabular}




\section{Anexo XIV.- Encuesta de satisfacción en el curso web con los iPods}

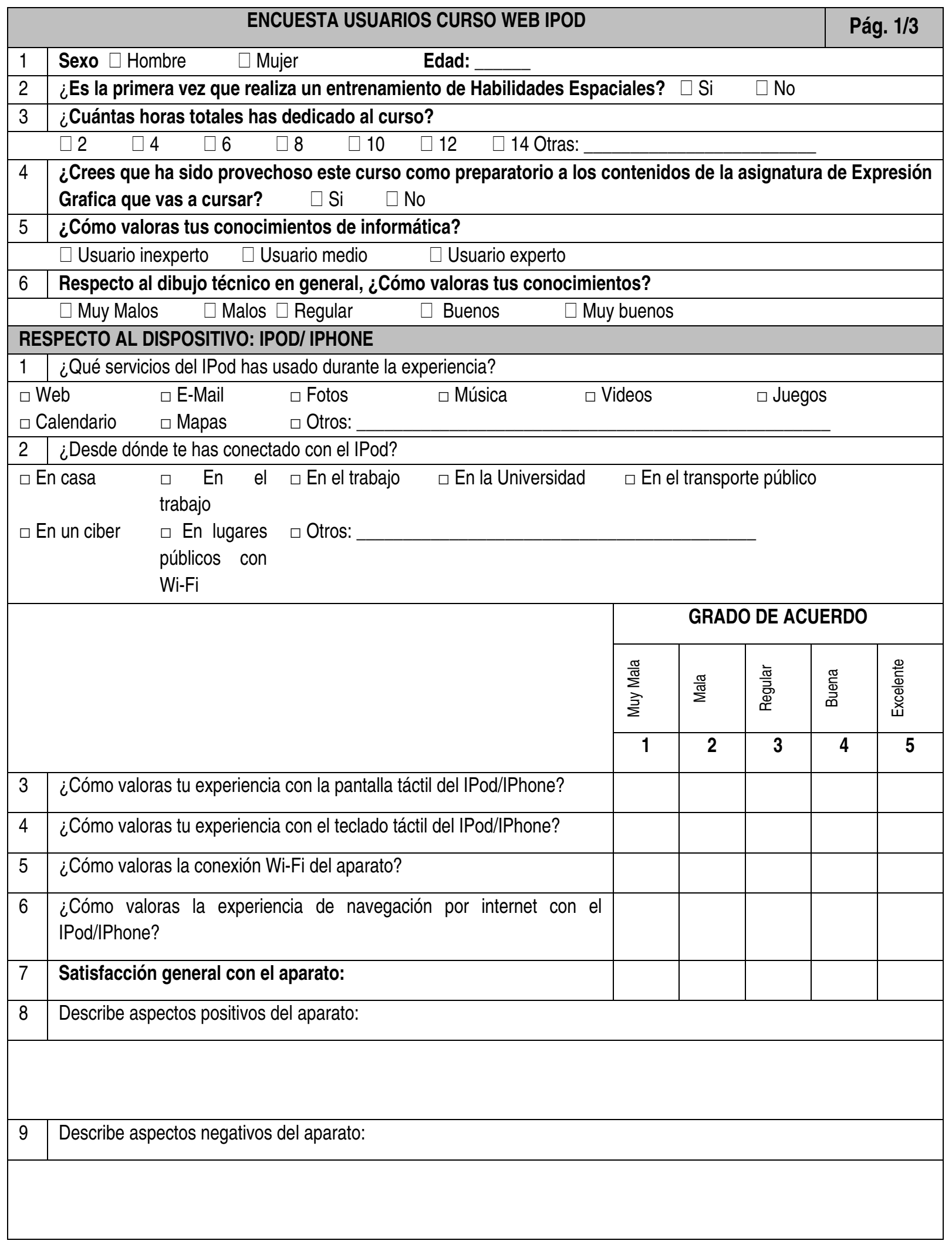




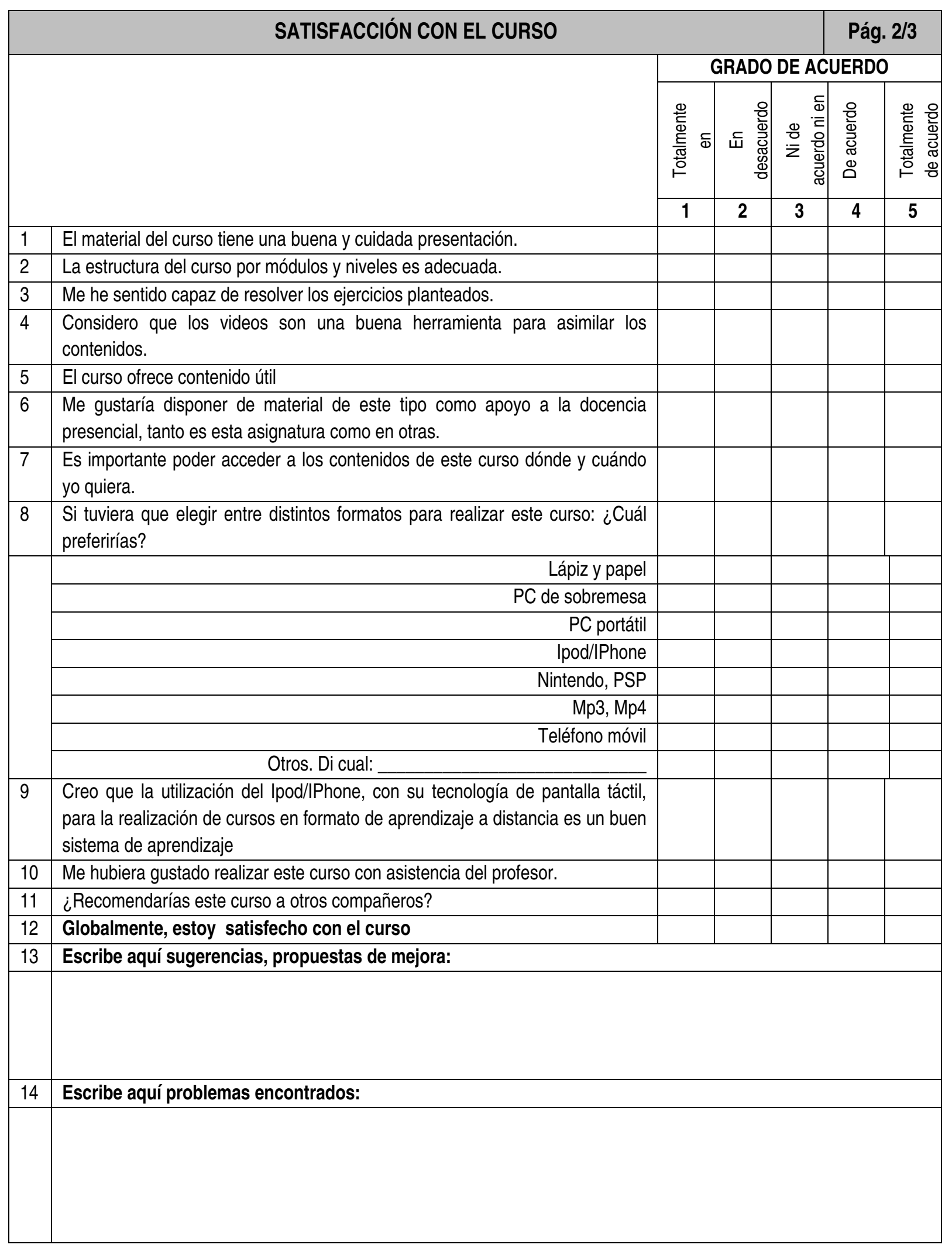




\begin{tabular}{|c|c|c|c|c|c|}
\hline VALORACIÓN DE LOS MÓDULOS & & & & & $.3 / 3$ \\
\hline VALORA CON UNA ESCALA DE 1 a 5 el grado de dificultad de cada uno de & & RAD & $\overline{\mathrm{DE} D}$ & ULTR & \\
\hline & 公 $\frac{\circ}{\mathbb{m}}$ & 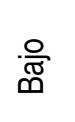 & 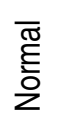 & 운 & $\stackrel{3}{\sum} \frac{0}{2}$ \\
\hline & 1 & 2 & 3 & 4 & 5 \\
\hline MÓDULO 1 & & & & & \\
\hline NIVEL 1 & & & & & \\
\hline NIVEL 2 & & & & & \\
\hline NIVEL 3 & & & & & \\
\hline MÓDULO 2 & & & & & \\
\hline NIVEL 1 & & & & & \\
\hline NIVEL 2 & & & & & \\
\hline NIVEL 3 & & & & & \\
\hline NIVEL 4 & & & & & \\
\hline MÓDULO 3 & & & & & \\
\hline NIVEL 1 & & & & & \\
\hline NIVEL 2 & & & & & \\
\hline NIVEL 3 & & & & & \\
\hline MÓDULO 4 & & & & & \\
\hline NIVEL 1 & & & & & \\
\hline NIVEL 2 & & & & & \\
\hline NIVEL 3 & & & & & \\
\hline MÓDULO 5 & & & & & \\
\hline NIVEL 1 & & & & & \\
\hline NIVEL 2 & & & & & \\
\hline
\end{tabular}




\section{Anexo XV.- Puntuaciones obtenidas en el curso web con los iPods}

\begin{tabular}{|c|c|c|c|c|}
\hline № & Sexo & PreMRT & \begin{tabular}{|l|} 
PostMRT \\
\end{tabular} & Grupo \\
\hline 1 & 0 & 31 & 34 & 1 \\
\hline 2 & 0 & 37 & 40 & 1 \\
\hline 3 & 0 & 35 & 37 & 1 \\
\hline 4 & 0 & 30 & 34 & 1 \\
\hline 5 & 0 & 7 & 12 & 1 \\
\hline 6 & 0 & 4 & 7 & 1 \\
\hline 7 & 0 & 8 & 12 & 1 \\
\hline 8 & 1 & 9 & 11 & 1 \\
\hline 9 & 0 & 25 & 27 & 1 \\
\hline 10 & 0 & 16 & 14 & 1 \\
\hline 11 & 1 & 16 & 17 & 1 \\
\hline 12 & 0 & 13 & 20 & 1 \\
\hline 13 & 0 & 15 & 17 & 1 \\
\hline 14 & 0 & 16 & 21 & 1 \\
\hline 15 & 0 & 11 & 10 & 1 \\
\hline 16 & 0 & 32 & 34 & 1 \\
\hline 17 & 0 & 21 & 22 & 1 \\
\hline 18 & 1 & 22 & 19 & 1 \\
\hline 19 & 0 & 18 & 24 & 1 \\
\hline 20 & 0 & 26 & 28 & 1 \\
\hline 21 & 1 & 13 & 12 & 1 \\
\hline 22 & 1 & 11 & 15 & 1 \\
\hline 23 & 1 & 17 & 19 & 1 \\
\hline 24 & 1 & 13 & 16 & 1 \\
\hline 25 & 0 & 10 & 14 & 1 \\
\hline 26 & 1 & 5 & 4 & 1 \\
\hline 27 & 0 & 23 & 18 & 1 \\
\hline 28 & 1 & 6 & 6 & 1 \\
\hline 29 & 1 & 6 & 8 & 1 \\
\hline 30 & 1 & 13 & 15 & 1 \\
\hline 31 & 0 & 16 & 24 & 2 \\
\hline 32 & 1 & 30 & 37 & 2 \\
\hline 33 & 0 & 29 & 39 & 2 \\
\hline 34 & 0 & 37 & 38 & 2 \\
\hline 35 & 0 & 9 & 19 & 2 \\
\hline 36 & 0 & 10 & 36 & 2 \\
\hline 37 & 0 & 12 & 15 & 2 \\
\hline 38 & 0 & 17 & 40 & 2 \\
\hline 39 & 0 & 16 & 28 & 2 \\
\hline 40 & 0 & 22 & 21 & 2 \\
\hline 41 & 0 & 16 & 34 & 2 \\
\hline 42 & 0 & 15 & 26 & 2 \\
\hline 43 & 0 & 25 & 40 & 2 \\
\hline
\end{tabular}




\begin{tabular}{|r|r|r|r|r|}
\hline № & Sexo & \multicolumn{1}{|l|}{ PreMRT } & PostMRT & Grupo \\
\hline 44 & 0 & 10 & 27 & 2 \\
\hline 45 & 0 & 35 & 27 & 2 \\
\hline 46 & 0 & 24 & 24 & 2 \\
\hline 47 & 0 & 17 & 26 & 2 \\
\hline 48 & 1 & 17 & 24 & 2 \\
\hline 49 & 1 & 11 & 28 & 2 \\
\hline 50 & 0 & 26 & 24 & 2 \\
\hline 51 & 1 & 24 & 40 & 2 \\
\hline 52 & 1 & 14 & 19 & 2 \\
\hline 53 & 1 & 12 & 24 & 2 \\
\hline 54 & 0 & 19 & 26 & 2 \\
\hline 55 & 0 & 19 & 21 & 2 \\
\hline 56 & 1 & 15 & 14 & 2 \\
\hline 57 & 0 & 26 & 37 & 2 \\
\hline 58 & 1 & 7 & 10 & 2 \\
\hline 59 & 1 & 11 & 20 & 2 \\
\hline 60 & 1 & 16 & 18 & 2 \\
\hline 61 & 0 & 20 & 30 & 2 \\
\hline 62 & 1 & 23 & 29 & 2 \\
\hline 63 & 0 & 20 & 28 & 2 \\
\hline 64 & 0 & 21 & 26 & 2 \\
\hline 65 & 0 & 12 & 22 & 2 \\
\hline 66 & 0 & 24 & 37 & 2 \\
\hline 67 & 0 & 26 & 27 & 2 \\
\hline 68 & 1 & 14 & 17 & 2 \\
\hline & & & & \\
\hline
\end{tabular}

Sexo: $0=$ hombre $;=$ mujer

Grupo: $\mathbf{1}=$ experimental; 2 = control 


\section{Anexo XVI.- Análisis estadístico del curso web con los iPods}

Resumen descriptivo de las variables utilizadas. Resúmenes de casos

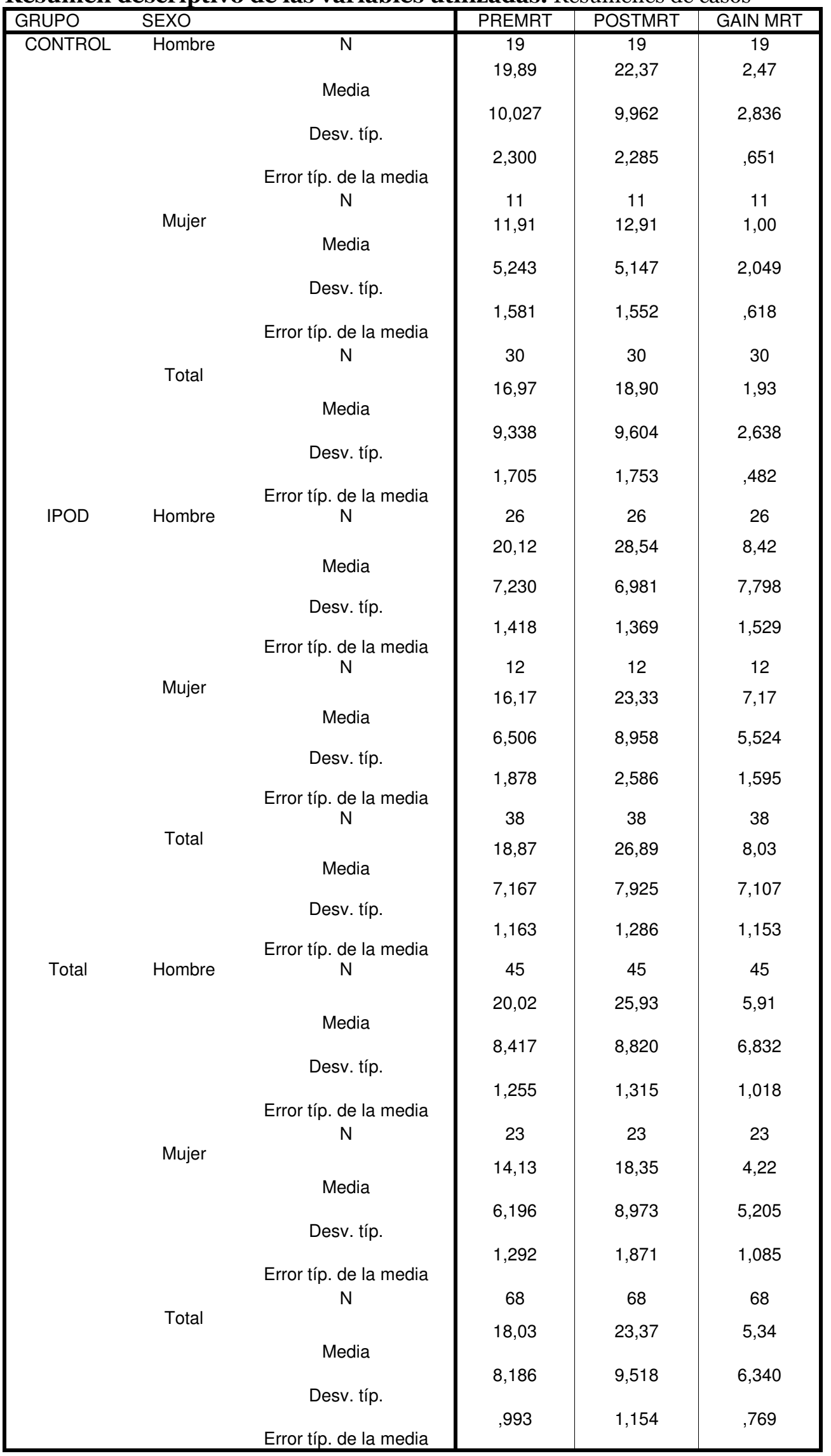




\section{Análisis de la varianza (ANOVA II).}

Pruebas de los efectos inter-sujetos

Variable dependiente: PREMRT

\begin{tabular}{|l|r|r|r|r|r|}
\hline Fuente & \multicolumn{1}{c|}{$\begin{array}{c}\text { Suma de } \\
\text { cuadrados } \\
\text { tipo III }\end{array}$} & gl & \multicolumn{1}{c|}{$\begin{array}{c}\text { Media } \\
\text { cuadrática }\end{array}$} & \multicolumn{1}{c|}{$\mathrm{F}$} & Significación \\
\hline Modelo corregido & $632,922(\mathrm{a})$ & 3 & 210,974 & 3,501 &, 020 \\
Intersección & 17471,036 & 1 & 17471,036 & 289,899 &, 000 \\
SEXO & 536,788 & 1 & 536,788 & 8,907 &, 004 \\
grupo & 75,582 & 1 & 75,582 & 1,254 &, 267 \\
SEXO * grupo & 61,420 & 1 & 61,420 & 1,019 &, 317 \\
Error & 3857,019 & 64 & 60,266 & & \\
Total & 26594,000 & 68 & & & \\
Total corregida & 4489,941 & 67 & & \\
\hline
\end{tabular}

\section{Análisis de varianza univariante. ANCOVA}

Pruebas de los efectos inter-sujetos

Variable dependiente: POSTMRT

\begin{tabular}{|l|r|r|r|r|r|}
\hline & \multicolumn{1}{c|}{$\begin{array}{c}\text { Suma de } \\
\text { cuadrados } \\
\text { tipo III }\end{array}$} & gl & \multicolumn{1}{c|}{$\begin{array}{c}\text { Media } \\
\text { cuadrática }\end{array}$} & \multicolumn{1}{c|}{$\mathrm{F}$} & Significación \\
\hline Modelo corregido & $4358,162(\mathrm{a})$ & 4 & 1089,540 & 40,102 &, 000 \\
Intersección & 898,612 & 1 & 898,612 & 33,075 &, 000 \\
SEXO & 83,911 & 1 & 83,911 & 3,088 &, 084 \\
grupo & 454,957 & 1 & 454,957 & 16,745 &, 000 \\
PREMRT & 2204,208 & 1 & 2204,208 & 81,130 &, 000 \\
grupo * PREMRT & 137,962 & 1 & 137,962 & 5,078 &, 028 \\
Error & 1711,647 & 63 & 27,169 & & \\
Total & 43201,000 & 68 & & & \\
Total corregida & 6069,809 & 67 & & & \\
\hline
\end{tabular}

a $\mathrm{R}$ cuadrado $=, 718$ ( $\mathrm{R}$ cuadrado corregida $=, 700)$

Estimaciones de los parámetros

Variable dependiente: POSTMRT

\begin{tabular}{|l|l|l|l|l|l|}
\hline & & & & & \multicolumn{2}{|c|}{ Intervalo de confianza al } \\
& & & & & \\
& & & & $\begin{array}{l}\text { Límite } \\
\text { inferiorLímite } \\
\text { superiorLímite } \\
\text { inferiorLímite } \\
\text { superior }\end{array}$ & $\begin{array}{c}\text { Límite } \\
\text { superior }\end{array}$ \\
\hline
\end{tabular}




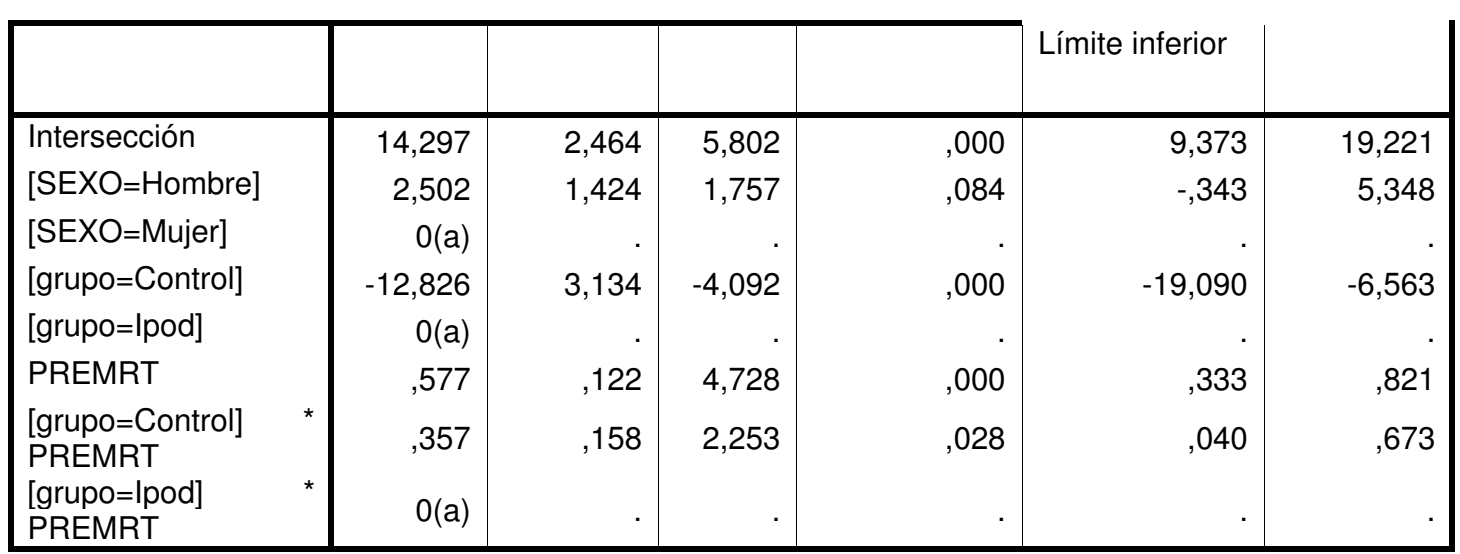

a Al parámetro se le ha asignado el valor cero porque es redundante.

\section{Gráfico}

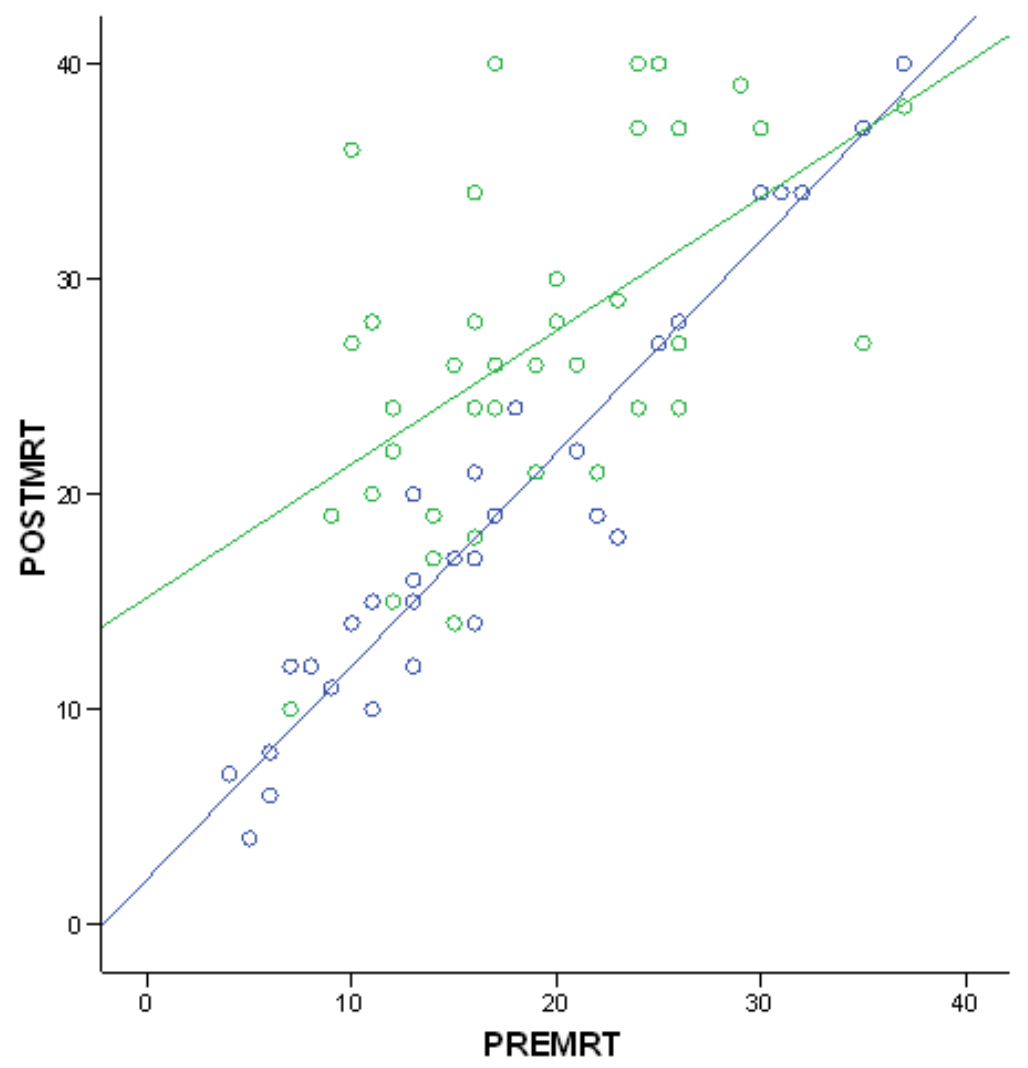




\section{Anexo XVII.- Actividades del grupo de trabajo}

\begin{tabular}{|c|c|}
\hline ACTIVIDADES & PARTICIPANTES \\
\hline 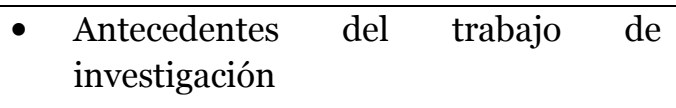 & Norena Martín Dorta \\
\hline $\begin{array}{l}\text { - Planteamiento del proyecto: idea } \\
\text { inicial de las necesidades y soportes }\end{array}$ & $\begin{array}{l}\text { Isabel Sánchez Berriel } \\
\text { Miguel Jonás Bravo García } \\
\text { Juan Antonio Hernández Cordovez } \\
\text { Norena Martín Dorta }\end{array}$ \\
\hline \multicolumn{2}{|l|}{ - $\quad$ Estudio previo: } \\
\hline $\begin{array}{l}\text { Exploración de dispositivos y sistemas } \\
\text { operativos }\end{array}$ & $\begin{array}{l}\text { Isabel Sánchez Berriel } \\
\text { Miguel Jonás Bravo García } \\
\text { Juan Antonio Hernández Cordovez } \\
\text { Norena Martín Dorta }\end{array}$ \\
\hline $\begin{array}{l}\text { Exploración del estándar 3D, la } \\
\text { máquina virtual y el tipo de } \\
\text { conexiones }\end{array}$ & $\begin{array}{l}\text { Isabel Sánchez Berriel } \\
\text { Miguel Jonás Bravo García } \\
\text { Juan Antonio Hernández Cordovez }\end{array}$ \\
\hline $\begin{array}{l}3 \cdot 3 \text { Elección del dispositivos, } \mathrm{SO}, \mathrm{API} \\
3 \mathrm{D} \text {, la máquina virtual y las } \\
\text { conexiones }\end{array}$ & $\begin{array}{l}\text { Isabel Sánchez Berriel } \\
\text { Miguel Jonás Bravo García } \\
\text { Juan Antonio Hernández Cordovez } \\
\text { Norena Martín Dorta }\end{array}$ \\
\hline $\begin{array}{l}\text { Exploración y propuesta de la } \\
\text { tipología de ejercicios a desarrollar }\end{array}$ & Norena Martín Dorta \\
\hline \multicolumn{2}{|l|}{ - $\quad$ Arquitectura del sistema: } \\
\hline Diseño de la arquitectura del sistema & $\begin{array}{l}\text { Isabel Sánchez Berriel } \\
\text { Miguel Jonás Bravo García } \\
\text { Juan Antonio Hernández Cordovez } \\
\text { Norena Martín Dorta }\end{array}$ \\
\hline $\begin{array}{l}\text { Establecimiento de requisitos entre } \\
\text { las aplicaciones }\end{array}$ & $\begin{array}{l}\text { Isabel Sánchez Berriel } \\
\text { Miguel Jonás Bravo García } \\
\text { Juan Antonio Hernández Cordovez } \\
\text { Norena Martín Dorta }\end{array}$ \\
\hline $\begin{array}{l}\text { - Programación de las aplicaciones: } \\
\text { aplicación de escritorio, juego de } \\
\text { móvil, aplicación de servidor y base de } \\
\text { datos }\end{array}$ & $\begin{array}{l}\text { Isabel Sánchez Berriel } \\
\text { Miguel Jonás Bravo García } \\
\text { Juan Antonio Hernández Cordovez }\end{array}$ \\
\hline $\begin{array}{l}\text { - Implementación de las distintas } \\
\text { aplicaciones. Primeras pruebas sobre } \\
\text { el dispositivo móvil. Primera versión } \\
\text { del juego de móvil }\end{array}$ & $\begin{array}{l}\text { Isabel Sánchez Berriel } \\
\text { Miguel Jonás Bravo García } \\
\text { Juan Antonio Hernández Cordovez } \\
\text { Norena Martín Dorta }\end{array}$ \\
\hline $\begin{array}{l}\text { - } \text { Primera prueba de usabilidad con } \\
\text { usuarios: encuestas de perfil de } \\
\text { usuarios, test con usuarios y } \\
\text { encuestas de satisfacción }\end{array}$ & Norena Martín Dorta \\
\hline
\end{tabular}


- Informe de los resultados de la $1^{\mathrm{a}}$ Norena Martín Dorta prueba de usabilidad: errores detectados en la aplicación móvil. Elaboración de propuestas de mejora

- Implementación de las mejoras Isabel Sánchez Berriel propuestas Miguel Jonás Bravo García Juan Antonio Hernández Cordovez

- Segunda prueba de usabilidad con Norena Martín Dorta usuarios: encuestas de perfil de usuarios, test con usuarios y encuestas de satisfacción

- Informe de los resultados de la $2^{\mathrm{a}}$ Norena Martín Dorta prueba de usabilidad.

- Informe final: estadísticas de usuarios Norena Martín Dorta

- Estudio preliminar 2009. Diseño, Norena Martín Dorta evaluación y análisis de resultados 
Anexo XVIII.- Puntuaciones obtenidas en el curso Building with Blocks

\begin{tabular}{|l|l|l|l|l|}
\cline { 2 - 5 } \multicolumn{1}{c|}{} & MRT & DAT & MRT & DAT \\
\hline Estudiante & Pre-Test & Pre-Test & Post-Test & Post-Test \\
\hline 1 & 16 & 17 & 21 & 29 \\
\hline 2 & 6 & 22 & 11 & 42 \\
\hline 3 & 9 & 28 & 14 & 35 \\
\hline 4 & 13 & 49 & 13 & 55 \\
\hline 5 & 17 & 28 & 22 & 42 \\
\hline 6 & 10 & 48 & 25 & 58 \\
\hline 7 & 8 & 49 & 19 & 56 \\
\hline 8 & 9 & 35 & 13 & 33 \\
\hline 9 & 13 & 19 & 16 & 20 \\
\hline 10 & 9 & 29 & 15 & 40 \\
\hline 11 & 8 & 28 & 12 & 31 \\
\hline 12 & 11 & 24 & 11 & 29 \\
\hline
\end{tabular}




\section{Anexo XIX.- Encuesta de Perfil de Usuarios}

\begin{tabular}{|c|c|c|}
\hline \multicolumn{3}{|c|}{ PERFIL DE USUARIOS (1 de 3) } \\
\hline \multicolumn{3}{|c|}{ DATOS GENERALES } \\
\hline 1 & Sexo: & $\begin{array}{l}\square \text { Hombre } \\
\square \text { Mujer }\end{array}$ \\
\hline 2 & Edad: & \\
\hline 3 & Lateralidad & $\begin{array}{l}\text { Diestro } \\
\square \text { Zurdo } \\
\square \text { Ambidiestro }\end{array}$ \\
\hline 4 & Titulación que cursa: & \\
\hline 5 & Curso: & $\begin{array}{l}\text { Primero } \\
\square \text { Segundo } \\
\square \text { Tercero } \\
\square \text { Cuarto } \\
\square \text { Quinto } \\
\end{array}$ \\
\hline 6 & Accede a Universidad vía: & $\begin{array}{l}\text { Bachiller } \\
\square \text { FP/Ciclos } \\
\square \text { Otra Carrera } \\
\square \text { Mundo laboral } \\
\square \text { Otras }\end{array}$ \\
\hline 7 & ¿Trabajas actualmente? & $\begin{array}{l}\square \text { Sí } \\
\square \text { No }\end{array}$ \\
\hline 8 & $\begin{array}{llll}\text { ¿Has estudiado dibujo } & \text { con } \\
\text { anterioridad? } & & \\
\end{array}$ & $\begin{array}{l}\square \text { Sí } \\
\square \text { No }\end{array}$ \\
\hline 9 & ¿Cuántos años? & 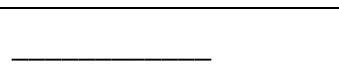 \\
\hline 10 & $\begin{array}{l}\text { ¿En qué niveles? (ESO, Bachiller, } \\
\text { Ciclos formativos, Universidad, etc.) }\end{array}$ & $\begin{array}{l}\text { ESO, Bachiller } \\
\square \text { Ciclos formativos } \\
\square \text { Universidad } \\
\square \text { Otros }\end{array}$ \\
\hline 11 & ¿Has utilizado alguna aplicación CAD? & $\begin{array}{l}\square \text { Sí } \\
\square \text { No }\end{array}$ \\
\hline 12 & Di cúal: & \\
\hline 13 & $\begin{array}{l}\text { Respecto al dibujo técnico en general, } \\
\text { ¿Cómo valoras tus conocimientos? }\end{array}$ & $\begin{array}{l}\square \text { Muy Malos } \\
\square \text { Malos } \\
\square \text { Regular } \\
\square \text { Buenos } \\
\square \text { Muy buenos }\end{array}$ \\
\hline
\end{tabular}




\begin{tabular}{|c|c|c|}
\hline \multicolumn{3}{|c|}{ PERFIL DE USUARIOS (2 de 3) } \\
\hline \multicolumn{3}{|c|}{ NUEVAS TECNOLOGÍAS } \\
\hline 14 & $\begin{array}{l}\text { ¿Qué grado de interés tienes por el } \\
\text { mundo de la informática, los } \\
\text { ordenadores y los avances } \\
\text { tecnológicos en general? }\end{array}$ & $\begin{array}{l}\square \text { Nada } \\
\square \text { Poco } \\
\square \text { Algo } \\
\square \text { Bastante } \\
\square \text { Mucho }\end{array}$ \\
\hline 15 & $\begin{array}{l}\text { ¿Cómo valoras tus conocimientos de } \\
\text { informática? }\end{array}$ & $\begin{array}{l}\square \text { Usuario inexperto } \\
\square \text { Usuario medio } \\
\square \text { Usuario experto }\end{array}$ \\
\hline 16 & $\begin{array}{l}\text { ¿Qué tecnologías usas de la siguiente } \\
\text { lista? }\end{array}$ & $\begin{array}{l}\text { Móvil } \\
\square \text { MP3/MP4 } \\
\square \text { Consolas de sobremesa } \\
\square \text { Consolas portátiles } \\
\square \text { GPS } \\
\square \text { Cámaras digitales } \\
\square \text { PDA/Palm } \\
\square \text { Pc sobremesa } \\
\square \text { Pc portátil } \\
\square \text { Otras: } \\
\square \text { Ninguna }\end{array}$ \\
\hline 17 & $\begin{array}{l}\text { ¿Cuántas horas diarias utilizas el } \\
\text { ordenador? }\end{array}$ & $\begin{array}{l}\square<1 \mathrm{~h} \\
\square 1-2 \mathrm{~h} \\
\square 2-4 \mathrm{~h} \\
\square 4-8 \mathrm{~h} \\
\square>8 \mathrm{~h} \\
\end{array}$ \\
\hline 18 & Utilizas el ordenador para: & $\begin{array}{l}\text { Estudiar } \\
\square \text { Trabajar } \\
\square \text { Entretenimiento } \\
\square \text { No lo uso } \\
\square \text { Otros: } \\
\end{array}$ \\
\hline 19 & $\begin{array}{l}\text { ¿Con qué frecuencia te conectas a } \\
\text { internet? }\end{array}$ & $\begin{array}{l}\square \text { Nunca } \\
\square \text { Rara vez } \\
\square \text { Una vez al mes } \\
\square \text { Dos o tres veces a la semana } \\
\square \text { Todos los días }\end{array}$ \\
\hline 20 & ¿Dónde te sueles conectar a internet? & $\begin{array}{l}\square \text { Desde casa } \\
\square \text { Universidad } \\
\square \text { Trabajo } \\
\square \text { Ciber } \\
\square \text { Casa de amigo } \\
\square \text { No me conecto } \\
\end{array}$ \\
\hline 21 & $\begin{array}{l}\text { ¿Qué tipo de conexión tienes en casa? } \\
\text { (Marca varias si fuera necesario) }\end{array}$ & $\begin{array}{l}\text { Inalámbrica } \\
\square \text { ADSL } \\
\square \text { Teléfono } \\
\square \text { TV Cable } \\
\square \text { Otras } \\
\square \text { No dispongo } \\
\end{array}$ \\
\hline 22 & $\begin{array}{l}\text { ¿Qué servicios de internet usas } \\
\text { habitualmente? }\end{array}$ & $\begin{array}{l}\square \text { E-mail } \\
\square \text { Chats } \\
\square \text { Búsquedas web } \\
\square \text { Juegos } \\
\square \text { Descargas(música, pelis, etc) } \\
\square \text { Otros: }\end{array}$ \\
\hline
\end{tabular}




\begin{tabular}{|c|c|c|}
\hline \multicolumn{3}{|c|}{ PERFIL DE USUARIOS (3 de 3) } \\
\hline \multicolumn{3}{|c|}{ JUEGOS } \\
\hline 23 & ¿Juegas habitualmente a videojuegos? & $\begin{array}{l}\square \text { Sí } \\
\square \text { No }\end{array}$ \\
\hline 24 & ¿Cuántas horas le dedicas? & $\begin{array}{l}\mathrm{H} \text { día } \\
\square \text { H semana }\end{array}$ \\
\hline 25 & ¿Qué plataformas utilizas? & $\begin{array}{l}\square \text { PC (Ordenador) } \\
\square \text { Sony PSP PlayStation Portátil } \\
\square \text { Sony PlayStation(PS1,PS2 ó PSP3) } \\
\square \text { Nintendo Wii } \\
\square \text { Nintendo DS o DS Lite } \\
\square \text { Nintendo Game Boy Advance (GBA, SP) } \\
\square \text { Nintendo GameCube } \\
\square \text { Microsoft Xbox ó Xbox } 360 \\
\square \text { Nokia N-Gage y N-Gage QD } \\
\square \text { Sega Dreamcast } \\
\square \text { Game Park } 32 \text { (GP32) } \\
\square \text { GP2X } \\
\square \text { TELÉFONO MÓVIL }\end{array}$ \\
\hline 26 & $\begin{array}{l}\text { Títulos de juegos a los que sueles } \\
\text { jugar: }\end{array}$ & 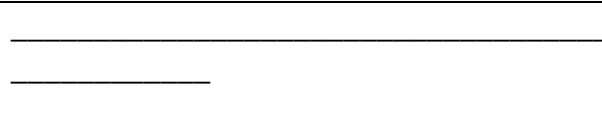 \\
\hline 27 & $\begin{array}{l}\text { ¿Juegas habitualmente a juegos de } \\
\text { móvil? }\end{array}$ & $\begin{array}{l}\square \text { Sí } \\
\square \text { No }\end{array}$ \\
\hline 28 & ¿A qué juegos? & \\
\hline \multicolumn{3}{|c|}{ USO DEL MÓVIL } \\
\hline 28 & ¿Tienes teléfono móvil? & $\begin{array}{l}\square \text { Sí } \\
\square \text { No }\end{array}$ \\
\hline 29 & Marca y modelo: & \\
\hline 30 & $\begin{array}{l}\text { ¿Qué servicios del teléfono móvil } \\
\text { utilizas? }\end{array}$ & $\begin{array}{l}\text { Internet } \\
\square \text { SMS } \\
\square \text { MMS } \\
\square \text { Descarga de juegos } \\
\square \text { Descarga de música } \\
\square \text { Descarga de tonos } \\
\square \text { Cámara digital } \\
\square \text { Oír música } \\
\square \text { Ver Vídeos } \\
\square \text { Otros }\end{array}$ \\
\hline 31 & ¿Qué tipo de contrato tiene? & $\begin{array}{l}\square \text { Contrato } \\
\square \text { Prepago }\end{array}$ \\
\hline 32 & ¿Qué operador de telefonía utilizas? & $\begin{array}{l}\square \text { Movistar } \\
\square \text { Vodafone } \\
\square \text { Orange } \\
\square \text { Yoigo } \\
\square \text { Otros }\end{array}$ \\
\hline 33 & $\begin{array}{l}\text { ¿Cuántos SMS mandas diariamente } \\
\text { aproximadamente? }\end{array}$ & $\longrightarrow$ \\
\hline 34 & $\begin{array}{l}\text { ¿Quién costea el consumo de tu } \\
\text { móvil? }\end{array}$ & $\begin{array}{l}\square \text { Yo } \\
\square \text { Mis padres } \\
\square \text { El trabajo } \\
\square \text { Otros }\end{array}$ \\
\hline
\end{tabular}




\section{Anexo XX.- Consentimiento informado}

\section{CONSENTIMIENTO INFORMADO}

La información se suministrará a los sujetos objeto de la investigación de forma escrita por los investigadores que participaran en el proyecto, incluyendo los objetivos del estudio y los beneficios esperados. Los encuestados tendrán la oportunidad de preguntar sobre los pormenores de la investigación.

Yo quien suscribe

este documento estoy de acuerdo en participar en la investigación: Uso de dispositivos móviles de pantalla táctil para la mejora de las habilidades espaciales en estudiantes de Ingeniería.

En el estudio se me han explicado los objetivos y procedimientos de esta investigación. Mi participación es voluntaria y la no aceptación no afectará mis relaciones en el futuro con los profesores de los estudios que estoy cursando, los que me seguirán atendiendo en caso de ser necesario, según las normas de la Universidad. Soy consciente y estoy de acuerdo en que mis sesiones sean grabadas. Concedo el permiso al grupo de investigación de este proyecto, perteneciente a la Universidad de La Laguna, a utilizar las grabaciones realizadas para uso interno, con la finalidad de utilizar los datos obtenidos en la investigación citada anteriormente.

Renuncio a mi derecho de inspeccionar y revisar la grabación antes de su utilización por los investigadores.

Me comprometo a no hablar a nadie de lo que le hemos realizado en esta sesión.

Para que así conste y por mi libre voluntad firmo este documento junto con la investigadora del proyecto que me brinda la explicación, a los días del mes 200

Por tanto al firmar este documento autorizo me incluyan en esta investigación.

Firma del encuestado

Firma del encuestador

POLÍTICA DE CONFIDENCIALIDAD Y PROTECCIÓN DE DATOS DE CARÁCTER PERSONAL FACILITADOS POR LOS USUARIOS A LA UNIVERSIDAD DE LA LAGUNA (ULL)

De acuerdo con el contenido de la Ley Orgánica 15/1999, de 13 de diciembre, sobre protección de datos de carácter personal, se informa a los usuarios los siguientes puntos:

1) Para la participación en este trabajo de investigación puede ser necesario que el usuario facilite datos de carácter personal. En este caso, el suministro de los datos será siempre voluntario y con consentimiento expreso del usuario. 
Con este objetivo, siempre que sea necesario facilitar datos de carácter personal, y con carácter previo al acceso al formulario correspondiente, aparecerá esta hoja informativa, que el usuario deberá aceptar expresamente escogiendo la opción "HE LEÍDO LA POLÍTICA DE CONFIDENCIALIDAD DE LA ULL Y EL ACEPTO EXPRESAMENTE".

2) Los datos de carácter personal facilitados por los usuarios serán registrados en un fichero automatizado de datos de carácter personal titularidad de LA UNIVERSIDAD DE LA LAGUNA. Este fichero está bajo la responsabilidad de la ULL, que declara que ha adoptado los niveles de seguridad exigibles legalmente.

3) La finalidad de la recogida de los datos de carácter personal es para su utilización en la mejora de los servicios ofrecidos por esta Universidad, con el objetivo de ofrecer servicios nuevos y/o para adecuarlos a las preferencias reales de los usuarios;

4) Los datos contenidos en el fichero serán utilizados, única y exclusivamente, por el grupo de investigación DEHAES de la ULL, sin que esté prevista su cesión. Si para algún servicio concreto fuera previsible la cesión de los datos, se comunicaría expresamente al usuario en el formulario correspondiente.

5) Excepto en los casos en que se indique lo contrario, las respuestas a las preguntas sobre datos personales serán voluntarias, y el hecho de no contestar no comportará una disminución en la calidad del servicio correspondiente.

6) El usuario tiene la posibilidad de ejercer los derechos de acceso, rectificación, cancelación y oposición, en la forma y el alcance previstos legalmente. Para el ejercicio de este derecho, la persona interesada se podrá dirigir al grupo de investigación DEHAES mediante correo electrónico, dirigido a dehaes@ull.es, o comunicación escrita dirigida al Departamento de Expresión Gráfica en Arquitectura e Ingeniería, A. Ángel Guimerá Jorge, s/n. E.U.A.T. 2ª planta. 38204. La Laguna. Tenerife. 


\section{Anexo XXI.- Instrucciones para los observadores}

\section{INSTRUCCIONES PARA LOS OBSERVADORES \\ Perfil Usuario: USUARIO NO EXPERTO}

\section{1) Bienvenida al usuario}

Hola nombre del que está probando, me llamo nombre del responsable sesión de pruebas y voy a acompañarte en esta sesión.

2) Realización de la encuesta "Perfil de Usuarios"

El usuario debe rellenar la encuesta "Perfil de Usuarios", donde se le piden datos personales y datos técnicos.

3) Antes de comenzar, coméntale al usuario que no le estamos haciendo un test a él, sino a la aplicación.

Probablemente ya lo sepas, pero te explicaré porqué hemos venido aquí. Estamos probando una aplicación sobre la que aún estamos trabajando y queremos ver lo que le parece a la gente que la usa.

Se trata de una aplicación en forma de juego para dispositivos móviles de pantalla táctil. La intención es que la pruebes y nos den su opinión para mejorarla.

Quiero que quede claro desde el principio que estamos probando la aplicación, no a ti. Es necesario que este aspecto te quede bien claro.

Queremos oír exactamente lo que piensas, no te preocupes por si crees que pueden sentarnos mal tus comentarios. Queremos mejorar la aplicación, de ahí la necesidad de conocer honestamente lo que te parece.

A medida que avancemos en este proceso de evaluación te iré pidiendo que pienses en alto para que me digas exactamente lo que pasa por tu mente. Todo esto nos ayudará.

4) Se le dice que puede preguntar dudas en cualquier momento, pero eso no quiere decir que se le dé una solución a la tarea.

Si tiene alguna pregunta durante la evaluación, hazla. Puede que no tengas respuesta inmediata porque de lo que se trata es de ver cómo reaccionas sin alguien al lado. No obstante, trataré de responder a cualquier pregunta que tengas cuando hayas terminado.

5) Explicar un poco como el laboratorio y el porqué de la webcam.

Con tu permiso, vamos a grabar la sesión. Esta información nos ayudará a mejorar la aplicación.

6) Comentar que puede dejar la tarea cuando quiera sino no está a gusto con el test.

Puedes dejar la evaluación cuando quieras si no estás a gusto

7) Firma del Consentimiento Informado y Confidencialidad

Además es importante destacar que no debes comentar a nadie lo que te hemos enseñado en esta sesión.

Por favor, lee la declaración siguiente y firma donde se indica. Gracias. Se trata de un documento "EI CONSENTIMIENTO INFORMADO", mediante el que aceptas participar en este estudio y la POLITICA DE CONFIDENCIALIDAD Y PROTECCION DE DATOS DE CARÁCTER PERSONAL FACILITADOS POR LOS USUARIOS.

(Se le lee el documento "Consentimiento informado" y se le explica los párrafos importantes) 
Gracias por participar en este estudio.

8) Se facilita las "Instrucciones para el usuario" (Anexo XX) y el aparato.

9) Realización de las tareas de evaluación de la aplicación en función del guión de tareas facilitado.

Se puede sugerir que comente en voz alta las dudas que le puedan surgir, si se producen fallos en la aplicación, etc. Y lo anote al final de la página que se le ha entregado.

¿Tiene alguna pregunta antes de empezar?

10) Realización de la "Encuesta de Satisfacción de Usuarios" 


\section{Anexo XXII.- Instrucciones para los usuarios}

\section{INSTRUCCIONES PARA EL USUARIO}

\section{TAREA 1: Familiarizarse con la pantalla táctil.}

Desde el menú de Inicio (Fig. 1) accede al Navegador de Internet "Internet Explorer" (Fig. 2). Ve a google (http://www.google.es ) y haz una búsqueda de un periódico (el país o el mundo) y accede a alguna de sus noticias.

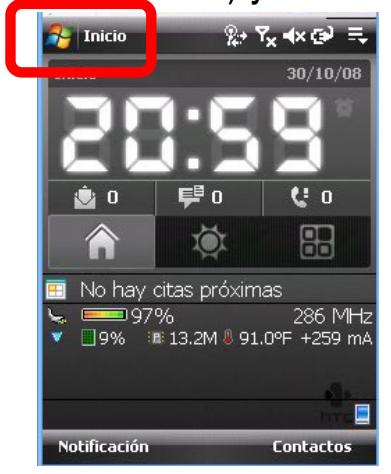

Figura 1

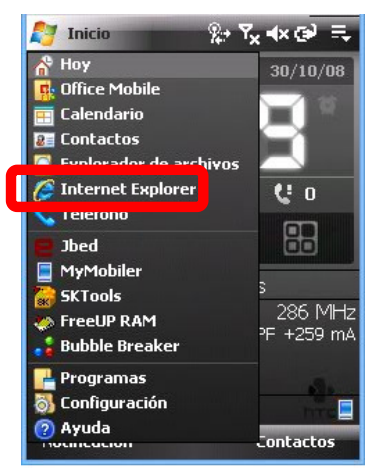

Figura 2

TAREA 2: Ejecutar la aplicación.

Desde el menú de Inicio (Fig. 3) accede a la aplicación Jbed (Fig. 4) y luego al juego "Construyendo con bloques" (Fig. 5).

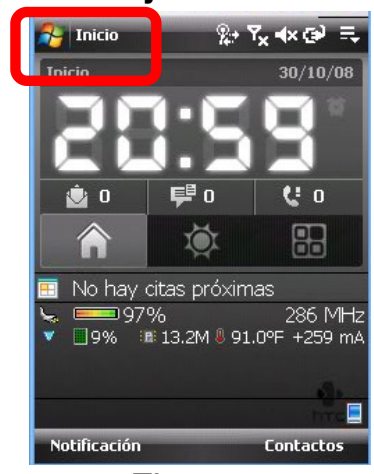

Figura 3

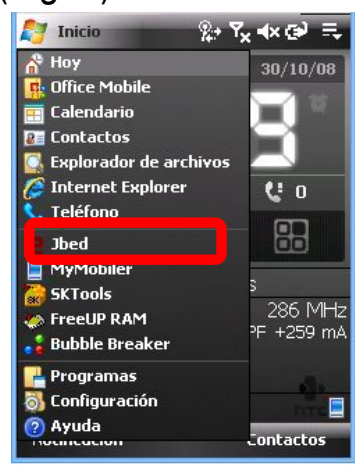

Figura 4

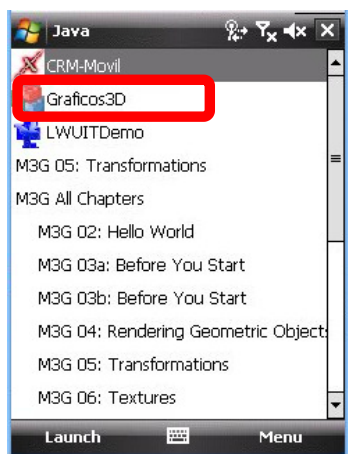

Figura 5

Accede a Menú (Fig. 6) $\Rightarrow$ Ayuda (Fig. 7). Lee las instrucciones y "Comienza el juego".

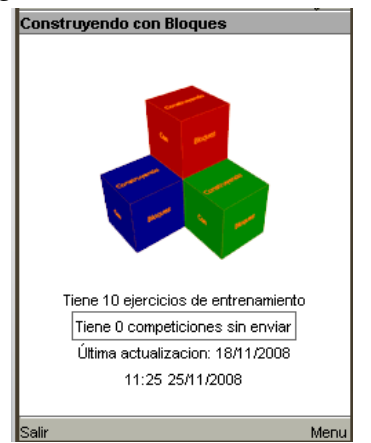

Figura 6

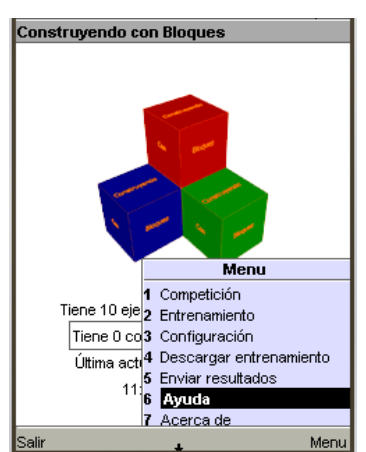

Figura 7

DATOS DE ACCESO: USUARIO: CONTRASEÑA:

INCIDENCIAS: Anota aquí las incidencias 


\section{Anexo XXIII.- Encuesta de satisfacción de usuarios}

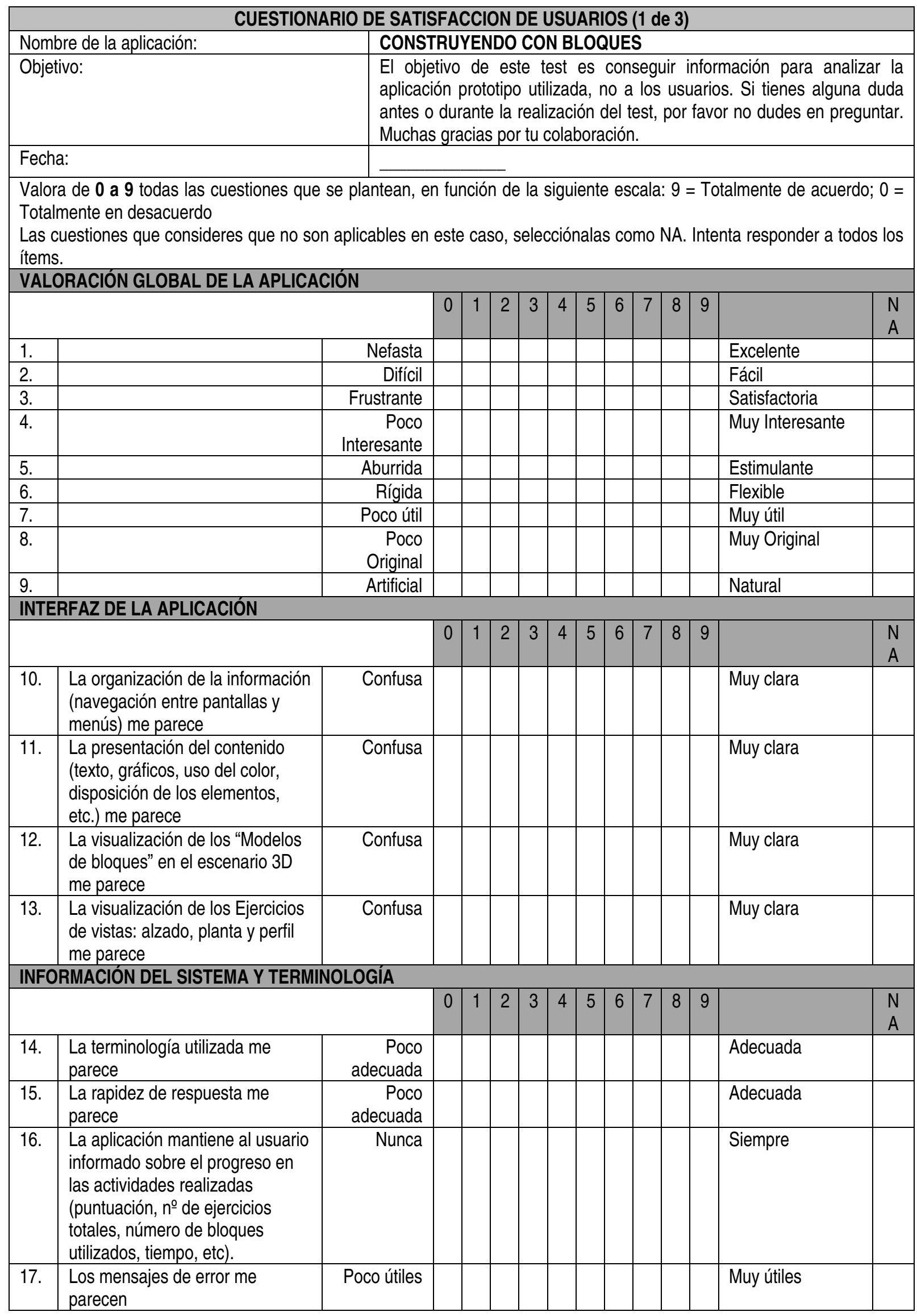


CUESTIONARIO DE SATISFACCION DE USUARIOS (2 de 3 )

FACILIDAD DE APRENDIZAJE DE LA APLICACIÓN

\begin{tabular}{|c|c|c|c|c|c|c|c|c|c|c|c|c|c|c|}
\hline \multicolumn{3}{|c|}{ 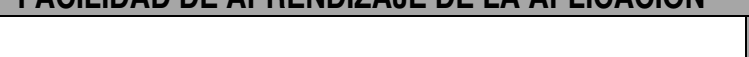 } & \multirow[t]{2}{*}{0} & \multirow[t]{2}{*}{1} & \multirow[t]{2}{*}{2} & \multirow[t]{2}{*}{3} & \multirow[t]{2}{*}{4} & \multirow[t]{2}{*}{5} & \multirow[t]{2}{*}{6} & \multirow[t]{2}{*}{7} & \multirow[t]{2}{*}{8} & \multirow[t]{2}{*}{9} & \multirow{2}{*}{ Fácil } & \multirow{2}{*}{$\begin{array}{l}\mathrm{N} \\
\mathrm{A} \\
\end{array}$} \\
\hline 18. & $\begin{array}{l}\text { El aprendizaje de la } \\
\text { aplicación me parece }\end{array}$ & Difícil & & & & & & & & & & & & \\
\hline 19. & $\begin{array}{l}\text { La aplicación me parece } \\
\text { intuitiva (los procedimientos } \\
\text { de navegación y ejecución } \\
\text { de tareas se aprenden de } \\
\text { forma rápida) }\end{array}$ & Nunca & & & & & & & & & & & Siempre & \\
\hline 20. & $\begin{array}{l}\text { Completar los ejercicios me } \\
\text { ha resultado sencillo }\end{array}$ & Difícil & & & & & & & & & & & Fácil & \\
\hline 21. & $\begin{array}{l}\text { Los mensajes de ayuda en } \\
\text { pantalla me parecen }\end{array}$ & Poco útiles & & & & & & & & & & & Muy útiles & \\
\hline 22. & $\begin{array}{l}\text { La ayuda que proporciona la } \\
\text { aplicación es fácil de } \\
\text { comprender (ayuda, } \\
\text { mensajes en pantalla y otra } \\
\text { documentación) }\end{array}$ & Confusa & & & & & & & & & & & Muy clara & \\
\hline 23. & $\begin{array}{l}\text { Podría usar la aplicación sin } \\
\text { instrucciones escritas (ayuda } \\
\text { de la aplicación) }\end{array}$ & Nunca & & & & & & & & & & & Siempre & \\
\hline \multicolumn{15}{|c|}{ CAPACIDADES DE LA APLICACIÓN } \\
\hline & & & 0 & 1 & 2 & 3 & 4 & 5 & 6 & 7 & 8 & 9 & & $\begin{array}{l}\mathrm{N} \\
\mathrm{A}\end{array}$ \\
\hline 24. & $\begin{array}{l}\text { La velocidad de la aplicación } \\
\text { me parece }\end{array}$ & Demasiado lenta & & & & & & & & & & & $\begin{array}{l}\text { Suficientemente } \\
\text { rápida }\end{array}$ & \\
\hline 25. & $\begin{array}{l}\text { Errores cuando uso la } \\
\text { aplicación (fiabilidad) }\end{array}$ & Muchos & & & & & & & & & & & Pocos & \\
\hline 26. & $\begin{array}{l}\text { La corrección de los errores } \\
\text { me parece }\end{array}$ & Difícil & & & & & & & & & & & Fácil & \\
\hline \multicolumn{15}{|c|}{ ASPECTOS TÉCNICOS } \\
\hline & & & 0 & 1 & 2 & 3 & 4 & 5 & 6 & 7 & 8 & 9 & & $\begin{array}{l}\mathrm{N} \\
\mathrm{A}\end{array}$ \\
\hline 27. & $\begin{array}{l}\text { La operación de } \\
\text { añadir/eliminar bloques me } \\
\text { parece }\end{array}$ & Difícil & & & & & & & & & & & Fácil & \\
\hline 28. & $\begin{array}{l}\text { El modo de interacción } \\
\text { (moverse) con el escenario } \\
\text { 3D me parece }\end{array}$ & Difícil & & & & & & & & & & & Fácil & \\
\hline 29. & $\begin{array}{l}\text { La operación de hacer zoom } \\
\text { (ampliar/reducir) me parece }\end{array}$ & Difícil & & & & & & & & & & & Fácil & \\
\hline 30. & $\begin{array}{l}\text { La experiencia con la } \\
\text { pantalla táctil del aparato la } \\
\text { valoro como }\end{array}$ & Muy Mala & & & & & & & & & & & Muy Buena & \\
\hline 31. & $\begin{array}{l}\text { La experiencia con el } \\
\text { teclado táctil del aparato la } \\
\text { valoro como }\end{array}$ & Muy Mala & & & & & & & & & & & Muy Buena & \\
\hline 32. & $\begin{array}{l}\text { El tiempo empleado para } \\
\text { realizar cada ejercicio me } \\
\text { parece }\end{array}$ & Excesivo & & & & & & & & & & & Adecuado & \\
\hline 33. & $\begin{array}{l}\text { La clasificación de los } \\
\text { ejercicios por tipos y niveles } \\
\text { (bloques y vistas; nivel } 1 \text { y 2) } \\
\text { me parece }\end{array}$ & Confuso & & & & & & & & & & & Claro & \\
\hline 34. & $\begin{array}{l}\text { El número de ejercicios de } \\
\text { cada nivel me parece }\end{array}$ & Excesivo & & & & & & & & & & & Adecuado & \\
\hline
\end{tabular}




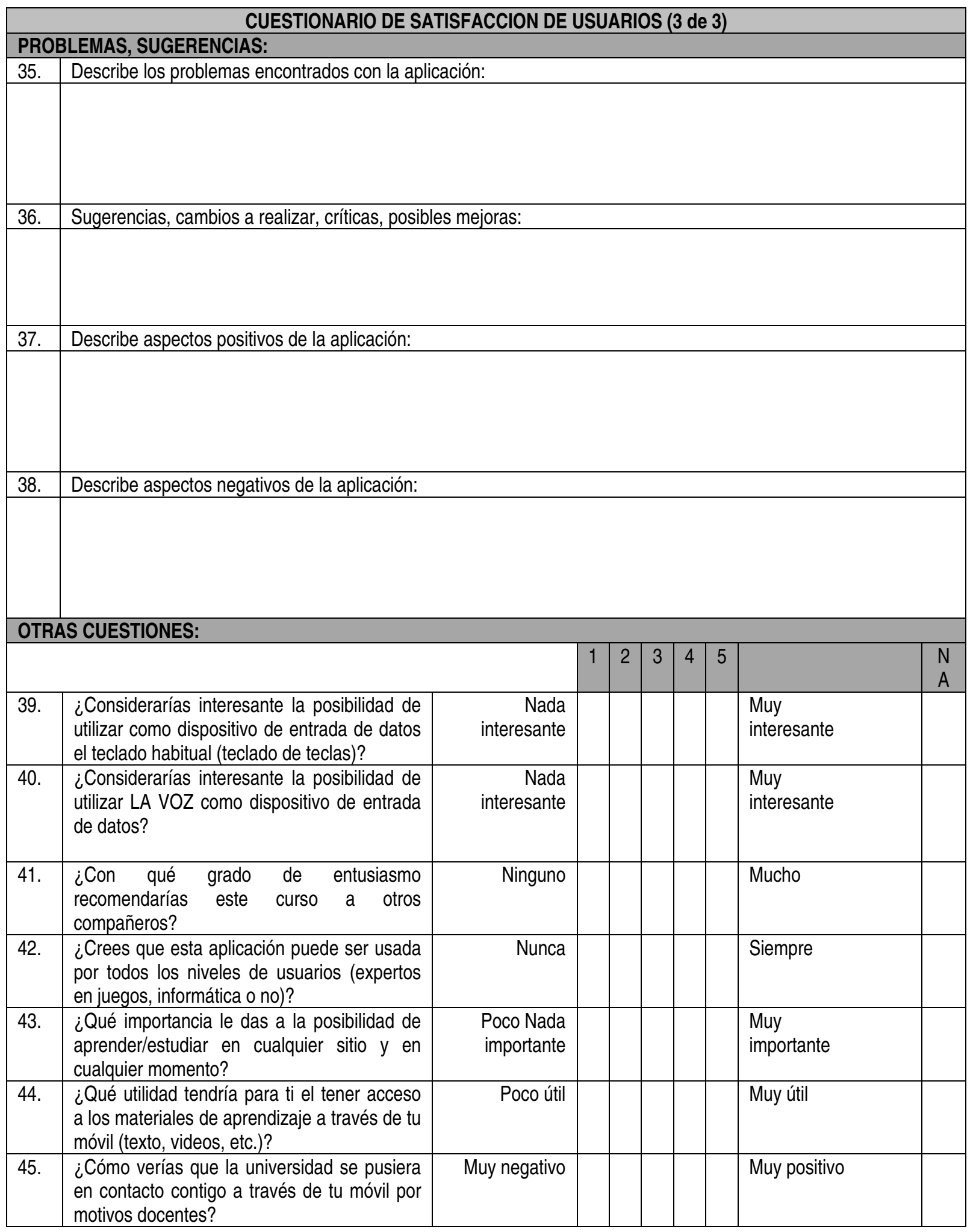

¿Tienes experiencia previa con pantallas táctiles?

$\square$ Sí

$\square$ No 


\section{Anexo XXIV.- Encuesta de satisfacción de usuarios 2009 ( $n=26)$}

Octubre de 2009

Encuestas: 26

Preguntas: 44

\begin{tabular}{|c|c|c|}
\hline \multirow{2}{*}{$\begin{array}{l}\text { Pregunta } \\
\text { Sexo }\end{array}$} & \multicolumn{2}{|c|}{ Respuestas } \\
\hline & $\begin{array}{l}\text { Hombre } \\
17\end{array}$ & $\begin{array}{l}\text { Mujer } \\
9\end{array}$ \\
\hline & 65,38 & 34,62 \\
\hline Edad: & Promedio & \\
\hline & 18,46 & \\
\hline
\end{tabular}

¿Cómo valoras tu experiencia con Muy Mala

Mala

Regular

Buena

Excelente

la pantalla y el teclado táctil del

dispositivo?

\begin{tabular}{|c|c|c|c|c|c|}
\hline & 0 & 2 & 3 & 18 & 3 \\
\hline & 0,00 & 7,69 & 11,54 & 69,23 & 11,54 \\
\hline \multirow{3}{*}{$\begin{array}{l}\text { ¿Cómo valoras tu experiencia con } \\
\text { la red wifi del dispositivo? }\end{array}$} & Muy Mala & Mala & Regular & Buena & Excelente \\
\hline & 0,00 & 3,00 & 8,00 & 10,00 & 5,00 \\
\hline & 0,00 & 11,54 & 30,77 & 38,46 & 19,23 \\
\hline
\end{tabular}

¿Qué utilidades le has dado al

aparato? (dónde lo he usado, si lo

he utilizado cómo mi telfono)

Describe aspectos positivos del

aparato

Describe aspectos negativos del

aparato 


\begin{tabular}{|c|c|c|c|c|c|}
\hline \multirow{3}{*}{$\begin{array}{l}\text { ¿Cómo valoras tu experiencia con } \\
\text { la informática y las nuevas } \\
\text { tecnologías? }\end{array}$} & Muy Mala & Mala & Regular & Buena & Muy buena \\
\hline & 0 & 2 & 3 & 14 & 0 \\
\hline & 0,00 & 7,69 & 11,54 & 53,85 & 0,00 \\
\hline \multirow{3}{*}{$\begin{array}{l}\text { Respecto al dibujo técnico en } \\
\text { general, ¿Cómo valoras tus } \\
\text { conocimientos? }\end{array}$} & Muy Malos & Malos & Regular & Buenos & Muy buenos \\
\hline & 1 & 6 & 13 & 6 & 0 \\
\hline & 3,85 & 23,08 & 50,00 & 23,08 & 0,00 \\
\hline \multirow{3}{*}{$\begin{array}{l}\text { ¿Crees que este curso puede ser } \\
\text { provechoso como preparatorio a } \\
\text { los contenidos de la asignatura de } \\
\text { Expresión Grafica? }\end{array}$} & $\begin{array}{l}\text { Totalmente en } \\
\text { desacuerdo }\end{array}$ & En desacuerdo & $\begin{array}{l}\text { Ni de acuerdo } \\
\text { ni en } \\
\text { desacuerdo }\end{array}$ & De acuerdo & $\begin{array}{l}\text { Totalmente de } \\
\text { acuerdo }\end{array}$ \\
\hline & 0 & 0 & 0 & 19 & 7 \\
\hline & 0,00 & 0,00 & 0,00 & 73,08 & 26,92 \\
\hline \multirow{3}{*}{$\begin{array}{l}\text { ¿Consideras necesario que se den } \\
\text { cursos intensivos de este tipo para } \\
\text { los estudiantes con dificultades en } \\
\text { dibujo? }\end{array}$} & $\begin{array}{l}\text { Totalmente en } \\
\text { desacuerdo }\end{array}$ & En desacuerdo & $\begin{array}{l}\text { Ni de acuerdo } \\
\text { ni en } \\
\text { desacuerdo }\end{array}$ & De acuerdo & $\begin{array}{l}\text { Totalmente de } \\
\text { acuerdo }\end{array}$ \\
\hline & 0 & 0 & 2 & 7 & 17 \\
\hline & 0,00 & 0,00 & 7,69 & 26,92 & 65,38 \\
\hline \multirow[t]{3}{*}{$\begin{array}{l}\text { ¿Consideras que este curso te } \\
\text { puede servir en el desempeño de tu } \\
\text { vida profesional? }\end{array}$} & $\begin{array}{l}\text { Totalmente en } \\
\text { desacuerdo }\end{array}$ & En desacuerdo & $\begin{array}{l}\text { Ni de acuerdo } \\
\text { ni en } \\
\text { desacuerdo }\end{array}$ & De acuerdo & $\begin{array}{l}\text { Totalmente de } \\
\text { acuerdo }\end{array}$ \\
\hline & 0 & 0 & 11 & 11 & 4 \\
\hline & 0,00 & 0,00 & 42,31 & 42,31 & 15,38 \\
\hline \multirow[t]{2}{*}{$\begin{array}{l}\text { Recomendaría este curso a mis } \\
\text { compañeros }\end{array}$} & $\begin{array}{l}\text { Totalmente en } \\
\text { desacuerdo }\end{array}$ & En desacuerdo & $\begin{array}{l}\text { Ni de acuerdo } \\
\text { ni en } \\
\text { desacuerdo }\end{array}$ & De acuerdo & $\begin{array}{l}\text { Totalmente de } \\
\text { acuerdo }\end{array}$ \\
\hline & 0 & 0 & 0 & 18 & 8 \\
\hline
\end{tabular}




\begin{tabular}{|c|c|c|c|c|c|}
\hline & 0,00 & 0,00 & 0,00 & 69,23 & 30,77 \\
\hline \multirow[t]{3}{*}{$\begin{array}{l}\text { Creo que este curso es una buena } \\
\text { herramienta para el desarrollo de la } \\
\text { capacidad espacial }\end{array}$} & $\begin{array}{l}\text { Totalmente en } \\
\text { desacuerdo }\end{array}$ & En desacuerdo & $\begin{array}{l}\text { Ni de acuerdo } \\
\text { ni en } \\
\text { desacuerdo }\end{array}$ & De acuerdo & $\begin{array}{l}\text { Totalmente de } \\
\text { acuerdo }\end{array}$ \\
\hline & 0 & 0 & 4 & 12 & 10 \\
\hline & 0,00 & 0,00 & 15,38 & 46,15 & 38,46 \\
\hline \multirow[t]{3}{*}{$\begin{array}{l}\text { El contenido del curso me ha } \\
\text { resultado claro }\end{array}$} & $\begin{array}{l}\text { Totalmente en } \\
\text { desacuerdo }\end{array}$ & En desacuerdo & $\begin{array}{l}\text { Ni de acuerdo } \\
\text { ni en } \\
\text { desacuerdo }\end{array}$ & De acuerdo & $\begin{array}{l}\text { Totalmente de } \\
\text { acuerdo }\end{array}$ \\
\hline & 0 & 0 & 0 & 18 & 8 \\
\hline & 0,00 & 0,00 & 0,00 & 69,23 & 30,77 \\
\hline \multirow[t]{3}{*}{$\begin{array}{l}\text { He entendido bien los ejercicios de } \\
\text { este curso. }\end{array}$} & $\begin{array}{l}\text { Totalmente en } \\
\text { desacuerdo }\end{array}$ & En desacuerdo & $\begin{array}{l}\text { Ni de acuerdo } \\
\text { ni en } \\
\text { desacuerdo }\end{array}$ & De acuerdo & $\begin{array}{l}\text { Totalmente de } \\
\text { acuerdo }\end{array}$ \\
\hline & 0 & 0 & 0 & 17 & 9 \\
\hline & 0,00 & 0,00 & 0,00 & 65,38 & 34,62 \\
\hline \multirow[t]{3}{*}{$\begin{array}{l}\text { Me he sentido capaz de resolver los } \\
\text { ejercicios planteados. }\end{array}$} & $\begin{array}{l}\text { Totalmente en } \\
\text { desacuerdo }\end{array}$ & En desacuerdo & $\begin{array}{l}\text { Ni de acuerdo } \\
\text { ni en } \\
\text { desacuerdo }\end{array}$ & De acuerdo & $\begin{array}{l}\text { Totalmente de } \\
\text { acuerdo }\end{array}$ \\
\hline & 0 & 1 & 2 & 16 & 7 \\
\hline & 0,00 & 3,85 & 7,69 & 61,54 & 26,92 \\
\hline \multirow{3}{*}{$\begin{array}{l}\text { Creo que este curso se puede } \\
\text { desarrollar en cualquier momento y } \\
\text { lugar fuera del aula de clase (en } \\
\text { casa, en el autobús, en el tranvía, } \\
\text { etc.) }\end{array}$} & $\begin{array}{l}\text { Totalmente en } \\
\text { desacuerdo }\end{array}$ & En desacuerdo & $\begin{array}{l}\text { Ni de acuerdo } \\
\text { ni en } \\
\text { desacuerdo }\end{array}$ & De acuerdo & $\begin{array}{l}\text { Totalmente de } \\
\text { acuerdo }\end{array}$ \\
\hline & 0 & 1 & 4 & 10 & 11 \\
\hline & 0,00 & 3,85 & 15,38 & 38,46 & 42,31 \\
\hline \multirow[t]{3}{*}{ Valora la interfaz de la aplicación } & O(CONFUSA) & 1 & 2 & 3 & 4(CLARA) \\
\hline & 1 & 1 & 5 & 11 & 8 \\
\hline & 3,85 & 3,85 & 19,23 & 42,31 & 30,77 \\
\hline
\end{tabular}




\begin{tabular}{|c|c|c|c|c|c|}
\hline \multirow[t]{3}{*}{ Valora la AYUDA de la aplicación } & 0(CONFUSA) & 1 & 2 & 3 & $\overline{4(C L A R A)}$ \\
\hline & 0 & 0 & 8 & 11 & 7 \\
\hline & 0,00 & 0,00 & 30,77 & 42,31 & 26,92 \\
\hline \multirow{3}{*}{$\begin{array}{l}\text { Valora la INTERACCIÓN CON EL } \\
\text { ENTORNO 3D la aplicación }\end{array}$} & 0(DIFICIL) & 1 & 2 & 3 & 4(FACIL) \\
\hline & 0 & 0 & 5 & 15 & 6 \\
\hline & 0,00 & 0,00 & 19,23 & 57,69 & 23,08 \\
\hline
\end{tabular}

\begin{tabular}{|c|c|c|c|c|c|}
\hline \multirow{3}{*}{$\begin{array}{l}\text { ¿Qué ejercicios te parecieron más } \\
\text { difíciles? }\end{array}$} & Bloques & Vistas & & & \\
\hline & 2 & 24 & & & \\
\hline & 7,69 & 92,31 & & & \\
\hline \multirow[t]{3}{*}{$\begin{array}{l}\text { Los ejercicios de este curso } \\
\text { estimulan mi interés por aprender }\end{array}$} & $\begin{array}{l}\text { Totalmente en } \\
\text { desacuerdo }\end{array}$ & En desacuerdo & $\begin{array}{l}\text { Ni de acuerdo } \\
\text { ni en } \\
\text { desacuerdo }\end{array}$ & De acuerdo & $\begin{array}{l}\text { Totalmente de } \\
\text { acuerdo }\end{array}$ \\
\hline & 0 & 0 & 4 & 15 & 7 \\
\hline & 0,00 & 0,00 & 15,38 & 57,69 & 26,92 \\
\hline \multirow[t]{3}{*}{$\begin{array}{l}\text { Me gustaría realizar más ejercicios } \\
\text { de los propuestos porque despiertan } \\
\text { mi motivación }\end{array}$} & $\begin{array}{l}\text { Totalmente en } \\
\text { desacuerdo }\end{array}$ & En desacuerdo & $\begin{array}{l}\text { Ni de acuerdo } \\
\text { ni en } \\
\text { desacuerdo }\end{array}$ & De acuerdo & $\begin{array}{l}\text { Totalmente de } \\
\text { acuerdo }\end{array}$ \\
\hline & 0 & 0 & 7 & 14 & 5 \\
\hline & 0,00 & 0,00 & 26,92 & 53,85 & 19,23 \\
\hline \multirow[t]{3}{*}{$\begin{array}{l}\text { Creo que el uso de ejercicios de este } \\
\text { tipo puede ayudarme a desarrollar } \\
\text { mi capacidad espacial }\end{array}$} & $\begin{array}{l}\text { Totalmente en } \\
\text { desacuerdo }\end{array}$ & En desacuerdo & $\begin{array}{l}\text { Ni de acuerdo } \\
\text { ni en } \\
\text { desacuerdo }\end{array}$ & De acuerdo & $\begin{array}{l}\text { Totalmente de } \\
\text { acuerdo }\end{array}$ \\
\hline & 0 & 0 & 1 & 17 & 8 \\
\hline & 0,00 & 0,00 & 3,85 & 65,38 & 30,77 \\
\hline
\end{tabular}




\begin{tabular}{|c|c|c|c|c|c|}
\hline \multirow[t]{3}{*}{$\begin{array}{l}\text { Creo que el uso de ejercicios } \\
\text { tradicionales mediante lápiz y papel } \\
\text { es un buen sistema de aprendizaje }\end{array}$} & $\begin{array}{l}\text { Totalmente en } \\
\text { desacuerdo }\end{array}$ & En desacuerdo & $\begin{array}{l}\text { Ni de acuerdo } \\
\text { ni en } \\
\text { desacuerdo }\end{array}$ & De acuerdo & $\begin{array}{l}\text { Totalmente de } \\
\text { acuerdo }\end{array}$ \\
\hline & 1 & 3 & 8 & 12 & 2 \\
\hline & 3,85 & 11,54 & 30,77 & 46,15 & 7,69 \\
\hline \multirow[t]{3}{*}{$\begin{array}{l}\text { Creo que el uso de ejercicios } \\
\text { multimedia en ordenador es un buen } \\
\text { sistema de aprendizaje }\end{array}$} & $\begin{array}{l}\text { Totalmente en } \\
\text { desacuerdo }\end{array}$ & En desacuerdo & $\begin{array}{l}\text { Ni de acuerdo } \\
\text { ni en } \\
\text { desacuerdo }\end{array}$ & De acuerdo & $\begin{array}{l}\text { Totalmente de } \\
\text { acuerdo }\end{array}$ \\
\hline & 0 & 0 & 0 & 16 & 10 \\
\hline & 0,00 & 0,00 & 0,00 & 61,54 & 38,46 \\
\hline \multirow{3}{*}{$\begin{array}{l}\text { Creo que el uso de ejercicios } \\
\text { multimedia en dispositivos de mano } \\
\text { (móviles, PDAs, PSP, Nintendo) es } \\
\text { un buen sistema de aprendizaje }\end{array}$} & $\begin{array}{l}\text { Totalmente en } \\
\text { desacuerdo }\end{array}$ & En desacuerdo & $\begin{array}{l}\text { Ni de acuerdo } \\
\text { ni en } \\
\text { desacuerdo }\end{array}$ & De acuerdo & $\begin{array}{l}\text { Totalmente de } \\
\text { acuerdo }\end{array}$ \\
\hline & 0 & 0 & 1 & 15 & 10 \\
\hline & 0,00 & 0,00 & 3,85 & 57,69 & 38,46 \\
\hline \multirow[t]{3}{*}{$\begin{array}{l}\text { Si tuvieras que elegir el formato para } \\
\text { realizar un curso como este ¿qué } \\
\text { formato preferirías? }\end{array}$} & $\begin{array}{l}\text { Ejercicios en } \\
\text { Papel }\end{array}$ & $\begin{array}{l}\text { Ejercicios en } \\
\text { Ordenador }\end{array}$ & $\begin{array}{l}\text { Ejercicios en } \\
\text { Consolas de } \\
\text { mano: tipo PSP, } \\
\text { Nintendo, } \\
\text { Teléfonos } \\
\text { táctiles }\end{array}$ & Otros & \\
\hline & 1 & 9 & 16 & 0 & \\
\hline & 3,85 & 34,62 & 61,54 & 0,00 & \\
\hline \multirow[t]{3}{*}{$\begin{array}{l}\text { ¿Dónde preferirías realizar este } \\
\text { curso? }\end{array}$} & En casa & $\begin{array}{l}\text { En la } \\
\text { universidad }\end{array}$ & $\begin{array}{l}\text { En cualquier } \\
\text { sitio y lugar }\end{array}$ & Otros & \\
\hline & 13 & 2 & 11 & 0 & \\
\hline & 50,00 & 7,69 & 42,31 & 0,00 & \\
\hline
\end{tabular}




\begin{tabular}{|c|c|c|c|c|c|}
\hline $\begin{array}{l}\text { Me hubiera gustado realizar este } \\
\text { curso con asistencia del profesor. } \\
\text { Prefiero hacer el curso de forma } \\
\text { presencial aue a distancia }\end{array}$ & $\begin{array}{l}\text { Totalmente en } \\
\text { desacuerdo }\end{array}$ & En desacuerdo & $\begin{array}{l}\text { Ni de acuerdo } \\
\text { ni en } \\
\text { desacuerdo }\end{array}$ & De acuerdo & $\begin{array}{l}\text { Totalmente de } \\
\text { acuerdo }\end{array}$ \\
\hline & 2 & 7 & 14 & 2 & 1 \\
\hline & 7,69 & 26,92 & 53,85 & 7,69 & 3,85 \\
\hline \multicolumn{6}{|l|}{ VALORA EL FORMATO } \\
\hline \multirow[t]{3}{*}{ En papel } & O(NADA) & 1 & 2 & 3 & 4(MUCHO) \\
\hline & 8 & 2 & 12 & 3 & 1 \\
\hline & 30,77 & 7,69 & 46,15 & 11,54 & 3,85 \\
\hline \multirow[t]{3}{*}{ En ordenador } & O(NADA) & 1 & 2 & 3 & 4(MUCHO) \\
\hline & 0 & 0 & 2 & 16 & 8 \\
\hline & 0,00 & 0,00 & 7,69 & 61,54 & 30,77 \\
\hline \multirow{3}{*}{$\begin{array}{l}\text { En dispositivos portátiles: nintendo, } \\
\text { psp, dispositivos móviles de pantalla } \\
\text { grande, ipod, etc. }\end{array}$} & 0(NADA) & 1 & 2 & 3 & 4(MUCHO) \\
\hline & 0 & 0 & 2 & 10 & 14 \\
\hline & 0,00 & 0,00 & 7,69 & 38,46 & 53,85 \\
\hline \multicolumn{6}{|l|}{ Otros: } \\
\hline VALORACION GLOBAL DEL CURSO & 0 & 1 & & & 3 \\
\hline \multirow[t]{3}{*}{ NEFASTO-EXCELENTE } & 0(Nefasto) & 1 & 2 & 3 & 4(Excelente) \\
\hline & 0 & 0 & 5 & 15 & 6 \\
\hline & 0,00 & 0,00 & 19,23 & 57,69 & 23,08 \\
\hline \multirow[t]{3}{*}{ DIFICIL - FACIL } & 0(DIFICIL) & 1 & 2 & 3 & 4(FACIL) \\
\hline & 1 & 0 & 8 & 15 & 0 \\
\hline & 3,85 & 0,00 & 30,77 & 57,69 & 0,00 \\
\hline \multirow[t]{3}{*}{ FRUSTANTE-SATISFACTORIO } & $\begin{array}{l}\text { O(FRUSTANT } \\
\text { E) }\end{array}$ & 1 & 2 & 3 & 4(SATISFACTORIO) \\
\hline & 1 & 1 & 5 & 11 & 8 \\
\hline & 3,85 & 3,85 & 19,23 & 42,31 & 30,77 \\
\hline
\end{tabular}




\begin{tabular}{|c|c|c|c|c|c|}
\hline \multirow[t]{3}{*}{$\begin{array}{l}\text { POCO INTERESANTE - MUY } \\
\text { INTERESANTE }\end{array}$} & $\begin{array}{l}\text { O(POCO } \\
\text { INTERESANT } \\
\text { E) }\end{array}$ & 1 & 2 & 3 & $\begin{array}{l}\text { 4(MUY } \\
\text { INTERESANTE) }\end{array}$ \\
\hline & 0 & 1 & 4 & 12 & 9 \\
\hline & 0,00 & 3,85 & 15,38 & 46,15 & 34,62 \\
\hline \multirow[t]{3}{*}{ ABURRIDO - ESTIMULANTE } & 0(ABURRIDO) & 1 & 2 & 3 & 4(ESTIMULANTE) \\
\hline & 0 & 0 & 3 & 15 & 8 \\
\hline & 0,00 & 0,00 & 11,54 & 57,69 & 30,77 \\
\hline \multirow[t]{3}{*}{ POCO UTIL - MUY UTIL } & 0(POCO UTIL) & 1 & 2 & 3 & 4(MUY UTIL) \\
\hline & 0 & 0 & 4 & 10 & 12 \\
\hline & 0,00 & 0,00 & 15,38 & 38,46 & 46,15 \\
\hline \multicolumn{6}{|l|}{$\begin{array}{l}\text { En tu opinion, cuáles son las } \\
\text { ventajas de este curso }\end{array}$} \\
\hline $\begin{array}{l}\text { En tu opinion, cuáles son las } \\
\text { desventajas de este curso }\end{array}$ & & & & & \\
\hline
\end{tabular}

